\title{
ÁREA DE ESCAPE PARA CAMINHÕES DESGOVERNADOS
}

\section{Paulo Rogério Zanoli}

Dissertação apresentada à Escola de Engenharia de São Carlos da Universidade de São Paulo, como parte dos requisitos para obtenção do título de Mestre em Engenharia Civil com ênfase em Transportes.

ORIENTADOR: Prof. Assoc. José Reynaldo A. Setti 
Ficha catalográfica preparada pela Seção de Tratamento da Informação do Serviço de Biblioteca - EESC/USP

Zanoli, Paulo Rogério
Z33a Área de escape para

desgovernados / Paulo Rogério Zanoli. -- São Carlos, 2003.

Dissertação (Mestrado) - Escola de Engenharia de São Carlos-Universidade de São Paulo, 2003.

Área: Transportes.

Orientador: Prof. Assoc. José Reynaldo A. Setti.

1. Área de escape. 2. Caixa de retenção.

3. Caminhão desgovernado. 4. Declives longos e íngremes. 5. Frenagem. I. Título. 
FOLHA DE JULGAMENTO

Candidato: Engenheiro PAULO ROGERIO ZANOLI

Dissertação defendida e julgada em 14/04/2003 perante a Comissão Julgadora:

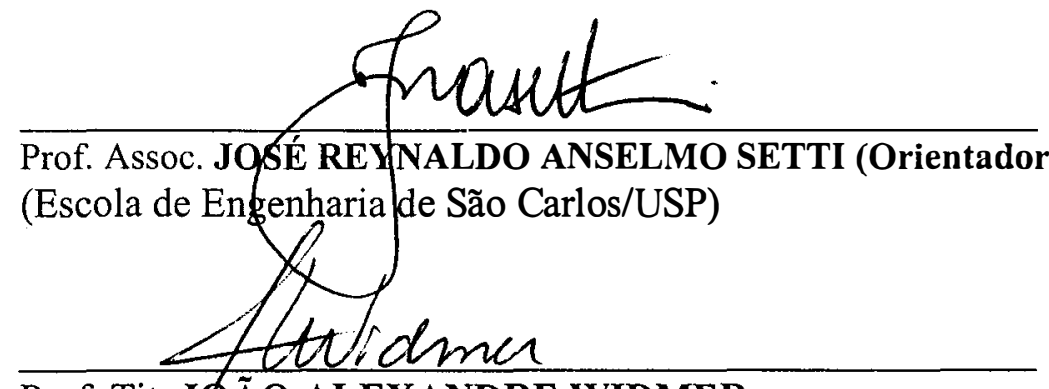

Prof. Tit. JøÃO ALEXANDRE WIDMER

ceprovado

(Escola de Engenharia de S̃̃o Carlos/USP)

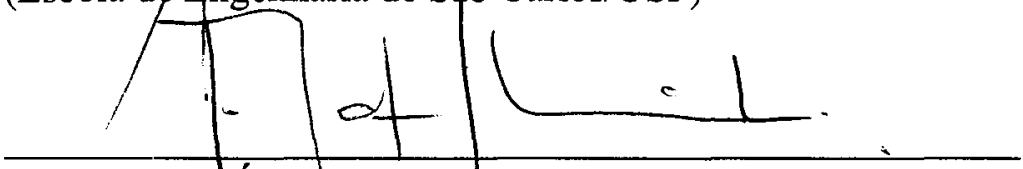

Prof. Dr. JOŞÉ MATTSUOSHAMOISHI

KPROVATO

(Universidade de BrasíliatinB)
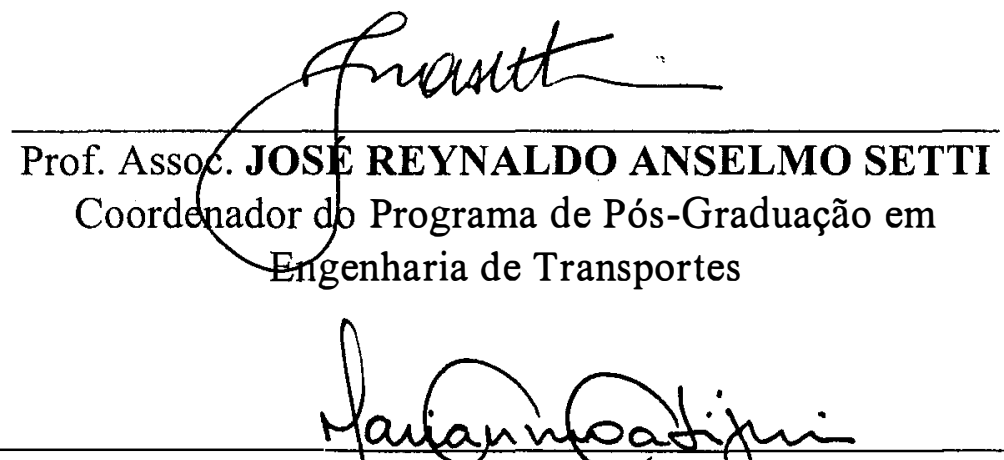

Profa. Assoc. MARIA DO CARMO CALIJURI

Presidente da Comissão de Pós-Graduação da EESC 


\section{DEDICATÓRIA}

Dedico este trabalho aos grandes professores da minha vida, meus pais: Paulo Zanoli Neto e Evanirde Benhossi Zanoli às minhas grandes amigas, minhas irmãs: Marileide Zanoli e Márcia Zanoli à grande alegria da minha vida, meu sobrinho: Rafael Hideki à mulher que eu amo, minha esposa: Patrícia Pazini ao grande presente que Deus me deu: meu bebê que está para chegar 
“...buscai primeiro o reino de Deus e a sua justiça, e todas estas coisas vos serão acrescentadas" (Mat. 6:33)

"É muito melhor ousar coisas dificeis, conquistar triunfos grandiosos, embora ameaçados de fracasso, do que se alinhar com espiritos mediocres que nem desfrutam muito nem sofrem muito, porque vivem em uma penumbra cinzenta, onde não conhecem vitória nem derrota" Theodore Roosevelt 


\section{AGRADECIMENTOS}

Ao Prof. José Reynaldo A. Setti pela orientação, incentivo e participação no desenvolvimento deste trabalho.

À CAPES e FIPAI pela concessão da bolsa de estudo, recurso financeiro indispensável para realização desta pesquisa.

À Concessionária Ecovias dos Imigrantes S/A pelo suporte técnico na coleta de dados.

A todos os professores e funcionários do departamento de Transportes da EESC/USP, pela amizade e o apoio oferecido durante todo este tempo.

A todos os colegas e amigos do departamento de Transportes, em especial aqueles que conviveram comigo na sala XY: Giovane, Cintia, Márcia Lika, Cira, Juliana, Ricardinho, Pastor, Sandra e Hélio.

À minha grande amiga desde os tempos de graduação, Giseli.

Aos professores Sergio H. Demarchi e Sandra Oda, da Universidade Estadual de Maringá, por incentivar e despertar meu interesse pela área de transportes. 


\section{SUMÁRIO}

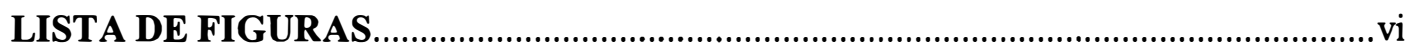

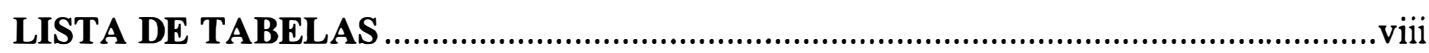

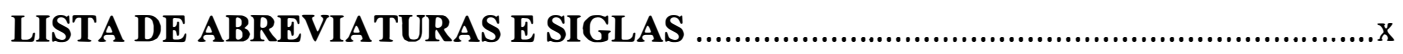

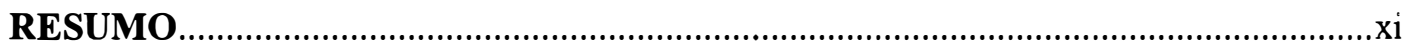

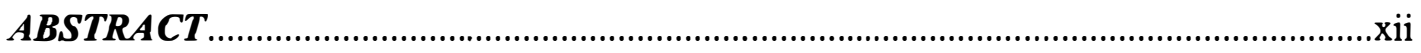

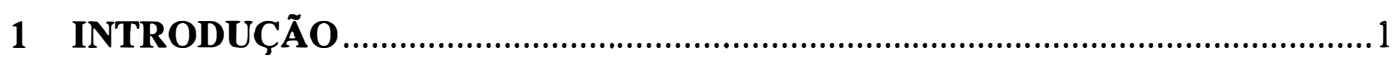

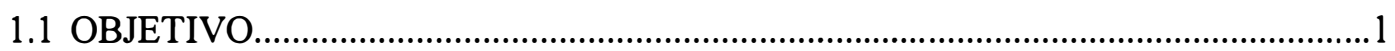

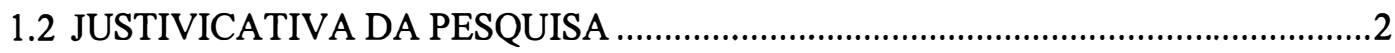

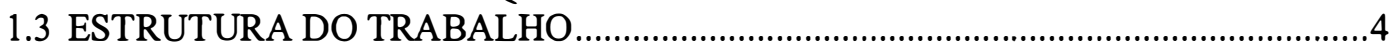

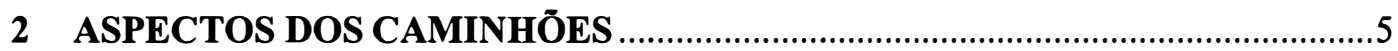

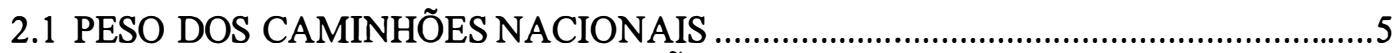



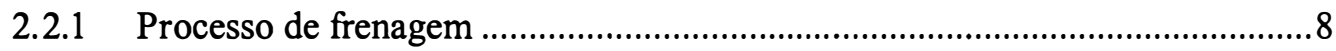



2.2.3 Comportamento térmico dos freios ................................................................ 11

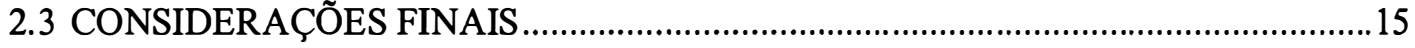

3 DISPOSITIVOS PARA CONTENÇÃO DE VEÍCULO DESGOVERNADOS.......16

3.1 LOCOMOÇÃO DE CAMINHÕES EM DECLIVES LONGOS E ÍNGREMES ..........16

3.1.1 Mecânica da locomoção de veículos rodoviários em declives ...........................17

3.1.2 Condução dos caminhões em declives longos e íngremes ...................................18

3.1.3 Ocorrência de acidentes envolvendo caminhões fora de controle.......................20

3.2 TIPOS DE DISPOSITIVOS PARA CONTENÇÃO DE VEÍCULOS

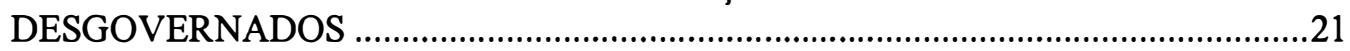

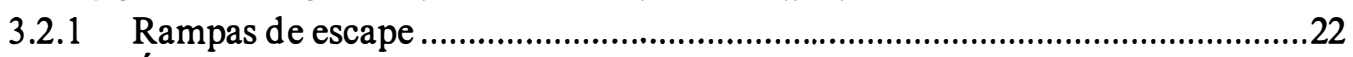

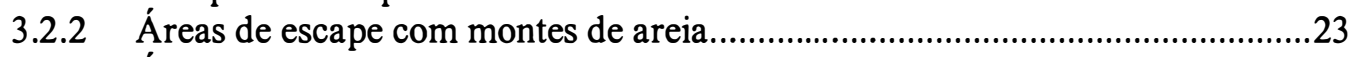

3.2.3 Áreas de escape com caixa de retenção .............................................................2.

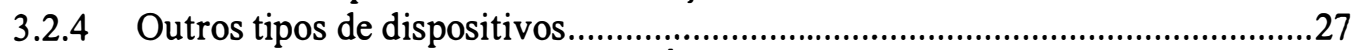

3.3 NECESSIDADE DE INSTALAÇÃO DE ÁREAS DE ESCAPE ….................................30



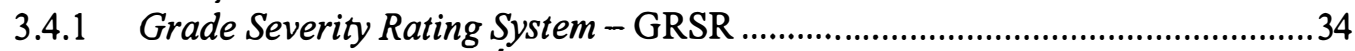

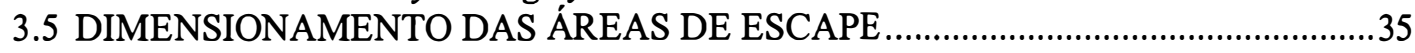

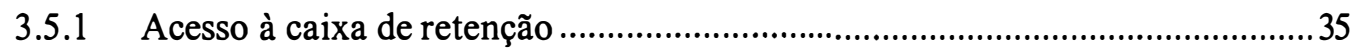

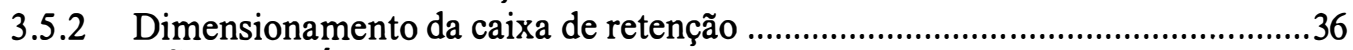

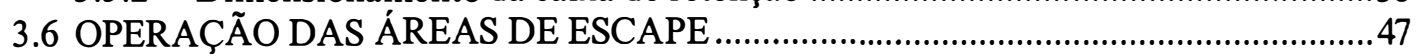




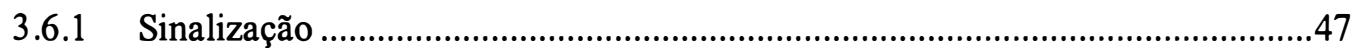

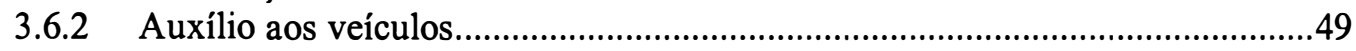

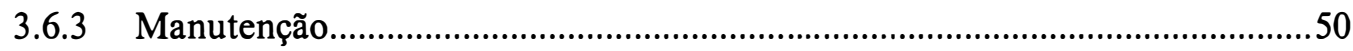

4 ESTUDO DE CASO

4.1 ANÁLISE DA DESACELERAÇÃO EM CAIXAS DE RETENÇÃO .............................52

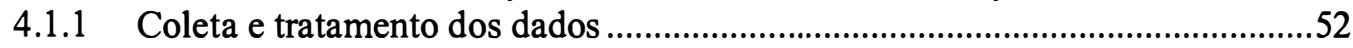

4.1.2 Determinação da desaceleração média ................................................................59

4.1.3 Análise da desaceleração média $\left(\mathrm{a}_{\mathrm{m}}\right)$...............................................................68

4.1.4 Modelo proposto para a desaceleração média ...................................................70

4.2 ANÁLISE DE LOCALIZAÇÃO DAS ÁREAS DE ESCAPE .......................................77

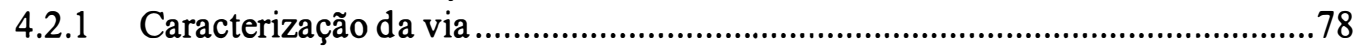



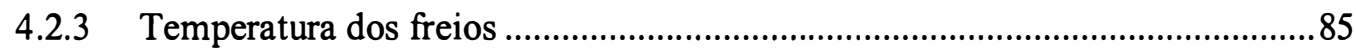

4.2.4 Número de acidentes envolvendo veículos desgovernados................................8

4.2.5 Localização das áreas de escape para a pista sul da Via Anchieta .....................87

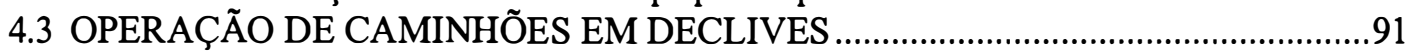

4.3.1 Estratégia de condução a ser adotada no declive................................................91

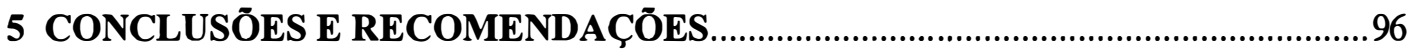

5.1 DISPOSITIVOS PARA CONTENÇÃO DE VEÍCULOS DESGOVERNADOS ...........96

5.2 ANÁLISE DA DESACELERAÇÃO EM CAIXAS DE RETENÇÃO.............................97

5.3 ANÁLISE DA LOCALIZAÇÃO DE ÁREAS DE ESCAPE...........................................98

5.4 OPERAÇÃO DE CAMINHỖES EM DECLIVES ….................................................99

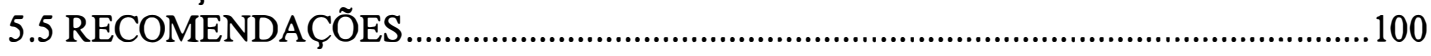

ANEXO A

ANEXO B

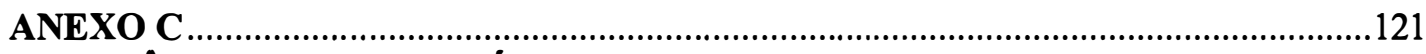

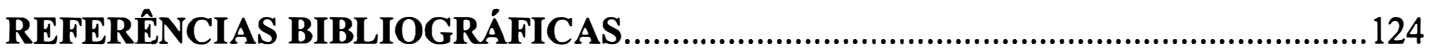




\section{LISTA DE FIGURAS}

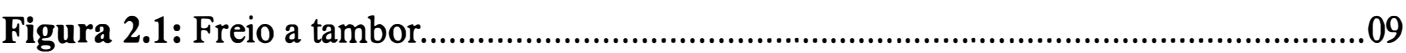

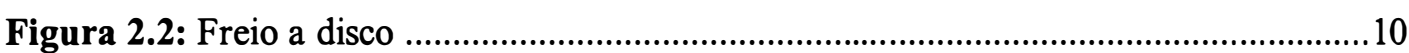

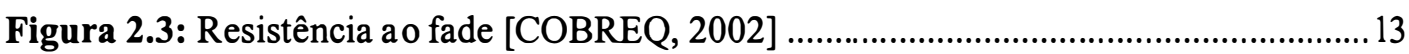

Figura 2.4: Recuperação das lonas e pastilhas de freio [COBREQ, 2002] ...........................14

Figura 2.5: Sensibilidade das lonas e pastilhas à velocidade [COBREQ, 2002] ..................15

Figura 3.1: Variação da resistência a o movimento.............................................................. 17

Figura 3.2: Evolução da temperatura do freio de serviço [Tetard et al., 1992] .....................20

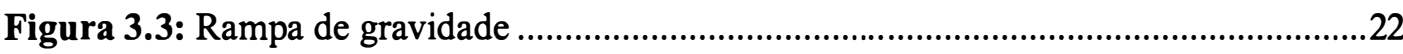

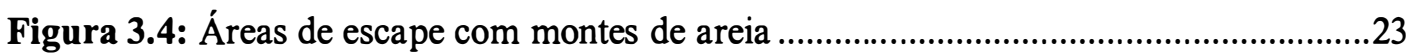

Figura 3.5: Área de escape para caminhões com caixa de retenção ....................................24



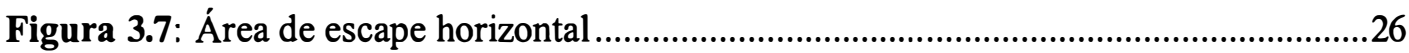

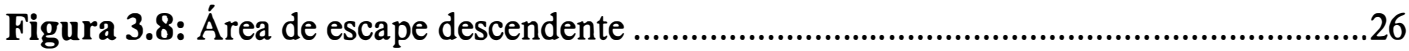

Figura 3.9: Esquema do sistema de retenção por correntes..................................................27

Figura 3.10: Esquema do sistema de retenção por discos de inércia.....................................28

Figura 3.11: Sistema de retenção com motores estacionários .............................................29

Figura 3.12: Sistema de retenção com bombas hidráulicas ..................................................29

Figura 3.13: Forças que atuam no veículo em movimento [AASHTO, 1994] ......................37

Figura 3.14: Relação entre desaceleração média e velocidade de entrada

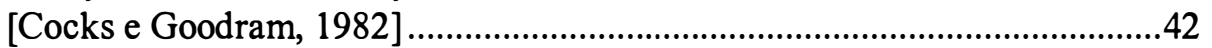

Figura 3.15: Esquema da profundidade da caixa de retenção............................................46

Figura 4.1: Caminhão entrando na caixa de retenção .........................................................53

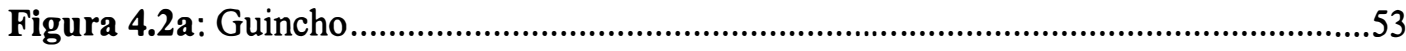

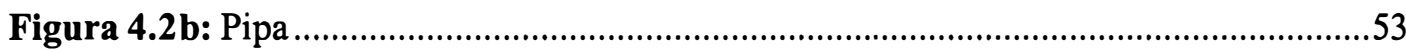

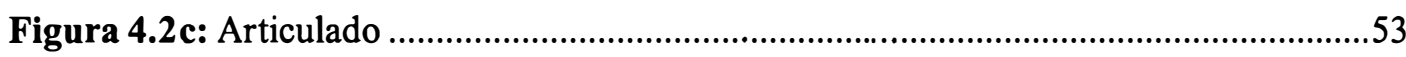

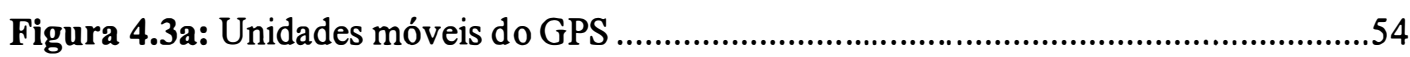

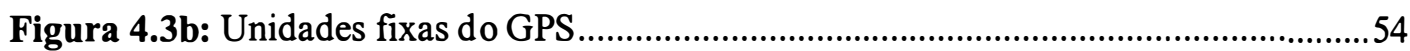


Figura 4.4: Seqüência de dados coletados pelo GPS para o teste 5 do caminhão rígido, $\mathrm{m}=23,29 \mathrm{t}$ . .55

Figura 4.5: Curvas de posição em função do tempo - caminhão rígido, $m=15,5 \mathrm{t}$...........57

Figura 4.6: Curvas de posição em função do tempo - caminhão rígido, $m=23,29 \mathrm{t}$.........58

Figura 4.7: Curvas de posição em função do tempo - caminhão articulado, $m=36,92$ t...58

Figura 4.8: Comportamento da velocidade a o longo da frenagem na caixa de brita para o teste 2 do caminhão rígido, $\mathrm{m}=23,29 \mathrm{t}$

Figura 4.9: Comportamento da desaceleração total para o teste 1 do caminhão rígido, $\mathrm{m}=15,5 \mathrm{t}$

Figura 4.10: Comportamento da desaceleração provocada pela resistência de rolamento da cinasita para o teste 5 do caminhão rígido, $\mathrm{m}=15,5 \mathrm{t}$

Figura 4.11: Variação de $a_{m}$ em função da velocidade de entrada .68

Figura 4.12: Comportamento da desaceleração média [Cocks e Goodram, 1982]...............69

Figura 4.13: Modelo para estimativa da desaceleração média devida à cinasita..................71

Figura 4.14: Conjuntos selecionados para calibração e validação do modelo......................72

Figura 4.15: Desaceleração média observada e estimada pelo modelo calibrado a partir do conjunto de dados .73

Figura 4.16: Diferenças entre a desaceleração média observada e estimada pelo modelo calibrado a partir do conjunto de dados A

Figura: 4.17: Desaceleração média observada e estimada pelo modelo calibrado a partir do conjunto de dados $\mathrm{A}$

Figura: 4.18: Diferenças entre a desaceleração média observada e estimada pelo modelo calibrado a partir do conjunto de dados B. .76

Figura 4.19: Traçado do trecho estudado digitalizado......................................................79

Figura 4.20: Velocidades de tombamento e escorregamento nas curvas.............................82

Figura 4.21: Forças atuantes no veículo sem freios em um declive .....................................83

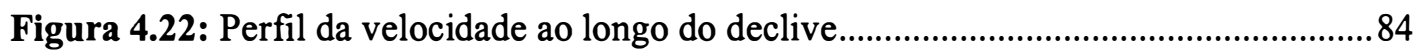

Figura 4.23: Perfil da temperatura dos freios ao longo do declive.........................................86

Figura 4.24: Aspectos do declive considerados no estudo de localização.............................8

Figura B.1: Perfil longitudinal da caixa de retenção medido em campo..............................119 


\section{LISTA DE TABELAS}

Tabela 1.1: Composição percentual da carga transportada por modo de transporte [GEIPOT, 2000]

Tabela 2.1: Limites legais de peso por eixo ou conjunto de eixos [CONTRAN, 1998 ].....06

Tabela 2.2: Pesos das classes de caminhões mais comuns

Tabela 3.1: Fatores considerados pelas agências de rodovias americanas para determinar a necessidade das áreas de escape [Eck, 1979]

Tabela 3.2: Fatores considerados pelas agências de rodovias americanas para determinar a localização de uma área de escape [Eck,1979].

Tabela 3.3: Distância aproximada do início do declive até a área de escape ........................33

Tabela 3.4: Valores de $R$ para diferentes materiais [Witheford, 1992] .................................39

Tabela 3.5: Valores da desaceleração média [QDoMR, 2000] ...........................................39

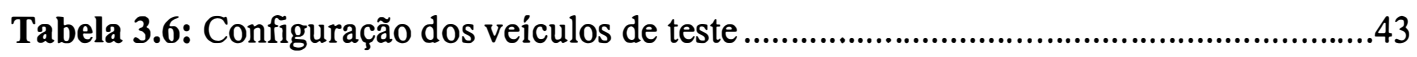

Tabela 3.7: Resumo dos resultados de desacelerações médias encontradas nos testes ........44

Tabela 4.1: Dados obtidos e selecionados no teste 1 do caminhão rígido, $\mathrm{m}=15,5 \mathrm{t}$........56

Tabela 4.2: Modelos calibrados para o movimento dos caminhões na caixa de retenção...60

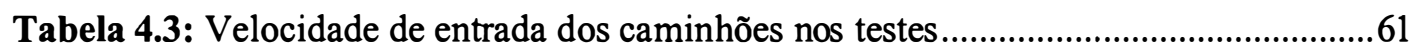

Tabela 4.4: Determinação da desaceleração provocada pela resistência do rolamento,

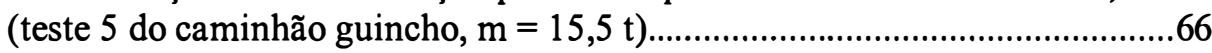

Tabela 4.5: Desacelerações médias encontradas em cada teste ..........................................67

Tabela 4.6: Equações da desaceleração provocada pela resistência de rolamento ................67

Tabela 4.7: Desacelerações médias observadas e estimadas através do modelo calibrado com dados do conjunto A.

Tabela 4.8: Desacelerações médias observadas e estimadas através do modelo calibrado com o conjunto de dados B 75

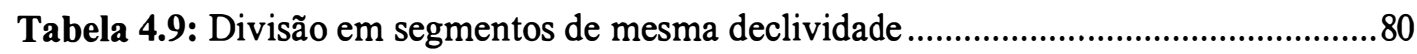

Tabela 4.10: Nomenclatura dos parâmetros e coeficientes do modelo de desempenho .......83

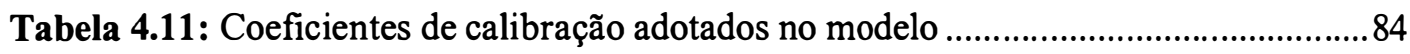

Tabela 4.12: Distribuição da ocorrência de acidentes ao longo do declive ..........................87

Tabela 4.13: Interação entre as possíveis condições nas curvas ..........................................90 
Tabela 4.14 Velocidades máximas em função da temperatura dos freios ...........................92

Tabela 4.15: Resultado de desempenho de um caminhão..................................................93

Tabela 4.16: Resultados da operação de caminhões no declive analisado ...........................94

Tabela 4.17: Operação dos caminhões variando a capacidade de carga ................................94

Tabela A.1: Dados coletados pelo GPS - teste 01 do caminhão com massa 15,5 t.............103

Tabela A.2: Dados coletados pelo GPS - teste 02 do caminhão com massa 15,5 t.............. 104

Tabela A.3: Dados coletados pelo GPS - teste 03 do caminhão com 15,5 t ........................ 105

Tabela A.4: Dados coletados pelo GPS - teste 04 do caminhão com massa 15,5 t.............. 106

Tabela A.5: Dados coletados pelo GPS - teste 05 do caminhão com massa 15,5 t..............107

Tabela A.6: Dados coletados pelo GPS - teste 06 do caminhão com massa 15,5 t..............108

Tabela A.7: Dados coletados pelo GPS - teste 07 do caminhão com massa 15,5 t.............109

Tabela A.8: Dados coletados pelo GPS - teste 08 do caminhão com massa 15,5 t.............110

Tabela A.9: Dados coletados pelo GPS - teste 01 do caminhão com massa 23,29 t...........111

Tabela A.10: Dados coletados pelo GPS - teste 02 do caminhão com massa 23,29 t ........112

Tabela A.11: Dados coletados pelo GPS - teste 03 do caminhão com massa 23,29 t.........113

Tabela A.12: Dados coletados pelo GPS - teste 04 do caminhão com massa 23,29 t ........114

Tabela A.13: Dados coletados pelo GPS - teste 05 do caminhão com massa 23,29 t.........115

Tabela A.14: Dados coletados pelo GPS - teste 06 do caminhão com massa 23,29 t.........116

Tabela A.15: Dados coletados pelo GPS - teste 01 do caminhão com massa 36,92 t.........117

Tabela A.16: Dados coletados pelo GPS - teste 02 do caminhão com massa 36,92 t.........118

Tabela B.1: Declividades ao longo do comprimento da caixa de retenção ...........................120 


\section{LISTA DE ABREVIATURAS E SIGLAS}

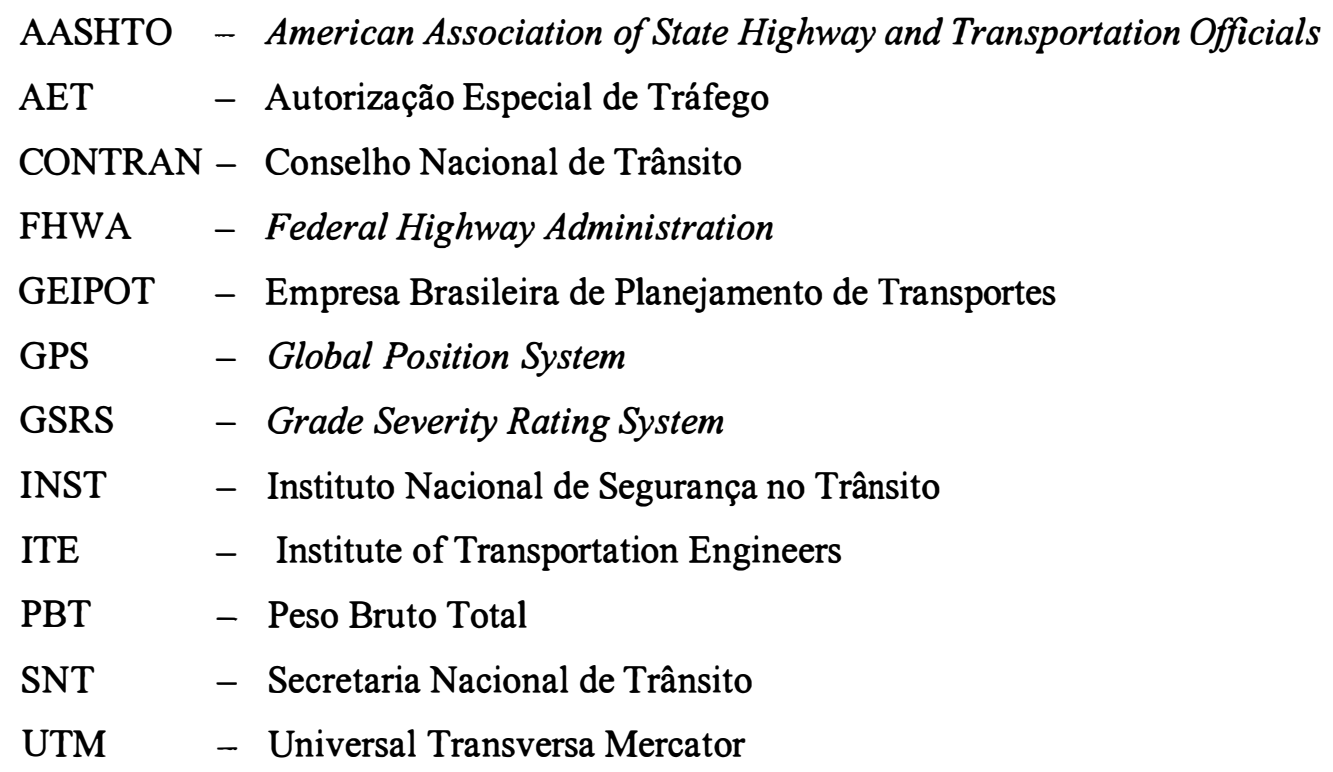


Zanoli, P. R. (2003). Área de escape para caminhões desgovernados. São Carlos, 2003. 128 p. Dissertação (Mestrado) - Escola de Engenharia de São Carlos, Universidade de São Paulo.

O objetivo desta dissertação foi estudar dispositivos para contenção de veículos desgovernados por falta de freios em declives longos e íngremes. Para tanto, fez-se uma revisão abrangente da literatura especializada e coletaram-se dados em testes realizados na área de escape construída no $\mathrm{km} \mathrm{42,7} \mathrm{da} \mathrm{pista} \mathrm{sul} \mathrm{da} \mathrm{Via} \mathrm{Anchieta,} \mathrm{onde} \mathrm{existe} \mathrm{um} \mathrm{declive} \mathrm{de}$ 12,8 km de extensão. A pesquisa relatada nesta dissertação focaliza três aspectos principais: a eficiência do dispositivo em deter caminhões sem freios, a localização do dispositivos e a determinação da velocidade segura de operação de caminhões nesse declive. Dados empíricos da desaceleração dos caminhões no dispositivo foram coletados com auxílio de GPS, o que permitiu estudar o comportamento dos caminhões dentro da caixa de retenção. Os dados coletados foram usados para a calibração de um modelo capaz de estimar a desaceleração média proporcionada pelo dispositivo em função da velocidade de entrada e do número de eixos do caminhão. Para a análise da localização do dispositivo, propôs-se um modelo que leva em consideração o perfil vertical do declive, a velocidade dos caminhões, a temperatura dos freios e a frequência de acidentes com veículos desgovernados ao longo do declive. A determinação da estratégia ótima de condução no declive consistiu em determinar a máxima velocidade que os caminhões podem percorrer o declive sem que os freios sofram superaquecimento. Os parâmetros usados na análise foram a massa bruta total do veículo e as reduções da sua caixa de câmbio. Foram estabelecidas velocidades e marchas máximas para 16 tipos de caminhão. Os resultados obtidos mostram que este tipo de dispositivo é capaz de deter caminhões desgovernados com seguraça e podem subsidiar projetos de novas áreas de escape no Brasil.

Palavras-chave: área de escape; caixa de retenção; caminhão desgovernado; declives longos e íngremes; frenagem. 


\section{ABSTRACT}

Zanoli, P. R. (2003). Escape areas for runaway trucks. São Carlos, SP, Brazil, 2003. 128 p.

M.Sc. Thesis - São Carlos School of Engineering, Universidade de São Paulo.

The objective of the dissertation was to study devices for arresting runaway trucks on long and steep downgrades. A comprehensive review of the literature was carried out and empirical data were collected by means of real life trials at an arrester bed build at a $12.8 \mathrm{~km}$ downgrade on the southward lanes of Via Anchieta, the old highway connecting the cities of São Paulo and Santos, in Brazil. The research reported focused on three major aspects: arresting capability of the escape area, location of the escape area and safe operating speeds for trucks on this downgrade. Truck deceleration data were collected during the trials by means of GPS equipment installed in the vehicles and were used to determine truck behavior within the arrester bed. A mathematical model, which allows the estimation of average deceleration as a function of entry speed and number of axles, was fitted to the observed data. The location study proposed a method to establish the points along the downgrade where arrester beds are needed, based on road profile, truck speed, brake temperature and accident data. Optimal driving strategies for truck drivers to negotiate safely the downgrade were also studied, in order to determine the downgrade maximum speed that would avoid brake overheating. The parameters used in this analysis were gross vehicle mass and gearbox characteristics. Safe maximum downgrade speeds and gears were established for 16 truck models. The results, which showed that arrester beds are capable of safely stopping runaway trucks in long and steep downgrades, may also be used to assist the design of new arrester beds in Brazil.

Keywords: truck escape areas; arrester bed; runway trucks; steep and long downgrade; truck braking. 


\section{INTRODUÇÃO}

Acidentes por falhas de freios são ocorrências potencialmente catastróficas em declives longos e íngremes, principalmente nos locais onde o tráfego de veículos pesados é alto. A perda de freio em declives é decorrente principalmente de uma maior solicitação do sistema de freios, sendo que a causa mais comum para essas falhas é o fade, ou seja, a perda da capacidade de frenagem por aquecimento do conjunto lona/tambor de freio, provocada pelo uso excessivo e prolongado do freio de serviço ao longo de um declive.

A implantação de áreas de escape, que são dispositivos para contenção de caminhões que perdem o controle em rodovias com declives longos e íngremes, visa reduzir o número de acidentes envolvendo veículos desgovernados, fornecendo aos motoristas uma oportunidade de frear o veículo de forma segura. O uso de uma área de escape numa situação de emergência depende, obviamente, de uma decisão do motorista; por isso, além da construção do dispositivo, faz-se necessário orientar os motoristas de caminhões sobre sua utilização e eficiência.

\subsection{OBJETIVO}

A meta da pesquisa desenvolvida foi analisar os dispositivos para contenção de veículos desgovernados por falta de freios e fornecer subsídios para sua disseminação no Brasil. Para tanto, foram estabelecidos os seguintes objetivos específicos:

(I) Estudar o estado da técnica relativo ao projeto e dimensionamento de dispositivos para contenção de veículos desgovernados, procurando 
estabelecer os principais aspectos de cada um e verificar sua aplicabilidade às condições das rodovias nacionais;

(II) Estudar, por meio de ensaios in situ, a caixa de retenção construída no km 42 da Via Anchieta, visando propor um modelo capaz de estabelecer a desaceleração média proporcionada pelo dispositivo em função da velocidade de entrada e das características do veículo desgovernado; e

(III) Propor um método para analisar a melhor localização do dispositivo para contenção de veículos desgovernados em declives longos, demonstrando sua aplicabilidade num estudo de caso focalizando a pista sul da Via Anchieta.

\subsection{JUSTIFICATIVA DA PESQUISA}

O primeiro aspecto a ser destacado como justificativa para o desenvolvimento da pesquisa proposta trata da importância econômica que o transporte rodoviário representa no cenário nacional. A Tabela 1.1 mostra como a modalidade rodoviária se destaca em relação às demais no transporte de cargas no Brasil [GEIPOT, 2000].

Tabela 1.1: Composição percentual da carga transportada por modo de transporte [GEIPOT, 2000]

\begin{tabular}{lc}
\hline Modo de Transporte & $\begin{array}{c}\text { Participação na distribuição de } \\
\text { cargas (\%) }\end{array}$ \\
\hline Aéreo & 0,33 \\
Aquaviário & 13,86 \\
Dutoviário & 4,46 \\
Ferroviário & 20,86 \\
Rodoviário & 60,49 \\
\hline
\end{tabular}

O segundo aspecto a ser destacado, refere-se ao aumento do risco de acidentes envolvendo veículos pesados, problema que se agrava em declives. A frota brasileira é composta por mais de 34 milhões de veículos, sendo que, mais de 4.700.000 são veículos de carga, (aproximadamente $14 \%$ do total). Apesar de os 
veículos de carga constituírem menos de um sexto da frota nacional, as estatísticas mostram que cerca de $30 \%$ dos acidentes ocorridos nas rodovias federais policiadas envolveram veículos de carga [GEIPOT, 2000].

A combinação de veículos de carga com trechos em declives longos e íngremes faz com que a probabilidade de ocorrência de acidentes seja ainda maior [AASHTO, 1994; SETRA, 1993; Witheford, 1992]. Estudos realizados na França mostram que nos trechos com declives acontecem $12 \%$ dos acidentes com caminhões, sendo que os mesmos percorrem apenas $8 \%$ de sua quilometragem em declives, e para declives com $4 \%$ de inclinação e mais de $6 \mathrm{~km}$ de extensão o risco de acidentes para os caminhões duplica [SETRA, 1993].

No Brasil, a Serra do Mar, um sistema montanhoso que se estende do Espírito Santo até o sul de Santa Catarina, representa uma barreira natural que dificulta a ligação interior-litoral. As rodovias construídas na Serra do Mar apresentam declives longos e íngremes e as mais importantes servem de ligação para os principais portos do país, como o Sistema Anchieta-Imigrantes (SP-150 e SP-160), que liga a capital paulista ao porto de Santos, e a rodovia BR-277, que liga a capital paranaense ao porto de Paranaguá. Essas rodovias recebem um tráfego intenso de caminhões que transportam produtos de importação e exportação.

Outro fator que justifica o desenvolvimento da pesquisa é o tráfego de veículos cada vez mais pesados. $O$ peso excessivo no eixo aumenta a possibilidade de fadiga, provoca defeitos mecânicos e exige maior solicitação dos freios, que se aquecem rapidamente e perdem parte de sua eficiência [Couto, 1999].

Cada vez mais motoristas e empresas de transporte procuram alternativas de proporcionar uma melhor eficiência econômica no transporte de cargas, tornando-se comum a prática de aumentar a quantidade de produtos transportados por viagem, com veículos de grandes dimensões, e, em alguns casos, até mesmo desrespeitandose os limites legais de peso. Essas ações reduzem a segurança do transporte rodoviário. 


\subsection{ESTRUTURA DO TRABALHO}

Este texto está organizado em cinco capítulos. O capítulo 1 esta a introdução, em que o objetivo e a justificativa dessa pesquisa são apresentados.

No capítulo 2, uma revisão literária mostra uma visão geral sobre os aspectos dos caminhões nacionais, no que diz respeito a peso e frenagem. Neste capítulo é feito um levantamento sobre a capacidade de carga dos veículos, de acordo regulamentações brasileiras, bem como discutem-se as características do sistema de freios de caminhões.

O capítulo 3 contém uma descrição dos diferentes tipos de dispositivos para contenção de veículos desgovernados, na qual os critérios de projeto, implantação e a escolha do dispositivo utilizado para contenção de veículos desgovernados são discutidos. Os resultados de pesquisas e ensaios desenvolvidos em outros países que avaliaram a eficiência de dispositivos para contenção são mostrados neste capítulo.

A descrição dos ensaios, a análise dos dados, os resultados obtidos referentes à determinação da desaceleração média em uma caixa de retenção, o estudo de caso que ilustra a aplicação de um método de determinação do local onde um dispositivo de contenção deve ser implantado e a avaliação da operação de caminhões nacionais em declives são apresentados no capítulo 4.

As conclusões encontradas com o desenvolvimento da pesquisa $\mathrm{e}$ as recomendações para o incremento de pesquisas futuras compõem o conteúdo do capítulo 5.

O anexo A apresenta os dados coletados pelo equipamento de GPS durante os testes realizados, o anexo $\mathrm{B}$ apresenta o perfil longitudinal da caixa de retenção estudada e o anexo $\mathrm{C}$ traz os resultados fornecidos pelo simulador de temperatura de freios, GSRS. Por fim, é apresentada a bibliografia revisada. 


\section{ASPECTOS DOS CAMINHÕES}

Neste capítulo descrevem-se os principais aspectos dos caminhões relacionados com a perda de freios em declives longos e íngremes. $\mathrm{O}$ primeiro aspecto a ser abordado diz respeito às características do peso dos caminhões que compõem a frota nacional. $\mathrm{O}$ segundo aspecto trata de frenagem e de sistemas de freios mais utilizados em caminhões.

\subsection{PESO DOS CAMINHÕES NACIONAIS}

Os veículos que trafegam pelas rodovias brasileiras, para ef eito de segurança, devem respeitar os limites legais estabelecidos pelas autoridades de trânsito e as restrições técnicas impostas pelos fabricantes de veículos, que estabelecem os valores máximos do peso bruto por eixo ou para um conjunto de eixos, de acordo com o número de pneus e espaçamento entre os eixos.

Os limites legais de pesos para caminhões no Brasil são definidos pelo CONTRAN [1998], através da Resolução 12/98 (Tabela 2.1). De acordo com a resolução, o peso bruto total por unidade ou combinações de veículos é de 45 toneladas. Entretanto, o peso máximo dos veículos também é limitado pelo fabricante, por meio de restrições técnicas, para atender às características do projeto do veículo. Os limites legais e os limites técnicos devem ser comparados e utiliza-se o menor deles, a fim de não se ultrapassar quaisquer das limitações [Mercedes Benz, 1994]. 
peso transmitido por eixo. Essa tolerância máxima é de 7,5\% sobre os limites legais de peso bruto transmitido por eixo do veículo.

As classes de caminhões mais comuns nas rodovias nacionais e o limite de peso bruto total desses veículos são apresentados na Tabela 2.2.

Tabela 2.2: Pesos das classes de caminhões mais comuns

\begin{tabular}{|c|c|c|c|}
\hline Nomenclatura & Configuração típica & Classe & PBTC \\
\hline 11 & & $\begin{array}{l}\text { Rígido } \\
\text { Leve }\end{array}$ & $16 \mathrm{t}$ \\
\hline 12 & & $\begin{array}{l}\text { Rígido } \\
\text { Pesado }\end{array}$ & $23 \mathrm{t}$ \\
\hline $11+1$ & & Articulado & $26 \mathrm{t}$ \\
\hline $11+2$ & & Leve & $33 \mathrm{t}$ \\
\hline $11+3$ & & & $41,5 \mathrm{t}$ \\
\hline $12+3$ & & $\begin{array}{c}\text { Articulado } \\
\text { Pesado }\end{array}$ & $45 \mathrm{t}$ \\
\hline $11+111$ & & & $45 \mathrm{t}$ \\
\hline
\end{tabular}

\subsection{SISTEMAS DE FREIOS DE CAMINHÕES}

O sistema de freios de um veículo tem como finalidade proporcionar ao motorista uma ação segura de desaceleração, com ou sem a redução da velocidade a zero, conforme as condições de tráfego o requerem e obedecendo aos requisitos preestabelecidos pelo fabricante e pela legislação vigente [Fernandes, 1994].

Os veículos pesados combinados podem realizar vários processos de frenagem. A atuação dos freios das rodas se dá de várias formas, por exemplo, com atuação dos freios das rodas de todos os eixos veiculares, com atuação dos freios das rodas dos eixos do semi-reboque apenas, sendo que a frenagem dos veículos ainda pode ser efetuada a partir de várias velocidades e outras condições iniciais, o que possibilita inúmeras condições operacionais durante o processo de frenagem [Fernandes, 2000]. 
Os sistemas de freios dos veículos subdividem-se em freio de serviço; freio de estacionamento e freios auxiliares. Os freios de serviço são usados em quase todos os processos de frenagem dos veículos, composto na maioria dos casos por tambores ou discos. Os freios de estacionamento são usados para imobilizar o veículo quando estacionado e os freios auxiliares proporcionam uma ação de frenagem sem usar as superfícies de atrito dos freios, como exemplo, o freio motor que requer a escolha de uma marcha adequada. Durante o processo de desaceleração do veículo o motorista deve distribuir o esforço de frenagem adequadamente entre os diferentes sistemas [Tetard et al., 1992].

As características do processo de frenagem e os tipos de freios mais utilizados em caminhões são apresentados a seguir.

\subsubsection{Processo de frenagem}

Durante seu movimento, os veículos, possuem energia mecânica na forma de energia cinética e/ou energia potencial. No processo de frenagem, o sistema de freios é responsável por transformar a energia mecânica do veículo em outras formas de energia, basicamente como energia térmica (na forma de calor), e uma pequena parcela em energia acústica (na forma de ruído).

O princípio do funcionamento dos freios baseia-se no atrito entre dois corpos que são comprimidos um contra o outro. Esse atrito é responsável por um dos maiores problemas que afetam o sistema de freios de um veículo, o superaquecimento do sistema, que além de danificar os freios, pode resultar em acidentes rodoviários. Os veículos com excesso de carga ou sob condições não recomendáveis de uso estão mais sujeitos a esse tipo de problema [Fernandes, 1994].

\subsubsection{Tipos de freios}

Os tipos de freios mais comuns nos veículos rodoviários de transporte de passageiros e cargas são descritos a seguir. 


\section{Freios a tambor}

É o freio constituído de um tambor solidário ao eixo da roda e por sapatas que ficam fixas a um espelho que, por sua vez, está ligado ao chassis. Sobre as sapatas são fixadas as lonas. $O$ processo de frenagem acontece por meio de uma aplicação radial das lonas na superficie interna do tambor (Figura 2.1).

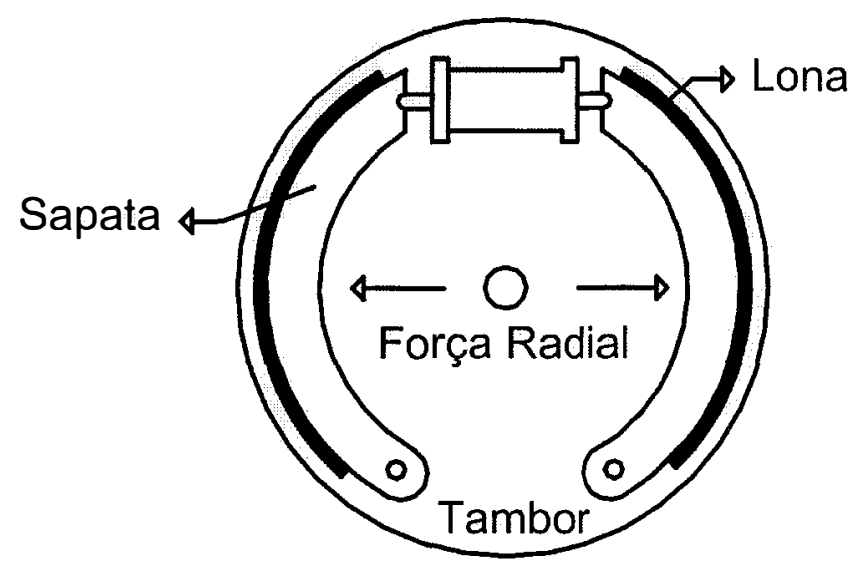

Figura 2.1: Freio a tambor

Os freios a tambor são utilizados normalmente nas rodas traseiras dos veículos de passeio e camionetas, sendo rara sua utilização nas rodas dianteiras destes veículos, e têm uso predominante nos freios dos caminhões médios e pesados, dos ônibus, dos reboques e dos semi-reboques [Fernandes, 1994]. O uso desse tipo de freio nos caminhões é justificado pelo seu alto fator de freio, o que exige menor esforço de aplicação das lonas contra o tambor [Limpert, 1992].

O fator de freio é dado pela razão entre a força de frenagem produzida no contato entre lonas e tambor e a força aplicada para comprimir as lonas contra o tambor. Quando esta relação é maior que a unidade, indica um menor esforço de aplicação das lonas contra o tambor [Fernandes, 1992].

Os freios a tambor são sensíveis à temperatura. Quando estes atingirem valores entre 400 a $530^{\circ} \mathrm{C}$ podem apresentar perda de eficiência na frenagem, afetando os coeficientes de atrito e aumentando o diâmetro do tambor, o que reduz o contato entre lona e tambor [Limpert, 1992]. 


\section{Freios a disco}

É o freio constituído de um disco solidário ao eixo da roda e por pastilhas que estão instaladas em uma pinça acoplada ao chassis. $O$ processo de frenagem se dá pela aplicação axial das pastilhas na superfície lateral do disco (Figura 2.2).

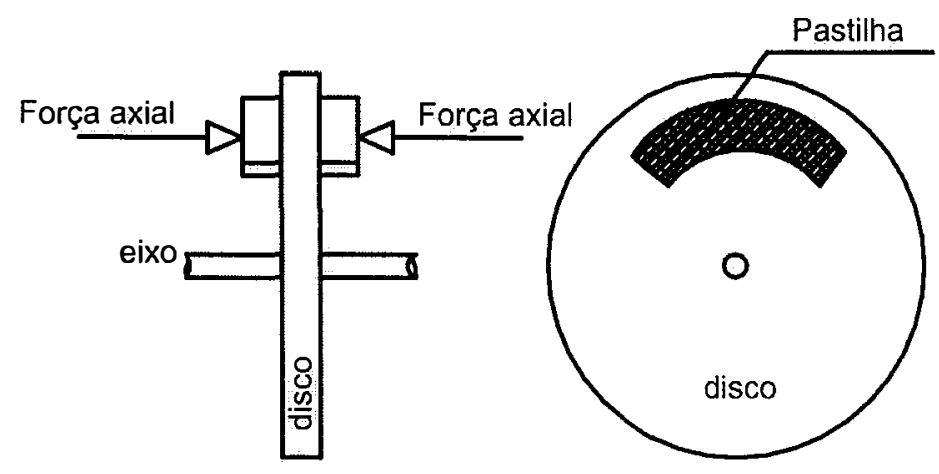

Figura 2.2: Freio a disco

Os freios a disco podem ser compostos por uma ou duas pastilhas. Nos freios com uma pastilha, apenas uma superficie lateral do disco é usada; nos freios a disco com duas pastilhas, as duas superfícies laterais são usadas. O mais comum é a utilização de freios a disco com duas pastilhas, pois proporciona maior área de atrito e uma geração de calor mais equilibrada no disco [Fernandes, 1994].

O desenvolvimento dos freios a disco aconteceu devido à procura por um freio que pudesse ser resfriado mais rapidamente que os a tambor, pois quanto mais frio o freio, melhor sua eficiência de frenagem. Os freios a disco possuem uma maior área de ventilação (todo o disco) e uma área de atrito relativamente pequena, que é igual à área da superficie da pastilha [Oliveira, 2002].

A maior vantagem dos freios a disco é sua capacidade de operar com pouco fade ou fadiga a altas temperaturas, entre 800 a $900^{\circ} \mathrm{C}$ [Limpert 1992]. O fade é o termo utilizado para designar o efeito da perda de atrito da lona ou pastilha, provocada pelo calor gerado durante as frenagens.

Os automóveis modernos possuem freio a disco nas rodas de ambos os eixos; caminhões leves utilizam freio a disco no eixo dianteiro; e nos caminhões pesados o 
predomínio ainda é do freio a tambor, mas nota-se uma tendência para que no futuro possam ser equipados com freio a disco [Fernandes, 1994].

\subsubsection{Comportamento térmico dos freios}

Os corpos que se atritam durante o processo de frenagem são lonas com tambores ou pastilhas com discos. A fricção entre esses corpos provoca um aumento de temperatura entre a lona e tambor ou entre pastilha e disco, o que eleva a temperatura do freio. As lonas e pastilhas são geralmente constituídas de materiais mau condutores de calor, permitindo que nos casos mais críticos apenas $5 \%$ do calor gerado na frenagem seja absorvido pelas lonas ou pastilhas [Iombriller, 1997].

Os veículos comerciais pesados podem produzir temperaturas máximas na superfície dos freios de aproximadamente 300 a $400^{\circ} \mathrm{C}$, que é uma temperatura suficiente para provocar perda de eficiência dos freios [Limpert,1992].

A temperatura máxima suportada pelo sistema de freio constitui um fator limitante no desempenho de frenagem. Para o estudo dos efeitos da temperatura no processo de frenagem são considerandos duas condições operacionais: a frenagem moderada de longa duração e a frenagem severa de pequena duração [Canale, 1989].

A frenagem de longa duração acontece quando o veículo está descendo uma rampa de grande extensão. Neste caso, todo calor gerado deve ser dissipado para o ambiente, mantendo a temperatura do sistema abaixo da máxima suportada pelos materiais que se atritam. As formas de dissipação do calor geradas durante a frenagem para o meio ambiente constituem um fator importante para o bom funcionamento dos freios.

A dissipação de energia faz-se pelos três modos usuais de transmissão de calor: uma pequena parte pela condução, em que o calor é transmitido para os componentes do freio; raramente por radiação; e principalmente pela convecção, transmitindo calor para as moléculas de ar próximas ao sistema de freio. A intensidade da conveç̧ão depende da área de exposição ao ambiente: quanto maior área, melhor será a troca de calor. 
Em uma frenagem severa e de pequena duração (emergência), toda energia convertida em calor acaba sendo armazenada na capacidade térmica do sistema de frenagem. A ação rápida provoca pouca transmissão de calor com o ambiente e alta absorção de energia no freio. Em ambas as condições operacionais, o aquecimento dos freios é inevitável.

O desempenho térmico dos freios, por sua vez está relacionado com a segurança no processo de frenagem, fazendo com que os sistemas e materiais utilizados na fabricação fossem sendo aperfeiçoados com passar dos anos. Com o aumento da velocidade e capacidade dos veículos, foram necessárias melhorias nas superfícies de contato dos freios através do emprego de materiais mais resistentes ao calor e capazes de oferecer aos motoristas uma desaceleração confiável [Iombriller, 1997].

Os materiais utilizados para confecção dos sistemas de freios devem apresentar características térmicas suficientes para resistir da melhor forma possível às elevadas temperaturas que ocorrem durante a frenagem. $\mathrm{Na}$ fabricação dos tambores e discos utiliza-se em geral ferro fundido ou aço, materiais que dissipam rapidamente o calor gerado na frenagem [Fernandes, 1994].

As pastilhas e lonas devem proporcionar uma elevada força de atrito; logo os materiais utilizados na fabricação dos componentes do freio devem apresentar elevados coeficientes de atrito e pouca sensibilidade a variação de temperatura e velocidade.

Na fabricação de lonas e pastilhas no Brasil, utiliza-se semi-metais ou asbesto (fibra de mineral incombustível). As lonas e pastilhas confeccionadas com semimetais visam estabelecer um melhor desempenho térmico, resistindo a temperaturas elevadas. As lonas e pastilhas de asbesto estão sendo substituídas por fibras de vidro, metais, carbono, cerâmicas e outras substâncias, devido a questões ambientais [Fernandes, 1994; Iombriller, 1997].

As principais características das lonas e pastilhas de freio, que determinam a segurança e o desempenho são a resistência ao fade, a recuperação e a sensibilidade à velocidade [COBREQ, 2002]. 


\section{Resistência ao Fade}

Todas as lonas e pastilhas de freios, quando submetidas a temperaturas elevadas, apresentam uma perda do atrito entre lona e tambor ou pastilha e disco (fade). A diferença está na rapidez com que os níveis de fade são atingidos [COBREQ, 2002]. As lonas e pastilhas de qualidade superior apresentam um melhor desempenho quando sujeitas a temperaturas elevadas. A eficiência de frenagem se perderá gradualmente quando o ponto de fade é atingido, que faz com que o motorista passe a pressionar com mais intensidade o pedal do freio. O fade gradual passa a ser um mecanismo de alerta para os motoristas, pois permite que exerça um controle adequado sobre o veículo [COBREQ, 2002].

Nas lonas de qualidade inferior, o fade acontece de súbito, o que pode provocar uma situação em que o motorista perde o controle do veículo. A Figura 2.3 ilustra o comportamento das lonas e pastilhas em função da variação de temperatura do disco ou tambor, em que as lonas e pastilhas de boa qualidade apresentam um fade gradual.

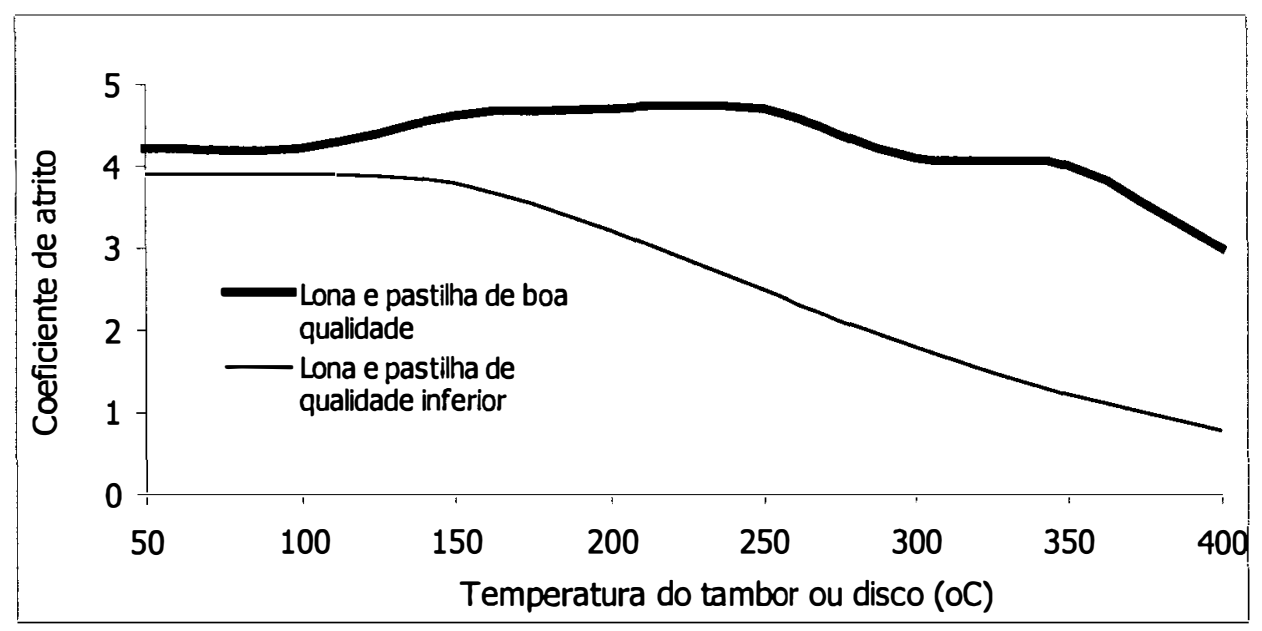

Figura 2.3: Resistência ao fade [COBREQ, 2002]

Como pode ser visto na Figura 2.3, o coeficiente de atrito dos freios feitos com materiais de qualidade inferior sofre uma redução mais acentuada, antecipando para temperaturas inferiores a $260^{\circ} \mathrm{C}$ a ocorrência do fade. 


\section{Recuperação}

A recuperação é a propriedade de voltar rapidamente ao nível de atrito original após os freios terem sido submetidos a elevadas temperaturas. Na Figura 2.4, observa-se o comportamento das pastilhas e lonas de boa qualidade (recuperação rápida), e de baixa qualidade (recuperação lenta) [COBREQ, 2002].

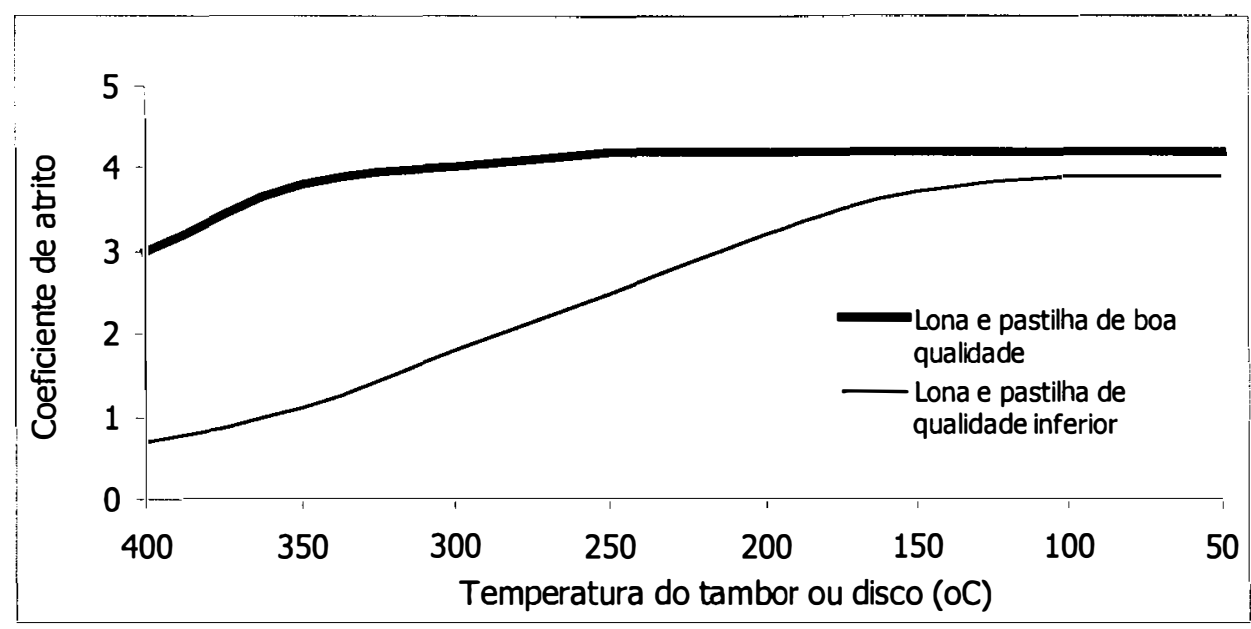

Figura 2.4: Recuperação das lonas e pastilhas de freio [COBREQ, 2002]

\section{Sensibilidade à velocidade}

A variação de velocidade oferece mudanças nas características de atrito dos freios. As lonas e pastilhas de boa qualidade são fabricadas para não apresentarem essa variação nas características de atrito. As lonas e pastilhas de qualidade inferior, quando submetidas a variações de velocidade, passam a frear o veículo a distâncias cada vez maiores, devido à redução do coeficiente de atrito [COBREQ, 2002].

A Figura 2.5 mostra o comportamento do coeficiente de atrito de lonas ou pastilhas em função da velocidade do veículo. É possível verificar que os materiais de boa qualidade apresentam uma sensibilidade à velocidade menor que os materiais de qualidade inferior. 


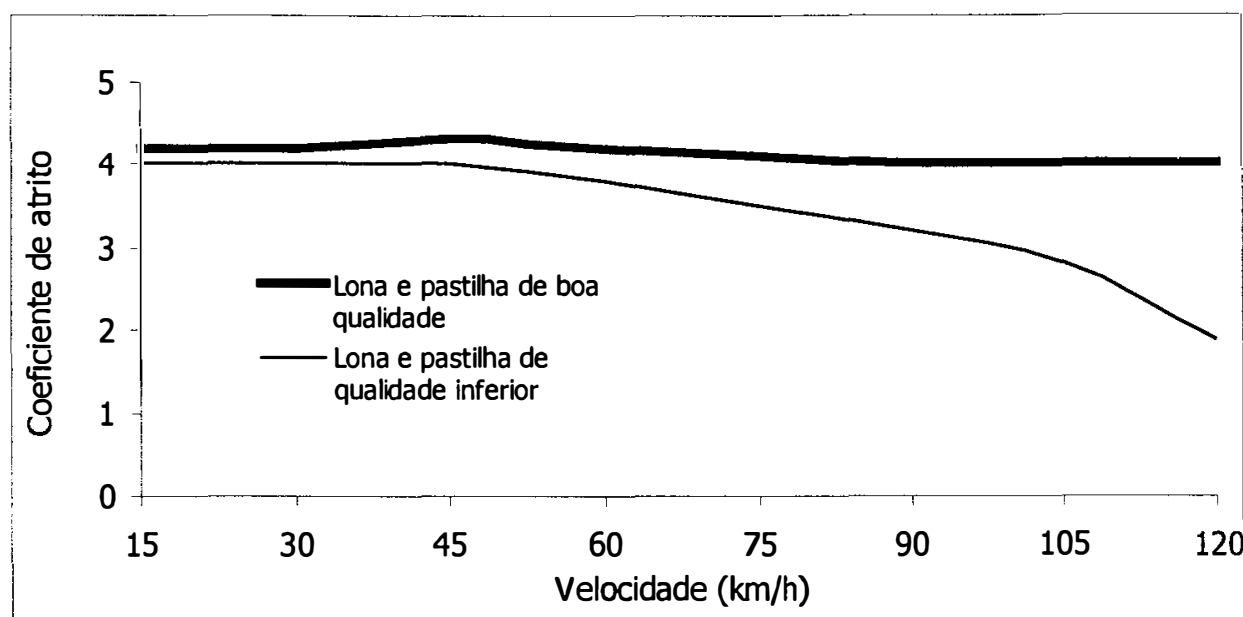

Figura 2.5: Sensibilidade das lonas e pastilhas à velocidade [COBREQ, 2002]

\subsection{CONSIDERAÇÕES FINAIS}

A investigação das características do peso e dos freios de caminhões serviu para auxiliar a análise das causas de acidentes em declives, e até mesmo informar sobre a importância de utilizar veículos em condições operacionais adequadas, contribuindo assim, com a redução de acidentes por falta de freios. No próximo capítulo são apresentados estudos mais detalhados sobre as características dos acidentes em declives e sobre os dispositivos implantados nas rodovias com a finalidade de conter veículos desgovernados. 


\section{DISPOSITIVOS PARA CONTENÇÃO DE VEÍCULOS DESGOVERNADOS}

Este capítulo apresenta uma revisão bibliográfica sobre os aspectos relacionados aos acidentes envolvendo caminhões fora de controle em declives longos e íngremes e sobre os dispositivos para contenção de veículos desgovernados, focalizando as principais causas de acidentes com caminhões e os critérios de projeto, implantação e operação dos diferentes tipos de dispositivos para contenção de veículos desgovernados.

\subsection{LOCOMOÇÃO DE CAMINHÕES EM DECLIVES LONGOS E ÍNGREMES}

A interação entre as forças que atuam no veículo (força motriz e forças de resistência) é responsável pelo movimento. No caso dos veículos rodoviários, a força motriz é oriunda do motor do caminhão e as forças de resistência consideradas são originárias do contato entre pavimento/pneumático, do deslocamento na atmosfera terrestre e do efeito das rampas. Quando a intensidade da força motriz for maior que a resultante das forças de resistência, o veículo está acelerando, caso contrário, o veículo está desacelerando. Quando a resultante das forças de resistência for igual a força motriz o veículo passa a trafegar com velocidade constante, conhecida como velocidade de equilíbrio.

Nos declives, o efeito da rampa funciona acelerando o caminhão, o que dificulta o controle desse tipo de veículo. O ideal é que nos declives os condutores utilizem o freio motor como meio de proporcionar uma força de resistência ao movimento de descida e controle da velocidade, evitando assim o uso excessivo do freio de serviço. 


\subsubsection{Mecânica da locomoção de veículos rodoviários em declives}

Conhecendo a força motriz produzida pelo motor e a intensidade das forças de resistência que atuam sobre o caminhão durante o movimento é possível verificar qual a velocidade de equilíbrio do veículo para diferentes condições de tráfego.

A resistência de movimento $(R)$ é composta por três parcelas, sendo que duas atuam no sentido contrário ao movimento, a resistência de rolamento $\left(R_{r}\right)$ e a resistência do ar $\left(R_{a}\right)$. A terceira parcela, a resistência de rampa $\left(R_{g}\right)$ só existe quando o veículo viaja em declives, atuando a favor do movimento ou em aclives, atuando contra o movimento. A soma das duas primeiras parcelas é chamada de resistência básica ou inerente ao movimento $\left(R_{t}\right)$, sua intensidade varia em função das características e da velocidade desenvolvida pelo veículo. A resistência de rampa depende exclusivamente da declividade e da massa do veículo [Setti, 2002].

Como a resistência básica depende da velocidade é possível obter uma curva que represente a variação da intensidade da resistência básica em função da velocidade. Na Figura 3.1 pode ser visto um exemplo de uma função $R_{t}$, ou seja, a variação da resistência ao movimento de um veículo em função da velocidade para um trecho plano. Se este mesmo veículo passar a trafegar por um declive, a parcela de resistência de rampa será somada à resistência básica, determinando assim, a curva de $R$, logo abaixo da curva $R_{t}$ por se tratar de um declive.



Figura 3.1: Variação da resistência ao movimento 
Como pode ser visto na Figura 3.1, a distância entre as curvas $R_{t}$ e $R$ para um determinada velocidade é igual a intensidade da resistência de rampa que atua no veículo em um declive com 5\% de inclinação. Supondo uma condição em que o veículo tenha que trafegar durante todo o declive a uma velocidade limite constante ( $\left.\mathrm{V}_{\text {limite }}\right)$ de $50 \mathrm{~km} / \mathrm{h}$ a força de frenagem solicitada para essa situação é dada pela distância entre a curva $R$ e o ponto em que a força motriz do caminhão é nula. Vale ressaltar que essa força de frenagem pode ser proveniente do freio de serviço e/ou do sistema de freios auxiliares como o freio motor.

\subsubsection{Condução dos caminhões em declives longos e íngremes}

Um dos problemas de condução de veículos em declive está na dificuldade de controlar a velocidade dos veículos pesados sem o uso excessivo dos freios. Existem diferentes sistemas de freios que são usados isoladamente ou em conjunto, conforme a estratégia de condução adotada pelo motorista. O motorista regula a velocidade mediante a distribuição da frenagem entre os sistemas de freios como o freio de serviço e os freios auxiliares.

O ideal é que em declives os motoristas adotem estratégias de controle de velocidade que minimizem o uso dos freios de serviço e, assim, evitem que a temperatura dos freios supere $250^{\circ} \mathrm{C}$ [Tetard, 1992]. A distribuição adequada dos esforços de frenagem entre os diferentes sistemas previne o aquecimento exagerado dos freios de serviço.

Um estudo realizado na via expressa do túnel Mont-Blanc, França, avaliou a relação da temperatura dos freios em função das estratégias de condução adotadas pelos motoristas em declives [Tetard et al., 1992]. Foi notado que aspectos pessoais, como a experiência e idade dos motoristas, influenciam na escolha da estratégia de condução: motoristas menos experientes tendem a adotar condutas mais arriscadas utilizando marchas inadequadas para percursos em declive; no entanto, alguns motoristas experientes desenvolvem maiores velocidades, o que também pode levar a fadiga do sistema de freios no caso de uma frenagem de emergência.

$\mathrm{Na}$ primeira estratégia avaliada, o motorista adota velocidades constantes, entre 13 a $60 \mathrm{~km} / \mathrm{h}$. O uso do freio de serviço variou de 0 a $10 \%$, a marcha adotada é 
a mais curta, proporcionando o uso máximo do freio motor. Essa estratégia é adotada por $60 \%$ dos motoristas e é mais freqüente entre motoristas com mais de 30 anos de idade. Os motoristas que adotam velocidades baixas, constantes e usam a capacidade máxima dos freios auxiliares quase não utilizam os freios de serviço durante a descida, o que proporciona menores temperaturas no sistema de freios.

$\mathrm{Na}$ segunda estratégia, viaja-se em de velocidades mais elevadas, entre 40 a $80 \mathrm{~km} / \mathrm{h}$, realizando troca de marchas nos diferentes trechos. Nos trechos com rampas acentuadas utiliza-se marcha mais curta, explorando mais o freio motor. Nos trechos com rampas de pouca inclinação, utiliza-se marcha mais longa. $\mathrm{O}$ uso do freio de serviço não ultrapassa $30 \%$ e ocorre durante os períodos de troca de marcha. Essa estratégia é adotada por $25 \%$ dos motoristas, independentemente da idade. Notou-se que nesse caso, os motoristas desenvolvem velocidades mais elevadas e irregulares e que é necessário usar mais o freio de serviço, provocando temperaturas mais elevadas no sistema de freios.

$\mathrm{Na}$ terceira estratégia estudada, os caminhões trafegam em velocidades semelhantes à primeira estratégia analisada, mas a marcha escolhida é a mais longa e o uso do freio de serviço é superior a $80 \%$. Essa estratégia é geralmente adotada por cerca de $10 \%$ dos motoristas, principalmente pelos mais jovens. Observou-se que os motoristas que desenvolvem velocidades baixas aplicam constantemente o freio de serviço durante a descida, causando temperaturas mais elevadas no sistema de freios, quando comparado com as estratégias anteriores, visto que há uma menor utilização do freio motor.

$\mathrm{Na}$ quarta estratégia o motorista adota velocidades idênticas às da segunda, mas um dispositivo retardador eletromagnético auxilia os freios de serviço. Poucos veículos dispõem desse sistema. Esse dispositivo é utilizado como um redutor de velocidade que substitui, na maioria dos casos, a aplicação do freio de serviço que permanece sob baixas temperaturas.

A segunda e a terceira estratégia constituem as de maior risco para ocorrência de falhas no freio de serviço, pois apresentaram as temperaturas mais elevadas durante a simulação. A primeira estratégia apresentou as menores temperaturas 
(Figura 3.2). Foi também notado que, geralmente a estratégia adotada pelos motoristas no início do declive permanece a mesma durante toda descida.

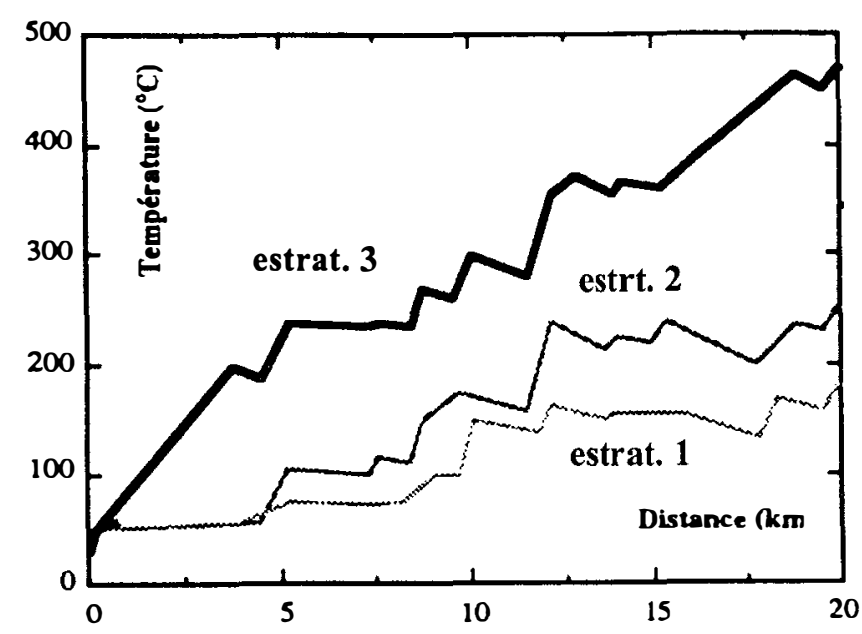

Figura 3.2: Evolução da temperatura do freio de serviço [Tetard et al., 1992]

\subsubsection{Ocorrência de acidentes envolvendo caminhões fora de controle}

O envolvimento de caminhões em acidentes rodoviários, em geral, representa perdas humanas e materiais de maior proporção quando comparado com acidentes envolvendo veículos menores. O número de caminhões representa uma pequena parte do montante de veículos da frota nacional, e mesmo assim é grande o número de acidentes envolvendo essa categoria de veículo em nossas rodovias.

Dados estatísticos da Secretaria Nacional de Tráfego (SNT), mostram que em aproximadamente $46 \%$ dos acidentes ocorridos em rodovias federais brasileiras envolveram caminhões [Moreno, 1995]. Parte desses acidentes está relacionado com caminhões que perderam o controle enquanto trafegavam por trechos em declive. Um estudo da tipologia dos acidentes, feito na França, relata que em declives maiores que $2 \%$, o risco de acidentes duplica para os veículos de passeio e é cinco vezes maior quando se trata de caminhões [SETRA, 1993]. Nestes casos, o uso excessivo dos freios de serviço leva a falhas no sistema e a perda de controle dos veículos que podem provocar acidentes graves [AASHTO, 1994]. As principais causas de acidentes em declives são a pouca ou nenhuma utilização do freio motor, 
defeito nos freios, sinalização inadequada e falta de informação aos motoristas [Bowman e Coleman, 1990].

Outro fator relacionado com acidentes em declives é o peso bruto total dos veículos. Num estudo realizado nos EUA, no qual foram analisados a tipologia dos acidentes com caminhões, notou-se que aproximadamente $73 \%$ dos caminhões que perderam o controle estavam com uma carga superior a 27 toneladas, e em $51 \%$ desses casos, a perda de controle foi provocada por superaquecimento no sistema de freios [Bowman e Coleman, 1990]. O peso excessivo aumenta a possibilidade de fadiga e defeitos que aceleram o desgaste do conjunto da suspensão como rolamentos, pneus, molas e articulações, que ficam mais sobrecarregados. O acréscimo de peso no caminhão exige maior solicitação dos freios, que se aquecem rapidamente e perdem parte de sua eficiência [Couto, 1999].

Um fator crítico em nosso país trata-se do estado de conservação da frota de caminhões. Estudos estatísticos revelam características preocupantes sobre a conservação da frota brasileira. Um levantamento feito pelo Instituto Nacional de Segurança no Trânsito (INST) com veículos de 10,6 anos de idade média mostra que 97\% desses veículos estavam com sistema de freios danificados [Moreno, 1995]. De modo geral, a frota de caminhões está mal conservada e é composta por veículos, que, no geral, tem mais de 14 anos de uso [Couto, 1999].

O número de acidentes envolvendo veículos fora de controle pode ser reduzido com ações que reforcem o uso adequado do sistema de freios, sinalização eficiente, educação e treinamento dos motoristas. As conseqüências desse tipo de acidente também podem ser minimizadas, por meio da implantação de dispositivos para contenção de veículos desgovernados em trechos com longos declives, adequados às características da rodovia. $\mathrm{O}$ objetivo da pesquisa relatada nesta dissertação é estudar esses dispositivos de contenção.

\subsection{TIPOS DE DISPOSITIVOS PARA CONTENÇÃO DE VEÍCULOS DESGOVERNADOS}

Os dispositivos para contenção de veículos desgovernados são mecanismos capazes de dissipar a energia cinética dos veículos fora de controle, substituindo os freios de 
serviço inoperantes. Esses dispositivos podem ser classificados de acordo com o mecanismo de frenagem. A classificação que abrange os tipos mais comuns apresenta as rampas de gravidade (em inglês, escape ramps), os montes de areia (em inglês, sandpiles) e os dispositivos que usam caixa de retenção (em inglês, arrester beds) [AASHTO, 1994; ITE, 1989; Witheford, 1992]. Outros tipos diferentes de dispositivos para contenção foram analisados por Jones [1982]. As características dos diferentes tipos de dispositivos de contenção serão discutidas a seguir.

\subsubsection{Rampas de escape}

Os dispositivos conhecidos como áreas ou rampas de escape (em inglês, escape ramps) na sua concepção mais simples são classificadas como rampas de gravidade, que são saídas pavimentadas ou não, geralmente de material compactado, construídas em um local conveniente, com uma rampa íngreme, nas quais os veículos desgovernados reduzem sua velocidade pelo efeito da resistência de rampa e uma pequena parcela de resistência de rolamento [AASHTO, 1994; ITE, 1989; Witheford, 1992]. A foto da Figura 3.3 mostra uma rampa de gravidade típica.

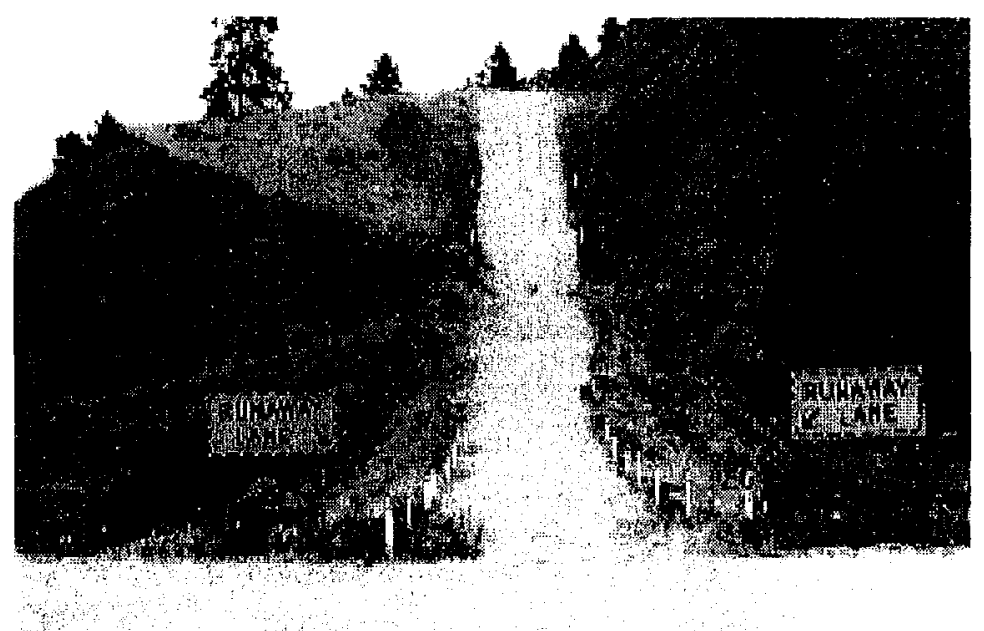

Figura 3.3: Rampa de gravidade

Contudo, a superfície de material compactado não evita que nos casos de perda total dos freios os veículos retomem o movimento de descida da rampa, saiam dos limites da área de escape e em alguns casos retornem para via. 
As áreas de escape com rampas de gravidade foram inicialmente construídas nos EUA, por apresentar facilidades na instalação e menores custos de construção, mas com o passar dos anos foram sendo substituídas por outros tipos áreas de escape, principalmente por dispositivos mais seguros, como os que usam superfície de material solto, que facilita a penetração dos pneus do veículo desgovernado e previne que os veículos totalmente sem freios retornem à via [Witheford, 1992].

\subsection{2 Áreas de escape com montes de areia}

Os dispositivos conhecidos como áreas de escape com montes de areia - em inglês sandpiles - são saídas não pavimentadas compostas por montes de areia ou terra (Figura 3.4), nas quais os veículos desgovernados reduzem sua velocidade pelo efeito da alta resistência de rolamento provocada pela fácil penetração dos pneus do veículo no material solto da superfície do dispositivo [AASHTO, 1994; ITE, 1989; Witheford, 1992].

Nesse tipo de dispositivo, o alto valor da resistência de rolamento provoca uma elevada intensidade de desaceleração, o que reduz a segurança de frenagem. As altas desacelerações representam riscos aos ocupantes do veículo desgovernado, embora proporcione um menor comprimento para frear os veículos. Os montes de areia podem representar uma alternativa em locais onde existe a necessidade de implantação de dispositivo para contenção, mas com pouco espaço físico disponível.

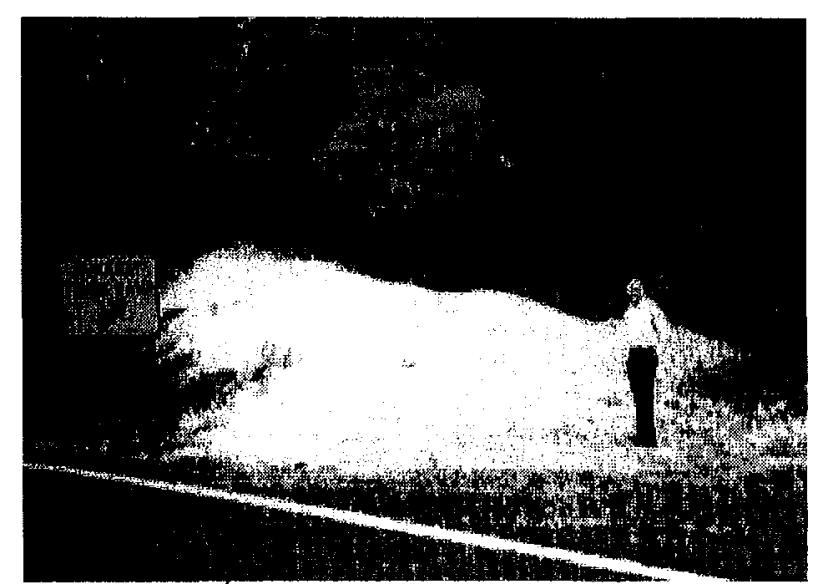

Figura 3.4: Areas de escape com montes de areia 


\subsection{3 Áreas de escape com caixa de retenção}

Os dispositivos com sistema de frenagem baseado em caixas de retenção, como a da Figura 3.5, são usados para frear caminhões desgovernados através da resistência de rolamento produzida pela penetração das rodas do veículo no material solto usado para o enchimento da caixa [Jones 1982].

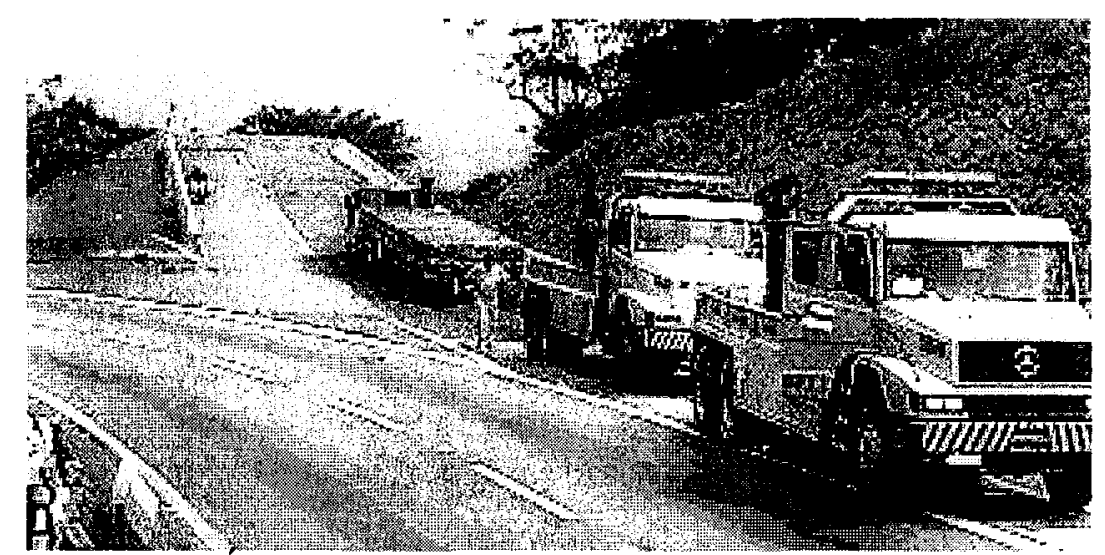

Figura 3.5: Area de escape para caminhões com caixa de retenção

As caixas de retenção podem ser construídas com qualquer declividade, já que não dependem da resistência de rampa para deter o veículo. Em muitos casos, constroem-se caixas de retenção em rampas de gravidade, tanto para reduzir a distância necessária para frenagem do caminhão como para prevenir seu retorno à rodovia [AASHTO, 1994].

Uma vantagem das áreas de escape baseadas na resistência de rampa e de rolamento é que, teoricamente, a desaceleração a que os veículos são submetidos é independente da massa do veículo e, portanto, os veículos pesados e leves percorrem a mesma distância até parar, por estarem sujeitos à mesma desaceleração. Outra vantagem desses dispositivos é que eles requerem pouca manutenção, não mais que uma recomposição da superfície do material na caixa após o uso do dispositivo e afofamento periódico para evitar a compactação do material de enchimento [Jones, 1982]. Um inconveniente desse tipo de dispositivo é a necessidade de um método de extração dos veículos e de um sistema de drenagem eficiente, capaz de coletar águas pluviais e outras substâncias como combustíveis, óleos e cargas líquidas dos caminhões [Jones, 1982]. 
Um levantamento sobre os tipos de áreas de escape mais utilizados nos estados americanos mostrou que o tipo mais comum, tanto para os dispositivos existentes como para os projetados, era a caixa de retenção. Os outros tipos encontrados eram montes de areia e rampas de gravidade [Witheford, 1992].

A caixa, como já visto, pode apresentar diferentes declividades, adaptantose às condições topográficas da via em que será implantada. De acordo com a declividade da caixa de retenção, as áreas de escape recebem as seguintes denominações:

\section{Áreas de escape ascendentes}

São as áreas de escape em que a resistência de rampa atua no sentido contrário ao do movimento e, juntamente com a resistência de rolamento, desaceleram o veículo. A intensidade da desaceleração tende a ser maior, pois é proveniente da soma de duas forças, o que resulta em um menor comprimento para frear o veículo (Figura 3.6).



Figura 3.6: Área de escape ascendente

As áreas de escape ascendentes são as mais utilizadas, por apresentar a vantagem de frear os veículos em menores comprimentos [AASHTO, 1994; ITE, 1989].

\section{Áreas de escape horizontais}

São as áreas de escape em que a ação da resistência de rampa é nula. A resistência de rolamento é a única força responsável para desacelerar o veículo. Geralmente, 
esses dispositivos requerem um maior comprimento para frear os veículos desgovernados. (Figura 3.7).

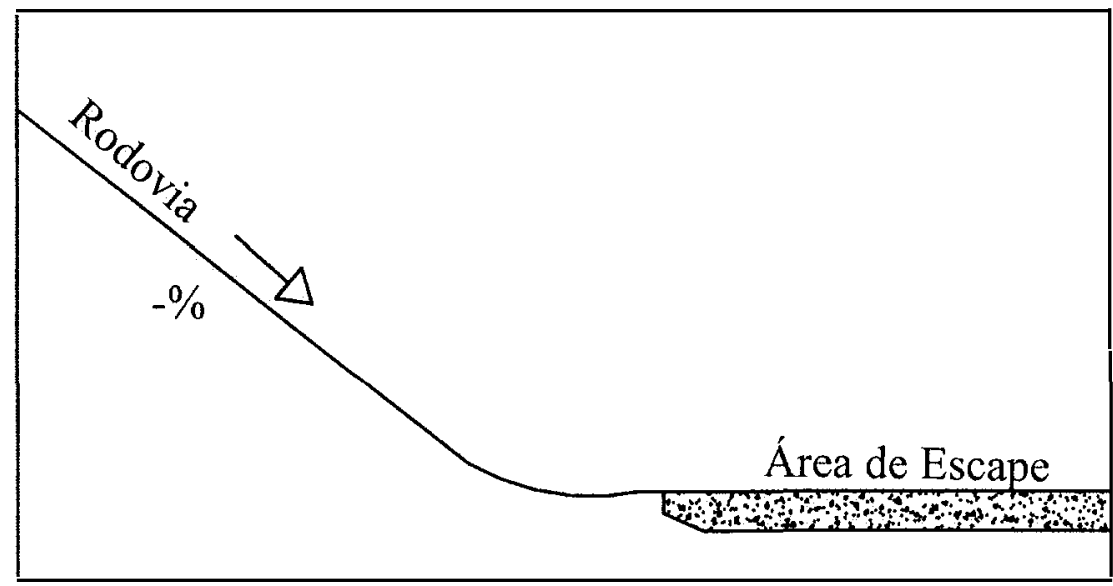

Figura 3.7: Área de escape horizontal

\section{Áreas de escape descendentes}

São áreas de escape em que a resistência de rolamento é a única força que desacelera os veículos, enquanto a resistência de rampa atua no mesmo sentido do movimento, acelerando o veículo. A soma vetorial entre as forças é responsável pela intensidade da desaceleração que tende a ser menor que nos casos anteriores, o que resulta em comprimentos maiores para frear o veículo (Figura 3.8).

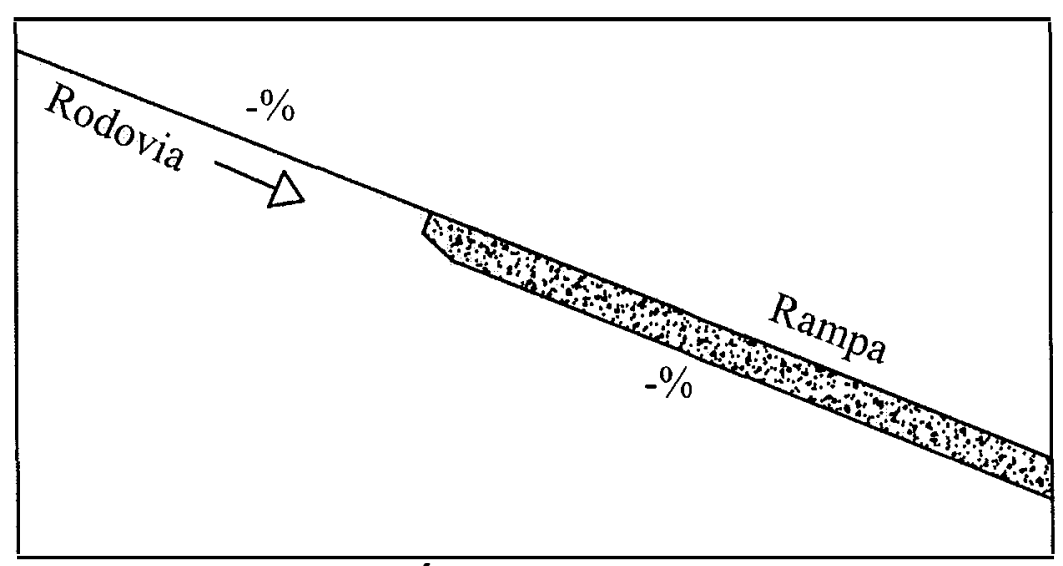

Figura 3.8: Área de escape descendente

Cada um dos tipos de áreas de escape é aplicado para uma situação em particular, adaptando-se as características topográficas do local onde será construído. 


\subsubsection{Outros tipos de dispositivos}

Jones [1992] avaliou outros tipos de dispositivos de veículos desgovernados. Os dispositivos estudados por Jones apresentam diferentes sistemas de retenção, como: retenção por correntes; discos de inércia; motores estacionários; e hidráulicos. A conclusão do estudo foi de que esses sistemas não são recomendados para uso em rodovias, visto que exigem manutenção constante (tal como reposição das redes, reposicionamento das correntes, etc.) ou funcionamento constante de motores.

\section{Sistema de retenção por correntes (chain arrester system)}

São sistemas baseados em correntes de âncora, nos quais se usam redes que estão conectadas a correntes muito pesadas acomodadas em fossos. Durante a frenagem, as correntes são arrastadas pelo caminhão desgovernado (Figura 3.9). A força para arrastar as correntes dissipa a energia cinética do veículo desgovernado. Após a retirada do veículo, as correntes são novamente acomodadas nos fossos e o sistema está pronto para ser utilizado novamente.

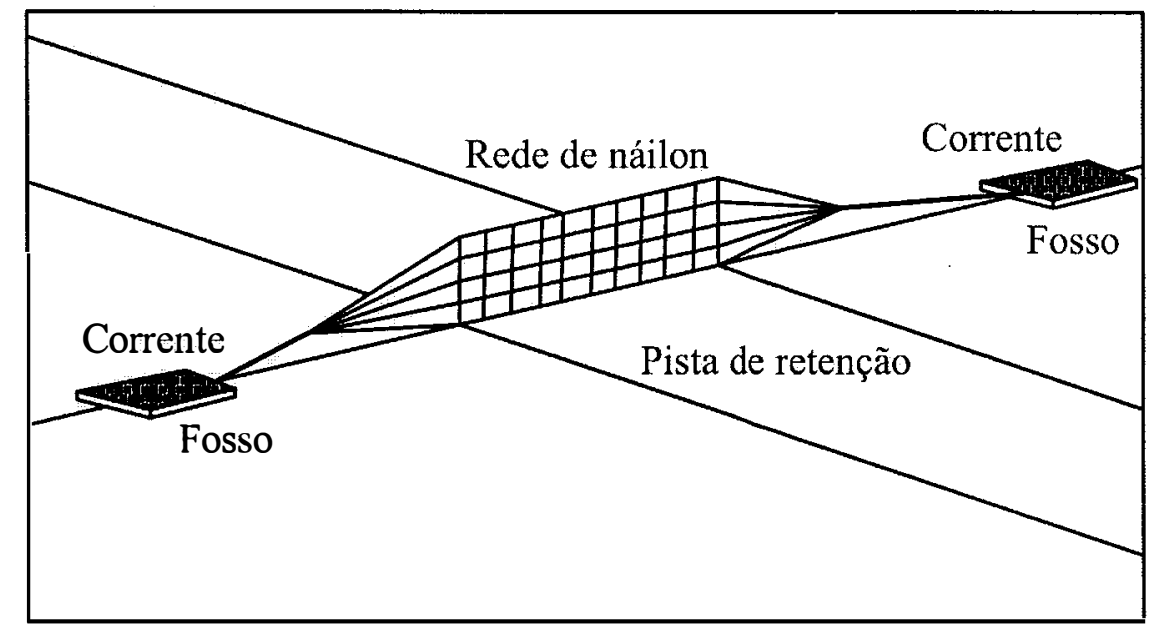

Figura 3.9: Esquema do sistema de retenção por correntes

As análises da intensidade da desaceleração em função da velocidade de entrada, quantidade de corrente e massa do veículo indicam que para os veículos mais pesados a desaceleração varia de 0,8 a 1,8 $g$ - sendo $g$ o valor da aceleração da gravidade - e que, para os veículos mais leves, a desaceleração pode atingir valores igual a $5 \mathrm{~g}$ [Jones, 1982]. Este sistema exige reposição periódica das redes que se danificam durante a colisão com os veículos. 


\section{Sistema de retenção com discos de inércia (inertia wheel arester system)}

São sistemas baseados em discos de inércia, nos quais se usa a energia cinética do caminhão para rotacionar discos de grande massa. Ao entrar na pista de retenção o veículo desgovernado choca-se contra a rede presa nas extremidades por discos de elevados momentos de inércia, como mostra o esquema da a Figura 3.10.

Esses dispositivos não são viáveis, pois além da reposição periódica das redes, a energia inercial acumulada nos disco durante a frenagem do veículo pode demorar várias horas para se dissipar completamente, enquanto os discos permanecem girando o dispositivo não pode ser usado.

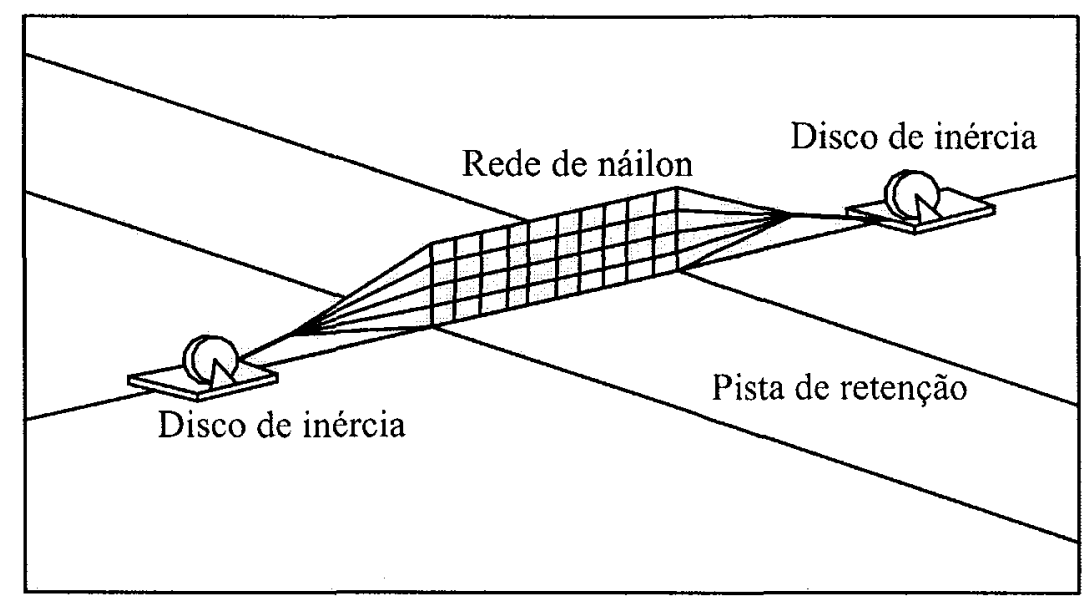

Figura 3.10: Esquema do sistema de retenção por discos de inércia

\section{Sistema de retenção por motores estacionários (arrester engine brake system)}

São sistemas similares aos usados em aeroportos militares, nos quais o caminhão arrasta uma rede conectada a fitas que, ao serem desenroladas de um carretel, são freadas por motores estacionários (Figura 3.11).

$\mathrm{Na}$ análise da intensidade da desaceleração em função da massa dos veículos, encontraram-se valores entre 0,52 a 0,88 $\mathrm{g}$. Esses valores foram obtidos para veículos com massa superior a 65 toneladas. Apesar de não terem sido feito testes, acredita-se que caminhões leves sofreriam níveis inaceitáveis de desaceleração, que poderiam atingir valores próximos à $10 \mathrm{~g}$ [Jones, 1982]. No caso do uso em rodovias, os motores teriam que ficar em funcionamento todo o tempo, o que torna inviável a implantação desses dispositivos. 


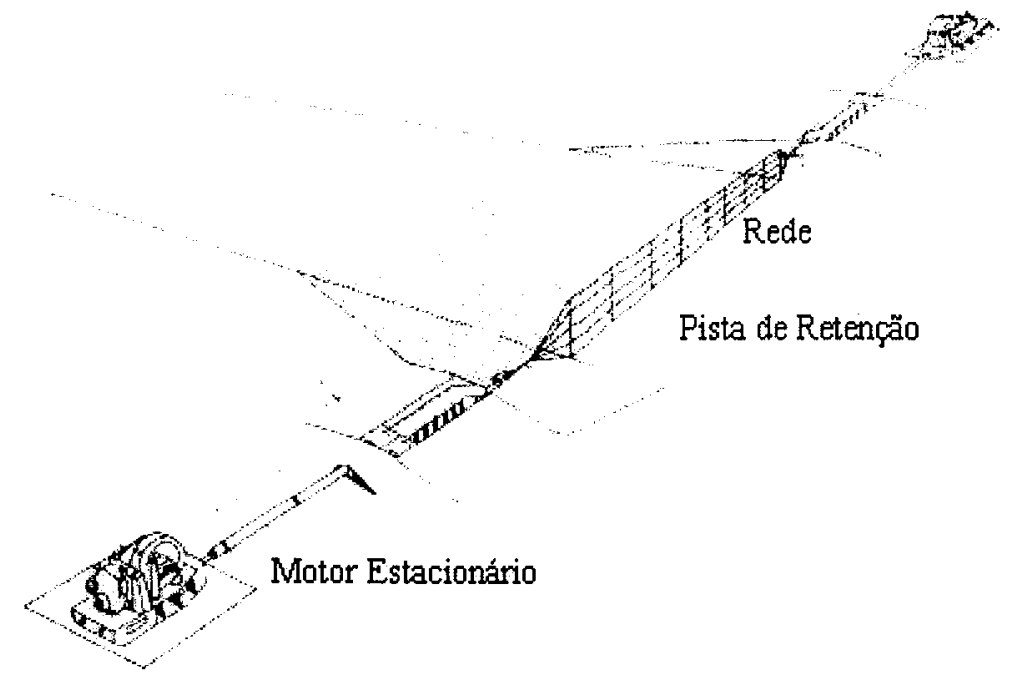

Figura 3.11: Sistema de retenção com motores estacionários

\section{Sistema de retenção hidráulico (hydraulic arrester system)}

São baseados em um sistema hidráulico de retenção, no qual a energia cinética do caminhão é dissipada pelo acionamento de bombas hidráulicas que bombeiam um liquido viscoso de um reservatório mais baixo para um mais alto (Figura 3.12).

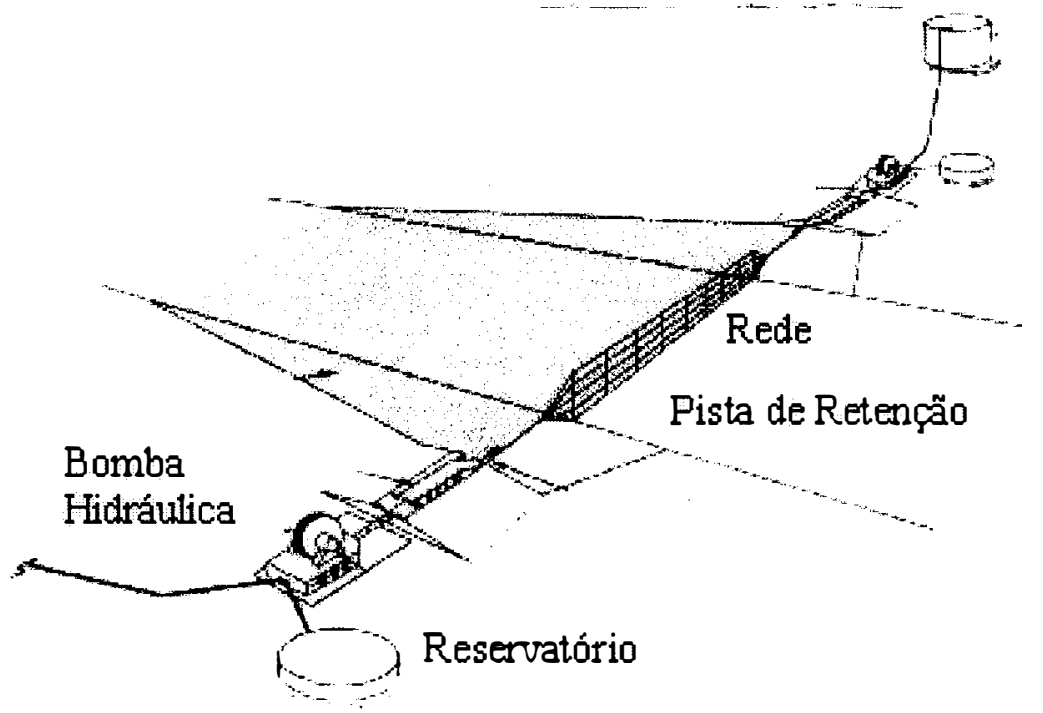

Figura 3.12: Sistema de retenção com bombas hidráulicas

Um problema comum a esses dispositivos e que também inviabiliza seu uso num ambiente em que existem diversos tipos de caminhão com pesos brutos totais variados é que o dispositivo deve ser projetado para conter veículos numa faixa estreita de PBT. Por isso, veículos mais leves seriam submetidos a desacelerações 
muito grandes e veículos mais pesados não seriam contidos pelo sistema. Por exemplo, um sistema baseado em correntes, dimensionado para caminhões de $25 \mathrm{t}$ de PBT seria incapaz de deter caminhões de $45 \mathrm{t}$ de PBT e teria efeito devastador se acionado por um veículo de $6 \mathrm{t}$.

\subsection{NECESSIDADE DE INSTALAÇÃO DE ÁREAS DE ESCAPE}

As áreas de escape são implantadas com a finalidade de interceptar veículos desgovernados. $\mathrm{O}$ custo de instalação desses dispositivos deve ser compensado por uma redução do número de vítimas e danos materiais dos caminhões que se envolvem em acidentes por falta de freios em declives. Por isso, um estudo sobre a utilidade e viabilidade de implantação da área de escape deve ser realizado para que o dispositivo implantado seja útil e ofereça maior segurança para o transporte de veículos rodoviários em declives.

Uma análise do registro de acidentes em conjunto com julgamento de engenharia deve ser feito para verificar a necessidade de se implantar áreas de escape em rodovias com longos declives [AASHTO, 1994; ITE, 1989; Witheford, 1992].

No Canadá, foi feito um estudo das variáveis envolvidas na determinação da necessidade de implantação de áreas de escape em rodovias em trechos montanhosos [Abdelwahab e Morral, 1997]. As variáveis analisadas foram as seguintes:

1. Características dos veículos;

2. Existência de áreas para verificação dos freios no início do declive;

3. Comportamento dos motoristas de caminhão antes e durante a descida;

4. Perfis em escala horizontal das velocidades desenvolvida pelos caminhões, das temperaturas dos freios e da localização dos acidentes ao longo do declive;

5. Identificação de locais onde a velocidade dos veículos excede o limite permitido e a temperatura dos freios atinge o valor de fade. 
Abdelwahab e Morral [1997] concluíram que é necessária a implantação de áreas de escape nos casos em que: a velocidade dos veículos desgovernados ultrapassar a velocidade de tombamento nas curvas horizontais da rodovia; a temperatura dos freios dos veículos ao longo do declive exceder o valor de fade; e a ocorrência de acidentes envolvendo veículos sem freios for significativa.

Nos Estados Unidos, foram distribuídos questionários para as agências de rodovias, a fim de conhecer os principais fatores considerados pelas agências estaduais para a verificação da necessidade de implantação de áreas de escape [Eck, 1979]. A Tabela 3.1 apresenta os fatores considerados e o número de agências que os citaram.

Tabela 3.1: Fatores considerados pelas agências de rodovias americanas para determinar a necessidade das áreas de escape [Eck, 1979]

\begin{tabular}{lc}
\hline \multicolumn{1}{c}{ Fatores considerados } & Número de agências \\
\hline Ocorrência de acidentes com veículos fora de controle & 14 \\
Comprimento do declive & 8 \\
Porcentagem de inclinação & 8 \\
Porcentagem de caminhões & 5 \\
Condições no final do declive & 4 \\
Trafego diário médio & 3 \\
Curvatura horizontal & 3 \\
Gravidade dos acidentes & 1 \\
Disponibilidade de faixa de domínio & 1 \\
Topografia & 1 \\
\hline
\end{tabular}

Para determinar quando a instalação de uma área de escape torna-se necessária, três critérios devem ser analisados: se existem problemas com veículos fora de controle; se o problema pode ser amenizado com um sistema de sinalização e informação adequado e se existem condições para construção de uma área de escape [Eck, 1979]. 


\subsection{LOCALIZAÇÃO DAS ÁREAS DE ESCAPE}

Ao se decidir pela instalação de uma área de escape como uma alternativa de aumentar a segurança em um trecho de via, torna-se necessária uma análise que auxilie a escolha do melhor local para ser construído o dispositivo, partindo do pressuposto de que o local escolhido interceptará o maior número possível de veículos desgovernados.

\section{AASHTO [1994] aconselha a realização de:}

1. Um estudo sobre o índice de acidentes nos trechos em declive: embora os acidentes envolvendo veículos desgovernados possam ocorrer em vários pontos do declive, uma análise mais detalhada poderá indicar pontos onde a quantidade registrada de acidentes se destaca;

2. Verificação da velocidade de tombamento nas curvas horizontais existentes no trecho em declive: deve-se procurar construir as áreas de escape antes de curvas horizontais que poderão provocar o tombamento dos veículos desgovernados devido ao excesso de velocidade;

3. Análise da temperatura do sistema de freios: neste caso, é indicada a utilização do programa de computador Grade Severity Rating System para determinar a temperatura dos freios ao longo do declive. Os veículos perdem os freios a partir do ponto em que a sua temperatura ultrapassar $260^{\circ} \mathrm{C}$ (ponto de fade).

4. Análise da velocidade dos veículos: a provável velocidade com que os veículos possam chegar até o dispositivo deve ser considerada na escolha do local de construção, de forma a evitar que os veículos desgovernados entrem na área de escape com velocidades muito altas.

Nos casos em que não houver possibilidade de realizar um estudo de localização, a área de escape deve ser construída no segundo terço do declive. Já nos casos em que houver a necessidade de mais dispositivos, estes devem ser separados por uma distância aproximada de $2 \mathrm{~km}$ [SETRA, 1993]. 
Nos EUA, engenheiros pesquisaram quais os fatores considerados pelas agências estaduais de rodovias para se determinar o local do declive a ser implantada a área de escape [Eck, 1979]. A Tabela 3.2 apresenta os fatores considerados e o número de agências que os citaram.

Tabela 3.2: Fatores considerados pelas agências de rodovias americanas para determinar a localização de uma área de escape [Eck,1979]

\begin{tabular}{lc}
\hline \multicolumn{1}{c}{ Fatores citados } & Número de agências \\
\hline Condições topográficas & 8 \\
Alinhamento Horizontal & 5 \\
Localização de acidentes & 5 \\
Condições no final do declive & 2 \\
Disponibilidade de faixa de domínio & 1 \\
Contribuição dos motoristas de caminhão & 1 \\
Velocidade dos veículos fora de controle & 1 \\
Comprimento do declive & 1 \\
\hline
\end{tabular}

Para auxiliar na análise do local a ser instalado a área de escape, nos trechos com declives maiores que $6 \%$ e com um tráfego de veículos comerciais superior a 150 por dia, pode-se utilizar a distância aproximada do começo do declive até a área de escape, como demonstra a Tabela 3.3. Essas distâncias devem ser analisadas em conjunto com outros fatores [QDoMR, 2000].

Tabela 3.3: Distância aproximada do início do declive até a área de escape

\begin{tabular}{cc}
\hline $\begin{array}{c}\text { Inclinação } \\
(\mathbf{\%})\end{array}$ & $\begin{array}{c}\text { Distância do início do declive até o } \\
\text { dispositivo } \mathbf{( k m )}\end{array}$ \\
\hline $6-10$ & 3,0 \\
$10-12$ & 2,5 \\
$12-15$ & 2,0 \\
$15-17$ & 1,5 \\
$>17$ & 1,0 \\
\hline
\end{tabular}


No Canadá, foi proposto um sistema para auxiliar a determinação da localização das áreas de escape. Nesse sistema, são consideradas as características do veículo (tipo, peso bruto e tipo de freio), características da via (comprimento e inclinação do declive, geometria e existência de uma área para verificação dos freios no topo do declive) e características pessoais do motorista (escolha da estratégia de condução) [Abdelwahab e Morral, 1997].

Essas variáveis são analisadas em conjunto com um histórico de registros de acidentes, velocidades dos veículos e o comportamento térmico dos freios que é estimado com o auxílio do programa Grade Severity Rating System - GSRS. O método desenvolvido foi aplicado em rodovias situadas em terrenos montanhosos. Os locais para implantação da área de escape foram determinados nos pontos do declive em que: a velocidade dos veículos sem freios excedia o limite imposto pela geometria da via; a temperaturas dos freios dos veículos atingia ou era maior que temperatura de fade; destacava-se a ocorrência de acidentes envolvendo veículos desgovernados; e as condições topográficas e geométricas do local fossem adequadas para construção do dispositivo.

Não existem regras claras que definam a escolha do local ideal para construir áreas de escape. A escolha final depende de um estudo de engenharia no qual os seguintes aspectos devem ser avaliados: topografia, espaço físico disponível, distância em relação ao topo do declive, geometria da via e redução de custos de construção do dispositivo [Witheford, 1992].

\subsubsection{Grade Severity Rating System - GSRS}

O GSRS é um modelo matemático capaz de estimar a temperatura dos freios dos veículos em função do peso bruto dos veículos, o percentual de inclinação, o espaço percorrido pelo caminhão utilizando os freios e a velocidade desenvolvida pelo veículo [Brian e Coleman, 1990].

O emprego do GSRS unido a outros aspectos do tráfego e da rodovia auxilia no estudo de localização de áreas de escape. O GSRS, desenvolvido pela Federal Highway Administration (FHWA), é capaz de contribuir para redução da incidência 
e gravidade dos acidentes com caminhões em declives, baseado na análise de temperatura dos freios.

A análise de temperatura pelo GSRS engloba fatores como: a dissipação do calor gerado na frenagem, temperatura inicial dos freios e o número de rotações do motor. O modelo considera um caminhão com cinco eixos, mantendo velocidade constante durante a descida e cuja rotação do motor se conserva próxima da máxima admissível. Em geral, considera-se o uso da marcha ideal para a velocidade que está sendo desenvolvida [Brian e Coleman, 1990].

A velocidade máxima de segurança deve ser estimada de acordo com a capacidade de frenagem, de forma a permitir uma parada de emergência em um ponto qualquer ou no final do declive. Essa frenagem de emergência provoca uma alta absorção de calor nos freios que, somada com a temperatura inicial do sistema, não deve ultrapassar a temperatura de fade, admitida como $260^{\circ} \mathrm{C}$, pois a partir desse valor o risco de fade aumenta consideravelmente [Brian e Coleman, 1990].

O GSRS foi implementado para um programa de computador na plataforma IBM PC. Para o funcionamento do programa são indispensáveis as seguintes informações: peso dos veículos, velocidade, inclinação e comprimento do declive. Os resultados permitem quantificar a temperatura dos freios do veículo a cada trecho de $0,8 \mathrm{~km}(0,5 \mathrm{milha})$.

\subsection{DIMENSIONAMENTO DAS ÁREAS DE ESCAPE}

Os principais itens de dimensionamento das áreas de escape envolvem a geometria $\mathrm{e}$ dimensão do acesso à caixa de retenção e as dimensões da caixa (comprimento, profundidade e largura).

\subsubsection{Acesso à caixa de retenção}

O trecho que liga a rodovia até o início da caixa deve proporcionar aos motoristas segurança no uso e na tomada de decisão entre entrar ou não no dispositivo.

$\mathrm{O}$ acesso à caixa deve ser tangente ou com uma suave curvatura em relação ao alinhamento da via, para minimizar os problemas com a falta de controle do 
veículo. Além disso, deve ser visível para permitir ao motorista um tempo de reação suficiente para analisar as possibilidades de utilizar ou não a área de escape [AASHTO, 1994]. As dimensões do acesso devem ser tais que os veículos desgovernados atinjam a caixa de retenção de forma que ambas as rodas dianteiras entrem simultaneamente na caixa, para que a desaceleração seja simétrica e mais segura [AASHTO, 1994; Witheford, 1992].

No caso de rodovias com várias faixas de rolamento, recomenda-se que o acesso até caixa de retenção seja composto por uma faixa auxiliar (taper) pavimentada com comprimento mínimo de 300 metros [Witheford, 1992].

\subsubsection{Dimensionamento da caixa de retenção}

As dimensões das caixas de retenção devem proporcionar uma entrada segura, níveis de desaceleração aceitáveis e um comprimento suficiente para frear os veículos desgovernados com diferentes velocidades. A eficácia da caixa de retenção depende de sua geometria, principalmente da profundidade e comprimento [ADoT, 1993].

\section{Comprimento}

O comprimento da caixa de retenção deve ser suficiente para dissipar toda energia cinética dos veículos desgovernados, parando-os com segurança. A extensão da caixa é determinada em função da velocidade de entrada dos veículos na área de escape e da intensidade da desaceleração provocada pelas resistências de rolamento e de rampa [AASHTO, 1994].

Para estimar a velocidade de entrada dos veículos na área de escape, deve-se considerar que o freio de serviço e os sistemas auxiliares de frenagem do veículo estejam totalmente inoperantes e verificar as forças que atuam no veículo em um declive [AASHTO, 1994]. Nesse caso, as seguintes forças devem ser analisadas:

(i) Componente do peso tangencial à direção do movimento (resistência de rampa), que é a força que nos declives provoca um aumento de velocidade. Sua intensidade depende do peso do veículo e da inclinação da via.

(ii) Resistência de rolamento, que é a força contrária ao movimento, proveniente do contato entre os pneus do veículo e a superfície da via. Sua intensidade é 
influenciada pelas características do material usado na superfície de rolamento.

(iii) Resistência do ar, uma força contrária ao movimento, mas que pode ser desconsiderada na estimativa da velocidade de entrada, o que provoca um aumento do fator de segurança.

A Figura 3.13 representa um esquema das forças que atuam no veículo em um declive usadas para estimar a intensidade da velocidade de entrada na caixa de retenção.

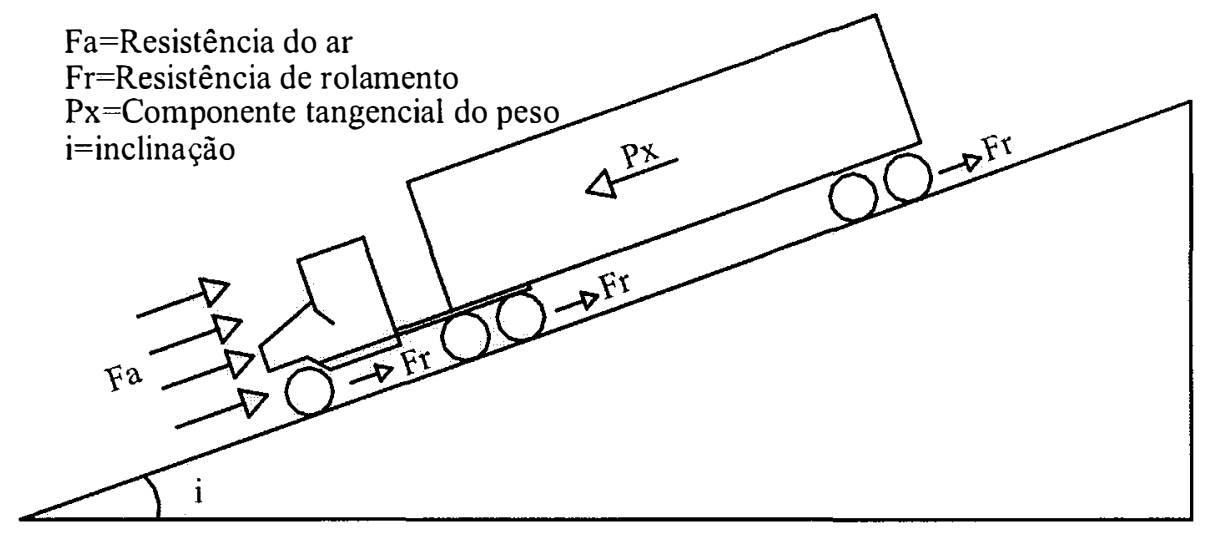

Figura 3.13: Forças que atuam no veículo em movimento [AASHTO, 1994]

O Departamento de Transportes de Idaho, nos EUA usa um modelo para determinar a velocidade do veículo em qualquer ponto do declive baseado na soma de energia do veículo [Stanley, 1978].

$$
\begin{gathered}
V=5.469 \cdot\left[0,03343 \cdot V_{0}{ }^{2}-H-K \cdot L-0,000016 \cdot V_{m} \cdot L\right. \\
\left.-\left(0,0012 \cdot F \cdot L \cdot V_{n}{ }^{2} / W\right)\right]^{1 / 2}
\end{gathered}
$$

em que : $\quad V:$ Velocidade (mph);

$V_{0}$ : Velocidade inicial (mph);

$L$ : Comprimento do declive ( $\mathrm{ft}$;

$H$ : Altura correspondente ao comprimento $L(\mathrm{ft})$; 
$K$ : Constante que incorpora o atrito da superfície e a perda mecânica independente da velocidade $(0,01675$ para pavimentos e 0,26175 para agregados);

$V_{m}$ : Média entre $V$ e $V_{0}$

$F$ : Área frontal do veículo $\left(\mathrm{ft}^{2}\right)$;

$V_{n}^{2}:$ Média entre $V^{2}$ e $V_{0}^{2}$; e

$W$ : Peso do veículo (lbs).

As áreas de escape devem ser construídas em locais onde a velocidade de entrada dos veículos não exceda $140 \mathrm{~km} / \mathrm{h}$. O ideal é que o comprimento seja dimensionado para velocidades de entrada dentro de um intervalo de 130 a $140 \mathrm{~km} / \mathrm{h}$ [AASHTO, 1994].

Outro fator que influencia no comprimento é a intensidade da desaceleração imposta sobre o veículo no interior da caixa de retenção. $O$ valor da desaceleração está relacionado com a profundidade da caixa, com as características do material de enchimento, a inclinação da caixa e as características do veículo.

Alguns modelos matemáticos foram propostos para determinar 0 comprimento da caixa de retenção necessário para frear veículos desgovernados. Um modelo proposto por Taragin [1945] determina o comprimento da caixa levando em consideração a velocidade de entrada, o percentual de inclinação da caixa e da resistência de rolamento do material, como mostra a Equação 3.2.

$$
L=\frac{V^{2}}{254(R \pm G)}
$$

em que : $\quad L$ : Comprimento para parar o veículo $(\mathrm{m})$;

$V$ : Velocidade de entrada $(\mathrm{km} / \mathrm{h})$;

G: Porcentagem da inclinação da caixa dividida por 100; e

$R$ : Coeficiente de rolamento do material (Tabela 3.4). 
Tabela 3.4: Valores de $R$ para diferentes materiais [Witheford, 1992]

\begin{tabular}{lc}
\hline \multicolumn{1}{c}{ Material da superfície } & $\boldsymbol{R}$ \\
\hline Concreto de cimento Portland & 0,010 \\
Concreto asfaltico & 0,012 \\
Cascalho compactado & 0,015 \\
Terra, arenosa e solta & 0,037 \\
Pedra britada solta & 0,050 \\
Cascalho solto & 0,100 \\
Areia & 0,150 \\
Cascalho arredondado & 0,250 \\
\hline
\end{tabular}

Testes realizados pela Roads and Traffic Authority - RTA da província de Queensland na Austrália, propõem uma fórmula diferente para a determinação do comprimento necessário para parar os veículos:

$$
L=\frac{V^{2}}{(26 a+2,55 X)}
$$

em que : $\quad L$ : Comprimento para parar o veículo, excluindo os 50 metros iniciais (m);

$V:$ Velocidade de entrada $(\mathrm{km} / \mathrm{h})$;

$a$ : desaceleração (Tabela 3.5); e

$X$ : inclinação (\%).

Neste modelo são desconsiderados os 50 metros iniciais do comprimento, por se tratar de uma zona de transição na profundidade da caixa de retenção [QDoMR, 2000; Waples, 1992].

Tabela 3.5: Valores da desaceleração média [QDoMR, 2000]

\begin{tabular}{|c|c|}
\hline Material & $a\left(m / s^{2}\right)$ \\
\hline Areia com $35 \mathrm{~cm}$ de profundidade & 2,8 \\
\hline Areia com $45 \mathrm{~cm}$ de profundidade & 3,4 \\
\hline Brita com $35 \mathrm{~cm}$ de profundidade & 3,0 \\
\hline Brita com $45 \mathrm{~cm}$ de profundidade & 3,7 \\
\hline
\end{tabular}


Um outro estudo para determinação do comprimento e profundidade da caixa de retenção considera o contato e a deformação do conjunto pneu-superfície de rolamento. Neste estudo, um modelo de simulação foi usado para predizer o comportamento dos veículos pesados quando freados em uma caixa de retenção [Losa, 1999]:

$$
S_{a}=\gamma_{b} \frac{W_{1}+W_{2}}{g} \int_{0}^{\gamma_{l}} \frac{v}{R_{a}+\left(W_{1}+W_{2}\right) \operatorname{sen} \alpha} d v
$$

em que: $\quad S_{a}$ : Distância de parada do veículo na caixa de retenção (m);

$\gamma_{b}$ : Fator de equivalência de massa, considerando a razão entre o momento de inércia e a massa dos componentes de rotação durante a frenagem (valor aproximado igual a 1,04);

$R_{a}:$ Força de frenagem;

$W_{1}$ : Peso do cavalo mecânico $(\mathrm{KN})$;

$W_{2}$ : Peso do semi reboque $(\mathrm{KN})$;

$V_{l}:$ Velocidade de entrada $(\mathrm{m} / \mathrm{s})$;

$V$ : Função horária da velocidade $(v=v(t))$; e

$\alpha$ : inclinação longitudinal da caixa de retenção.

O modelo encontrado fornece valores muito próximos aos do modelo de Taragin [1945] e pode auxiliar na escolha do material mais apropriado para a construção da caixa (Equação 3.4).

Testes com caixas de retenção foram feitos na Inglaterra pelo Transport Road Laboratory, entre 1966 e 1971. Os resultados indicaram que a intensidade da desaceleração média independe da velocidade e da massa do veículo, mas a forma, a granulometria dos materiais e a profundidade da caixa alteram a intensidade da desaceleração média. Os testes foram realizados com material em forma de grãos 
arredondados, em que as desacelerações médias encontradas variaram de 0,5 a 0,6 $\mathrm{g}$ [SETRA, 1993].

Num outro estudo, foram realizados ensaios com um caminhão rígido, com dois eixos e massa de 16,65 t, que entrou em uma área de escape com velocidades de 34, 66 e $90 \mathrm{Km} / \mathrm{h}$ resultando em desacelerações médias de 0,18;0,32 e 0,35 g respectivamente. As velocidades de entrada foram mensuradas com auxílio de um radar instalado no início da caixa. As desacelerações médias foram determinadas utilizando filmagens com câmeras de vídeo instaladas ao longo da caixa. Com a edição dos filmes foi possível estimar as desacelerações médias que apresentaram uma variação em função da velocidade de entrada. O valor máximo atingido durante os testes foi de $0,7 \mathrm{~g}$. Estudos anteriores sobre o material utilizado na área de escape analisada, indicavam uma desaceleração média de $0,3 \mathrm{~g}$ [Allison et al., 1979].

Pesquisadores australianos realizaram ensaios em uma caixa de retenção com veículo de passageiros, caminhão rígido e um caminhão articulado [Cocks e Goodram, 1982]. As velocidades de entrada dos veículos variaram de $11 \mathrm{~km} / \mathrm{h}$ a 63 $\mathrm{km} / \mathrm{h}$. A finalidade principal dos ensaios foi determinar a desaceleração média imposta sobre os veículos dentro da caixa e analisar os fatores que podem influenciar na intensidade da desaceleração média. As desacelerações médias foram determinadas utilizando a Equação 3.5, em função do comprimento de frenagem, que é a distância medida do início da caixa até o ponto em que o veículo parou; e da velocidade de entrada, que foi estimada com auxílio de um radar instalado na entrada da caixa.

$$
a=\frac{V_{i}^{2}}{2 L g}
$$

em que: $\quad a$ : desaceleração média $(g)$;

$V_{i:}$ Velocidade de entrada $(\mathrm{m} / \mathrm{s})$;

$L:$ Comprimento de frenagem (m); e

g: aceleração da gravidade $\left(9,81 \mathrm{~m} / \mathrm{s}^{2}\right)$. 
Os resultados da pesquisa indicaram que a intensidade da desaceleração média apresenta uma variação significativa em função da velocidade de entrada, das propriedades do material de enchimento da caixa, do tipo de veículo e da geometria da caixa. Observou-se que o comportamento da desaceleração sofre um aumento com o acréscimo da velocidade de entrada, atinge um valor máximo e, a partir desse ponto, a desaceleração média começa a sofrer uma redução com aumento da velocidade de entrada, como pode ser visto na Figura 3.14.

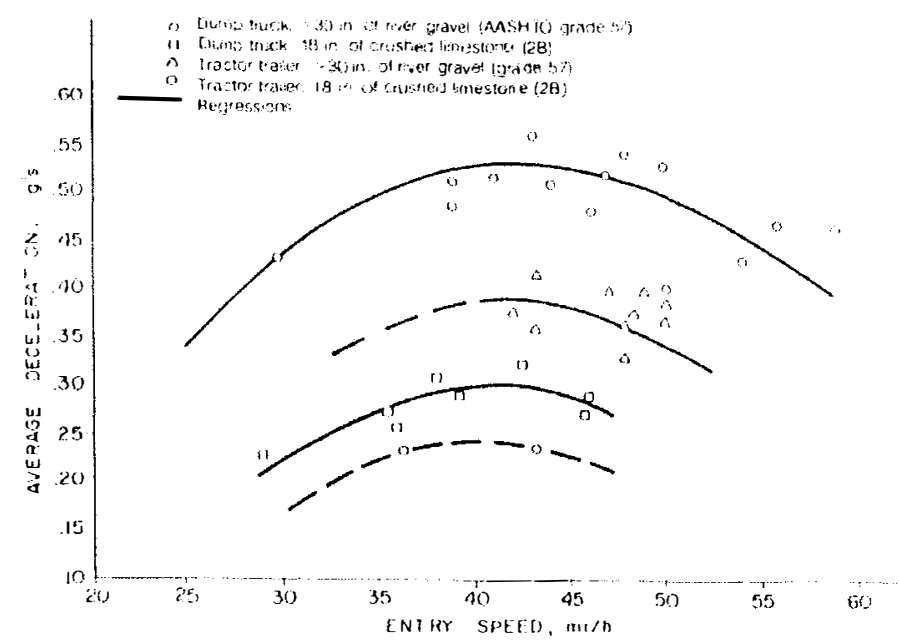

Figura 3.14: Relação entre desaceleração média e velocidade de entrada [Cocks e Goodram, 1982]

Alguns anos mais tarde, ainda na Austrália, foram realizados testes com diversos tipos de veículos articulados pesados e materiais de enchimento da caixa de retenção, [Leach e Ives, 1995] visando caracterizar o comportamento desse tipo de veículos em uma área de escape em função da velocidade de entrada. Os testes foram conduzidos com quatro veículos articulados do tipo: B-Double, com massas de 61,9 t; 62,2 t e 78,8 t; rodotrem, com massa de 62,6 t; semi-reboque, com massas de 17,6 t; 41,1 t e 41,3 t. As distâncias e as velocidades foram medidas com auxílio de instrumentos a laser e filmagens. Os dados coletados indicaram desacelerações médias na ordem de 0,35 a $0,40 \mathrm{~g}$, e mostraram que a intensidade da desaceleração varia ao longo do percurso de frenagem e se altera significativamente em função do tipo de veículo e das velocidades de entrada 
Nielsen et al. [1997] também realizaram ensaios para determinação da desaceleração média em caixas de retenção. Para a realização dos ensaios foram utilizados três caminhões articulados, variando-se as velocidades de entrada e o tipo de material de superfície da caixa de retenção (Tabela 3.6). As intensidades das desacelerações variaram entre 0,20 a $0,39 \mathrm{~g}$ e foram determinadas com uso de filmagens e equipamentos a laser para medir as velocidades e as distâncias. Os resultados foram determinados usando-se os dados coletados nos ensaios e aplicação das equações da mecânica clássica. Verificou-se que a intensidade da desaceleração varia ao longo do percurso de frenagem e o valor médio da desaceleração varia em função da velocidade de entrada, do tipo de veículo e do tipo de material da superfície da caixa.

Tabela 3.6: Configuração dos veículos de teste

\begin{tabular}{|c|c|c|c|}
\hline Veículo & $\begin{array}{c}\text { Massa } \\
(t)\end{array}$ & $\begin{array}{c}\text { Comprimento } \\
\text { (m) }\end{array}$ & $\begin{array}{c}\text { Intervalo de } \\
\text { velocidades de } \\
\text { entrada }(\mathrm{km} / \mathrm{h})\end{array}$ \\
\hline $90-00$ a000 $=-000$ & 61,9 & 23,7 & $30-80$ \\
\hline 10 & 62,6 & 18,8 & $30-75$ \\
\hline $80-6070 \%$ & 41,1 & 13,5 & $40-85$ \\
\hline
\end{tabular}

As características do material de enchimento da caixa influenciam o valor da desaceleração e, por conseqüência, o comprimento da caixa. Características como o coeficiente de rolamento, a granulometria e a resistência mecânica dos materiais estão relacionadas com a resistência de rolamento dentro da caixa. Para que o material apresente elevado coeficiente de resistência de rolamento, ele dever ter superfície regular, forma arredondada e ser predominantemente de mesma granulometria [AASHTO 1994].

Avaliando a revisão da literatura especializada, é possível verificar que a desaceleração média varia entre 0,20 e $0,6 \mathrm{~g}$, como resumido na Tabela 3.7. Pode-se 
notar que e os pesquisadores australianos dispõem do maior corpo de conhecimento sobre o comportamento da desaceleração em caixas de retenção, visto que realizaram testes com diferentes tipos caminhões com maior amplitude de variação da massa.

Tabela 3.7: Resumo dos resultados de desacelerações médias encontradas nos testes

\begin{tabular}{|c|c|c|c|c|c|}
\hline \multicolumn{4}{|l|}{ Desaceleração } & \multicolumn{2}{|c|}{ Características da rampa } \\
\hline média & Veículo & Fonte & Local & Profundidade & Material \\
\hline$\overline{0,35-0,39 \mathrm{~g}}$ & semi-reboque & Wambold et al. [1988] & EUA & $0,90 \mathrm{~m}$ & seixo rolado \\
\hline $0,35 \mathrm{~g}$ & semi-reboque & Cocks e Goodram [1982] & Austrália & $0,90 \mathrm{~m}$ & seixo rolado \\
\hline $0,50 \mathrm{~g}$ & caminhão rígido & Cocks e Goodram [1982] & Austrália & $0,90 \mathrm{~m}$ & seixo rolado \\
\hline $0,60 \mathrm{~g}$ & $\begin{array}{l}\text { veículos leves } \\
(4,5 \text { a } 11 \mathrm{t})\end{array}$ & Laker [1971] & Inglaterra & - & cinasita \\
\hline $0,3 \mathrm{~g}$ & caminhões & Jehu e Laker [1969] & Inglaterra & - & - \\
\hline 0,35 & $\begin{array}{l}\text { caminhão rígido } \\
(16,7 \mathrm{t})\end{array}$ & $\begin{array}{l}\text { Allison, Hahn e } \\
\text { Briden [1979] }\end{array}$ & EUA & $0,6 \mathrm{~m}$ & $\begin{array}{l}\text { "pea } \\
\text { gravel" }\end{array}$ \\
\hline $0,35-0,40 \mathrm{~g}$ & $\begin{array}{l}\text { semi-reboque } \\
(41 \text { a } 62 \text { t) }\end{array}$ & Leach e Ives [1995] & Austrália & $0,40 \mathrm{~m}$ & cinasita \\
\hline $0,38 \mathrm{~g}$ & - & $\begin{array}{l}\text { Queensland Road Planning } \\
\text { and Design Manual [2000] }\end{array}$ & Austrália & $0,45 \mathrm{~m}$ & pedregulho \\
\hline $0,35 \mathrm{~g}$ & - & $\begin{array}{l}\text { Queensland Road Planning } \\
\text { and Design Manual [2000] }\end{array}$ & Austrália & $0,45 \mathrm{~m}$ & areia \\
\hline $0,40-0,48 \mathrm{~g}$ & - & $\begin{array}{l}\text { Lits d'arrêts - Guide } \\
\text { techinique [1993] }\end{array}$ & França & 0,6 & seixo rolado \\
\hline
\end{tabular}

\section{Profundidade}

Como a intensidade da desaceleração imposta sobre o veículo varia em função da espessura do material, a profundidade da caixa de retenção está relacionada com a segurança do processo de frenagem do veículo [AASHTO, 1994; ITE, 1989; Witheford, 1992]. Dois aspectos devem ser analisados para dimensionar a profundidade de uma caixa de retenção. O primeiro aspecto trata da profundidade do trecho inicial. No começo da caixa é interessante evitar um afundamento acentuado das rodas do veículo; as caixas devem ter profundidades menores nos primeiros 
metros de seu comprimento, a fim de minimizar os efeitos de uma desaceleração brusca logo na entrada do dispositivo e até mesmo facilitar a extração dos veículos da caixa. Outro aspecto diz respeito à profundidade útil da caixa, pois com o passar do tempo, fatores externos como a contaminação (presença de folhas, sujeira, finos, óleos, combustíveis, etc) e a compactação do material diminuem a espessura útil do material, o que irá reduzir a eficiência de desaceleração do dispositivo.

As diretrizes da AASHTO recomendam que a caixa tenha uma profundidade mínima de $7,5 \mathrm{~cm}$ no ponto de entrada e durante os primeiros 30 a $60 \mathrm{~m}$ do comprimento da caixa a profundidade aumenta até $100 \mathrm{~cm}$ [AASHTO, 1994]. No estudo realizado por Witheford [1992] não são recomendadas profundidades menores que $45 \mathrm{~cm}$, visto que profundidades menores podem apresentar uma redução significativa na resistência de rolamento. Outra análise feita nos EUA indica profundidades mínimas de pelo menos $30 \mathrm{~cm}$, mas recomenda como ideal $15 \mathrm{~cm}$ de profundidade no início da caixa e de 46 a $90 \mathrm{~cm}$ nos primeiros 30 a 60 metros do comprimento da caixa [ITE, 1989].

Na França, utiliza-se um segmento inclinado com cerca de dois metros de comprimento no início da caixa, no qual a profundidade aumenta até um máximo de $50 \mathrm{~cm}$ [SETRA, 1993].

$\mathrm{Na}$ Austrália recomenda-se a construção de uma zona de transição de $50 \mathrm{~m}$ de comprimento, em que a profundidade vai aumentando gradualmente de 0 até 35 $\mathrm{cm}$. Nos próximos $100 \mathrm{~m}$ do comprimento da caixa, a profundidade continua constante e igual a $35 \mathrm{~cm}$; logo depois uma nova zona e transição de 25 metros até atingir uma profundidade de $45 \mathrm{~cm}$, como mostra a Figura 3.15 [QDoMR, 2000]. A zona de transição inicial não deve fazer parte do comprimento útil de frenagem da caixa de retenção. Esse segmento tem como finalidade amenizar os efeitos da desaceleração logo na entrada do dispositivo, proporcionando aos ocupantes do veículo desgovernado uma sensação de conforto e segurança durante a frenagem. Essa configuração proposta necessita de locais onde se tenha grande espaço disponível para a construção do dispositivo. 


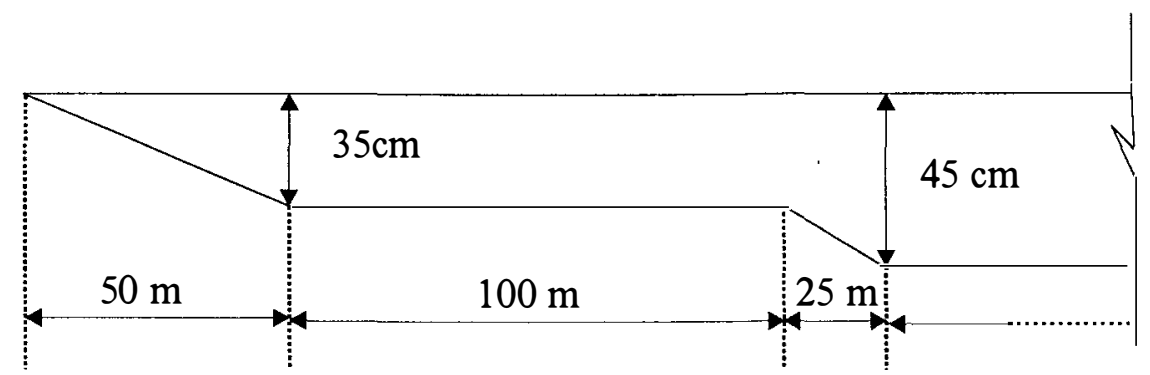

Figura 3.15: Esquema da profundidade da caixa proposto pelos australianos

Percebe-se que não existem fórmulas ou regras uniformes para se determinar a profundidade ideal da caixa de retenção. Desta forma, deve ser feita uma análise conjunta das características do material disponível e da intensidade da desaceleração desejável que melhor se ajuste às condições do local de instalação da área de escape. No caso da caixa de retenção analisada, que foi construída em um trecho com restrição de espaço, o comprimento de transição utilizado no início da caixa foi de aproximadamente 10 metros, em que a profundidade variou de 15 a $50 \mathrm{~cm}$. A partir da metade do comprimento um novo segmento de transição eleva a profundidade até aproximadamente $70 \mathrm{~cm}$. Segundo o piloto que conduziu o veículo durante os 16 ensaios realizados, em nenhuma das entradas na caixa o nível de desaceleração provocou uma sensação de desconforto acentuado e os efeitos são menores para velocidades de entrada maiores.

\section{Largura}

As caixas de retenção também podem ser classificadas de acordo com a largura. Quando apenas meio eixo do veículo penetra na caixa e a outra metade continua a rolar sobre o acostamento ou pista, tem-se uma caixa de meia largura. Nesse caso a desaceleração provocada é assimétrica, aumentando os riscos de danos e a necessidade de maiores comprimentos para parar os veículos [SETRA, 1993]. As caixas com larguras maiores que a largura dos veículos são chamadas de caixa de largura integral.

Prevendo uma situação de pânico por parte dos motoristas de veículos desgovernados, a largura da caixa de retenção deve ser dimensionada de forma a promover aspectos seguros, que facilitem a entrada do veículo com todas as rodas do eixo simultaneamente, provocando uma ação de frenagem com máxima segurança. 
Para que isso ocorra, a largura da caixa deve ser superior à largura dos veículos [AASHTO, 1994; ITE, 1989; Witheford, 1992].

O manual americano recomenda que a largura mínima da caixa de retenção deve ser de 8 metros, valor também indicado pelo ITE [1989], mas aconselha uma configuração ideal variando entre 9 e 12 metros [AASHTO, 1994]. A largura da caixa deve ser suficiente para acomodar mais de um veículo desgovernado, pois não é incomum que mais de um veículo utilize a área de escape em um curto intervalo de tempo.

Uma pesquisa realizada em 25 estados americanos sobre o uso da área de escape por mais de um veículo simultaneamente apresentou os seguintes resultados: 17 estados nunca registraram uso simultâneo, três estados disseram já ter registrado e outros cinco estados, que apresentam um longo tempo de experiência com áreas de escape com caixa de retenção, afirmaram que existe uma ocorrência significativa de uso simultâneo [Witheford, 1992].

Não há dúvida de que a largura da caixa deva ser superior à largura dos veículos, mas para dimensionar sem exageros é necessária uma análise da freqüência de acidentes, do volume de tráfego no local onde será instalado o dispositivo e uma estimativa do tempo gasto para retirar os veículos [AASHTO, 1994]. Essas variáveis podem ser usadas como ferramentas para auxiliar na determinação da largura. Vale ressaltar que quanto maior a dimensão da caixa maior será o custo de construção do dispositivo.

\subsection{OPERAÇÃO DAS ÁREAS DE ESCAPE}

A operação de áreas de escape envolve três aspectos principais: a sinalização, o auxílio aos veículos e a manutenção. As recomendações e experiências de outros países em relação à operação de áreas de escape serão discutidos a seguir.

\subsubsection{Sinalização}

O sucesso da operação das áreas de escape está em informar aos motoristas com antecedência a existência de áreas de escape [ITE, 1989]. Como os motoristas de 
veículos desgovernados em alta velocidade provavelmente estarão em uma situação de tensão, a localização adequada da sinalização antes da entrada facilita a tomada de decisão.

Pesquisadores americanos e franceses recomendam que no início do declive seja implantado um sistema de sinalização que informe aos motoristas a presença de área de escape no declive, bem como a distância que ela se encontra do topo do declive. Ao longo do trecho outras placas devem indicar a que distância se está do dispositivo e sob quais condições os motoristas devem utilizar o dispositivo [SETRA, 1993; Witheford, 1992]. Próximo ao acesso da área de escape a sinalização deve se intensificar a fim de conduzir com facilidade os motoristas até a entrada do dispositivo.

Normas norte-americanas recomendam sinalização próxima à entrada da rampa que proíba os motoristas de estacionar ou parar nas proximidades do dispositivo. $\mathrm{O}$ acesso e os limites da caixa devem ser delineados por algum tipo de sinalização luminosa, para facilitar o uso noturno [AASHTO, 1994].

Placas ao longo da via devem informar aos motoristas as características do declive, como inclinação e extensão do trecho de descida. Informações sobre regras de condução segura em declives devem fazer parte da sinalização, bem como avisos sobre a velocidade de segurança a ser desenvolvida, a necessidade se verificar os freios do veículo, uso do freio motor e até mesmo a marcha adequada a ser escolhida pelo motorista. Essas informações podem contribuir para redução da ocorrência de acidentes envolvendo veículos desgovernados [SETRA, 1993; Witheford, 1992 ].

Em caso de readequação da área de escape após a utilização ou mesmo durante a realização de manutenção, convém criar sistemas de sinalização para informar aos motoristas que a área de escape não está disponível. A sinalização horizontal de marcação do acesso à caixa deve ser diferenciada de uma saída normal, utilizando um tabuleiro de xadrez vermelho e branco com um metro de largura para evidenciar o acesso à área de escape [SETRA, 1993]. 


\subsubsection{Auxílio aos veículos}

O auxílio aos veículos que utilizaram a área de escape, deve ocorrer o mais rápido possível, para que o dispositivo volte a estar liberado para um novo uso. Com o afundamento dos pneus do caminhão no material solto da caixa de retenção, torna-se indispensável um mecanismo para retirá-lo e também prestar os primeiros serviços mecânicos e médicos quando necessário.

Pistas de serviço e blocos de ancoragem ao longo do comprimento devem fazer parte do dimensionamento das áreas de escape. No projeto de áreas de escape deve-se prever um modo fácil e rápido de retirada dos veículos, para que o dispositivo possa voltar a operar o mais rápido possível. Vale ressaltar que em alguns casos a rodovia também pode ficar interditada até o término do processo de retirada do veículo [Witheford, 1992].

Pesquisadores franceses recomendam a construção de uma pista de serviço paralela à caixa de retenção para auxiliar a retirada dos veículos. Essa pista deve ter em torno de cinco metros de largura, de modo que os veículos de apoio possam operar ao longo de todo comprimento da caixa. Nos casos em que não houver pista de serviço, torna-se necessário um local adjacente da caixa, para o estacionamento dos veículos de socorro. A presença de pista de serviço não dispensa a implantação dos blocos de ancoragem que podem ser do tipo pilar de fundação, com dois metros de profundidade e 50 centímetros de diâmetro. Esses blocos servem de apoio para os equipamentos, como guindastes, utilizados na retirada do veículo [SETRA, 1993].

Nos testes realizados pelos australianos com veículos articulados, a extração dos caminhões foi feita com auxílio de veículos reboques (caminhões pesados equipados com guincho) em alguns casos, mais de um veículo reboque era utilizado para aumentar a força de tração e arrastar os caminhões para fora da caixa de retenção. Esse processo de retirada dos veículos é difícil e demorado, pois os cabos que rebocam os veículos quebram freqüentemente. $O$ tempo gasto para cada extração ultrapassou 2 horas e em alguns casos até mais de 3 horas. Outro método de extração utilizados nos ensaios foi feito em conjunto com caminhões equipados com guindastes para levantar os veículos durante a retirada. Esse método reduziu em até 
uma hora o tempo de extração do veículo, mas apresenta um custo maior [Leach e Ives, 1995].

De modo geral, a retirada dos veículos da caixa de retenção é um processo demorado e quando aperfeiçoado para reduzir o tempo de extração, seu custo tornase elevado.

\subsubsection{Manutenção}

Os serviços de manutenção têm como finalidade conservar a eficiência da caixa de retenção, após cada uso e ao longo do tempo. Após cada uso, a superfície do material da caixa deve ser regularizada com auxílio de equipamentos adequados que possibilitem a movimentação e a reestruturação do material. Mesmo sem registro de uso da caixa, deve-se evitar que a eficiência de frenagem sofra uma redução brusca ao longo do tempo. Normas norte americanas recomendam evitar a compactação do material de enchimento e facilitar a drenagem, para isso, o material deve ser limpo e escarificado periodicamente [AASHTO, 1994].

O efeito da presença de finos, sujeira e o apodrecimento de folhas produzirão uma redução lenta e progressiva da eficiência da caixa. Convém acompanhar esta evolução para determinar o período ideal para realização de limpeza ou mesmo da substituição do material quando ocorrer uma perda acentuada da eficiência de frenagem do dispositivo [SETRA, 1993].

Witheford [1992] alerta sobre a necessidade de escarificação do material em intervalos periódicos e não somente após cada uso. Descreve também uma pesquisa sobre os efeitos da contaminação do agregado ao longo de tempo, por meio de um estudo realizado por Hayden [1982], em que se observa o acréscimo da distância para frear os veículos com o passar dos anos.

Deve-se ter uma atenção particular com vazamento de combustíveis ou cargas líquidas dos veículos que utilizaram a área de escape. Um sistema de drenagem especial deve ser instalado para recolher esses materiais, separadamente do sistema de drenagem de águas pluviais, evitando assim a contaminação do material da caixa e até mesmo problemas ambientais [AASHTO, 1994]. 
Neste capítulo foram apresentados os principais tipos de dispositivo para contenção de veículos desgovernados e um estudo das características de projeto para implantação de áreas de escape com caixa de retenção (necessidade, dimensionamento, localização e operação). Os assuntos que foram tratados neste capítulo servirão de suporte para o desenvolvimento do método de pesquisa adotado. 


\section{ESTUDO DE CASO}

Este capítulo apresenta um estudo da desaceleração em uma caixa de retenção construída no Brasil, um estudo de localização de áreas de escape ao longo de um declive e uma análise da operação de veículos pesados em declives longos e íngremes.

\subsection{ANÁLISE DA DESACLERAÇÃO EM CAIXAS DE RETENÇÃO}

Com intuito de avaliar a eficiência de frenagem em caixas de retenção foram realizados ensaios para verificar o comportamento da desaceleração em uma área de escape construída no $\mathrm{km} 42$ da pista sul da Via Anchieta. Neste capítulo do trabalho são descritos o procedimento dos ensaios, os dados coletados, as análises de desaceleração e os resultados obtidos.

\subsubsection{Coleta e tratamento dos dados}

\section{Descrição dos ensaios}

Os dados utilizados na pesquisa foram coletados por meio de ensaios realizados na área de escape com caixa de retenção construída no $\mathrm{km} 42,7$ na pista sul da Via Anchieta, trecho da Serra do Mar. Esses ensaios consistiram da entrada de três tipos de caminhões na área de escape com velocidades variáveis. A Figura 4.1 ilustra uma das entradas na área de escape. 


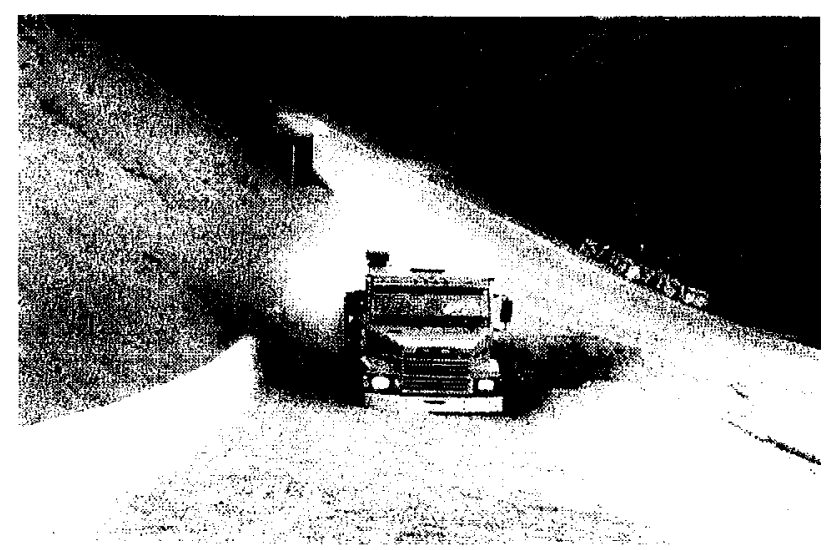

Figura 4.1: Caminhão entrando na caixa de retenção

A finalidade dos testes foi avaliar a eficiência da área de escape construída na Via Anchieta em frear diferentes tipos de veículos desgovernados em diversas velocidades. Os dados obtidos nos testes visam determinar a intensidade da desaceleração provocada pelo material de preenchimento da caixa.

Os testes foram realizados durante três dias em setembro de 2001. Os caminhões utilizados nos testes foram um caminhão rígido, equipado como guincho, com eixo traseiro tipo tandem e peso bruto total (PBT) de $15.500 \mathrm{~kg}$ (Figura 4.2a); um caminhão rígido, equipado como pipa, eixo traseiro tipo tandem e PBT de 23.290 kg (Figura 4.2b); e um caminhão articulado, composto por um cavalo mecânico (Scania 4x2), um semi reboque com eixo traseiro tipo tandem triplo e PBT de 36.920 kg (Figura 4.2c);

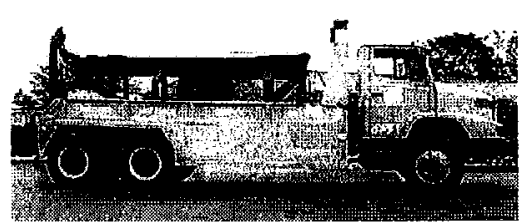

Figura 4.2a: Guincho

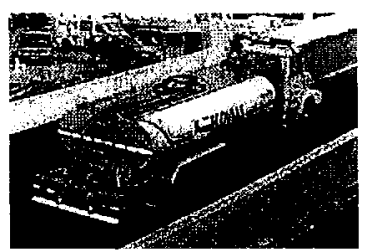

Figura 4.2b: Pipa

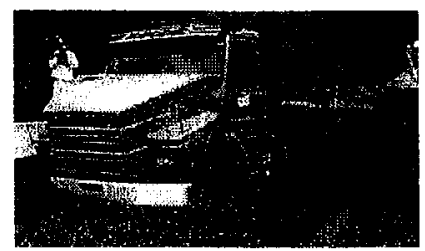

Figura 4.2c: Articulado

Com o caminhão guincho foram realizados oito testes com velocidades variando de 50 a $107 \mathrm{~km} / \mathrm{h}$; com o caminhão pipa, seis testes com velocidades de 47 a $95 \mathrm{~km} / \mathrm{h}$; e dois testes com o caminhão articulado com velocidades de 38 e 81 $\mathrm{km} / \mathrm{h}$;

Os caminhões foram conduzidos por um piloto de testes e a velocidade de entrada foi inicialmente controlada com auxílio do velocímetro do caminhão. A 
velocidade estipulada para a primeira entrada de cada caminhão foi de $40 \mathrm{~km} / \mathrm{h}$. Nos testes seguintes aumentou-se gradualmente a velocidade de acordo com 0 comportamento da frenagem do caminhão na caixa de retenção. Após cada teste, a distância de frenagem até a parada do veículo foi medida com uma trena. Essa distância corresponde ao comprimento entre o início da caixa de retenção e o párachoque dianteiro do caminhão.

Para a aquisição de dados da posição dos caminhões ao longo da caixa de retenção foi utilizado um equipamento GPS, que permitiu determinar as coordenadas UTM do veículo a cada décimo de segundo. No caso, o equipamento usado foi o DGPS Leica System 500. A antena foi instalada na parte superior da cabine dos caminhões (Figura 4.3a) e a unidade fixa em um muro de arrimo no final da caixa de retenção (Figura 4.3b).

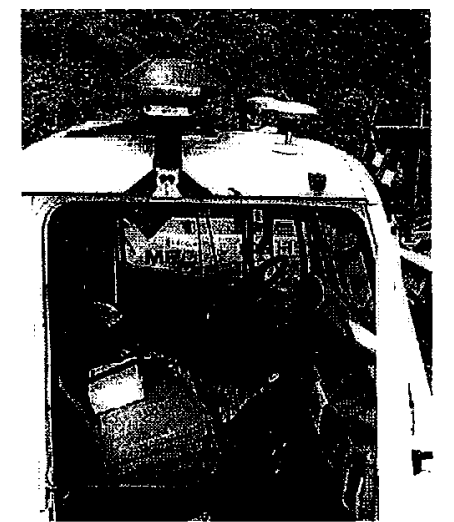

Figura 4.3a: Unidades móveis do GPS

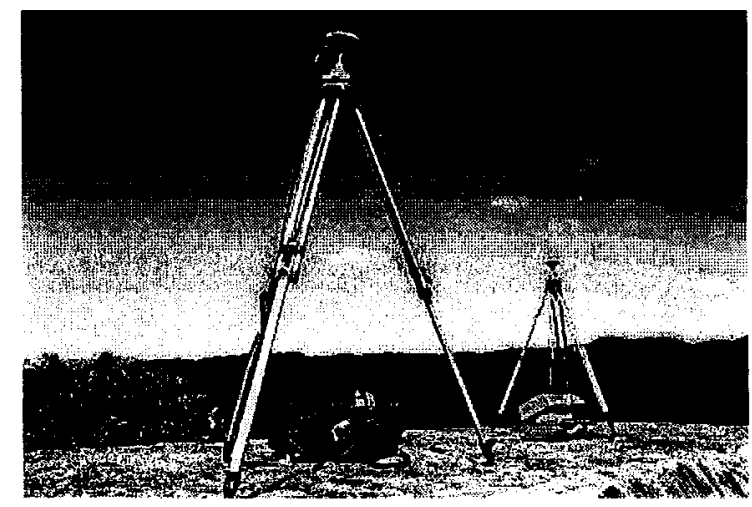

Figura 4.3b: Unidades fixas do GPS

\section{Dados coletados durante os testes}

Os dados coletados através do receptor GPS foram processados para se obter as coordenadas UTM do caminhão ao longo da caixa de retenção. Os resultados foram importados para uma planilha eletrônica e, para cada entrada na caixa foi elaborado um gráfico $x y$ com as coordenadas locais obtidas pelo GPS durante o movimento dos caminhões. $\mathrm{O}$ anexo $\mathrm{A}$ apresenta as coordenadas coletadas em todos os testes realizados. A Figura 4.4 mostra a trajetória do caminhão através de coordenadas locais, desde o início do movimento do caminhão até o final da frenagem na caixa de retenção. O início do movimento variou entre 300 a 500 metros a montante da 
entrada da caixa de retenção, para que os caminhões pudessem atingir a velocidade de entrada estipulada para cada um dos testes.

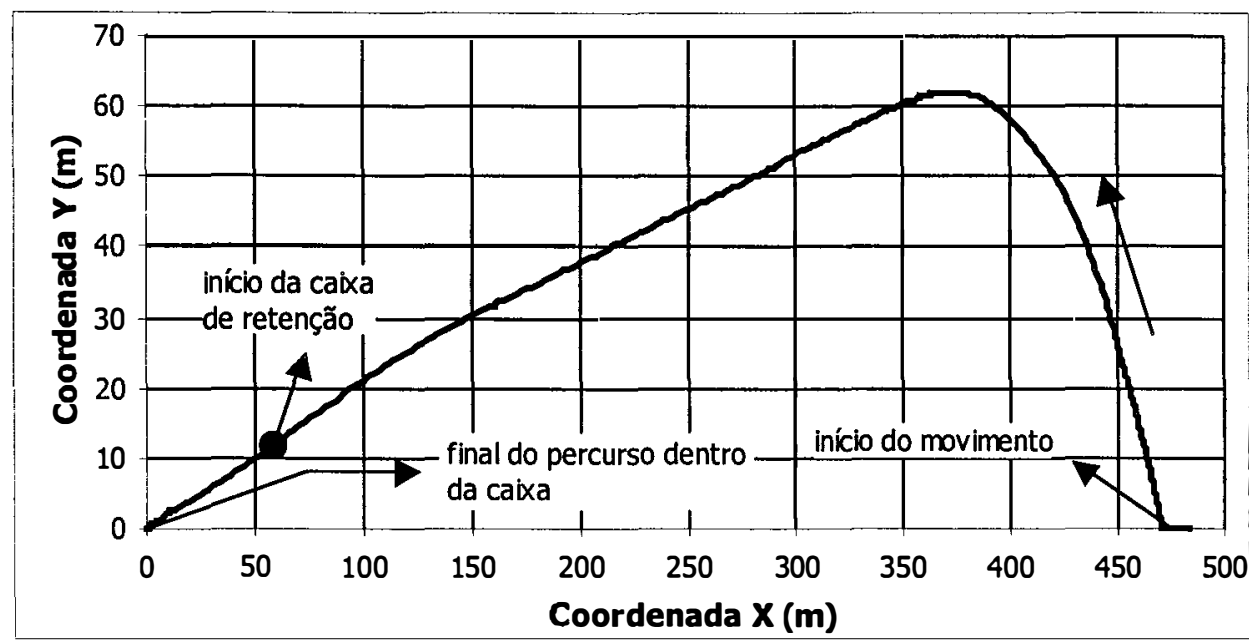

Figura 4.4: Seqüência de dados coletados pelo GPS para o teste 5 do caminhão rígido, $\mathrm{m}=23,29 \mathrm{t}$

Utilizando os valores das coordenadas $x$ e $y$ foi possível determinar a distância percorrida pelo caminhão a cada décimo de segundo e a distância acumulada até o fim do movimento. Para selecionar apenas os pontos dentro da caixa de retenção (durante o comprimento de frenagem), considerou-se o ponto $(0,0)$ como sendo a posição em que o caminhão parou na caixa de retenção (coluna "distância retroativa" da Tabela 4.1). Com a distância retroativa e a distância de frenagem medida no local foi possível selecionar as coordenadas $x$ e $y$ (locais) que representam a frenagem do caminhão dentro da caixa de retenção. Como exemplo do teste 1 do caminhão guincho, a distância de frenagem medida durante o ensaio foi de 26,2 metros; no entanto, como o ponto mais próximo obtido pelo GPS foi de $26,9 \mathrm{~m}$, este foi o valor considerado como sendo o ponto de início da frenagem (Tabela 4.1).

Na Tabela 4.1, a coluna "distância retroativa" indica a variação da posição do caminhão dentro da caixa de retenção até o final da frenagem. Adotando-se como tempo inicial zero, o que corresponde ao ponto em que o veículo entra na caixa de retenção, pode-se determinar o tempo total de desaceleração e os pares ordenados (tempo, distância) que representam o comportamento cinemático do caminhão durante o processo de frenagem pela caixa de retenção. Tabelas similares foram obtidas para todos os ensaios. 
Tabela 4.1: Dados obtidos e selecionados no teste 1 do caminhão rígido, $\mathrm{m}=15,5 \mathrm{t}$

\begin{tabular}{|c|c|c|c|c|c|}
\hline \multicolumn{2}{|c|}{ coordenadas locais } & \multirow{2}{*}{$\begin{array}{l}\text { distância percorrida } \\
\text { a cada } 0,1 \mathrm{~s}(\mathrm{~m})\end{array}$} & \multirow{2}{*}{$\begin{array}{c}\text { distância } \\
\text { acumulada (m }\end{array}$} & \multirow{2}{*}{$\begin{array}{l}\text { retroativa } \\
(\mathrm{m})\end{array}$} & \multirow{2}{*}{$\begin{array}{l}\text { tempo } \\
\text { (s) }\end{array}$} \\
\hline$x$ & $y$ & & & & \\
\hline 26,17 & 5,46 & 1,31 & 284,04 & $-26,93$ & 0,00 \\
\hline 24,86 & 5,20 & 1,33 & 285,37 & $-25,59$ & 0,10 \\
\hline 23,54 & 4,93 & 1,35 & 286,72 & $-24,24$ & 0,20 \\
\hline 22,20 & 4,65 & 1,36 & 288,09 & $-22,88$ & 0,30 \\
\hline 20,88 & 4,32 & 1,37 & 289,45 & $-21,51$ & 0,40 \\
\hline 19,57 & 4,05 & 1,33 & 290,78 & $-20,18$ & 0,50 \\
\hline 18,33 & 3,79 & 1,27 & 292,05 & $-18,91$ & 0,60 \\
\hline 17,11 & 3,56 & 1,24 & 293,30 & $-17,67$ & 0,70 \\
\hline 15,93 & 3,30 & 1,21 & 294,51 & $-16,46$ & 0,80 \\
\hline 14,81 & 3,04 & 1,15 & 295,66 & $-15,31$ & 0,90 \\
\hline 13,66 & 2,76 & 1,18 & 296,84 & $-14,13$ & 1,00 \\
\hline 12,56 & 2,48 & 1,14 & 297,98 & $-12,99$ & 1,10 \\
\hline 11,48 & 2,29 & 1,09 & 299,07 & $-11,90$ & 1,20 \\
\hline 10,44 & 2,12 & 1,06 & 300,12 & $-10,84$ & 1,30 \\
\hline 9,48 & 1,94 & 0,98 & 301,10 & $-9,86$ & 1,40 \\
\hline 8,55 & 1,71 & 0,96 & 302,06 & $-8,91$ & 1,50 \\
\hline 7,68 & 1,52 & 0,89 & 302,95 & $-8,01$ & 1,60 \\
\hline 6,83 & 1,35 & 0,86 & 303,81 & $-7,15$ & 1,70 \\
\hline 6,06 & 1,20 & 0,79 & 304,60 & $-6,37$ & 1,80 \\
\hline 5,33 & 1,09 & 0,74 & 305,34 & $-5,63$ & 1,90 \\
\hline 4,67 & 0,97 & 0,67 & 306,01 & $-4,96$ & 2,00 \\
\hline 4,04 & 0,87 & 0,64 & 306,65 & $-4,32$ & 2,10 \\
\hline 3,51 & 0,75 & 0,55 & 307,19 & $-3,77$ & 2,20 \\
\hline 3,01 & 0,62 & 0,51 & 307,70 & $-3,26$ & 2,30 \\
\hline 2,55 & 0,50 & 0,48 & 308,19 & $-2,78$ & 2,40 \\
\hline 2,11 & 0,42 & 0,44 & 308,63 & $-2,34$ & 2,50 \\
\hline 1,73 & 0,33 & 0,39 & 309,02 & $-1,94$ & 2,60 \\
\hline 1,36 & 0,25 & 0,38 & 309,40 & $-1,57$ & 2,70 \\
\hline 1,07 & 0,19 & 0,30 & 309,70 & $-1,27$ & 2,80 \\
\hline 0,80 & 0,13 & 0,27 & 309,97 & $-1,00$ & 2,90 \\
\hline 0,57 & 0,07 & 0,24 & 310,21 & $-0,75$ & 3,00 \\
\hline 0,37 & 0,04 & 0,20 & 310,41 & $-0,56$ & 3,10 \\
\hline 0,23 & 0,03 & 0,15 & 310,55 & $-0,41$ & 3,20 \\
\hline 0,11 & 0,01 & 0,12 & 310,68 & $-0,29$ & 3,30 \\
\hline 0,04 & 0,01 & 0,07 & 310,75 & $-0,22$ & 3,40 \\
\hline 0,00 & 0,00 & 0,04 & 310,78 & $-0,18$ & 3,50 \\
\hline 0,00 & 0,01 & 0,01 & 310,79 & $-0,18$ & 3,60 \\
\hline 0,00 & 0,01 & 0,00 & 310,79 & $-0,18$ & 3,70 \\
\hline 0,01 & 0,01 & 0,01 & 310,80 & $-0,17$ & 3,80 \\
\hline 0,05 & 0,03 & 0,05 & 310,84 & $-0,12$ & 3,90 \\
\hline 0,05 & 0,03 & 0,00 & 310,84 & 0,00 & 4,00 \\
\hline
\end{tabular}




\section{Tratamento preliminar dos dados}

Os dados coletados foram analisados visando determinar a componente da desaceleração devida à resistência de movimento provocada pelo material de enchimento da caixa (cinasita) e a componente da desaceleração devida à geometria da caixa de retenção.

A partir dos pares ordenados (tempo, distância) foi possível traçar curvas tempo x posição, que representam o deslocamento do caminhão dentro da caixa de retenção desde sua entrada até a parada total. As Figuras 4.5 a 4.7 apresentam os resultados resumidos de todos os testes. Como pode ser visto em cada figura, o eixo das abcissas representa o tempo a partir do instante em que o caminhão entra na caixa até o final da frenagem; o eixo das ordenadas representa a posição ocupada pelo caminhão dentro da caixa.

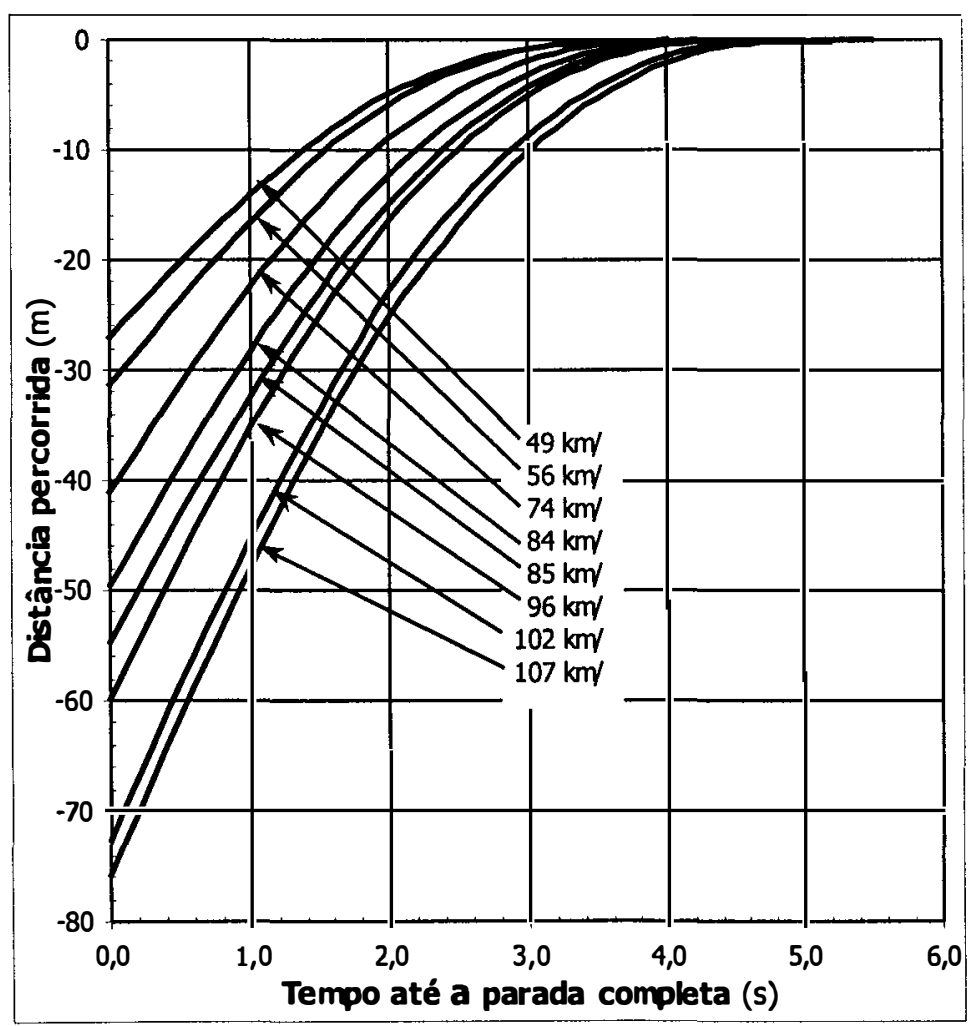

Figura 4.5: Curvas de posição em função do tempo - caminhão rígido, $m=15,5 \mathrm{t}$ 


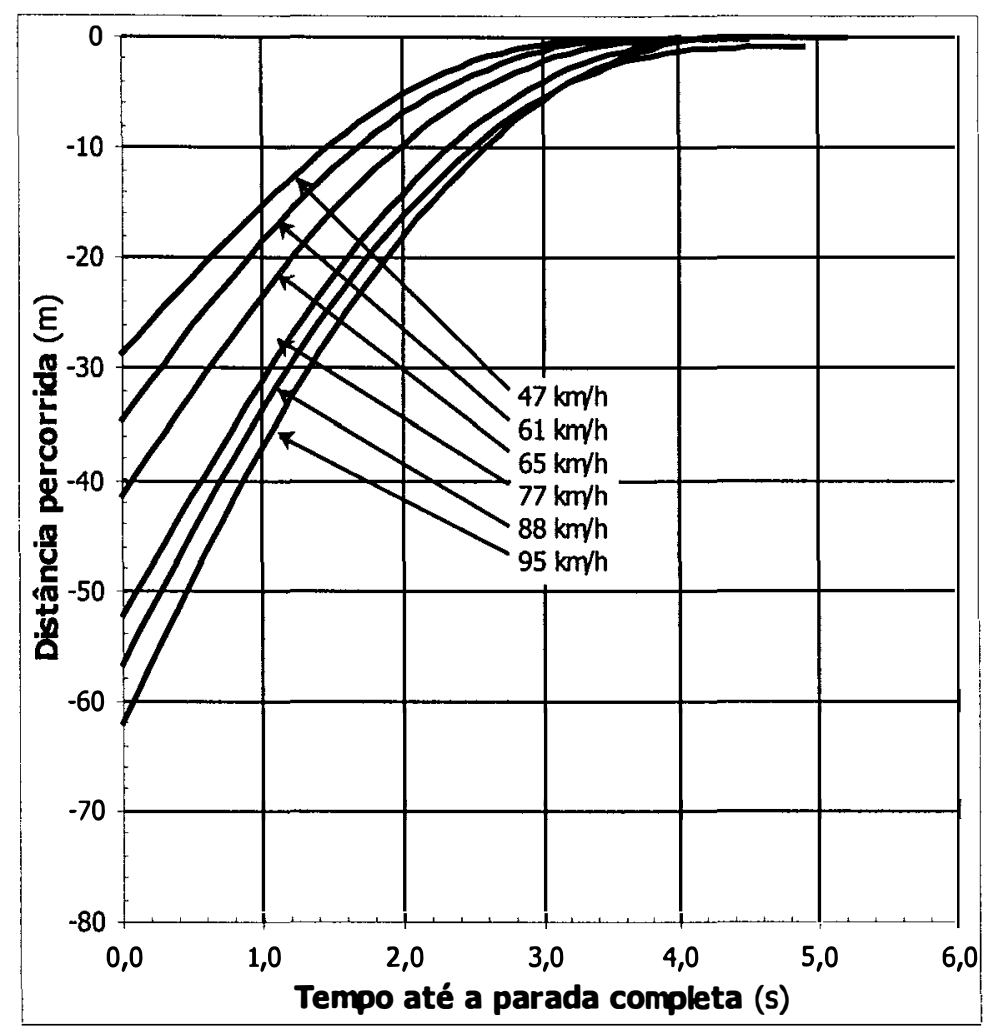

Figura 4.6: Curvas de posição em função do tempo - caminhão rígido, $m=23,29 \mathrm{t}$

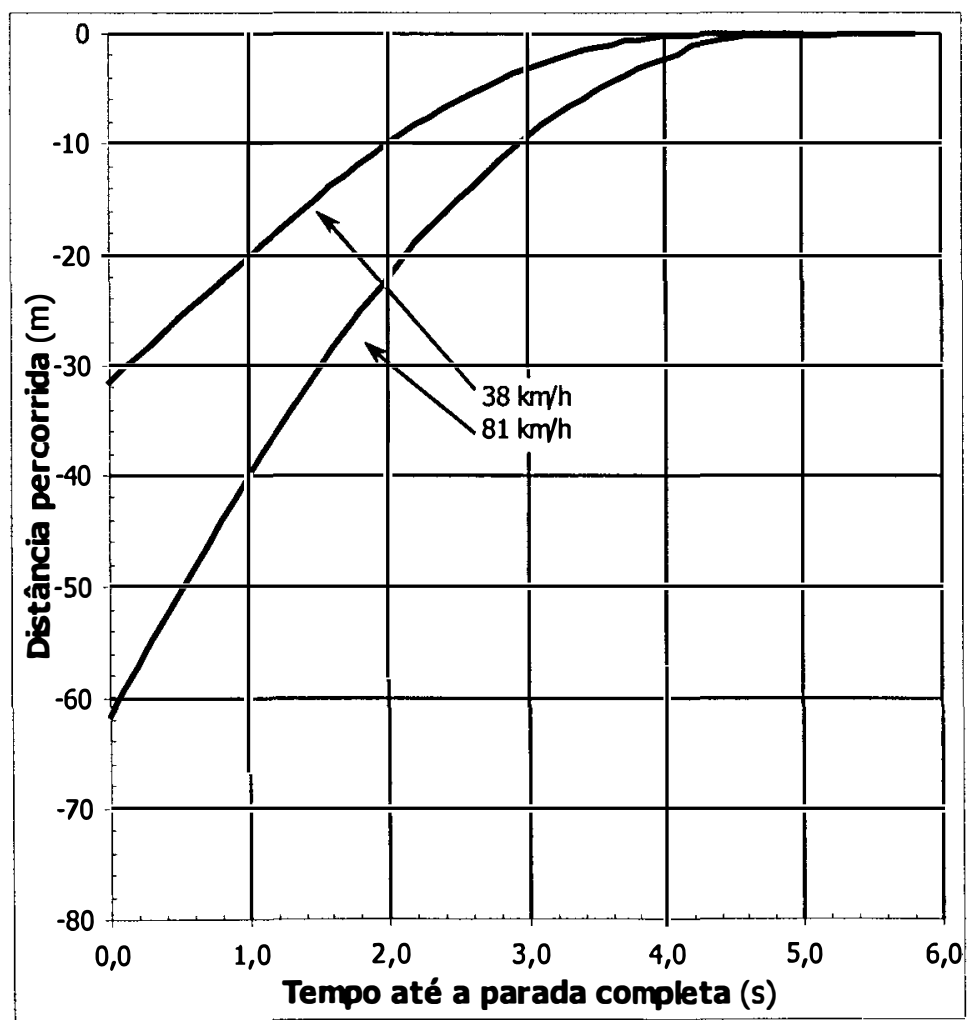

Figura 4.7: Curvas de posição em função do tempo - caminhão articulado, $\mathrm{m}=36,92 \mathrm{t}$ 
Observa-se nos gráficos que quanto maior a velocidade de entrada do caminhão, maior a distância percorrida dentro da caixa de retenção e maior o tempo necessário para parada total do caminhão.

\subsubsection{Determinação da desaceleração média}

A análise dos dados obtidos nas curvas de tempo x posição visou determinar um modelo matemático capaz de representar adequadamente a relação entre as duas variáveis. Submetendo os dados de posição e tempo à uma regressão, encontrou-se um modelo polinomial do quarto grau (Equação 4.1):

$$
S=a . t^{4}+b . t^{3}+c . t^{2}+d . t+e
$$

em que: $\quad S$ : posição do veículo na caixa de retenção $(\mathrm{m})$;

$t$ : tempo (s); e

$a, b, c, d$ e $e$ : coeficientes de calibração do modelo polinomial.

Os polinômios obtidos podem ser utilizados para representar o comportamento dos caminhões durante a frenagem dentro da caixa de retenção, sendo capazes de explicar $100 \%$ da variação observada no modelo $\left(R^{2}=1,00\right)$. Para todos os testes realizados foram calibrados modelos polinomiais do quarto grau que representam a variação de posição em função do tempo durante o percurso de frenagem, que são apresentados na Tabela 4.2.

A partir das funções horárias da posição é possível estimar a intensidade da desaceleração imposta aos veículos dentro da caixa de retenção, estimando as funções horárias da velocidade e as funções horárias da desaceleração capazes de representar o comportamento cinemático dos caminhões durante todo o tempo de frenagem. 
Tabela 4.2: Modelos calibrados para o movimento dos caminhões na caixa de retenção

\begin{tabular}{cccc}
\hline Caminhão Teste & \multicolumn{1}{c}{ Modelo } & $\boldsymbol{R}^{2}$ \\
\hline & 1 & $s=0,1044 t^{4}-0,8197 t^{3}-0,1476 t^{2}+13,726 t-26,951$ & 1,00 \\
& 2 & $s=0,1201 t^{4}-0,9579 t^{3}-0,0825 t^{2}+15,788 t-31,402$ & 1,00 \\
& 3 & $s=0,0908 t^{4}-0,7024 t^{3}-1,2419 t^{2}+20,662 t-41,182$ & 1,00 \\
guincho & 4 & $s=0,0845 t^{4}-0,7091 t^{3}-1,2705 t^{2}+23,418 t-49,734$ & 1,00 \\
$15,50 \mathrm{t}$ & 5 & $s=0,0934 t^{4}-0,8822 t^{3}-0,4691 t^{2}+23,594 t-54,622$ & 1,00 \\
& 6 & $s=0,0829 t^{4}-0,7327 t^{3}-1,3633 t^{2}+26,73 t-59,931$ & 1,00 \\
& 7 & $s=0,0944 t^{4}-0,9612 t^{3}-0,3651 t^{2}+28,521 t-72,482$ & 1,00 \\
& 8 & $s=0,069 t^{4}-0,7018 t^{3}-1,1476 t^{2}+29,814 t-75,794$ & 1,00 \\
\hline pipa & 1 & $s=0,159 t^{4}-1,3547 t^{3}+1,3772 t^{2}+13,082 t-28,569$ & 1,00 \\
$23,29 \mathrm{t}$ & 2 & $s=0,1279 t^{4}-1,0302 t^{3}-0,0122 t^{2}+16,972 t-34,594$ & 1,00 \\
& 3 & $s=0,1339 t^{4}-1,1911 t^{3}+0,6188 t^{2}+18,298 t-41,333$ & 1,00 \\
& 4 & $s=0,1299 t^{4}-1,239 t^{3}+0,736 t^{2}+21,538 t-52,299$ & 1,00 \\
& 5 & $s=0,09 t^{4}-0,8269 t^{3}-0,7588 t^{2}+24,347 t-56,628$ & 1,00 \\
& 6 & $s=0,0768 t^{4}-0,7363 t^{3}-1,044 t^{2}+26,4 t-61,887$ & 1,00 \\
\hline articulado & 1 & $s=0,0729 t^{4}-0,8285 t^{3}+1,4807 t^{2}+10,427 t-31,319$ & 1,00 \\
$36,92 \mathrm{t}$ & 2 & $s=0,0542 t^{4}-0,6111 t^{3}-0,3188 t^{2}+22,412 t-61,555$ & 1,00 \\
\hline & & & $s$
\end{tabular}

\section{Variação da velocidade durante a frenagem}

A derivada da equação horária do espaço (Equação 4.1) em função do tempo é igual à velocidade, logo, derivando-se as funções horárias do espaço obtidas, têm-se as funções horárias da velocidade dos caminhões durante a frenagem na caixa de retenção (Equação 4.2):

$$
\begin{gathered}
v=\frac{d s}{d t}=\frac{d\left(a . t^{4}+b . t^{3}+c . t^{2}+d . t+e\right)}{d t} \\
v=4 a \cdot t^{3}+3 b . t^{2}+2 c . . t+d
\end{gathered}
$$

em que: $\quad v$ : velocidade $(\mathrm{m} / \mathrm{s})$. 
Como as equações do espaço obtidas nos testes são do quarto grau, o resultado da derivada primeira em função do tempo será uma função polinomial do terceiro grau (Equação 4.3).

De acordo com a convenção adotada no processo de cálculo, o ponto em que o veículo entra na caixa de retenção é o instante $t=0$. Nesse ponto a velocidade dos caminhões será a máxima (velocidade de entrada). Após esse instante, o valor da velocidade sofre uma redução gradual até chegar a zero, no término da frenagem, como se mostra na Figura 4.8.

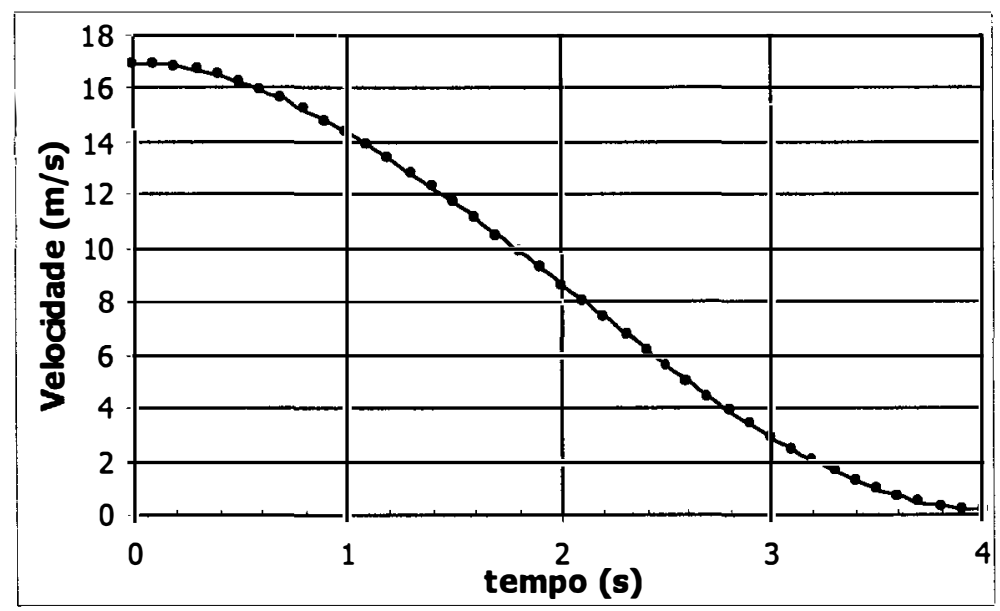

Figura 4.8: Comportamento da velocidade ao longo da frenagem na caixa de brita para o teste 2 do caminhão rígido, $\mathrm{m}=23,29 \mathrm{t}$

Substituindo o instante $t=0$ nas funções horárias da velocidade, estima-se a velocidade dos caminhões ao entrarem na caixa de retenção (Tabela 4.3).

Tabela 4.3: Velocidade de entrada dos caminhões nos testes

\begin{tabular}{cccc}
\hline \multirow{2}{*}{ Teste } & \multicolumn{3}{c}{ Velocidade de entrada (m/s) } \\
\cline { 2 - 4 } & Guincho & Pipa & Articulado \\
\hline 1 & 13,73 & 13,08 & 10,43 \\
2 & 15,79 & 16,97 & 22,41 \\
3 & 20,66 & 18,30 & \\
4 & 23,42 & 21,54 & \\
5 & 23,59 & 24,35 & \\
6 & 26,73 & 26,40 & \\
7 & 28,52 & & \\
8 & 29,81 & & \\
\hline
\end{tabular}




\section{Desaceleração total ao longo do tempo de frenagem}

A derivada da equação horária da velocidade em função do tempo é igual a aceleração, logo, derivando-se as funções horárias obtidas para a velocidade, têm-se as funções horárias da aceleração $\left(a_{t}\right)$ dos caminhões durante a frenagem na caixa de retenção (Equação 4.4).

$$
a=\frac{d v}{d t}=\frac{d\left(4 a . t^{3}+3 b \cdot t^{2}+2 c . t+d\right)}{d t}
$$

A desaceleração durante a frenagem na caixa de retenção é dada por funções do tipo:

$$
a_{t}=12 a \cdot t^{2}+6 b \cdot t+2 c
$$

em que: $\quad a_{i}$ : aceleração $\left(\mathrm{m} / \mathrm{s}^{2}\right)$.

A Figura 4.9 ilustra o comportamento da desaceleração em um dos testes. Os valores negativos da aceleração são justificados por se tratar de um trecho em que os caminhões estão sujeitos a uma força resultante contrária ao movimento, uma situação de desaceleração. Pode-se notar que a curva representativa da aceleração à qual o caminhão é submetido é uma parábola; portanto, no início da caixa de retenção, a intensidade da desaceleração é baixa e cresce rapidamente até um valor máximo; próximo ao final do comprimento de frenagem, a desaceleração passa a diminuir até o caminhão parar. Esse fenômeno é compatível com observações feitas em ensaios similares realizados nos EUA [Allison et al., 1979].

A desaceleração da equação 4.5 é a soma vetorial de duas componentes: uma componente devida à resistência de rolamento do material de enchimento da caixa de retenção e uma componente devida à resistência de rampa, que pode ser positiva ou negativa. 


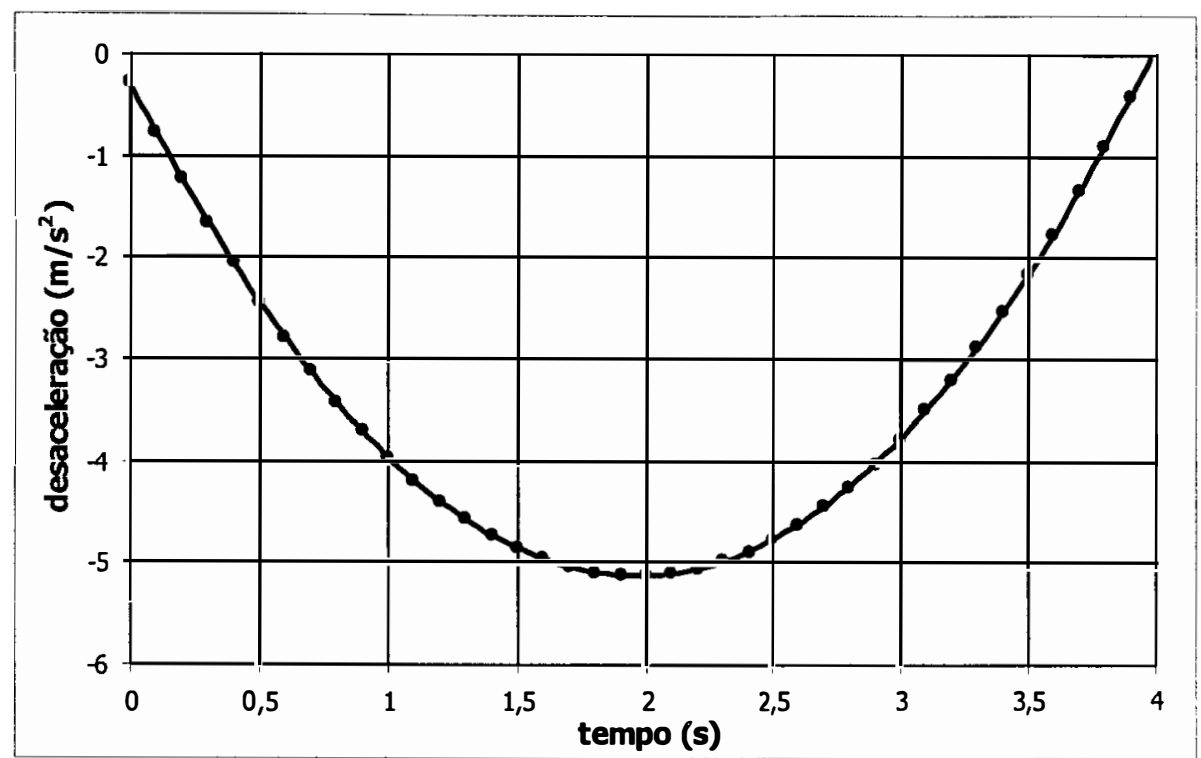

Figura 4.9: Comportamento da desaceleração total para o teste 1 do caminhão rígido, $\mathrm{m}=15,5 \mathrm{t}$

\section{Desaceleração proveniente da resistência de rolamento}

No item anterior foi determinada a desaceleração total provocada pela soma vetorial das forças que atuam no caminhão dentro da caixa de retenção (Equação 4.6).

$$
\vec{F}_{r}=\vec{R}_{r}+\vec{R}_{g}+\vec{R}_{a}
$$

em que: $\quad \vec{F}_{r}:$ Força resultante;

$\vec{R}_{r}:$ Resistência de rolamento;

$\vec{R}_{g}$ : Resistência de rampa; e

$\vec{R}_{a}$ : Resistência aerodinâmica.

A resistência aerodinâmica foi desprezada, pois apresenta uma intensidade muito pequena quando comparada com as demais forças. A resistência de rampa é dada pela componente tangencial do peso do caminhão na direção do movimento, e seu sentido de atuação depende da declividade da caixa: no caso de declives, a resistência de rampa acelera os caminhões e em aclives, desacelera. A caixa de retenção estudada possui um trecho em declive e o restante do comprimento em aclive. A resistência de rolamento é proveniente da deformação do material de enchimento da caixa de retenção. 
$\mathrm{Na}$ etapa seguinte, procurou-se estimar a intensidade da desaceleração provocada apenas pela resistência de rolamento. Determinou-se inicialmente a parcela de desaceleração proveniente da declividade da caixa, e então a desaceleração proveniente do material de preenchimento da caixa de retenção.

Com auxílio de uma estação total TC 400 Leica, foi possível obter um perfil vertical ao longo do comprimento da caixa de retenção. Com os dados coletados utilizando a estação total, foram obtidas as declividades a cada metro do comprimento da caixa (Anexo B). Conhecidas as declividades e os pesos dos veículos, utilizou-se a equação a seguir para determinar a intensidade da resistência de rampa:

$$
R_{g}=10 . G . i
$$

em que: $\quad R_{g}$ : Resistência de $\operatorname{rampa}(\mathrm{N})$;

$G$ : Peso do veículo (KN); e

$i$ : declividade da rampa (\%).

A resistência de rampa foi determinada para cada uma das posições ocupadas pelos caminhões dentro da caixa de retenção, usando-se o perfil longitudinal da superficie do material de enchimento da caixa, admitindo-se uma rampa constante entre os pontos levantados. Aplicando-se a segunda lei de Newton, foi obtida a parcela da desaceleração provocada pela resistência de rampa ao longo do comprimento de frenagem, como mostra a Equação 4.8.

$$
R_{g}=m \cdot a_{g} \therefore a_{g}=\frac{R_{g}}{m}
$$

em que: $\quad a_{g}$ : desaceleração provocada pela resistência de $\operatorname{rampa}\left(\mathrm{m} / \mathrm{s}^{2}\right)$; e $m$ : massa do veículo $(\mathrm{kg})$.

Com o resultado da soma vetorial entre a desaceleração total (obtida a partir da Equação 4.4) e a desaceleração provocada pela resistência de rampa (Equação 4.8), determinou-se a parcela provocada pela resistência de rolamento a cada intervalo de 0,1 segundos (Equação 4.9) para todos os testes: 


$$
\vec{a}_{t}=\vec{a}_{r}+\vec{a}_{g} \therefore \vec{a}_{r}=\vec{a}_{t}-\vec{a}_{g}
$$

em que: $\quad \vec{a}_{\boldsymbol{r}}$ : desaceleração provocada pela resistência de rolamento $\left(\mathrm{m} / \mathrm{s}^{2}\right)$

Um exemplo dos resultados obtido em um dos testes é apresentado na Tabela 4.4 .

O gráfico da Figura 4.10 mostra a desaceleração total, $a_{t}$, e a parcela da desaceleração proveniente da resistência de rolamento, $a_{r}$, para um dos testes realizados. Observa-se que a variação de $a_{r}$ durante o tempo de frenagem segue um comportamento parabólico. Para simplificação, o modelo que representa $a_{r}$ foi obtido através de análise de regressão, adotando-se um modelo polinomial do segundo grau.

Para cada seqüência de dados de $a_{r}$, foi determinado um valor médio $\left(a_{m}\right)$, por integração numérica. $\mathrm{O}$ valor de $a_{m}$ corresponde à altura do retângulo que forma uma área equivalente à área encontrada na integração numérica (Figura 4.10).

A Tabela 4.5 apresenta os valores da desaceleração média devida à resistência de rolamento, $a_{m}$, determinados de acordo o processo de cálculo descrito anteriormente. As intensidades da desaceleração são normalmente dadas em função da aceleração da gravidade $(g)$, considerando seu valor igual a $9,81 \mathrm{~m} / \mathrm{s}^{2}$.

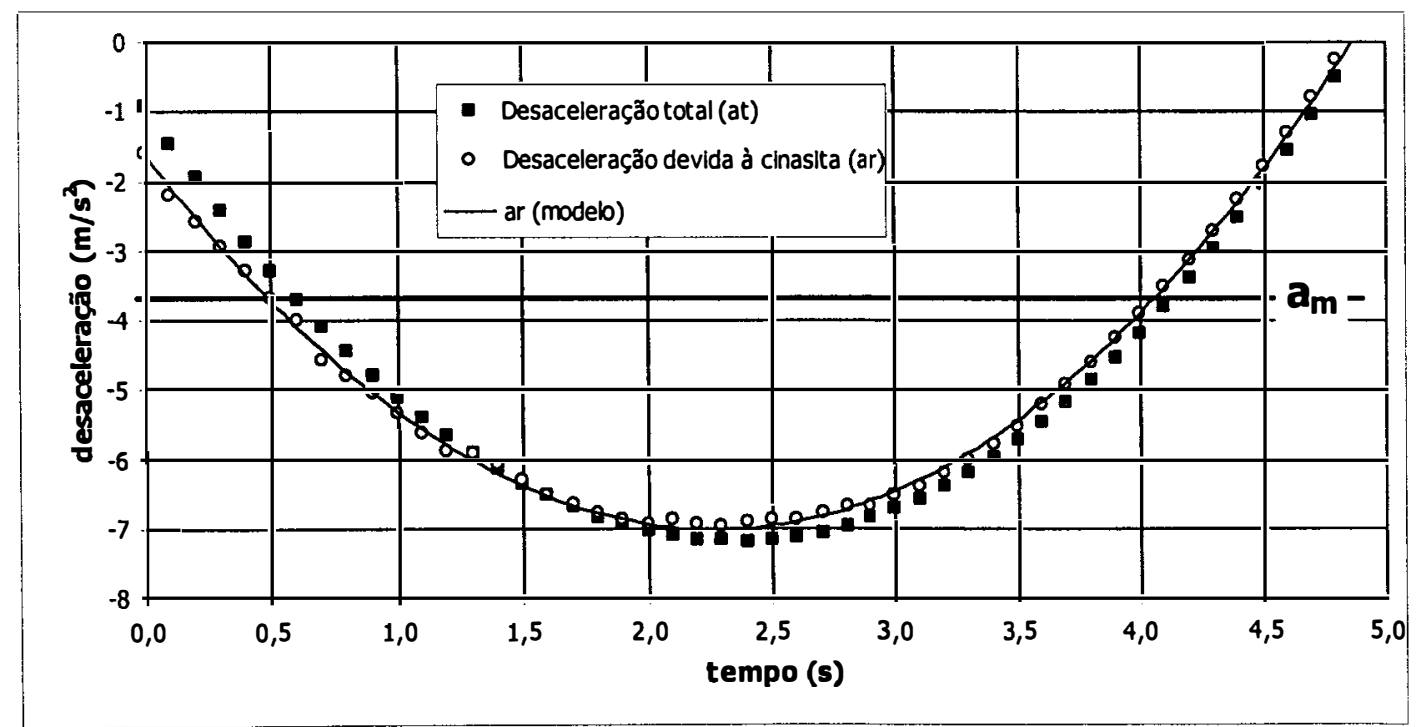

Figura 4.1 0: Comportamento da desaceleração provocada pela resistência de rolamento da cinasita para o teste 5 do caminhão rígido, $\mathrm{m}=15,5 \mathrm{t}$ 
Tabela 4.4: Determinação da desaceleração provocada pela resistência do rolamento, (teste 5 do caminhão rígido, $\mathrm{m}=15,5 \mathrm{t}$ )

\begin{tabular}{|c|c|c|c|c|c|}
\hline \multirow{2}{*}{ tempo (s) } & \multirow{2}{*}{ retroativa $(\mathrm{m})$} & \multirow{2}{*}{$R_{g}=10 . G . i$} & \multicolumn{3}{|c|}{ desacelerações $\left(\mathrm{m} / \mathrm{s}^{2}\right)$} \\
\hline & & & $a_{g}=R g / m$ & $a_{t}$ & $a_{r}=a_{t}-a_{g}$ \\
\hline 0,0 & $-54,58$ & $-10164,90$ & 0,66 & $-0,94$ & $-1,59$ \\
\hline 0,1 & $-52,28$ & $-11673,70$ & 0,75 & $-1,46$ & $-2,21$ \\
\hline 0,2 & $-49,96$ & $-10164,90$ & 0,66 & $-1,95$ & $-2,61$ \\
\hline 0,3 & $-47,64$ & $-8047,60$ & 0,52 & $-2,43$ & $-2,94$ \\
\hline 0,4 & $-45,31$ & $-6684,00$ & 0,43 & $-2,88$ & $-3,31$ \\
\hline 0,5 & $-43,02$ & $-5925,60$ & 0,38 & $-3,30$ & $-3,69$ \\
\hline 0,6 & $-40,82$ & $-4255,90$ & 0,27 & $-3,71$ & $-3,99$ \\
\hline 0,7 & $-38,66$ & $-7290,20$ & 0,47 & $-4,09$ & $-4,56$ \\
\hline 0,8 & $-36,53$ & $-5470,40$ & 0,35 & $-4,46$ & $-4,81$ \\
\hline 0,9 & $-34,38$ & $-4255,90$ & 0,27 & $-4,79$ & $-5,07$ \\
\hline 1,0 & $-32,28$ & $-3648,30$ & 0,24 & $-5,11$ & $-5,35$ \\
\hline 1,1 & $-30,23$ & $-3344,40$ & 0,22 & $-5,40$ & $-5,62$ \\
\hline 1,2 & $-28,24$ & $-3344,40$ & 0,22 & $-5,68$ & $-5,89$ \\
\hline 1,3 & $-26,33$ & 304,10 & $-0,02$ & $-5,93$ & $-5,91$ \\
\hline 1,4 & $-24,51$ & 1216,40 & $-0,08$ & $-6,15$ & $-6,07$ \\
\hline 1,5 & $-22,75$ & 760,30 & $-0,05$ & $-6,36$ & $-6,31$ \\
\hline 1,6 & $-21,06$ & 304,10 & $-0,02$ & $-6,54$ & $-6,52$ \\
\hline 1,7 & $-19,41$ & 760,30 & $-0,05$ & $-6,70$ & $-6,65$ \\
\hline 1,8 & $-17,83$ & 608,20 & $-0,04$ & $-6,83$ & $-6,80$ \\
\hline 1,9 & $-16,33$ & 912,30 & $-0,06$ & $-6,95$ & $-6,89$ \\
\hline 2,0 & $-14,91$ & 1368,40 & $-0,09$ & $-7,04$ & $-6,95$ \\
\hline 2,1 & $-13,54$ & 3648,30 & $-0,24$ & $-7,11$ & $-6,88$ \\
\hline 2,2 & $-12,24$ & 3496,30 & $-0,23$ & $-7,16$ & $-6,93$ \\
\hline 2,3 & $-11,00$ & 3344,40 & $-0,22$ & $-7,18$ & $-6,97$ \\
\hline 2,4 & $-9,83$ & 4104,00 & $-0,26$ & $-7,19$ & $-6,92$ \\
\hline 2,5 & $-8,76$ & 4559,60 & $-0,29$ & $-7,17$ & $-6,87$ \\
\hline 2,6 & $-7,75$ & 3800,20 & $-0,25$ & $-7,12$ & $-6,88$ \\
\hline 2,7 & $-6,80$ & 4255,90 & $-0,27$ & $-7,06$ & $-6,78$ \\
\hline 2,8 & $-5,91$ & 4255,90 & $-0,27$ & $-6,97$ & $-6,70$ \\
\hline 2,9 & $-5,09$ & 2888,50 & $-0,19$ & $-6,86$ & $-6,68$ \\
\hline 3,0 & $-4,32$ & 3040,50 & $-0,20$ & $-6,73$ & $-6,53$ \\
\hline 3,1 & $-3,63$ & 2736,50 & $-0,18$ & $-6,58$ & $-6,40$ \\
\hline 3,2 & $-3,00$ & 2736,50 & $-0,18$ & $-6,40$ & $-6,22$ \\
\hline 3,3 & $-2,44$ & 2888,50 & $-0,19$ & $-6,20$ & $-6,01$ \\
\hline 3,4 & $-1,94$ & 2888,50 & $-0,19$ & $-5,98$ & $-5,79$ \\
\hline 3,5 & $-1,51$ & 2888,50 & $-0,19$ & $-5,73$ & $-5,55$ \\
\hline 3,6 & $-1,14$ & 4104,00 & $-0,26$ & $-5,47$ & $-5,20$ \\
\hline 3,7 & $-0,83$ & 4104,00 & $-0,26$ & $-5,18$ & $-4,91$ \\
\hline 3,8 & $-0,59$ & 4104,00 & $-0,26$ & $-4,87$ & $-4,60$ \\
\hline 3,9 & $-0,40$ & 4104,00 & $-0,26$ & $-4,53$ & $-4,27$ \\
\hline 4,0 & $-0,27$ & 4104,00 & $-0,26$ & $-4,18$ & $-3,91$ \\
\hline 4,1 & $-0,19$ & 4104,00 & $-0,26$ & $-3,80$ & $-3,53$ \\
\hline 4,2 & $-0,17$ & 4104,00 & $-0,26$ & $-3,40$ & $-3,13$ \\
\hline 4,3 & $-0,17$ & 4104,00 & $-0,26$ & $-2,98$ & $-2,71$ \\
\hline 4,4 & $-0,17$ & 4104,00 & $-0,26$ & $-2,53$ & $-2,26$ \\
\hline 4,5 & $-0,15$ & 4104,00 & $-0,26$ & $-2,06$ & $-1,80$ \\
\hline 4,6 & $-0,12$ & 4104,00 & $-0,26$ & $-1,57$ & $-1,31$ \\
\hline 4,7 & $-0,11$ & 4104,00 & $-0,26$ & $-1,06$ & $-0,79$ \\
\hline 4,8 & $-0,08$ & 4104,00 & $-0,26$ & $-0,52$ & $-0,26$ \\
\hline 4,9 & 0,00 & 3648,30 & $-0,24$ & 0,04 & 0,27 \\
\hline
\end{tabular}


Tabela 4.5: Desacelerações médias encontradas em cada teste

\begin{tabular}{ccccccc}
\hline \multirow{2}{*}{ teste } & \multicolumn{2}{c}{ caminhảo de 15,5 t } & \multicolumn{2}{c}{ caminhhảo de 23,29t } & \multicolumn{2}{c}{ caminhão de 36,92 t } \\
\cline { 2 - 7 } & $\mathrm{V}(\mathrm{m} / \mathrm{s})$ & $\mathrm{a}_{\mathrm{m}}(\mathrm{g})$ & $\mathrm{V}(\mathrm{m} / \mathrm{s})$ & $\mathrm{a}_{\mathrm{m}}(\mathrm{g})$ & $\mathrm{V}(\mathrm{m} / \mathrm{s})$ & $\mathrm{a}_{\mathrm{m}}(\mathrm{g})$ \\
\hline 1 & 49 & 0,38 & 47 & 0,38 & 38 & 0,24 \\
2 & 57 & 0,42 & 61 & 0,44 & 81 & 0,40 \\
3 & 74 & 0,49 & 66 & 0,45 & & \\
4 & 84 & 0,51 & 78 & 0,48 & & \\
5 & 85 & 0,50 & 88 & 0,51 & & \\
6 & 96 & 0,55 & 95 & 0,53 & & \\
7 & 103 & 0,55 & & & & \\
8 & 107 & 0,55 & & & & \\
\hline
\end{tabular}

Os modelos polinomiais do segundo grau que representam o comportamento da parcela de desaceleração provocada pela resistência de rolamento em função do tempo de frenagem são apresentados na Tabela 4.6, na qual verifica-se também o $R^{2}$ obtido em cada uma das regressões. Nestes modelos, $t=0$ no início da frenagem pela caixa de retenção.

Tabela 4.6: Equações da desaceleração provocada pela resistência de rolamento

\begin{tabular}{cccc}
\hline caminhão & teste & equação da desaceleração $\left(\boldsymbol{a}_{\boldsymbol{r}}\right)$ & $\boldsymbol{R}^{2}$ \\
\hline & 1 & $a=1,1811 t^{2}-4,507 t-1,0235$ & 0,998 \\
& 2 & $a=1,3798 t^{2}-5,3282 t-0,8695$ & 0,998 \\
rígido & 3 & $a=1,0195 t^{2}-3,7557 t-3,1219$ & 0,999 \\
$\mathrm{~m}=15,50 \mathrm{t}$ & 5 & $a=0,9349 t^{2}-3,713 t-3,1843$ & 0,999 \\
& 6 & $a=1,0467 t^{2}-4,7561 t-1,616$ & 0,999 \\
& 7 & $a=1,0705 t^{2}-5,3148 t-1,2323$ & 0,998 \\
& 8 & $a=0,7698 t^{2}-3,7546 t-2,8148$ & 0,998 \\
\hline & 1 & $a=1,8287 t^{2}-7,6995 t+2,0248$ & 0,999 \\
rígido & 2 & $a=1,4698 t^{2}-5,7453 t-0,6979$ & 0,999 \\
$\mathrm{~m}=23,29 \mathrm{t}$ & 3 & $a=1,5275 t^{2}-6,6391 t+0,5307$ & 0,999 \\
& 4 & $a=1,4697 t^{2}-6,867 t+0,8211$ & 0,999 \\
& 5 & $a=0,9996 t^{2}-4,4246 t-2,1376$ & 0,999 \\
& 6 & $a=0,8629 t^{2}-3,9638 t-2,6335$ & 0,998 \\
\hline articulado & 1 & $a=0,8357 t^{2}-4,63 t+2,2311$ & 0,998 \\
$\mathrm{~m}=36,92 \mathrm{t}$ & 2 & $a=0,6035 \mathrm{t}^{2}-3,2532 t-1,2112$ & 0,998 \\
\hline
\end{tabular}




\subsubsection{Análise da desaceleração média $\left(a_{m}\right)$}

Como pode ser visto na Tabela 4.5, a desaceleração média devida à resistência de rolamento $\left(a_{m}\right)$ varia em função da velocidade com que os caminhões entraram na caixa de retenção e em função do tipo de caminhão. A Figura 4.11 mostra melhor essa variação de $a_{m}$.

Observando a Figura 4.11, percebe-se que para caminhões do mesmo tipo, ou seja, caminhão rígido com 3 eixos, as desacelerações médias encontradas são semelhantes para velocidades de entrada similares, mesmo para veículos de diferentes massas. Para o caminhão articulado com 5 eixos, a desaceleração média sofre uma redução.

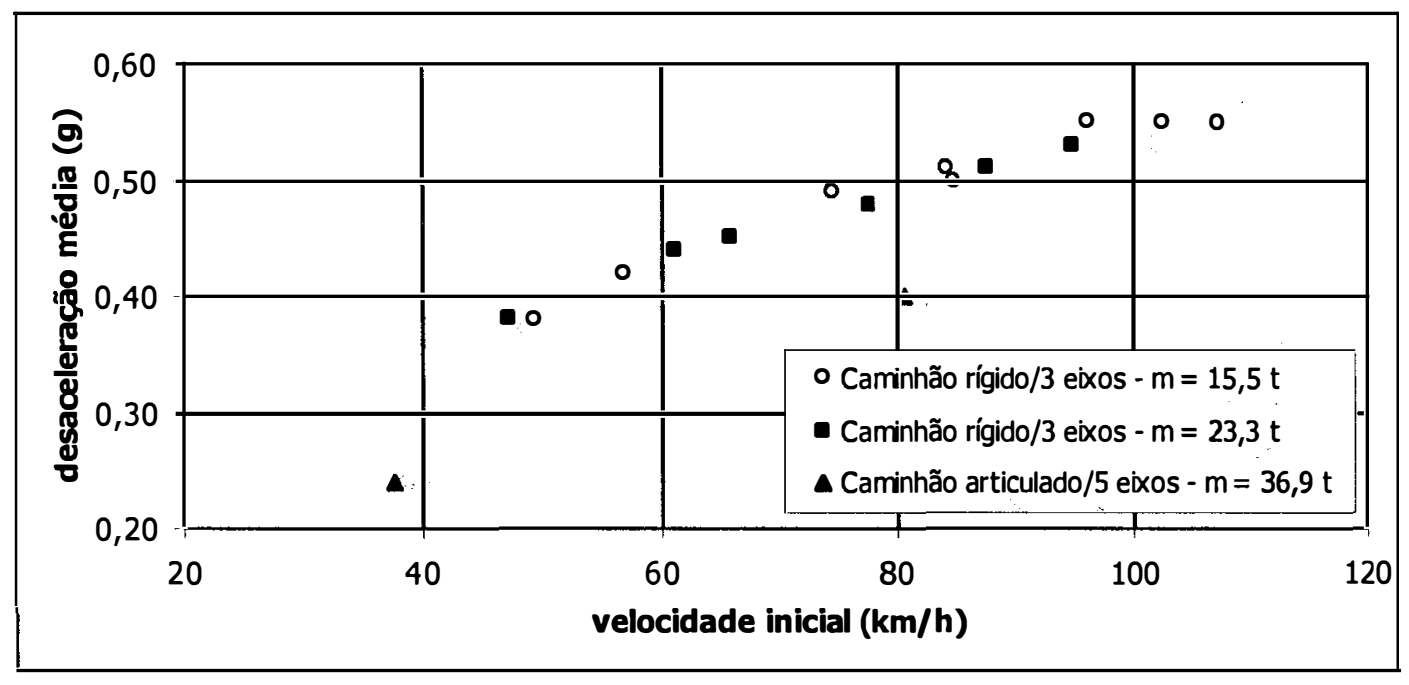

Figura 4.11: Variação de $a_{m}$ em função da velocidade de entrada

Os resultados mostram que para o caminhão com o qual foi realizado o maior número de entradas na caixa $(\mathrm{m}=15,5 \mathrm{t})$, a desaceleração média cresce com $\mathrm{o}$ aumento da velocidade de entrada até atingir um ponto máximo igual a 0,55 g, e a partir desse ponto o valor permanece constante para as observações seguintes (96, 103 e $107 \mathrm{~km} / \mathrm{h}$ ). Para os demais caminhões utilizados nos testes, pode-se notar que a desaceleração média também cresce com o aumento da velocidade mas, devido ao número restrito de observações feitas com esses veículos, não foi possível verificar o mesmo comportamento para velocidades mais elevadas. 
Comparando-se os resultados obtidos com observações feitas por pesquisadores australianos [Cocks e Goodram, 1982], pode-se verificar a ocorrência de um comportamento semelhante para a desaceleração média. Nesse estudo, verificou-se também um aumento da desaceleração média com acréscimo da velocidade de entrada, até atingir um valor máximo e a partir desse ponto a desaceleração média passa a diminuir, como mostra a Figura 4.12. A desaceleração média máxima ocorre para velocidade de entrada de aproximadamente $50 \mathrm{~km} / \mathrm{h}$. Deve-se ressaltar que as maiores velocidades de entrada desenvolvidas foram muito menores que as observadas nos ensaios realizados, além de outras diferenças nas características das caixas de retenção. Os ensaios australianos foram feitos em uma caixa horizontal e de comprimento restrito, na qual os veículos com velocidades maiores ultrapassavam os limites de comprimento da caixa.

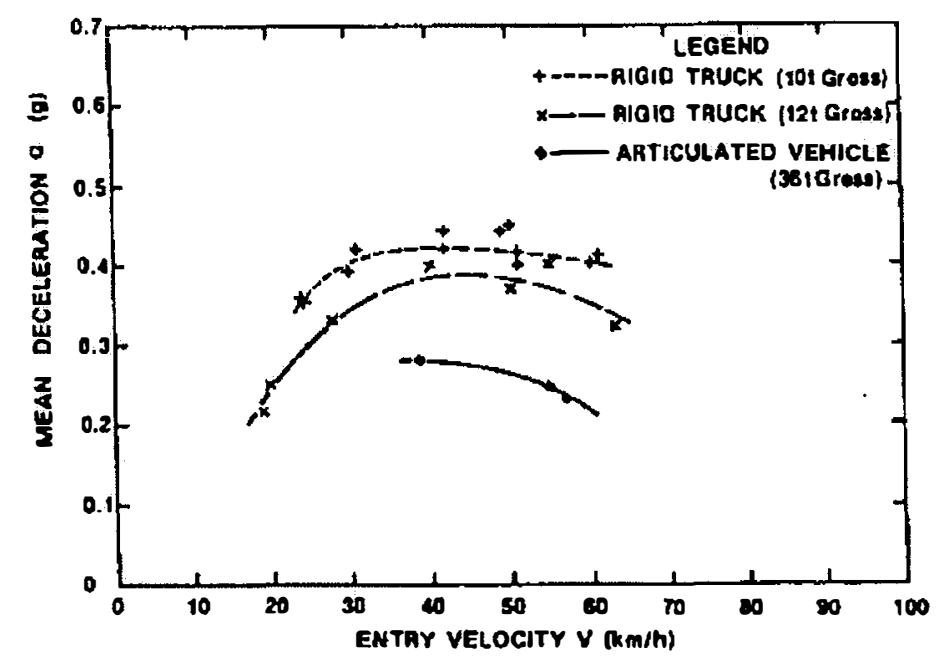

Figura 4.12: Comportamento da desaceleração média [Cocks e Goodram, 1982]

Outro fator importante avaliado por Cocks e Goodram [1982] é a relação entre as características do veículo e a desaceleração média. De acordo com a pesquisa australiana, o tipo de caminhão e a configuração dos eixos são aspectos que influenciam a desaceleração média. Como pode ser visto na Figura 4.12, os caminhões articulados, que possuem um maior número de eixos, apresentam uma desaceleração menor quando comparados aos caminhões rígidos. Outra questão apresentada no estudo diz respeito à relação entre a massa do caminhão e a 
desaceleração média, que segundo os pesquisadores exerce uma menor influência na intensidade da desaceleração média.

Observando os resultados dos ensaios realizados na Via Anchieta, pode-se dizer que, aspectos como a influência das características do caminhão e a relação pouco significativa da massa na intensidade da desaceleração média são compatíveis com as observações feitas pelos australianos. No entanto, limitações impostas pelo comprimento da caixa analisada e pela restrição de tempo disponível impediram a realização de mais ensaios com toda gama de velocidades para os três tipos de veículos. Baseado nos resultados encontrados para o caminhão rígido de 15 t é plausível considerar que todos os caminhões poderiam seguir o comportamento apresentado por Cocks e Goodram [1982], embora a velocidade para atingir a desaceleração máxima seja maior.

A revisão da literatura consultada mostrou que a desaceleração média recomendada e determinada em diferentes pesquisas varia entre 0,2 e $0,6 \mathrm{~g}$, intervalo ao qual pertencem os valores observados nos testes realizados na Via Anchieta.

\subsubsection{Modelo proposto para a desaceleração média}

Como os dados obtidos e a revisão da literatura indicam que a desaceleração média varia em função da velocidade de entrada e do tipo de caminhão, decidiu-se calibrar um modelo capaz de representar a variação da parcela da desaceleração média devida à resistência de rolamento em função destas duas variáveis.

Observando-se o gráfico da Figura 4.13, que mostra a variação da desaceleração média em função da velocidade de entrada do caminhão para o caso dos 14 ensaios realizados com caminhões rígidos de três eixos, pode-se notar que a forma geral da curva é logarítmica. No mesmo gráfico, pode ser também observado que essa função logarítmica, multiplicada por um fator de escala, também poderia ser usada para explicar a variação da desaceleração média observada para o caminhão articulado de cinco eixos, apesar de se dispor apenas de duas observações para tal tipo de veículo. Por conseguinte, o modelo adotado tem a seguinte formulação geral: 


$$
a_{m}=\left[k_{1} \cdot \ln \left(V_{i}\right)+k_{2}\right] \cdot\left(k_{3} \cdot N+k_{4}\right)
$$

em que: $\quad a_{m}$ : desaceleração média;

$V_{i}$ : velocidade de entrada $(\mathrm{km} / \mathrm{h})$;

$N$ : número de eixos; e

$k_{1}, \ldots, k_{4}$ : coeficientes de calibração do modelo.

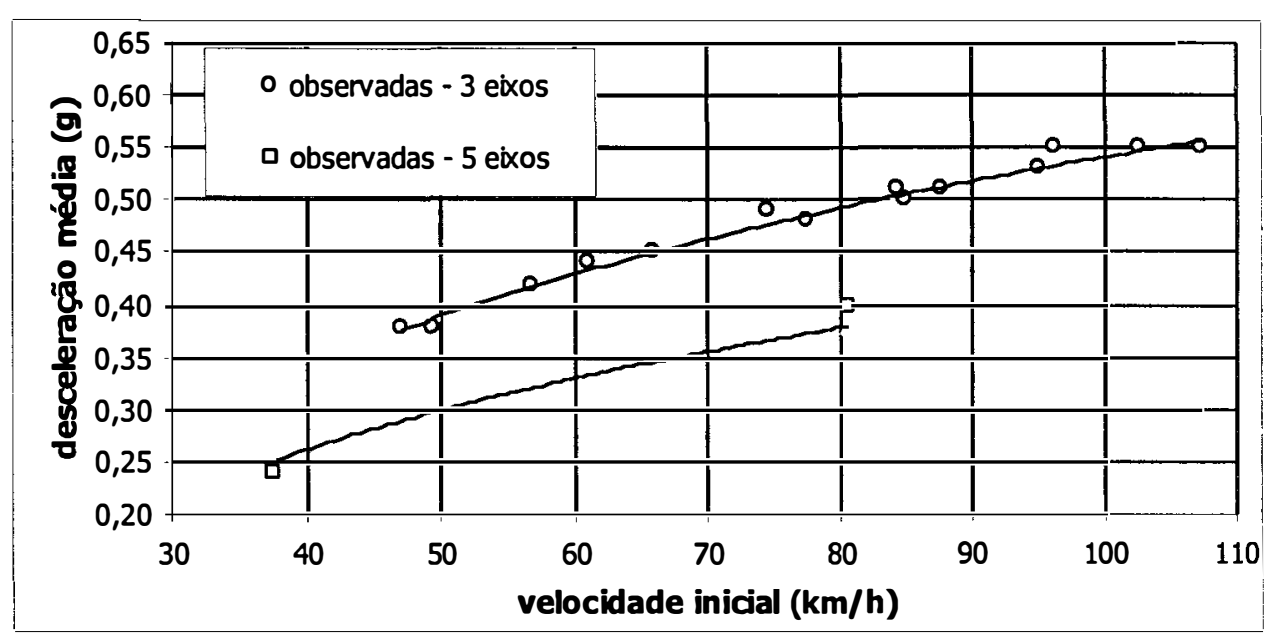

Figura 4.13: Modelo para estimativa da desaceleração média devida à cinasita

O primeiro termo da Equação 4.10 representa a curva logarítmica e o segundo termo é o fator de escala, que varia em função do número de eixos do caminhão.

\section{Calibração e validação do modelo proposto}

As observações experimentais da desaceleração média para os caminhões rígidos de 3 eixos foram divididas em dois conjuntos de dados: um conjunto $A$, composto pelos valores que foram utilizados na calibração do modelo; e conjunto $B$, composto pelos valores utilizados na validação do modelo.

A seleção dos dados de cada conjunto foi feita através de um processo de escolha semi-aleatório. Das 14 observações para os caminhões com 3 eixos, sete foram utilizadas na calibração e as demais, na validação do modelo proposto.

A seleção dos dados de calibração foi semi-aleatória na medida em que se evitou que duas observações com velocidade de entrada muito próximas fizessem parte do mesmo conjunto de dados. Por isso, foram selecionadas quatro observações 
do caminhão de $m=15,5 \mathrm{t}$ e três do caminhão de $m=23,29$ t. Na Figura 4.14 podem ser visto os pontos selecionados para calibração (conjunto $A$ ), os pontos selecionados para a validação (conjunto $B$ ) e o modelo logarítmico calibrado a partir do conjunto A.

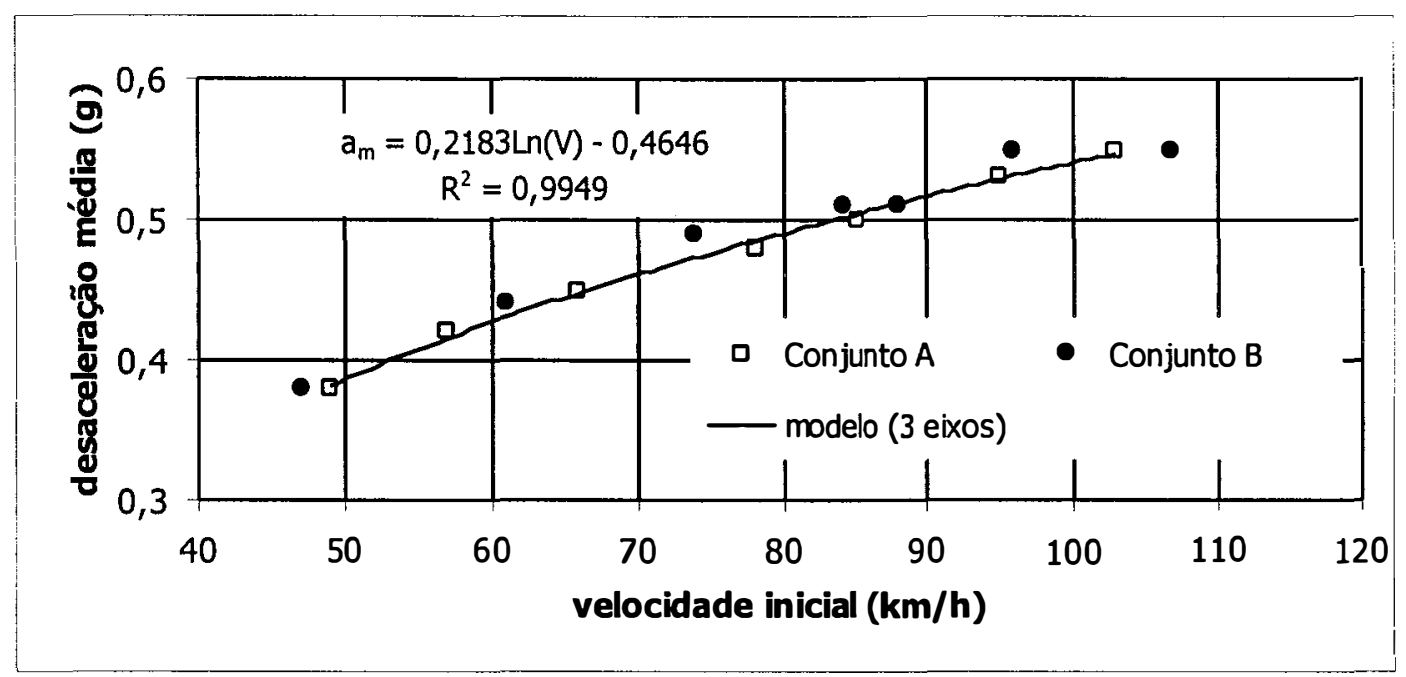

Figura 4.14: Conjuntos selecionados para calibração e validação do modelo

$$
\begin{aligned}
& \text { O modelo proposto, calibrado com o conjunto A, é dado por: } \\
& a_{m}=\left(0,2183 \cdot \ln V_{i}-0,4646\right) \cdot(-0,1154 \cdot N+1,3462)
\end{aligned}
$$

A partir do modelo calibrado foram determinados os valores estimados da desaceleração média para as velocidades correspondentes aos pontos do conjunto B. $\mathrm{Na}$ Tabela 4.7 são comparados os valores estimados e observados das desacelerações médias para o caminhão de três eixos (conjunto $\mathrm{B}, \mathrm{m}=15,5 \mathrm{t}$ e $23,29 \mathrm{t}$ ) e para $\mathrm{o}$ caminhão de 5 eixos $(m=36,92 t)$.

A Figura 4.15 mostra as observações (conjunto B) e as curvas obtidas através do modelo calibrado, para caminhões de 3 e de 5 eixos. Pode-se notar que o modelo proposto ajusta-se adequadamente às observações empíricas. A Figura 4.16 mostra as diferenças entre os valores observados (conjunto B) e os estimados através do modelo proposto 
Tabela 4.7: Desacelerações médias observadas e estimadas através do modelo calibrado com dados do conjunto A

\begin{tabular}{cccccc}
\hline \multirow{2}{*}{ Veículo } & Teste & $\boldsymbol{V}(\mathbf{k m} / \mathbf{h})$ & \multicolumn{3}{c}{ desaceleração média $\mathbf{( g )}$} \\
\hline & 1 & 49 & 0,38 & 0,38 & 0,00 \\
& 2 & 57 & 0,42 & 0,42 & 0,00 \\
rígido & 3 & 74 & 0,47 & 0,49 & 0,02 \\
$\mathrm{~m}=15,50 \mathrm{t}$ & 5 & 84 & 0,50 & 0,51 & 0,01 \\
& 6 & 85 & 0,51 & 0,50 & 0,01 \\
& 7 & 103 & 0,55 & 0,55 & 0,02 \\
& 8 & 107 & 0,56 & 0,55 & 0,00 \\
& 1 & 47 & 0,38 & 0,38 & 0,01 \\
\hline & 2 & 61 & 0,43 & 0,44 & 0,01 \\
rígido & 3 & 66 & 0,45 & 0,45 & 0,00 \\
& 4 & 78 & 0,49 & 0,48 & 0,01 \\
& 4 & 88 & 0,51 & 0,51 & 0,00 \\
& 5 & 95 & 0,53 & 0,53 & 0,00 \\
\hline articulado & 1 & 38 & 0,27 & 0,24 & 0,03 \\
$\mathrm{~m}=36,92$ & 2 & 81 & 0,43 & 0,40 & 0,03 \\
\hline
\end{tabular}

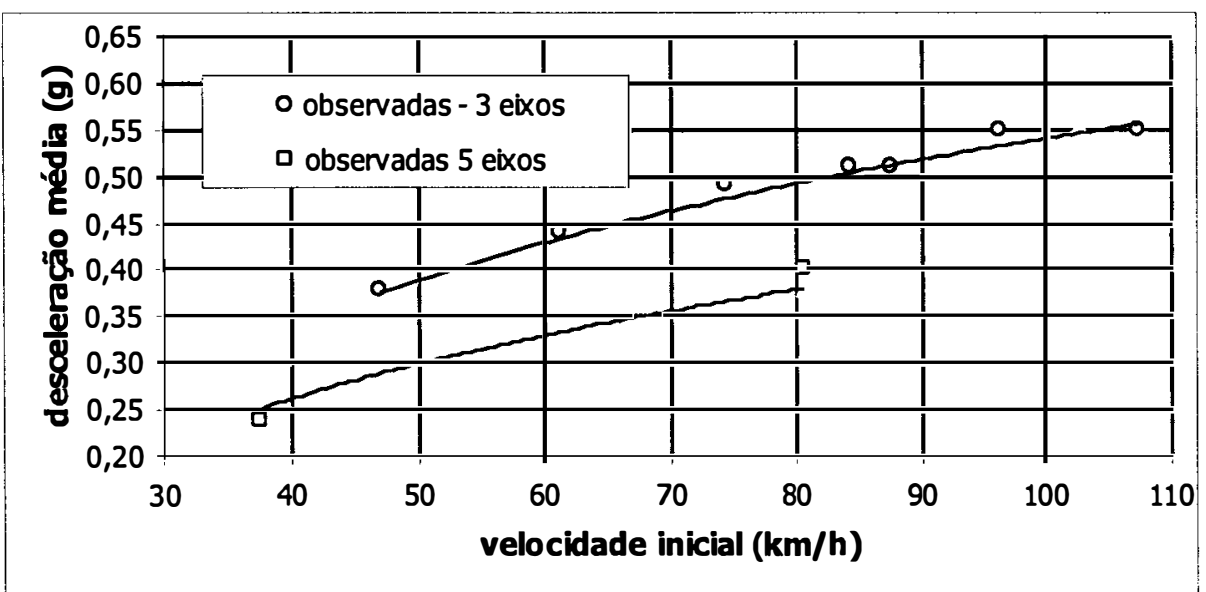

Figura 4.15: Desaceleração média observada e estimada pelo modelo calibrado a partir do conjunto de dados 


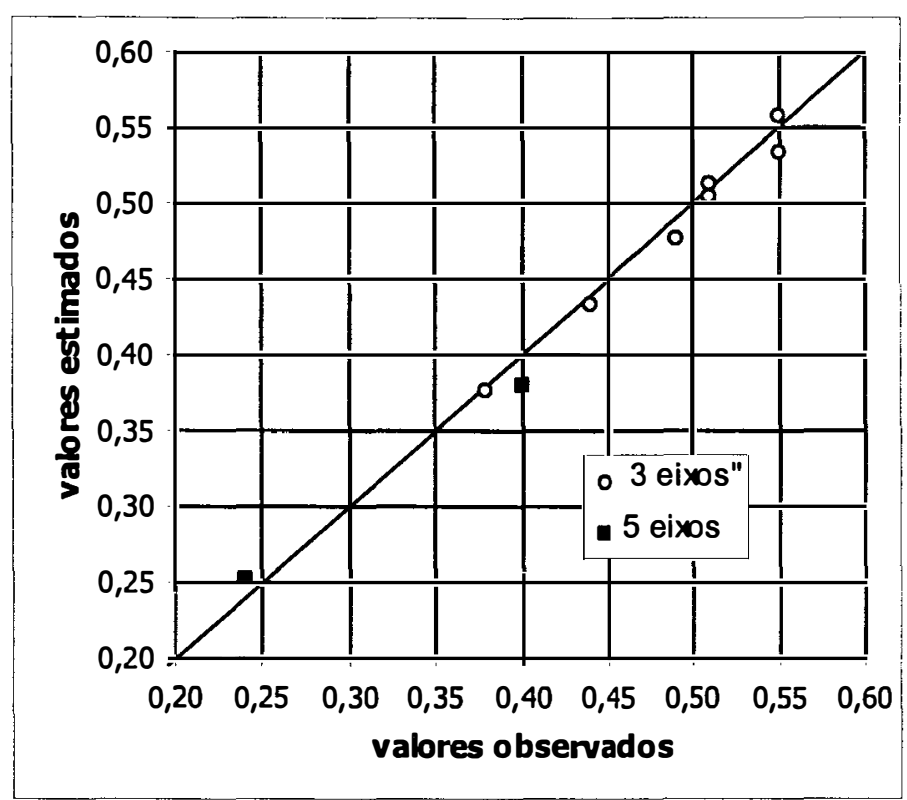

Figura 4.16: Diferenças entre a desaceleração média observada e estimada pelo modelo calibrado a partir do conjunto de dados $\mathrm{A}$

Para avaliar o ef eito da escolha do conjunto de dados utilizado na calibração sobre o modelo proposto, foi feita uma inversão dos conjuntos de dados, ou seja, o conjunto $B$ foi usado para calibrar o modelo, ao passo que o conjunto A foi usado para sua validação. Com isso, foram obtidas novas constantes de calibração e o modelo proposto passou a ser:

$$
a_{m}=\left(0,2145 \cdot \ln V_{i}-0,4417\right) \cdot(-0,1250 \cdot N+1,3750)
$$

A Tabela 4.8 compara os valores observados e estimados para a desaceleração usando-se o modelo da Equação 4.11. As Figuras 4.17 e 4.18 mostram o ajuste do modelo ao conjunto de dados usados para a sua validação. Pode-se perceber que a diferença entre os dois modelos pode ser desprezada e qualquer um dos dois modelos pode ser usado para estimar a desaceleração em função da velocidade inicial e do número de eixos do caminhão. 
Tabela 4.8: Desacelerações médias observadas e estimadas através do modelo calibrado com o conjunto de dados $\mathrm{B}$

\begin{tabular}{cccccc}
\hline \multirow{2}{*}{ Veículo } & Teste & $\boldsymbol{V}(\mathbf{k m} / \mathbf{h})$ & Teórica & Experimental & Diferança \\
\hline & 1 & 49 & 0,39 & 0,38 & 0,01 \\
& 2 & 57 & 0,42 & 0,42 & 0,00 \\
rígido & 3 & 74 & 0,48 & 0,49 & 0,01 \\
$\mathrm{~m}=15,50 \mathrm{t}$ & 5 & 84 & 0,51 & 0,51 & 0,00 \\
& 5 & 85 & 0,51 & 0,50 & 0,01 \\
& 7 & 96 & 0,54 & 0,55 & 0,01 \\
& 8 & 103 & 0,55 & 0,55 & 0,00 \\
rígido & 1 & 47 & 0,38 & 0,38 & 0,00 \\
$\mathrm{~m}=23,29$ & 3 & 61 & 0,44 & 0,44 & 0,00 \\
& 2 & 78 & 0,46 & 0,45 & 0,01 \\
& 5 & 88 & 0,52 & 0,51 & 0,01 \\
& 6 & 95 & 0,54 & 0,53 & 0,01 \\
\hline articulado & 1 & 38 & 0,25 & 0,24 & 0,01 \\
$\mathrm{~m}=36,92$ & 2 & 81 & 0,38 & 0,40 & 0,02 \\
\hline
\end{tabular}

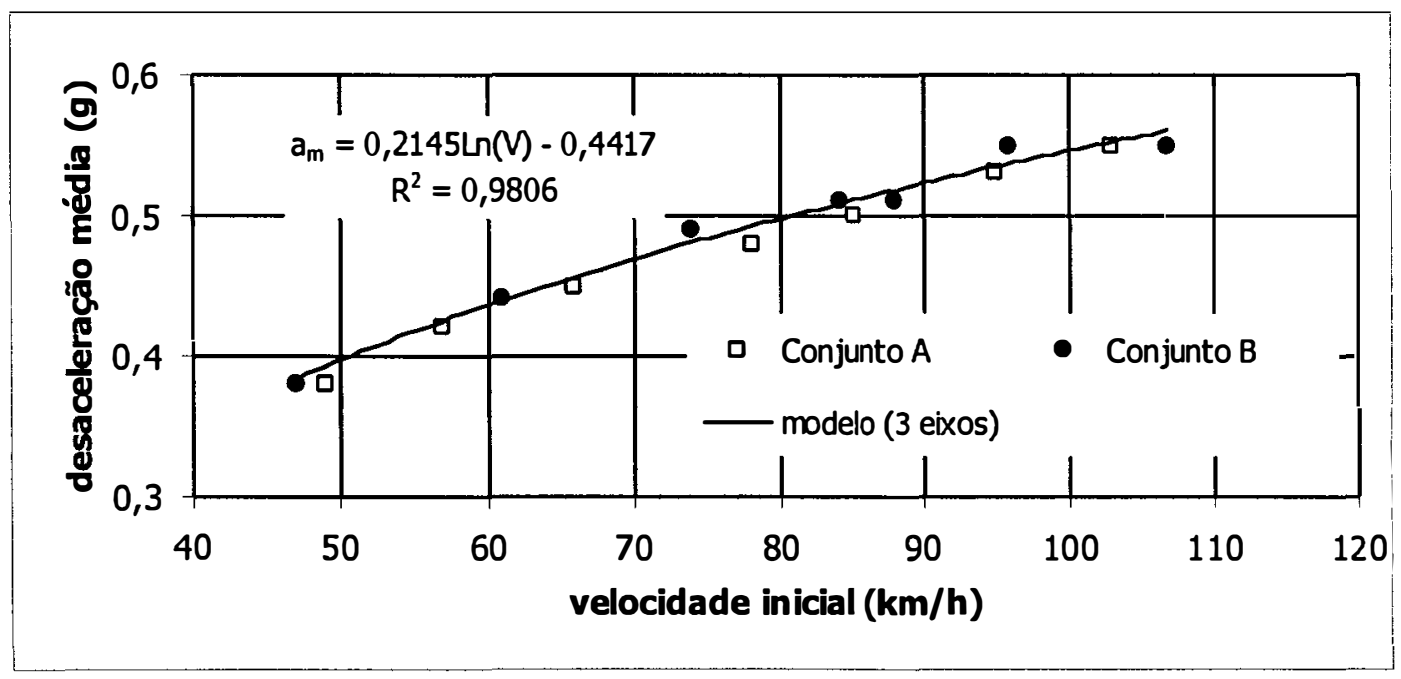

Figura 4.17: Desaceleração média observada e estimada pelo modelo calibrado a partir do conjunto de dados $\mathrm{A}$ 


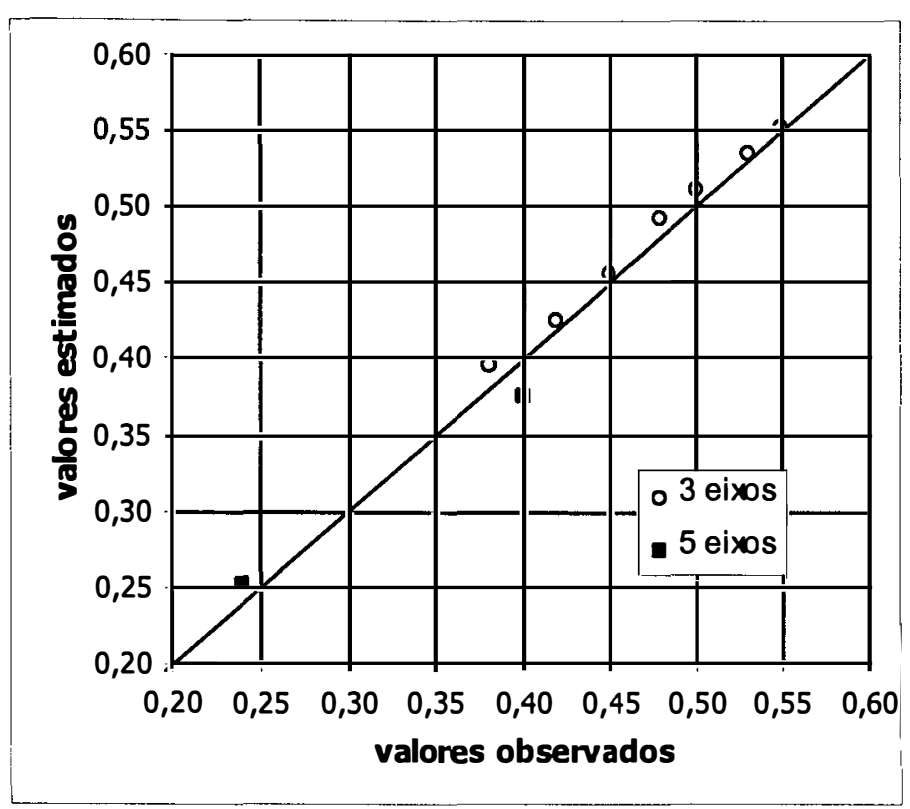

Figura 4.18: Diferenças entre a desaceleração média observada e estimada pelo modelo calibrado a partir do conjunto de dados $\mathrm{B}$

Deve-se ressaltar que, como os modelos matemáticos foram calibrados por meio de regressões e a gama de observações nos testes é restrita, o uso do modelo como subsídio para o projeto de novas caixas de retenção só será válido dentro dos mesmos parâmetros de velocidade, pesos e tipos de veículos e para dispositivos com características geométricas compatíveis com o analisado. Idealmente, seriam necessários mais ensaios com outros tipos de caminhões para que se pudesse estabelecer um modelo com maior segurança.

Como a capacidade de frenagem da caixa de retenção construída na Via Anchieta se apresenta dentro dos valores encontrados na literatura e normas de projetos americanas e australianas, pode-se considerar que os modelos propostos possam ser usados para estimar a desaceleração média devida ao material de enchimento da caixa. Entretanto, o uso dos modelos propostos deve levar em consideração fatores de segurança compatíveis com nível de risco aceitável para as características do local onde será implantado o dispositivo, tornando indispensável um julgamento de engenharia. 


\subsection{ANÁLISE DE LOCALIZAÇÃO DAS ÁREAS DE ESCAPE}

A escolha do local para instalação da área de escape indicará o sucesso ou fracasso de seu uso. Uma área de escape mal localizada não interceptará os veículos fora de controle e será considerado um dispositivo sem utilidade. Para escolha do melhor local é conveniente um estudo de engenharia na via ou trecho em que será construída a área de escape.

Não existem regras firmes para a escolha do local de instalação da área de escape [AASHTO, 1994]. Uma análise conjunta de diversos fatores como índice de acidentes, condições topográficas, espaço físico disponível, velocidade, conduta dos motoristas, características dos caminhões, análise da temperatura dos freios dos caminhões e outros podem auxiliar na determinação de trechos da via em que seria viável a implantação de uma área de escape.

Um estudo para verificar a necessidade e a localização de áreas de escape foi feito para pista sul da Via Anchieta, no trecho da Serra do Mar ( $\mathrm{km} \mathrm{42,2}$ ao $\mathrm{km}$ $53,00)$. O método proposto para a análise de localização foi baseado na pesquisa desenvolvida no Canadá por Abdelwahab e Morral [1997], envolvendo variáveis que representam as características dos veículos e do declive. Dentre os estudos encontrados na revisão bibliográfica, considerou-se que esse foi o mais completo e procura estabelecer os trechos do declive que são mais indicados para a implantação de áreas de escape, em função das características da via, velocidade desenvolvida pelos veículos, temperatura dos freios e índices de acidentes envolvendo veículos desgovernados.

O método proposto para determinar os locais do trecho estudado mais indicados para implantação de áreas de escape envolve 4 etapas distintas: avaliar os aspectos geométricos e o perfil longitudinal do declive, caracterização da via; estimar o perfil de velocidade desenvolvida por um caminhão sem freio ao longo do declive; estimar a temperatura dos freios do caminhão durante a descida, perfil de temperatura; e analisar o número de acidentes registrados no trecho envolvendo veículos desgovernados. As atividades desenvolvidas em cada uma das etapas são: 
1) Caracterização da via, visa obter os raios e a superelevação das curvas horizontais que compõem o trecho, as inclinações e extensão dos declives e o coeficiente de atrito do pavimento;

2) Perfil de velocidade, visa determinar o comportamento da velocidade desenvolvida ao longo do declive, supondo um cenário em que um veículo sem freio percorre todo o declive com velocidade imposta pelas forças de resistência e limitada pelas características geométricas da via;

3) Perfil de temperatura, visa estimar o comportamento da temperatura dos freios do caminhão ao longo do declive com auxílio do GSRS; e

4) Número de acidentes, visa obter dados de registros de acidentes envolvendo veículos que perderam o freio ao longo da descida.

Após a realização das etapas citadas é possível verificar em quais curvas do trecho avaliado ocorrem as seguintes situações: a velocidade do veículo sem freio supera o valor da velocidade limite da curva (tombamento ou esgorregamento); a temperatura do freio do caminhão excede o valor de fade; o caminhão desgovernado atinge velocidades próximas a $100 \mathrm{~km} / \mathrm{h}$; e o número de acidentes envolvendo veículos sem freios é significativo. Com a análise conjunta das situações mencionadas é possível detectar os pontos do declive que mais necessitam da implantação de uma área de escape.

\subsubsection{Caracterização da via}

Para definir as velocidades limites de tombamento e escorregamento nas curvas horizontais do trecho pesquisado é preciso conhecer os raios de curvatura, a superelevação e o coeficiente de atrito transversal. De acordo com a empresa que administra o trecho, a Ecovias S/A, a superelevação transversal existente no trecho é de $0,05 \mathrm{~m} / \mathrm{m}$ e o coeficiente de atrito estático é igual a 0,62 (medido in loco).

Como o trecho em declive possui 43 curvas horizontais, os raios dessas curvas tiveram que ser estimados a partir da digitalização de uma planta da Via Anchieta feita em 1970. O projeto foi fornecido pela Ecovias e faz parte da mapoteca da empresa. A Figura 4.19 mostra o trecho estudado digitalizado. 
Após digitalização do mapa, a figura foi importada para o programa de computador AutoCad com uma escala gráfica adequada. Utilizando-se os comandos arcos e linhas, foi possível esboçar o eixo da pista sul, como pode ser visto na Figura 4.19. As linhas mais espessas representam o eixo do trecho estudado. Em cada uma das curvas foi inserido um arco capaz de representar o eixo da curva. Os valores dos raios inseridos são fornecidos pelo programa AutoCad e variaram entre 95 e $750 \mathrm{~m}$.

Traçado da Pista Sul

Via Anchieta - Trecho da Serra do Mar (km 40,2 à km 53,0)
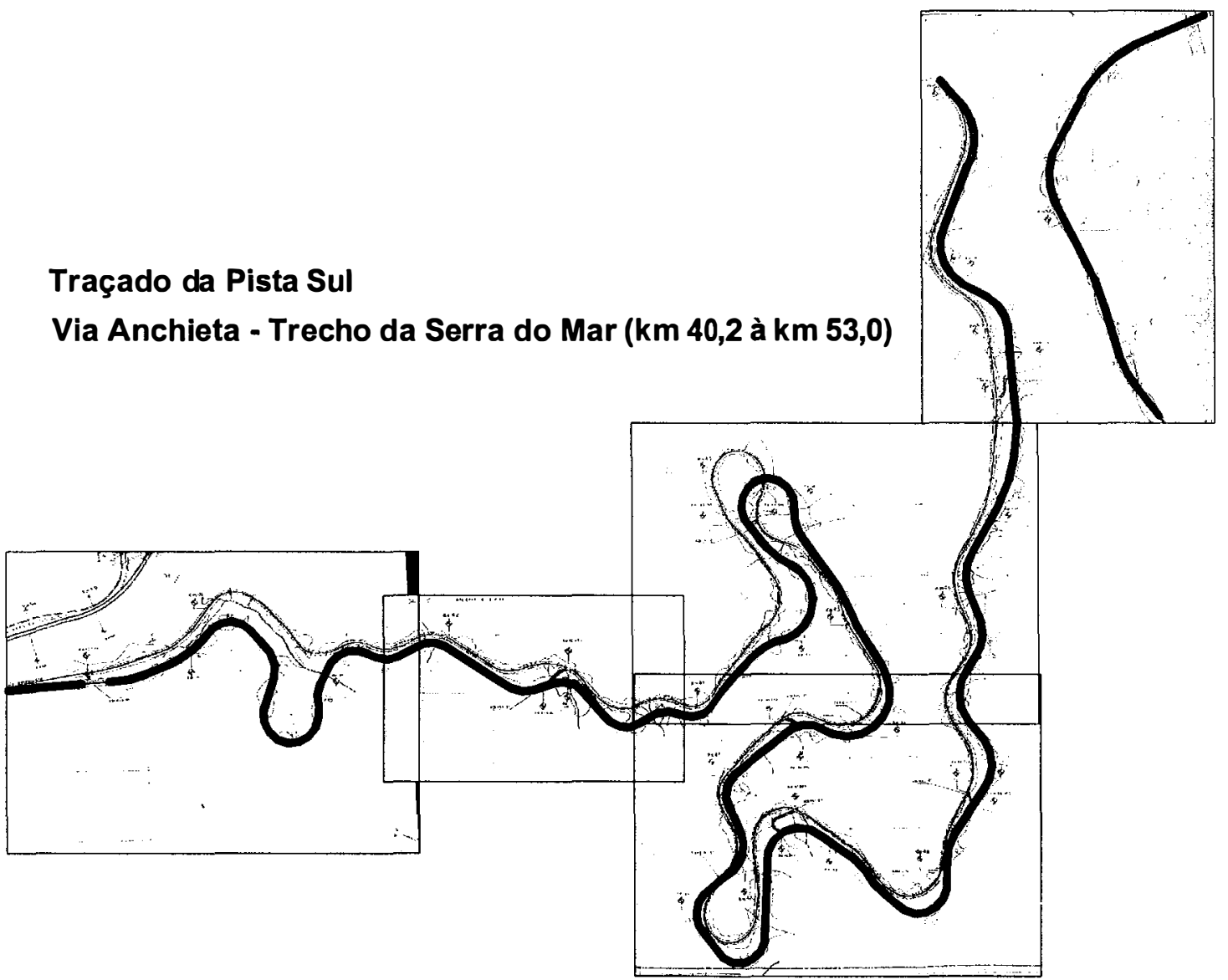

Figura 4.19: Traçado do trecho estudado digitalizado 
Do projeto fornecido pela Ecovias também constava o perfil longitudinal de toda a Via Anchieta, do qual foram extraídas as inclinações e extensão do trecho utilizado na realização do estudo de localização. Os $12,8 \mathrm{~km}$ de extensão do declive estudado foram divididos em segmentos de mesma inclinação. A Tabela 4.9 mostra a subdivisão do trecho utilizado no estudo de localização.

Tabela 4.9: Divisão em segmentos de mesma declividade

\begin{tabular}{ccccc}
\hline Segmento & $\mathbf{k m}$ (inicial) & $\mathbf{k m}$ (final) & $\begin{array}{c}\text { Comprimento } \\
\text { (m) }\end{array}$ & Declividade (\%) \\
\hline 1 & 40,20 & 40,60 & 400 & 2,5 \\
2 & 40,60 & 45,55 & 4950 & 6,0 \\
3 & 45,55 & 46,15 & 600 & 5,5 \\
4 & 46,15 & 46,75 & 600 & 4,5 \\
5 & 46,75 & 47,55 & 800 & 5,5 \\
6 & 47,55 & 49,95 & 2400 & 6,0 \\
7 & 49,95 & 50,55 & 600 & 5,5 \\
8 & 50,55 & 52,55 & 2000 & 6,0 \\
9 & 52,55 & 53,00 & 450 & 5,5 \\
\hline
\end{tabular}

\subsubsection{Perfil de velocidade}

Um dos fatores utilizados para avaliar a localização de áreas de escape é o comportamento da velocidade desenvolvida pelo caminhão sem freios ao longo do declive [Abdelwahab e Morral, 1997]. Esse perfil de velocidade permite conhecer a velocidade na qual um caminhão sem freio chega até uma determinada curva horizontal, onde a velocidade é limitada pelas condições de tombamento ou escorregamento. Outra vantagem de se conhecer o comportamento da velocidade ao longo da descida é poder estimar, em qualquer ponto do trecho, a que velocidade o veículo se encontra, o que auxilia na escolha de localização de áreas de escape, partindo do propósito de que se deve evitar que veículos desgovernados atinjam velocidades elevadas.

As velocidades máximas que podem ser desenvolvidas nas curvas horizontais do trecho analisado foram definidas em função da velocidade limite de escorregamento ou de tombamento, adotando-se a menor entre elas. De acordo com 
as diretrizes de projeto geométrico da AASHTO [AASHTO, 1994], a velocidade limite de escorregamento de um veículo é dada por:

$$
V_{s}=\sqrt{127 . r(e+f)}
$$

em que: $\quad V_{s}$ : velocidade limite de escorregamento do veículo $(\mathrm{km} / \mathrm{h})$;

$r$ : raio da curva horizontal $(\mathrm{m})$;

e: superelevação transversal $(\mathrm{m} / \mathrm{m})$; e

$f:$ coeficiente de atrito transversal.

A velocidade limite para tombamento é calculada por:

$$
V_{r}=\sqrt{\left(\frac{e . h+b}{h}\right) g \cdot r}
$$

em que: $\quad V_{r}$ : velocidade limite de tombamento de veículo $(\mathrm{km} / \mathrm{h})$;

b: $1 / 2$ bitola do eixo traseiro $(\mathrm{m})$;

$h$ : altura do centro de gravidade do caminhão; e

$g$ : aceleração da gravidade $\left(9,81 \mathrm{~m} / \mathrm{s}^{2}\right)$.

A partir dos dados fornecidos pela Ecovias $(f=0,62$ e $e=0,05 \mathrm{~m} / \mathrm{m})$ e considerando a altura típica do centro de gravidade de um caminhão $(h)$ como sendo igual a $1,80 \mathrm{~m}$ e que a bitola traseira média de um caminhão é 1,96 $\mathrm{m}$, isto é, $b=0,98 \mathrm{~m}$, foram determinadas as velocidades de tombamento $\left(V_{r}\right)$ e escorregamento $\left(V_{s}\right)$ nas 43 curvas horizontais que compõem o trecho, como mostra a Figura 4.20.

Cada um dos pontos da Figura 4.20 representa uma curva do declive, nas quais pode-se perceber que $V_{r}<V_{s}$, o tombamento ocorre antes do escorregamento e, 
por conseguinte, a maior velocidade que um caminhão poderá desenvolver nas curvas é igual velocidade de tombamento.

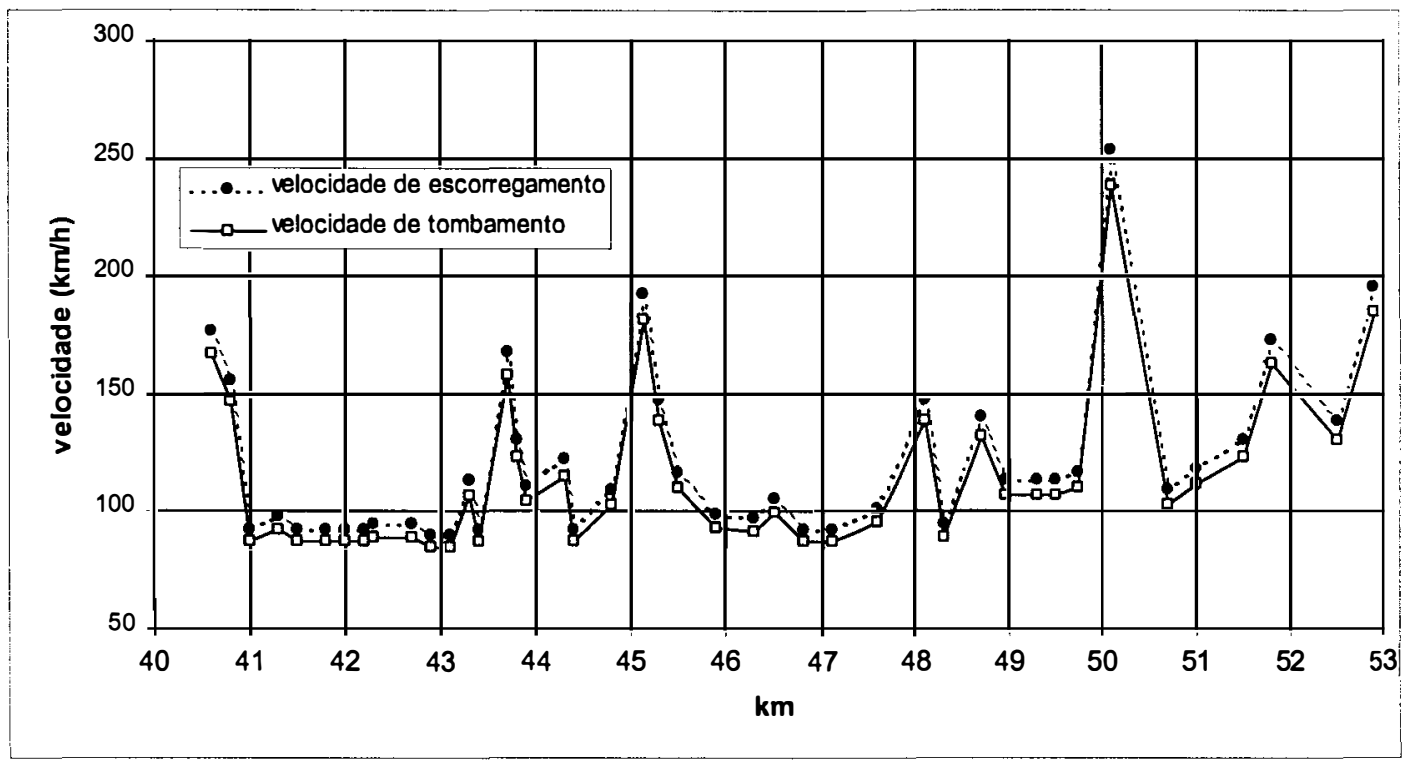

Figura 4.20: Velocidades de tombamento e escorregamento nas curvas

Para determinar o comportamento da velocidade entre as curvas foi utilizado um modelo de desempenho denominado TruPer [Demarchi, 1999]. O TruPer é uma macro criada em Visual Basic 5.0 e que funciona como suplemento do Excel, e que simula o desempenho de veículos em uma via. O simulador considera o desempenho de um veículo isolado, ou seja, que a velocidade do veículo em um determinado instante é exclusivamente limitada por seu próprio desempenho. As velocidades e distâncias são determinadas para intervalos de tempos preestabelecidos, o que permite determinar a variação de velocidade ao longo do trecho estudado. O modelo funciona conforme as características da mecânica da locomoção de veículos rodoviários, considera a troca de marchas e a potência do motor variando em função do número de rotações.

Para a realização da simulação, o TruPer utiliza como parâmetros de entrada a velocidade do caminhão no início da descida, as características mecânicas do caminhão, as forças de resistência, além do comprimento e a declividade. 
As características dos caminhões são adotadas para estimar a intensidade das forças de resistência ao movimento. A força tratora é considerada como nula. As forças consideradas pelo modelo são mostradas na Figura 4.21. A Tabela 4.10 apresenta a nomenclatura dos parâmetros e coeficientes utilizados no modelo na condição em que o veículo está completamente sem freio e desengatado.

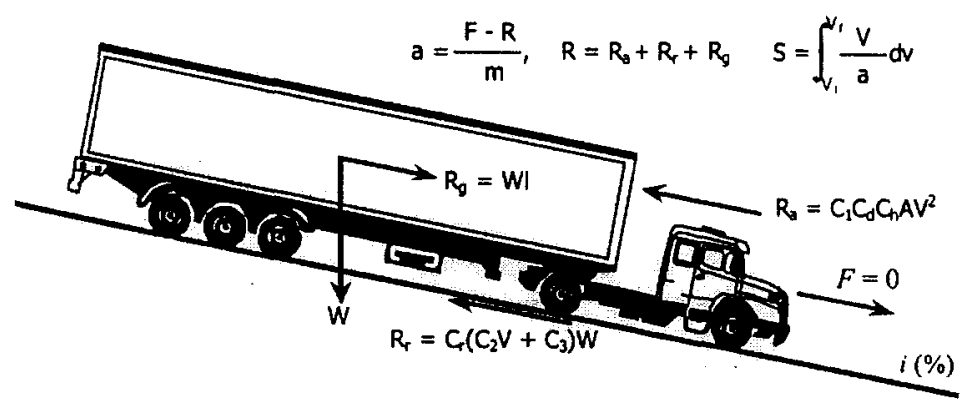

Figura 4.21: Forças atuantes no veículo sem freios em um declive

Tabela 4.10: Nomenclatura dos parâmetros e coeficientes do modelo de desempenho

\begin{tabular}{llll}
\hline & Definição & \multicolumn{2}{c}{ Definição } \\
\hline$V_{i}$ & velocidade no início do trecho $(\mathrm{km} / \mathrm{h})$ & $R_{a}$ & resistência aerodinâmica $(\mathrm{N})$ \\
$V_{f}$ & velocidade no final do trecho $(\mathrm{km} / \mathrm{h})$ & $R_{g}$ & resistência de rampa $(\mathrm{N})$ \\
$V$ & velocidade instantânea & $i$ & inclinação da rampa $(\mathrm{m} / \mathrm{m})$ \\
$a$ & aceleração $\left(\mathrm{m} / \mathrm{s}^{2}\right)$ & $C_{1}$ & constante $=0,047285$ \\
$S$ & posição $(\mathrm{m})$ & $C_{d}$ & coeficiente de arrasto aerodinâmico \\
$F$ & força motriz $(\mathrm{N})$ & $C_{h}$ & coeficiente de correção devido à altitude \\
$W$ & peso do veículo $(\mathrm{KN})$ & $A$ & área frontal $\left(\mathrm{m}^{2}\right)$ \\
$m$ & massa do veículo $(\mathrm{kg})$ & $C_{2}$ & constante para o tipo de pneu \\
$R$ & resistência total $(\mathrm{N})$ & $C_{3}$ & constante para o tipo de pneu \\
$R r$ & resistência de rolamento $(\mathrm{N})$ & $C_{r}$ & coeficiente de rolamento \\
\hline & & &
\end{tabular}

Para o caminhão tipo utilizado na simulação de desempenho foram adotados os parâmetros apresentados na Tabela 4.11. 
Tabela 4.11: Coeficientes de calibração adotados no modelo

\begin{tabular}{llll}
\hline Coeficientes & Valor & Condição & Fonte \\
\hline$C_{d}$ & 0,80 & $\begin{array}{l}\text { caminhão cavalo } \\
\text { semi-reboque }\end{array}$ & Demarchi [2000] e \\
$C_{h}$ & 1,00 & - & - \\
$A$ & 7,50 & $\begin{array}{l}\text { caminhão cavalo } \\
\text { semi-reboque }\end{array}$ & Demarchi [2000] e \\
$C_{2}$ & 0,0255 & PAE [1996] \\
$C_{3}$ & 4,1 & $\begin{array}{l}\text { Pneu radial } \\
\text { condição do asfalto }\end{array}$ & SAE [1996] \\
$C_{r}$ & 1,2 & SAE [1996] \\
\hline
\end{tabular}

O perfil de velocidade foi determinado utilizando como veículo tipo, um caminhão articulado pesado com PBTC igual a $45 \mathrm{t}$. Foi adotada uma velocidade inicial no topo do declive de $60 \mathrm{~km} / \mathrm{h}$. As características geométricas e o perfil longitudinal são os apresentados no item caracterização do trecho. A Figura 4.22 representa o perfil de velocidade do veículo-tipo sem freio para todo o trecho analisado e as velocidades limites $\left(V_{r}\right)$ nas 43 curvas do declive, determinado através do TruPer. Cada um dos quadrados no gráfico representa uma curva do trecho.



Figura 4.22: Perfil da velocidade ao longo do declive

Nos casos em que a velocidade do caminhão superou a velocidade limite da curva, um novo trecho de simulação foi considerado a partir desse ponto, utilizando como velocidade inicial, nesse novo segmento, a velocidade de tombamento na 
curva. Na Figura 4.22 é possível identificar quais as curvas em que o veículo sem freios tombaria, baseado nos pontos em que o círculo, que representa a velocidade do caminhão sem freio, é maior que o quadrado que representa a velocidade de tombamento na curva.

\subsubsection{Temperatura dos freios}

Como o excesso de temperatura nos freios dos caminhões é uma das principais causas de acidentes em declives envolvendo veículos desgovernados, estimar a intensidade da temperatura ao longo da descida auxilia na avaliação de localização, sendo possível verificar em quais trechos a temperatura de caminhão se aproxima ou supera o valor limite de segurança $\left(260^{\circ} \mathrm{C}\right)$.

GSRS foi usado para simular o comportamento da temperatura dos freios durante o movimento do caminhão no declive e utiliza como parâmetros de entrada a inclinação, o comprimento do declive, a velocidade e a massa do veículo e a temperatura inicial dos freios. O resultado fornecido pelo GSRS é mostrado no Anexo C

A simulação do comportamento da temperatura dos freios foi feita considerando-se as características longitudinais do trecho estudado e um veículo com massa igual a $45 \mathrm{t}$, cuja velocidade média no trecho é de $65 \mathrm{~km} / \mathrm{h}$. O simulador fornece a temperatura dos freios a cada $800 \mathrm{~m}$. A Figura 4.23 apresenta o perfil de temperatura dos freios obtido ao longo do declive analisado para o veículo-tipo adotado.

Como pode ser visto na Figura 4.23, a temperatura aumenta ao longo do declive e, a partir do $\mathrm{km} \mathrm{43,} \mathrm{o} \mathrm{sistema} \mathrm{de} \mathrm{freio} \mathrm{do} \mathrm{veículo} \mathrm{já} \mathrm{estará} \mathrm{sujeito} \mathrm{a} \mathrm{uma}$ temperatura próxima da temperatura de fade $\left(260^{\circ} \mathrm{C}\right)$. 


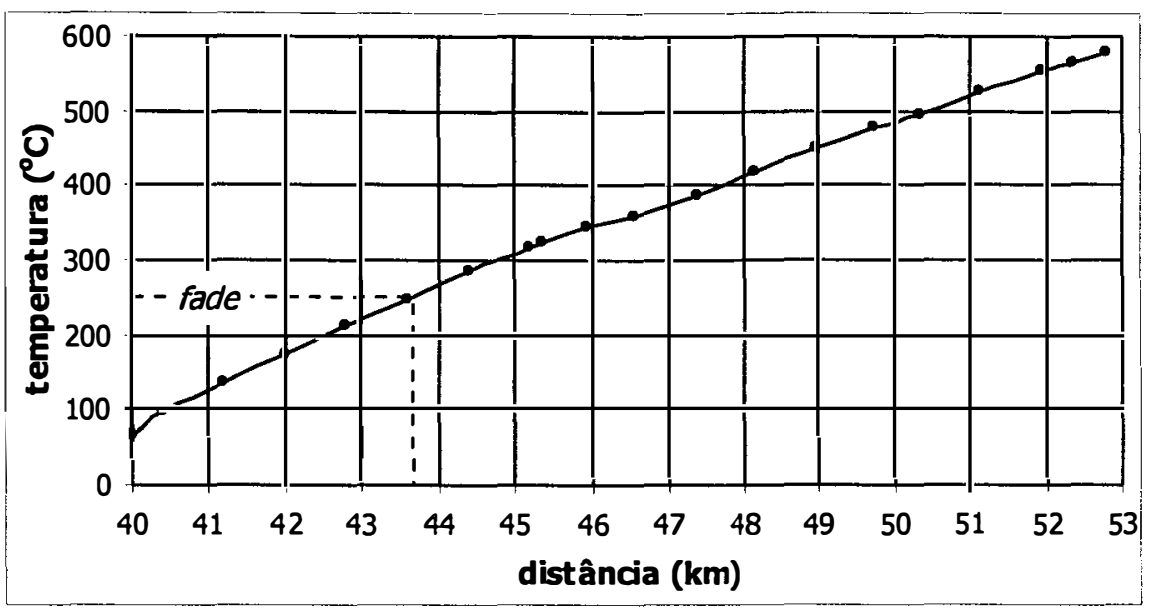

Figura 4.23: Perfil da temperatura dos freios ao longo do declive

\subsubsection{Número de acidentes envolvendo veículos desgovernados}

A avaliação da ocorrência de acidentes envolvendo veículos desgovernados em um declive auxilia na verificação da necessidade e da localização de uma área de escape [AASHTO, 1994; Abdelwahab e Morral, 1997; ITE, 1989; Witheford, 1992]. Para o trecho estudado, foram utilizados dados de registros de acidentes ocorridos no período de agosto/2000 a abril/2002, fornecidos pela Ecovias. Do total de acidentes ocorridos entre o $\mathrm{km} \mathrm{40,2} \mathrm{e} \mathrm{o} \mathrm{km} \mathrm{53,0} \mathrm{da} \mathrm{pista} \mathrm{sul} \mathrm{da} \mathrm{Via} \mathrm{Anchieta,} \mathrm{foram}$ selecionados apenas os que tiveram como causa a falta de freios. Neste banco de dados também constava o local $(\mathrm{km})$ onde foi registrado o acidente. Na Tabela 4.12 pode ser visto a distribuição, a cada 100 metros, da ocorrência de acidentes ao longo do trecho em declive. Para melhor compreensão da tabela, os números da segunda linha representam a posição na rodovia a cada 100 metros, como exemplo km 33,0, 33,1 e assim sucessivamente.

Avaliar a ocorrência de acidentes por falta de freios, bem como os pontos do declive onde o índice desse tipo de acidente se destaca é um dos aspectos que devem ser utilizados para analisar a necessidade de um dispositivo para contenção. Deve-se ressaltar a importância de um estudo engenharia para explicar o por que da ocorrência de acidentes com veículos sem freios para então optar pela construção ou não de uma área de escape no local. 
Tabela 4.12: Distribuição da ocorrência de acidentes ao longo do declive

\begin{tabular}{ccccccccccccc}
\hline \multicolumn{7}{c}{ Ocorrência de acidentes provocados por falta de freios $08 / 2000$} & $-04 / 2002)$ \\
\multicolumn{7}{c}{ Rodovia SP-150 (Via Anchieta) } \\
\hline Km & 0,0 & 0,1 & 0,2 & 0,3 & 0,4 & 0,5 & 0,6 & 0,7 & 0,8 & 0,9 & Soma Acumulado \\
\hline 33 & 0 & 0 & 0 & 0 & 0 & 1 & 0 & 0 & 0 & 0 & 1 & 1 \\
40 & 0 & 0 & 0 & 0 & 0 & 1 & 0 & 0 & 1 & 0 & 2 & 3 \\
41 & 1 & 0 & 0 & 0 & 0 & 1 & 0 & 0 & 0 & 0 & 2 & 5 \\
42 & 5 & 0 & 0 & 0 & 0 & 2 & 0 & 1 & 2 & 2 & 12 & 17 \\
43 & 7 & 0 & 0 & 0 & 1 & 2 & 0 & 0 & 2 & 0 & 12 & 29 \\
44 & 3 & 1 & 1 & 1 & 0 & 3 & 2 & 2 & 0 & 0 & 13 & 42 \\
45 & 4 & 2 & 1 & 1 & 0 & 1 & 0 & 0 & 1 & 0 & 10 & 52 \\
46 & 8 & 0 & 0 & 0 & 0 & 1 & 0 & 0 & 0 & 0 & 9 & 61 \\
47 & 4 & 0 & 1 & 1 & 0 & 0 & 0 & 0 & 1 & 0 & 7 & 68 \\
48 & 2 & 0 & 0 & 0 & 0 & 1 & 1 & 0 & 0 & 0 & 4 & 72 \\
49 & 4 & 0 & 1 & 0 & 0 & 0 & 0 & 0 & 0 & 1 & 6 & 78 \\
50 & 4 & 0 & 0 & 0 & 0 & 0 & 1 & 1 & 1 & 1 & 8 & 86 \\
51 & 5 & 0 & 0 & 0 & 0 & 2 & 1 & 0 & 2 & 0 & 10 & 96 \\
52 & 7 & 0 & 1 & 0 & 0 & 0 & 0 & 1 & 0 & 0 & 9 & 105 \\
53 & 5 & 0 & 1 & 0 & 0 & 0 & 0 & 0 & 0 & 0 & 6 & 111 \\
54 & 1 & 0 & 0 & 0 & 0 & 1 & 0 & 0 & 0 & 1 & 3 & 114 \\
55 & 3 & 0 & 0 & 0 & 0 & 0 & 0 & 0 & 0 & 0 & 3 & 117 \\
57 & 1 & 0 & 1 & 0 & 0 & 0 & 0 & 0 & 0 & 0 & 2 & 119 \\
63 & 1 & 0 & 0 & 0 & 0 & 0 & 0 & 0 & 0 & 0 & 1 & 120 \\
\hline
\end{tabular}

\subsubsection{Localização das áreas de escape para a pista sul da Via Anchieta}

De acordo com o método de determinação de localização proposto por Abdelwahab e Morral, [1997], a análise conjunta entre os aspectos determinados anteriormente fornece subsídios para detectar trechos do declive que são mais indicados para a implantação de áreas de escape. O método consiste em identificar os pontos em que: a velocidade caminhão excede o valor de tombamento; a temperatura do freio do caminhão excede a temperatura de fade; e exista a presença de algum objeto estacionário que possa aumentar a gravidade de um acidente envolvendo veículos sem freios.

O método proposto neste trabalho consiste em avaliar para todas as curvas do trecho a velocidade de tombamento, a temperatura do freio, o número de acidentes próximo ao início da curva e o valor da velocidade com que o caminhão sem freio pode atingir. A Figura 5.24 mostra os aspectos envolvidos no estudo de localização. 
Perfil longitudinal do trecho estudado

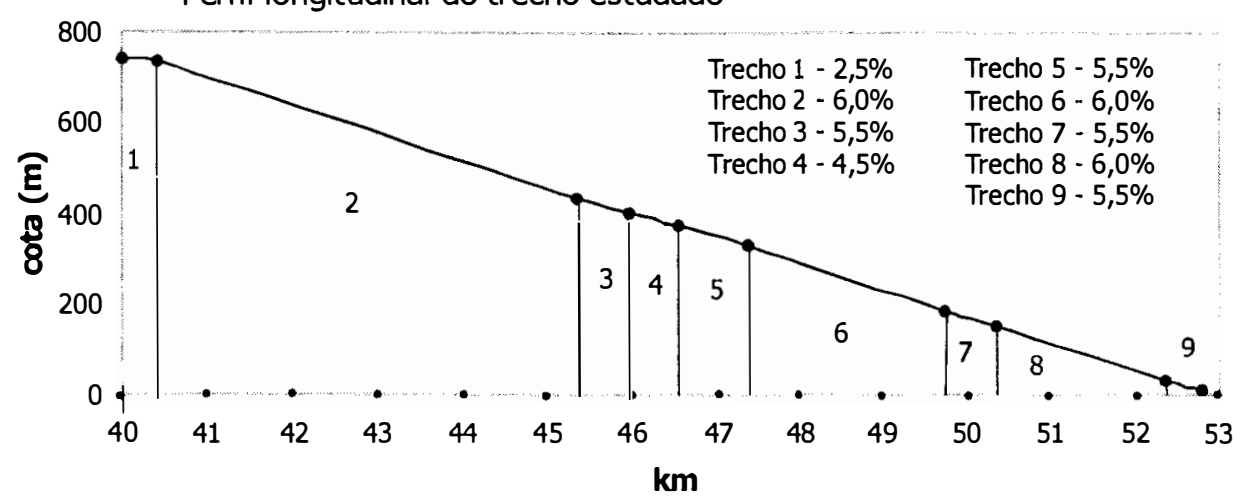

Temperatura do freio

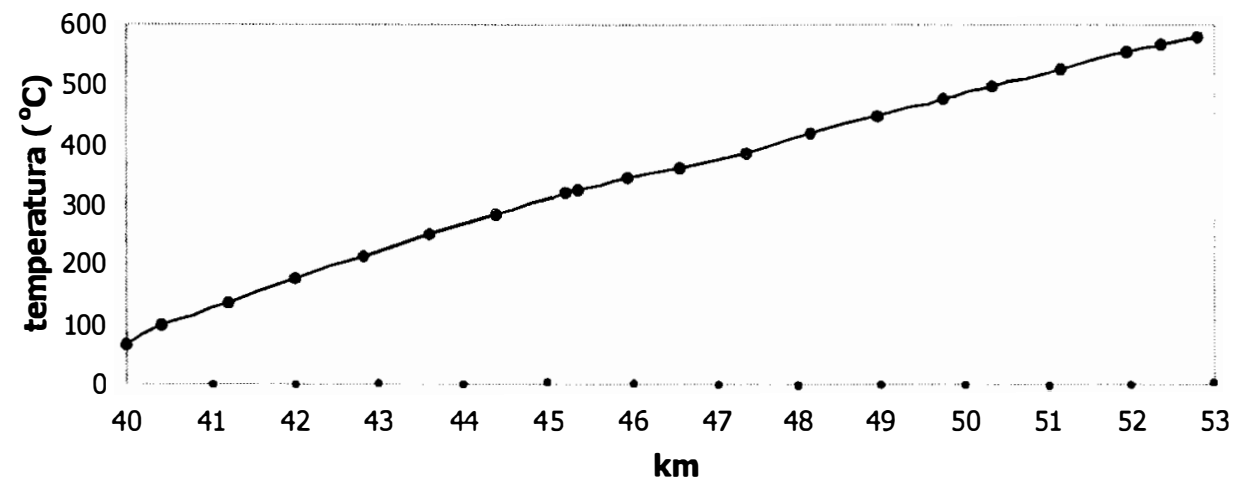

Perfil da velocidade

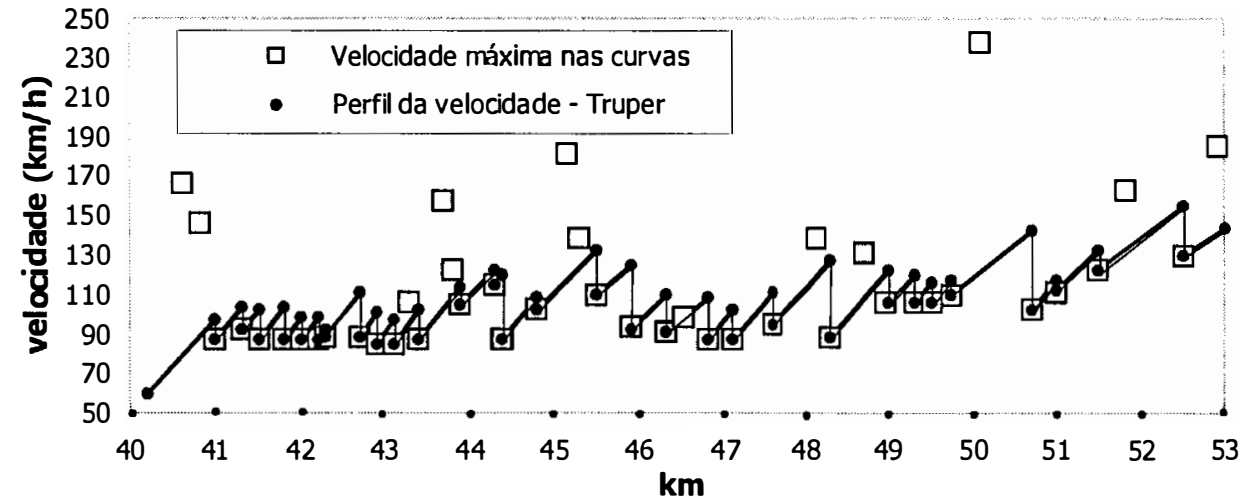

Número de acidentes com veículos sem freio

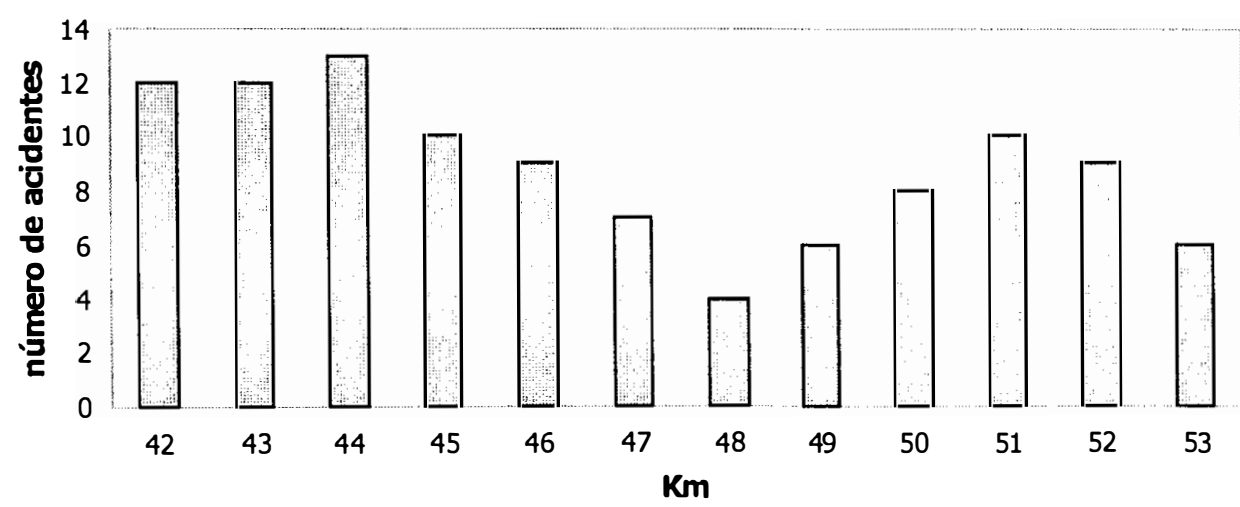

Figura 4.24: Aspectos do declive considerados no estudo de localização 
Os resultados são apresentados segundo a forma proposta por Abdelwahab e Morral [1997]. A partir da Figura 4.24, foram avaliadas as possíveis condições que poderiam ocorrer em cada uma das curvas do trecho. Essas condições foram representadas por uma legenda, em que:

- a letra $V$ identifica as curvas nas quais a velocidade do caminhão excede o valor de tombamento;

- a letra $T$ identifica as curvas nas quais a temperatura dos freios do caminhão ultrapassa o valor de fade;

- a letra $A$ indica que próximo à curva houve uma ocorrência significativa de acidentes envolvendo veículos sem freios; e

- a letra $E$ representa curvas em que os caminhões atingem uma velocidade superior a $100 \mathrm{~km} / \mathrm{h}$.

O valor de $100 \mathrm{~km} / \mathrm{h}$ foi adotado por se tratar de uma velocidade considerada como de risco para ser desenvolvida no trecho analisado e os ensaios realizados na área de escape construída no trecho mostraram que o comprimento da caixa foi suficiente para frear caminhões com velocidades máximas próximas deste valor.

Os resultados da interação entre as possíveis condições nas curvas do declive são mostrados na Tabela 4.13.

No estudo de caso realizado para o declive da pista sul da Via Anchieta foi desconsiderada a presença de objetos estacionários que poderiam aumentar a gravidade de acidentes com veículos fora do controle, visto que o trecho está situado em plena Serra do Mar. Duas condições foram acrescentadas: as condições $A$ e $E$. A condição $E$ auxilia a identificar as curvas em que os caminhões sem freios possam chegar com velocidades consideradas elevadas para o trecho em questão. As curvas que receberam a condição $A$, são aquelas que registraram um número de acidentes maior ou igual a três num raio de 100 metros do início da curva ou registraram ao menos cinco acidentes num raio de 200 metros do início da curva.

Por meio dos resultados obtidos (Tabela 4.12), verifica-se que as curvas do declive que satisfazem ao maior número de condições, que segundo Abdelwahab e 
Morral [1997] constituem os pontos mais críticos para se instalar dispositivos de contenção seriam as dos km 44,4; 44,8;45,9;47,1;49,0; 50,7; 51,0 e 51,5. Deve-se ressaltar que o método teórico aplicado pode servir como subsídio para determinar o local de implantação do dispositivo, mas a escolha final depende de um estudo de engenharia no qual aspectos como a topografia do terreno, o espaço físico disponível, a geometria da via e os custos de construção sejam analisados.

Tabela 4.13: Interação entre as possíveis condições nas curvas

\begin{tabular}{llllll}
\hline Curva & $\begin{array}{l}\text { Início da } \\
\text { curva (km) }\end{array}$ & Condições & Curva & $\begin{array}{l}\text { Início da } \\
\text { curva (km) }\end{array}$ & Condições \\
\hline 1 & 40,6 & $*$ & 23 & 45,5 & V; T; E \\
2 & 40,8 & $*$ & 24 & 45,9 & V; T; A; E \\
3 & 41,0 & V & 25 & 46,3 & V; T; E \\
4 & 41,3 & V; E & 26 & 46,5 & T \\
5 & 41,5 & V; E & 27 & 46,8 & V; T; E \\
6 & 41,8 & V; E & 28 & 47,1 & V; T; A; E \\
7 & 42,0 & V; A & 29 & 47,6 & V; T; E \\
8 & 42,2 & V & 30 & 48,1 & T; E \\
9 & 42,3 & V & 31 & 48,3 & V; T; E \\
10 & 42,7 & V; A; E & 32 & 48,7 & T; E \\
11 & 42,9 & V; A; E & 33 & 49,0 & V; T; A, E \\
12 & 43,1 & V; A & 34 & 49,3 & V; T; E \\
13 & 43,3 & $*$ & 35 & 49,5 & V; T; E \\
14 & 43,4 & V; E & 36 & 49,8 & V; T; E \\
15 & 43,7 & $*$ & 37 & 50,1 & T; A; E \\
16 & 43,8 & T; E & 38 & 50,7 & V; T; A; E \\
17 & 43,9 & V; T; E & 39 & 51,0 & V; T; A; E \\
18 & 44,3 & V; T; E & 40 & 51,5 & V; T; A; E \\
19 & 44,4 & V; T; A; E & 41 & 51,8 & T; A; E \\
20 & 44,8 & V; T; A; E & 42 & 52,5 & V; T; E \\
21 & 45,1 & T; A; E & 43 & 52,9 & T; A; E \\
22 & 45,3 & T; A; E & & & \\
\hline & & & & & \\
\hline
\end{tabular}




\subsection{OPERAÇÃO DE CAMINHÕES EM DECLIVES}

Após definir os critérios de projetos de áreas de escape, o estudo da operação de caminhões em declives serve para avaliar como a estratégia de condução adotada pelo motorista pode contribuir para evitar a ocorrência de veículos sem freios nos declives longos e íngremes. Essa avaliação da estratégia de condução foi aplicada para as características da pista sul da Via Anchieta e aspectos de caminhões nacionais utilizando o TruPer.

\subsubsection{Estratégia de condução a ser adotada no declive}

A determinação da estratégia de condução em declives baseia-se em estimar qual a marcha máxima que deve ser usada pelos motoristas durante a descida, para diferentes caminhões sob diversas condições de peso, para que não seja ultrapassada a. velocidade máxima de segurança que o caminhão poderia desenvolver ao longo do declive.

Neste estudo de caso, a estratégia de condução em declives foi avaliada para as características da pista sul da Via Anchieta, criando-se cenários para 16 caminhões nacionais de diferentes marcas e pesos.

Para determinar a velocidade máxima de segurança a ser desenvolvida pelos caminhões no trecho estudado, duas variáveis foram levadas em consideração: a temperatura dos freios e a velocidade limite imposta pela geometria da via (escorregamento e tombamento).

A temperatura dos freios do caminhão ao longo do declive foi estimada com auxílio do GSRS, visando determinar a velocidade máxima que o veículo pode desenvolver ao longo do declive sem ultrapassar a temperatura de fade, em função da massa do veículo e das características do declive (inclinação e comprimento). Foram considerados vários cenários de simulação para o declive do estudo de caso, variando-se as massas dos veículos. As velocidades máximas e as temperaturas máximas correspondentes, fornecidas pelo GSRS, são apresentados na Tabela 4.14. 
Tabela 4.14: Velocidades máximas em função da temperatura dos freios

\begin{tabular}{cccc}
\hline Massa (t) & Vmáx (km/h) & Tmáx $\left({ }^{\circ} \mathbf{F}\right)$ & Tmáx $\left({ }^{\circ} \mathbf{C}\right)$ \\
\hline 45,0 & 16 & 480 & 249 \\
43,0 & 18 & 486 & 252 \\
40,0 & 20 & 483 & 251 \\
38,0 & 21 & 473 & 245 \\
36,0 & 25 & 484 & 251 \\
34,0 & 29 & 500 & 260 \\
31,0 & 34 & 494 & 256 \\
29,0 & 43 & 499 & 259 \\
27,0 & 48 & 460 & 238 \\
25,0 & 60 & 467 & 242 \\
22,5 & 80 & 423 & 217 \\
\hline
\end{tabular}

Outro fator considerado na determinação da velocidade máxima que pode ser desenvolvida no trecho avaliado é a limitação geométrica da via. O trecho em declive é composto por 43 curvas horizontais para as quais foram determinadas as velocidades de tombamento e de escorregamento. Dentre as velocidades estimadas, nenhuma delas é menor que as velocidades máximas determinadas em função da temperatura, o que leva a adotar como velocidade máxima de segurança para o declive da pista sul da Via Anchieta os valores apresentados na Tabela 4.14.

A etapa seguinte foi definir qual a marcha deveria ser usada por um determinado caminhão para percorrer todo trecho em serra da Pista sul da Via Anchieta desenvolvendo uma velocidade tal que se evite que os freios atinjam a temperatura de fade. A análise foi feita para 16 modelos de caminhões nacionais com diferentes pesos brutos totais.

As características de desempenho dos caminhões foram determinadas com auxílio do TruPer, que permite determinar o esforço trator dos veículos em função a velocidade desenvolvida, bem como conhecer as faixas de velocidades para cada marcha, conforme as características mecânicas dos veículos. A Tabela 4.15 exemplifica como o resultado de desempenho dos caminhões é apresentado, utilizando-se o TruPer. Nessa tabela é possível observar as características do caminhão, a força motriz e o intervalo de velocidades para cada marcha. 
Tabela 4.15: Resultado de desempenho de um caminhão

\begin{tabular}{|c|c|c|c|c|c|c|c|c|c|}
\hline \multicolumn{10}{|c|}{ marcha } \\
\hline \multicolumn{2}{|c|}{1} & \multicolumn{2}{|c|}{2} & \multicolumn{2}{|c|}{3} & \multicolumn{2}{|c|}{4} & \multicolumn{2}{|c|}{5} \\
\hline $\mathrm{V}(\mathrm{km} / \mathrm{h})$ & $\mathrm{Ft}(\mathrm{N})$ & $V(k m / h)$ & $\mathrm{Ft}(\mathrm{N})$ & $\mathrm{V}(\mathrm{km} / \mathrm{h})$ & $\mathrm{Ft}(\mathrm{N})$ & $\mathrm{V}(\mathrm{km} / \mathrm{h})$ & $\mathrm{Ft}(\mathrm{N})$ & $V(\mathrm{~km} / \mathrm{h})$ & $\mathrm{Ft}(\mathrm{N})$ \\
\hline 0,00 & 0,00 & 0,00 & 0,00 & 0,00 & 0,00 & 0,00 & 0,00 & 0,00 & 0,00 \\
\hline 4,35 & 26132,96 & 8,19 & 13873,43 & 14,19 & 8007,49 & 23,62 & 4810,70 & 36,62 & 3103,68 \\
\hline 5,22 & 30033,40 & 9,83 & 15944,10 & 17,03 & 9202,63 & 28,35 & 5528,71 & 43,94 & 3566,91 \\
\hline 6,09 & 31203,53 & 11,47 & 16565,29 & 19,87 & 9561,18 & 33,07 & 5744,12 & 51,26 & 3705,88 \\
\hline 6,96 & 31203,53 & 13,11 & 16565,29 & 22,71 & 9561,18 & 37,80 & 5744,12 & 58,58 & 3705,88 \\
\hline 7,83 & 31203,53 & 14,74 & 16565,29 & 25,55 & 9561,18 & 42,52 & 5744,12 & 65,91 & 3705,88 \\
\hline 8,70 & 31203,53 & 16,38 & 16565,29 & 28,38 & 9561,18 & 47,25 & 5744,12 & 73,23 & 3705,88 \\
\hline 9,57 & 30423,44 & 18,02 & 16151,16 & 31,22 & 9322,15 & 51,97 & 5600,51 & 80,55 & 3613,24 \\
\hline 10,44 & 29253,31 & 19,66 & 15529,96 & 34,06 & 8963,60 & 56,69 & 5385,11 & 87,88 & 3474,26 \\
\hline 11,31 & 27693,13 & 21,30 & 14701,70 & 36,90 & 8485,54 & 61,42 & 5097,90 & 95,20 & 3288,97 \\
\hline 12,18 & 26132,96 & 22,94 & 13873,43 & 39,74 & 8007,49 & 66,14 & 4810,70 & 102,52 & 3103,68 \\
\hline
\end{tabular}

Por exemplo, pode-se observar na Tabela 4.14 que para caminhões com PBT igual a 22,5 toneladas, a velocidade máxima de segurança seria $80 \mathrm{~km} / \mathrm{h}$. Para que um caminhão Mercedez MB 1414 possa respeitar esse limite de velocidade utilizando o freio motor, recomenda-se que ele percorra o declive analisado engrenado na quarta marcha (Tabela 4.15). Como a velocidade máxima que esse modelo de caminhão pode desenvolver na quarta marcha é de $66,14 \mathrm{~km} / \mathrm{h}$ e na quinta marcha sua velocidade máxima pode chegar a $102,52 \mathrm{~km} / \mathrm{h}$, velocidade acima da recomendada no trecho $(80 \mathrm{~km} / \mathrm{h})$, o motorista deverá descer a serra com o caminhão em quarta, para preservar os freios de serviço para uso em uma situação de emergência.

$\mathrm{Na}$ Tabela 4.16 é apresentado o resumo dos resultados para os diferentes modelos de caminhões, seus respectivos PBT, as velocidades limites para o declive analisado em função da temperatura dos freios do caminhão, a marcha mais adequada e a velocidade máxima que o caminhão conseguirá desenvolver na marcha adotada. 
Tabela 4.16: Resultados da operação de caminhões no declive analisado

\begin{tabular}{ccccc}
\hline Caminhão & PBTC $(\mathbf{t})$ & $\mathbf{V}_{\text {limite }}(\mathbf{k m} / \mathbf{h})$ & marcha & $\mathbf{V}_{\text {max }}(\mathbf{k m} / \mathbf{h})$ \\
\hline Ford1415 & 23 & 80 & 4 & 66,5 \\
Ford1422 & 23 & 80 & 4 & 57,5 \\
Ford4030 & 40 & 20 & 4 & 20,2 \\
MB 1718 S & 31 & 34 & 2 & 23,9 \\
MB 1721 S & 33 & 30 & 2 & 22,2 \\
MB 2220 RTR & 45 & 16 & 2 & 14,9 \\
MB L 1414 & 23 & 80 & 4 & 66,1 \\
MB LS 1630 & 42 & 18 & 3 & 16,6 \\
MB LS 1935 & 45 & 16 & 2 & 14,4 \\
MB 2325rj & 42 & 18 & 3 & 16,6 \\
Volvo NL12 RTR & 45 & 16 & 2 & 12,6 \\
Volvo NL 10 280 & 45 & 16 & 10 & 13,6 \\
VW 16170 & 23 & 80 & 5 & 78,3 \\
VW 16220 & 23 & 80 & 5 & 72,4 \\
VW 35300 & 35 & 29 & 4 & 26,1 \\
Scania R113 & 45 & 16 & 6 & 14,9 \\
\hline
\end{tabular}

Para os caminhões com PBT igual a 45 toneladas foram determinadas as marchas que esses veículos deveriam adotar para o declive analisado, operando com 80,60 e $50 \%$ de sua capacidade de carregamento (Tabela 4.17).

Tabela 4.17: Operação dos caminhões variando a capacidade de carga

\begin{tabular}{cccccc}
\hline Caminhão & Capacidade (\% & Peso (t) & Vlimite (km/h) & marcha & Vmáx (km/h) \\
\hline \multirow{3}{*}{ MB 220 RTR } & 80 & 36 & 25 & 3 & 21,5 \\
& 60 & 27 & 48 & 4 & 30,6 \\
& 50 & 22,5 & 80 & 5 & 58,1 \\
\hline \multirow{3}{*}{ MB LS 1935 } & 80 & 36 & 25 & 3 & 20,2 \\
& 60 & 27 & 48 & 5 & 40,4 \\
& 50 & 22,5 & 80 & 6 & 59,0 \\
\hline \multirow{3}{*}{ Volvo NL12 RTR } & 80 & 36 & 25 & 4 & 24,7 \\
& 60 & 27 & 48 & 5 & 35,1 \\
& 50 & 22,5 & 80 & 7 & 71,2 \\
Volvo NL 10 280 & 80 & 36 & 25 & 11 & 19,0 \\
& 60 & 27 & 48 & 13 & 38,0 \\
& 50 & 22,5 & 80 & 15 & 77,0 \\
\hline \multirow{3}{*}{ Scania R113 } & 80 & 36 & 25 & 8 & 23,1 \\
& 60 & 27 & 48 & 11 & 45,3 \\
& 50 & 22,5 & 80 & 13 & 70,4 \\
\hline
\end{tabular}


Comparando-se os resultados mostrados nas Tabelas 4.16 e 4.17, observa-se que quanto menor a massa do caminhão, maior a marcha que poderia se usada e maior a velocidade que poderá ser desenvolvida no declive, como esperado.

Os resultados de operação veículos em declive apresentam situações em que os caminhões, sujeitos a estratégia de condução recomendada, estarão usando toda a capacidade do freio motor e os freios de serviço só serão acionados no caso de surgir a necessidade de uma parada de emergência.

Deve-se destacar que, um sistema de sinalização que informe a estratégia de condução mais segura, de acordo com as condições do caminhão e do declive, auxilia os motoristas menos experientes na escolha da estratégia de condução mais adequada para trafegar em declives longos e íngremes. Essas ações contribuem para a redução da ocorrência de acidentes envolvendo caminhões sem freios. 


\section{CONCLUSÕES E RECOMENDAÇÕES}

Os objetivos da pesquisa consistem em estudar a técnica relativo ao projeto e dimensionamento de dispositivos para contenção de veículos desgovernados e a realização de um estudo de caso envolvendo três aspectos:

1. Análise da desaceleração média em caixas de retenção, visando propor um modelo capaz de estabelecer a desaceleração média proporcionado pelo dispositivo analisado em função da velocidade de entrada e das características do veículo desgovernado;

2. Determinação da localização, visando propor um método para analisar a melhor localização do dispositivo de contenção de veículos desgovernados em declives longos e íngremes; e

3. Operação de caminhões em declives, visando analisar a estratégia de condução adotada pelos motoristas nos declives.

Pode-se concluir que os objetivos estabelecidos na pesquisa foram atingidos.

\subsection{DISPOSITIVOS PARA CONTENÇÃO DE VEÍCULOS DESGOVERNADOS}

Através do estudo realizado por meio da revisão da literatura sobre os diferentes tipos de dispositivos para contenção de veículos desgovernados e dos resultados observados nos ensaios em campo, conclui-se que a área de escape composta por uma caixa de retenção é o tipo de dispositivo que apresenta uma capacidade de desaceleração eficaz e segura para frear diferentes tipos de veículos nos mais 
diversos cenários de descontrole, ou seja, perda parcial ou total dos freios, ocorrência de falhas mecânicas, etc.

Com as observações feitas durante os ensaios de entrada na área de escape com caixa de retenção implantada na Via Anchieta, foi possível verificar que o dispositivo é capaz de desacelerar com eficácia e segurança diferentes tipos de veículos em diversas velocidades. A intensidade da desaceleração imposta sobre o caminhão foi suficiente para dissipar toda energia cinética dos caminhões com segurança para o veículo e o motorista. Deve-se ressaltar que para os 16 testes realizados, em apenas um deles o caminhão sofreu danos, com a quebra de uma correia do motor. Segundo o motorista que conduziu o caminhão durante os testes, em nenhuma das entradas realizadas o efeito da desaceleração provoca sensações de desconforto acentuada.

Outro aspecto a ser considerado é o fato de que os veículos que entram na caixa ficam retidos, o que possibilita que os responsáveis pela rodovia possam avaliar as causas da perda de controle do veículo. Nos casos em que o caminhão perdeu o controle por estar em condições precárias de uso, pode-se aplicar as penalidades cabíveis à situação e até mesmo tirar o veículo de circulação.

\subsection{ANÁLISE DA DESACELERAÇÃO EM CAIXAS DE RETENÇÃO}

Com os dados obtidos nos testes foi possível propor modelos matemáticos que expressassem o comportamento da desaceleração imposta sobre os caminhões proveniente do material de enchimento da caixa.

A primeira constatação diz respeito ao método empregado na obtenção de dados durante os testes na área de escape estudada. A utilização de equipamentos de GPS resultou em uma coleta de dados eficiente, capaz de fornecer valores que representam com precisão o comportamento cinemático dos caminhões durante a frenagem. Com dados captados pelos receptores do GPS foi possível conhecer a posição do veículo a cada 0,1 segundo.

Com os valores dos pares ordenados (posição $\times$ tempo) pode-se obter, por meio de uma análise de regressão, um modelo polinomial do quarto grau capaz de 
explicar a variação de posição dos caminhões ao longo do comprimento de frenagem. A partir do modelo de posição chegou-se ao comportamento da desaceleração ao longo da frenagem, expresso matematicamente por um polinômio do segundo grau. Isso explica o comportamento parabólico da desaceleração ao longo do tempo de frenagem.

O passo seguinte foi determinar modelos matemáticos que representassem adequadamente a desaceleração devida à resistência de rolamento do material da caixa. A partir do cálculo da desaceleração média obtida para cada teste e observando-se a distribuição gráfica desses resultados em função da velocidade, constatou-se que a configuração dos eixos e a velocidade de entrada do caminhão na caixa são duas variáveis que influenciam significativamente a intensidade da desaceleração.

Como foi visto, as desacelerações obtidas para os caminhões rígidos com três eixos e massas 15,5 t e 23,29 t apresentam valores semelhantes para velocidade de entrada similares, o que indica que a massa do veículo é pouco significativa na determinação da desaceleração. Já os valores de desacelerações obtidos para 0 caminhão articulado de massa igual a 36,92 t são menores, e esse tipo de veículo percorre um maior comprimento de frenagem até dissipar toda sua energia cinética. Avaliando-se este comportamento, conclui-se que, quanto maior o número de eixos, maior será o comprimento de caixa necessário para frear o caminhão.

Os modelos matemáticos de desaceleração, calibrados através de análise de regressão, têm a sua aplicação restrita às condições em que foram feitos os testes, ou seja, apenas para a mesma gama de velocidades, os mesmos tipos de caminhões e para caixas de retenção com as mesmas características geométricas e com material de enchimento semelhante ao da caixa analisada.

\subsection{ANÁLISE DA LOCALIZAÇÃO DE ÁREAS DE ESCAPE}

O estudo de localização foi feito por meio da aplicação de um método de determinação dos locais mais indicados para implantação de áreas de escape. $\mathrm{O}$ método utilizado baseou-se em um estudo desenvolvido no Canadá que foi adaptado 
às características do trecho em serra da Via Anchieta, pista sul, com inclusão de mais dois aspectos analisados: a velocidade com que o veículo chega no início da curva e o número de acidentes no trecho envolvendo veículos sem freio.

Com a aplicação desse método utilizando dados e variáveis que potencializam a ocorrência de veículos desgovernados obtidos para o trecho do estudo de caso, foi possível identificar os pontos do declive que estão mais sujeitos a ocorrência de acidentes envolvendo veículo sem freio, por sua vez, os pontos mais indicados para implantação de áreas de escape. O que leva a concluir a aplicabilidade do método para fornecer subsídios na escolha do local ideal para a construção de um dispositivo de contenção.

A área de escape analisada está localizada no início da curva do $\mathrm{km} \mathrm{42,7,}$ pode-se concluir que este dispositivo foi implantado em um local adequado, visto que neste ponto a velocidade máxima com que um veículo poderia chegar no início desta curva é maior que $100 \mathrm{~km} / \mathrm{h}$ e excede o valor tombamento, o número de acidentes envolvendo veículos sem freio próximo a curva é considerado significativo e a temperatura do freio neste ponto já ultrapassa os $200^{\circ} \mathrm{C}$. Embora a temperatura de fade ainda não tenha sido atingida esse valor pode começar a provocar perda na eficiência de frenagem. Vale ressaltar, que o local onde foi implantada a área de escape oferece boas condições topográficas e espaço suficiente para as dimensões do dispositivo além do que a área de escape foi implantado do lado direto da via, posição ideal, e o acesso à caixa de retenção foi construído tangente a curva do km 42,7 , facilitando a entrada dos veículos desgovernados.

O estudo de localização realizado para a pista sul da Via Anchieta indica que existem outros pontos ao longo do trecho da serra indicados para a implantação de áreas de escape.

\subsection{OPERAÇÃO DE CAMINHÕES EM DECLIVES}

O estudo realizado visa propor aos motoristas de caminhões a estratégia de condução que deve ser adotada para percorrer todo declive sem problemas de aquecimento excessivo nos freios. Os resultados foram obtidos em função das características 
mecânicas dos caminhões e da velocidade máxima que um veículo pode percorrer o declive sem que a temperatura dos freios atinja o valor de fade. Para que isso ocorra, a estratégia recomendada considera que os caminhões estejam utilizando a capacidade máxima do freio o motor, a fim de preservar o freio de serviço para uma frenagem de emergência.

Pode-se concluir que, boa parte da ocorrência de veículos desgovernados em declives, poderia ser evitada se os motoristas adotassem uma estratégia de condução em função dos aspectos do caminhão que ele está conduzindo e das condições do trecho por qual ela está viajando. Para que isso ocorra, deve-se utilizar uma marcha ideal, para aproveitar a capacidade máxima do freio motor e desenvolver velocidades menores em declives, quanto maior a massa do caminhão menor deve ser a velocidade. A aplicação prática dessas ações nas rodovias esbarra na falta de experiência dos motoristas, por isso as regras de conduta de caminhões em declives devem ser informadas para os motoristas de forma reforçada, seja por meio de sinalização implantada na rodovia ou durante o aprendizado para adquirir habilitação para conduzir caminhões.

\subsection{RECOMENDAÇÕES}

Este trabalho apresentou os resultados relacionados com os critérios de projeto de áreas de escape com caixa de retenção e um estudo de operação dos caminhões em declives. Os resultados encontrados podem ser eventualmente utilizados como subsídios para o projeto de novos dispositivos de contenção ou até mesmo como diretrizes para se desenvolver métodos mais adequados para análise dos critérios de projeto de áreas de escape. Os resultados encontrados no trabalho não esgotam a necessidade de pesquisas futuras sobre o assunto, visto que alguns aspectos possam ser bem mais explorados.

Recomenda-se, em relação à coleta de dados, que sejam realizados mais ensaios de entrada na caixa de retenção com caminhões pesados e leves, variando os tipos de caminhões (configuração dos eixos) e as massas. Os resultados obtidos com análise de dados coletados através de uma maior diversidade de testes têm como propósito obter, de forma mais precisa, a influência da massa, do número de eixos e 
da velocidade de entrada no comportamento da desaceleração média e ao longo do comprimento de frenagem.

Um ponto a ser discutido é a real influência da massa do veículo na intensidade da desaceleração. Para avaliar essa questão, recomenda-se também que sejam feitos ensaios variando a massa do mesmo caminhão, para então poder constatar com maior exatidão a relação entre massa e desaceleração.

Como os modelos matemáticos foram calibrados por meio de análise de regressão, quanto maior heterogeneidade de condições ensaiadas em campo mais detalhado será o modelo obtido, capaz de representar uma gama maior de cenários e auxiliar com maior nível de confiança o projeto de novas áreas de escape a serem implantadas no Brasil. 


\section{ANEXO A: Dados coletados pelo GPS}

As Tabelas A.1 a A.16 apresentam as coordenadas locais captadas pelos receptores do equipamento de GPS, DGPS Leica System 500 durante o movimento dos caminhões nos 16 ensaios realizados. 
Tabela A.1: Dados coletados pelo GPS - teste 01 do caminhão com massa 15,5 t

\begin{tabular}{|c|c|c|c|c|c|c|c|c|c|c|c|c|c|}
\hline \multicolumn{14}{|c|}{ Coordenadas locais } \\
\hline $\mathbf{x}$ & $y$ & $\mathbf{x}$ & $y$ & $\mathbf{x}$ & $y$ & $\mathbf{x}$ & $y$ & $\mathbf{x}$ & $y$ & $\mathbf{x}$ & $y$ & $\mathbf{x}$ & $y$ \\
\hline 303,68 & 51,55 & 291,01 & 49,86 & 256,93 & 44,49 & 204,29 & 36,48 & 147,60 & 27,95 & 91,34 & 19,30 & 35,25 & 7,40 \\
\hline 303,65 & 51,55 & 290,52 & 49,79 & 255,94 & 44,34 & 203,05 & 36,29 & 146,34 & 27,77 & 90,09 & 19,06 & 33,96 & 7,13 \\
\hline 303,63 & 51,54 & 290,03 & 49,71 & 254,93 & 44,20 & 201,81 & 36,13 & 145,07 & 27,58 & 88,86 & 18,83 & 32,66 & 6,85 \\
\hline 303,60 & 51,54 & 289,53 & 49,64 & 253,93 & 44,05 & 200,55 & 35,91 & 143,80 & 27,40 & 87,63 & 18,61 & 31,38 & 6,59 \\
\hline 303,57 & 51,55 & 289,02 & 49,55 & 252,91 & 43,90 & 199,30 & 35,73 & 142,53 & 27,20 & 86,39 & 18,39 & 30,09 & 6,30 \\
\hline 303,52 & 51,54 & 288,53 & 49,48 & 251,90 & 43,74 & 198,05 & 35,54 & 141,25 & 27,02 & 85,14 & 18,13 & 28,77 & 6,02 \\
\hline 303,45 & 51,52 & 288,03 & 49,41 & 250,87 & 43,60 & 196,79 & 35,35 & 139,99 & 26,84 & 83,90 & 17,88 & 27,45 & 5,74 \\
\hline 303,39 & 51,53 & 287,49 & 49,32 & 249,82 & 43,44 & 195,54 & 35,20 & 138,71 & 26,67 & 82,67 & 17,64 & 26,17 & 5,46 \\
\hline 303,32 & 51,51 & 286,95 & 49,24 & 248,77 & 43,30 & 194,27 & 34,99 & 137,44 & 26,48 & 81,43 & 17,40 & 24,86 & 5,20 \\
\hline 303,22 & 51,48 & 286,39 & 49,17 & 247,71 & 43,14 & 193,01 & 34,80 & 136,15 & 26,30 & 80,19 & 17,15 & 23,54 & 4,93 \\
\hline 303,11 & 51,47 & 285,83 & 49,07 & 246,63 & 43,00 & 191,75 & 34,64 & 134,88 & 26,12 & 78,96 & 16,92 & 22,20 & 4,65 \\
\hline 302,99 & 51,45 & 285,24 & 48,98 & 245,53 & 42,83 & 190,49 & 34,48 & 133,60 & 25,94 & 77,71 & 16,68 & 20,88 & 4,32 \\
\hline 302,84 & 51,42 & 284,66 & 48,88 & 244,44 & 42,68 & 189,24 & 34,30 & 132,33 & 25,77 & 76,46 & 16,44 & 19,57 & 4,05 \\
\hline 302,67 & 51,41 & 284,05 & 48,78 & 243,32 & 42,48 & 187,99 & 34,14 & 131,06 & 25,60 & 75,23 & 16,20 & 18,33 & 3,79 \\
\hline 302,50 & 51,40 & 283,43 & 48,68 & 242,20 & 42,36 & 186,72 & 33,97 & 129,78 & 25,41 & 73,98 & 15,96 & 17,11 & 3,56 \\
\hline 302,31 & 51,38 & 282,78 & 48,56 & 241,07 & 42,17 & 185,47 & 33,78 & 128,53 & 25,25 & 72,74 & 15,72 & 15,93 & 3,30 \\
\hline 302,13 & 51,36 & 282,14 & 48,46 & 239,91 & 42,04 & 184,22 & 33,62 & 127,26 & 25,06 & 71,50 & 15,48 & 14,81 & 3,04 \\
\hline 301,91 & 51,33 & 281,47 & 48,35 & 238,76 & 41,88 & 182,96 & 33,42 & 126,00 & 24,90 & 70,25 & 15,23 & 13,66 & 2,76 \\
\hline 301,67 & 51,30 & 280,79 & 48,23 & 237,58 & 41,71 & 181,69 & 33,23 & 124,75 & 24,73 & 69,00 & 14,98 & 12,56 & 2,48 \\
\hline 301,45 & 51,27 & 280,10 & 48,11 & 236,41 & 41,56 & 180,43 & 33,04 & 123,51 & 24,55 & 67,77 & 14,74 & 11,48 & 2,29 \\
\hline 301,20 & 51,25 & 279,37 & 47,97 & 235,22 & 41,37 & 179,17 & 32,85 & 122,27 & 24,37 & 66,53 & 14,47 & 10,44 & 2,12 \\
\hline 300,93 & 51,21 & 278,64 & 47,86 & 234,01 & 41,21 & 177,92 & 32,66 & 121,02 & 24,19 & 65,29 & 14,22 & 9,48 & 1,94 \\
\hline 300,64 & 51,17 & 277,90 & 47,73 & 232,80 & 41,04 & 176,66 & 32,48 & 119,79 & 24,02 & 64,06 & 13,96 & 8,55 & 1,71 \\
\hline 300,35 & 51,14 & 277,14 & 47,60 & 231,58 & 40,86 & 175,40 & 32,30 & 118,56 & 23,83 & 62,81 & 13,69 & 7,68 & 1,52 \\
\hline 300,03 & 51,09 & 276,36 & 47,47 & 230,36 & 40,68 & 174,14 & 32,11 & 117,33 & 23,64 & 61,58 & 13,42 & 6,83 & 1,35 \\
\hline 299,70 & 51,04 & 275,57 & 47,35 & 229,13 & 40,49 & 172,88 & 31,90 & 116,09 & 23,46 & 60,34 & 13,13 & 6,06 & 1,20 \\
\hline 299,36 & 51,00 & 274,75 & 47,19 & 227,90 & 40,30 & 171,62 & 31,71 & 114,86 & 23,27 & 59,12 & 12,87 & 5,33 & 1,09 \\
\hline 299,00 & 50,96 & 273,93 & 47,07 & 226,68 & 40,12 & 170,35 & 31,51 & 113,63 & 23,09 & 57,88 & 12,57 & 4,67 & 0,97 \\
\hline 298,62 & 50,90 & 273,08 & 46,93 & 225,43 & 39,92 & 169,09 & 31,30 & 112,37 & 22,86 & 56,65 & 12,30 & 4,04 & 0,87 \\
\hline 298,22 & 50,85 & 272,23 & 46,80 & 224,19 & 39,73 & 167,83 & 31,11 & 111,14 & 22,69 & 55,41 & 12,00 & 3,51 & 0,75 \\
\hline 297,81 & 50,81 & 271,34 & 46,66 & 222,96 & 39,53 & 166,56 & 30,90 & 109,91 & 22,49 & 54,17 & 11,70 & 3,01 & 0,62 \\
\hline 297,38 & 50,75 & 270,44 & 46,53 & 221,72 & 39,33 & 165,30 & 30,70 & 108,68 & 22,28 & 52,93 & 11,42 & 2,55 & 0,50 \\
\hline 296,95 & 50,69 & 269,53 & 46,38 & 220,48 & 39,14 & 164,04 & 30,49 & 107,43 & 22,08 & 51,69 & 11,14 & 2,11 & 0,42 \\
\hline 296,51 & 50,64 & 268,60 & 46,24 & 219,24 & 38,92 & 162,78 & 30,29 & 106,19 & 21,88 & 50,46 & 10,85 & 1,73 & 0,33 \\
\hline 296,08 & 50,59 & 267,66 & 46,11 & 218,00 & 38,72 & 161,52 & 30,09 & 104,95 & 21,67 & 49,20 & 10,56 & 1,36 & 0,25 \\
\hline 295,64 & 50,53 & 266,69 & 45,96 & 216,76 & 38,51 & 160,27 & 29,90 & 103,72 & 21,48 & 47,96 & 10,26 & 1,07 & 0,19 \\
\hline 295,19 & 50,46 & 265,74 & 45,83 & 215,51 & 38,30 & 159,01 & 29,71 & 102,48 & 21,26 & 46,70 & 9,96 & 0,80 & 0,13 \\
\hline 294,75 & 50,42 & 264,78 & 45,69 & 214,28 & 38,09 & 157,74 & 29,51 & 101,24 & 21,04 & 45,45 & 9,67 & 0,57 & 0,07 \\
\hline 294,29 & 50,34 & 263,81 & 45,55 & 213,03 & 37,89 & 156,47 & 29,30 & 100,00 & 20,83 & 44,19 & 9,37 & 0,37 & 0,04 \\
\hline 293,85 & 50,28 & 262,84 & 45,40 & 211,78 & 37,68 & 155,22 & 29,11 & 98,78 & 20,62 & 42,92 & 9,09 & 0,23 & 0,03 \\
\hline 293,39 & 50,21 & 261,87 & 45,25 & 210,53 & 37,49 & 153,96 & 28,92 & 97,53 & 20,40 & 41,65 & 8,81 & 0,11 & 0,01 \\
\hline 292,92 & 50,14 & 260,89 & 45,10 & 209,28 & 37,28 & 152,68 & 28,72 & 96,29 & 20,18 & 40,37 & 8,52 & 0,04 & 0,01 \\
\hline 292,45 & 50,07 & 259,91 & 44,97 & 208,05 & 37,10 & 151,41 & 28,53 & 95,06 & 19,96 & 39,09 & 8,25 & 0,00 & 0,00 \\
\hline 291,97 & 50,02 & 258,92 & 44,80 & 206,79 & 36,90 & 150,15 & 28,34 & 93,82 & 19,74 & 37,82 & 7,97 & & \\
\hline 291,49 & 49,93 & 257,93 & 44,65 & 205,54 & 36,67 & 148,88 & 28,15 & 92,59 & 19,52 & 36,54 & 7,69 & & \\
\hline
\end{tabular}


Tabela A.2: Dados coletados pelo GPS - teste 02 do caminhão com massa 15,5 t

\begin{tabular}{|c|c|c|c|c|c|c|c|c|c|c|c|c|c|}
\hline \multicolumn{14}{|c|}{ Coordenadas locais } \\
\hline $\mathbf{x}$ & $\mathbf{y}$ & $\mathbf{x}$ & $\mathbf{y}$ & $\mathbf{x}$ & $\mathbf{y}$ & $\mathbf{x}$ & $\mathbf{y}$ & $\mathbf{x}$ & $\mathbf{y}$ & $\mathbf{x}$ & $\mathbf{y}$ & $\mathbf{x}$ & $\mathbf{y}$ \\
\hline 248,34 & 43,32 & 233,57 & 48,67 & 193,58 & 43,16 & 134,00 & 32,81 & 68,56 & 20,41 & 6,39 & 5,08 & 0,00 & 0,00 \\
\hline 248,34 & 43,33 & 233,03 & 48,55 & 192,62 & 42,78 & 132,53 & 32,58 & 67,12 & 20,08 & 5,59 & 4,97 & 0,00 & 0,00 \\
\hline 248,32 & 43,32 & 232,45 & 48,42 & 191,54 & 42,56 & 131,07 & 32,36 & 65,68 & 19,71 & 4,84 & 4,87 & 0,00 & 0,00 \\
\hline 248,31 & 43,31 & 231,85 & 48,32 & 190,45 & 42,33 & 129,61 & 32,11 & 64,20 & 19,43 & 4,16 & 4,75 & 0,00 & 0,00 \\
\hline 248,28 & 43,30 & 231,23 & 48,21 & 189,34 & 42,12 & 128,16 & 31,86 & 62,76 & 19,06 & 3,53 & 4,63 & 0,00 & 0,00 \\
\hline 248,25 & 43,29 & 230,63 & 48,05 & 188,28 & 41,80 & 126,69 & 31,64 & 61,32 & 18,70 & 2,95 & 4,51 & 0,00 & 0,00 \\
\hline 248,21 & 43,29 & 229,98 & 47,93 & 187,19 & 41,53 & 125,23 & 31,40 & 59,86 & 18,32 & 2,45 & 4,40 & 0,00 & 0,00 \\
\hline 248,17 & 43,29 & 229,31 & 47,81 & 186,13 & 41,14 & 123,77 & 31,14 & 58,42 & 17,98 & 1,99 & 4,29 & 0,00 & 0,00 \\
\hline 248,12 & 43,27 & 228,65 & 47,66 & 184,93 & 40,98 & 122,31 & 30,92 & 56,96 & 17,60 & 1,58 & 4,20 & 0,00 & 0,00 \\
\hline 248,07 & 43,26 & 227,93 & 47,55 & 183,71 & 40,84 & 120,84 & 30,67 & 55,50 & 17,22 & 1,22 & 4,12 & 0,00 & 0,00 \\
\hline 248,01 & 43,25 & 227,24 & 47,39 & 182,63 & 40,40 & 119,37 & 30,43 & 54,05 & 16,85 & 0,91 & 4,05 & 0,00 & 0,00 \\
\hline 247,95 & 43,24 & 226,50 & 47,26 & 181,50 & 40,05 & 117,93 & 30,17 & 52,59 & 16,46 & 0,65 & 3,97 & 0,00 & 0,00 \\
\hline 247,89 & 43,23 & 225,72 & 47,18 & 180,25 & 39,87 & 116,47 & 29,95 & 51,13 & 16,08 & 0,44 & 3,91 & 0,00 & 0,00 \\
\hline 247,81 & 43,20 & 224,95 & 47,05 & 178,95 & 39,77 & 114,98 & 29,72 & 49,66 & 15,69 & 0,27 & 3,84 & 0,00 & 0,00 \\
\hline 247,72 & 43,21 & 224,20 & 46,88 & 177,63 & 39,64 & 113,53 & 29,45 & 48,20 & 15,30 & 0,14 & 3,81 & 0,00 & 0,00 \\
\hline 247,63 & 43,19 & 223,41 & 46,73 & 176,43 & 39,32 & 112,01 & 29,30 & 46,72 & 14,91 & 0,05 & 3,76 & 0,00 & 0,00 \\
\hline 247,53 & 43,18 & 222,62 & 46,55 & 175,06 & 39,23 & 110,53 & 29,08 & 45,26 & 14,52 & 0,01 & 3,74 & 0,00 & 0,00 \\
\hline 247,43 & 43,16 & 221,77 & 46,44 & 173,70 & 39,09 & 109,07 & 28,84 & 43,78 & 14,13 & 0,00 & 3,73 & 0,00 & 0,00 \\
\hline 247,31 & 43,14 & 220,90 & 46,33 & 172,36 & 38,92 & 107,59 & 28,60 & 42,30 & 13,76 & 0,00 & 0,04 & 0,00 & 0,00 \\
\hline 247,16 & 43,12 & 220,06 & 46,16 & 171,02 & 38,74 & 106,08 & 28,41 & 40,82 & 13,37 & 0,01 & 0,06 & 0,00 & 0,00 \\
\hline 247,02 & 43,08 & 219,14 & 46,08 & 169,70 & 38,47 & 104,61 & 28,21 & 39,34 & 12,97 & 0,06 & 0,05 & 0,00 & 0,00 \\
\hline 242,64 & 50,16 & 218,23 & 45,94 & 168,37 & 38,20 & 103,21 & 27,87 & 37,84 & 12,58 & 0,08 & 0,04 & 0,00 & 0,00 \\
\hline 246,67 & 43,02 & 217,33 & 45,77 & 166,98 & 38,04 & 101,77 & 27,62 & 36,35 & 12,20 & 0,07 & 0,04 & 0,00 & 0,00 \\
\hline 242,21 & 50,15 & 216,43 & 45,56 & 165,59 & 37,83 & 100,21 & 27,44 & 34,86 & 11,81 & 0,05 & 0,03 & 0,00 & 0,00 \\
\hline 241,98 & 50,14 & 215,51 & 45,38 & 164,20 & 37,63 & 98,78 & 27,16 & 33,37 & 11,43 & 0,04 & 0,03 & 0,00 & 0,00 \\
\hline 241,74 & 50,07 & 214,55 & 45,23 & 162,78 & 37,44 & 97,28 & 26,96 & 31,87 & 11,06 & 0,05 & 0,02 & 0,00 & 0,00 \\
\hline 241,49 & 50,01 & 213,58 & 45,07 & 161,40 & 37,19 & 95,88 & 26,59 & 30,37 & 10,67 & 0,06 & 0,02 & 0,00 & 0,00 \\
\hline 241,22 & 49,94 & 212,57 & 45,02 & 159,98 & 36,98 & 94,39 & 26,39 & 28,87 & 10,29 & 0,06 & 0,02 & 0,00 & 0,00 \\
\hline 240,90 & 49,93 & 211,59 & 44,86 & 158,57 & 36,75 & 92,90 & 26,17 & 27,36 & 9,89 & 0,06 & 0,01 & 0,00 & 0,00 \\
\hline 240,62 & 49,83 & 210,64 & 44,65 & 157,16 & 36,51 & 91,46 & 25,89 & 25,85 & 9,50 & 0,06 & 0,01 & 0,00 & 0,00 \\
\hline 240,29 & 49,80 & 209,61 & 44,53 & 155,72 & 36,30 & 90,00 & 25,62 & 24,35 & 9,04 & 0,06 & 0,01 & 0,00 & 0,00 \\
\hline 239,94 & 49,75 & 208,64 & 44,34 & 154,31 & 36,04 & 88,51 & 25,38 & 22,88 & 8,64 & 0,06 & 0,01 & 0,00 & 0,00 \\
\hline 239,58 & 49,70 & 207,64 & 44,19 & 152,85 & 35,88 & 87,11 & 25,00 & 21,44 & 8,29 & 0,06 & 0,00 & 0,00 & 0,00 \\
\hline 239,23 & 49,61 & 206,64 & 44,02 & 151,42 & 35,64 & 85,58 & 24,83 & 20,02 & 7,98 & 0,00 & 0,00 & 0,00 & 0,00 \\
\hline 238,85 & 49,54 & 205,63 & 43,86 & 149,98 & 35,41 & 84,11 & 24,56 & 18,66 & 7,71 & 0,00 & 0,00 & 0,00 & 0,00 \\
\hline 238,42 & 49,52 & 204,63 & 43,68 & 148,54 & 35,17 & 82,63 & 24,28 & 17,32 & 7,44 & 0,00 & 0,00 & 0,00 & 0,00 \\
\hline 238,00 & 49,44 & 203,63 & 43,51 & 147,09 & 34,93 & 81,20 & 23,93 & 16,01 & 7,05 & 0,00 & 0,00 & 0,00 & 0,00 \\
\hline 237,59 & 49,36 & 202,60 & 43,36 & 145,64 & 34,70 & 80,04 & 23,14 & 14,73 & 6,72 & 0,00 & 0,00 & 0,00 & 0,00 \\
\hline 237,15 & 49,27 & 201,56 & 43,23 & 144,20 & 34,44 & 78,55 & 22,92 & 13,47 & 6,51 & 0,00 & 0,00 & 0,00 & 0,00 \\
\hline 236,69 & 49,19 & 200,54 & 43,05 & 142,76 & 34,19 & 77,12 & 22,54 & 12,26 & 6,30 & 0,00 & 0,00 & 0,00 & 0,00 \\
\hline 236,22 & 49,09 & 199,49 & 42,93 & 141,28 & 33,99 & 75,69 & 22,22 & 11,13 & 6,06 & 0,00 & 0,00 & 0,00 & 0,00 \\
\hline 235,73 & 49,02 & 198,42 & 42,82 & 139,83 & 33,75 & 74,25 & 21,90 & 10,06 & 5,82 & 0,00 & 0,00 & 0,00 & 0,00 \\
\hline 235,22 & 48,92 & 197,35 & 42,73 & 138,37 & 33,51 & 72,76 & 21,65 & 9,05 & 5,58 & 0,00 & 0,00 & 0,00 & 0,00 \\
\hline 234,66 & 48,89 & 196,04 & 42,98 & 136,92 & 33,26 & 71,37 & 21,24 & 8,10 & 5,38 & 0,00 & 0,00 & 0,00 & 0,00 \\
\hline 234,13 & 48,78 & 194,94 & 42,87 & 135,46 & 33,04 & 69,99 & 20,79 & 7,22 & 5,22 & 0,00 & 0,00 & 0,00 & 0,00 \\
\hline
\end{tabular}


Tabela A.3: Dados coletados pelo GPS - teste 03 do caminhão com massa 15,5 t

\begin{tabular}{|c|c|c|c|c|c|c|c|c|c|c|c|c|c|}
\hline \multicolumn{14}{|c|}{ Coordenadas locais } \\
\hline$\underline{x}$ & $\mathbf{y}$ & $\mathbf{x}$ & $\mathbf{y}$ & $\mathbf{x}$ & $\mathbf{y}$ & $\mathbf{x}$ & $\mathbf{y}$ & $\mathbf{x}$ & $\mathbf{y}$ & $\mathbf{x}$ & $\mathbf{y}$ & $\mathbf{x}$ & $\mathbf{y}$ \\
\hline 353,32 & 63,28 & 336,15 & 61,85 & 291,88 & 55,65 & 227,54 & 45,99 & 146,74 & 28,58 & 61,89 & 12,75 & 1,13 & 0,18 \\
\hline 353,26 & 63,28 & 335,41 & 61,75 & 290,64 & 55,45 & 225,89 & 45,74 & 144,84 & 28,29 & 59,97 & 12,32 & 0,94 & 0,12 \\
\hline 353,18 & 63,29 & 334,66 & 61,65 & 289,39 & 55,24 & 224,22 & 45,51 & 142,95 & 28,01 & 58,05 & 11,91 & 0,82 & 0,07 \\
\hline 353,10 & 63,29 & 333,90 & 61,55 & 288,12 & 55,04 & 222,55 & 45,26 & 141,06 & 27,71 & 56,15 & 11,50 & 0,74 & 0,02 \\
\hline 353,01 & 63,28 & 333,12 & 61,43 & 286,84 & 54,83 & 220,87 & 45,01 & 139,16 & 27,42 & 54,23 & 11,07 & 0,70 & 0,00 \\
\hline 352,91 & 63,27 & 332,32 & 61,33 & 285,55 & 54,63 & 219,16 & 44,76 & 137,27 & 27,12 & 52,31 & 10,65 & 0,69 & 0,00 \\
\hline 352,81 & 63,28 & 331,51 & 61,22 & 284,25 & 54,42 & 217,45 & 44,51 & 135,39 & 26,83 & 50,39 & 10,20 & 0,73 & 0,00 \\
\hline 352,69 & 63,29 & 330,66 & 61,13 & 282,93 & 54,21 & 215,75 & 44,22 & 133,50 & 26,54 & 48,46 & 9,76 & 0,78 & 0,00 \\
\hline 352,55 & 63,29 & 329,82 & 61,03 & 281,59 & 54,00 & 214,01 & 43,97 & 131,64 & 26,23 & 46,54 & 9,32 & 0,82 & 0,01 \\
\hline 352,40 & 63,29 & 328,95 & 60,93 & 280,24 & 53,80 & 212,27 & 43,72 & 129,75 & 25,92 & 44,61 & 8,88 & 0,84 & 0,01 \\
\hline 352,22 & 63,29 & 328,06 & 60,82 & 278,89 & 53,59 & 211,91 & 38,49 & 127,87 & 25,61 & 42,68 & 8,45 & 0,82 & 0,01 \\
\hline 352,02 & 63,28 & 327,17 & 60,71 & 277,55 & 53,38 & 210,15 & 38,23 & 125,98 & 25,30 & 40,75 & 8,04 & 0,81 & 0,00 \\
\hline 351,81 & 63,27 & 326,25 & 60,60 & 276,20 & 53,17 & 206,93 & 43,09 & 122,69 & 30,02 & 38,82 & 7,62 & 0,82 & 0,00 \\
\hline 351,58 & 63,26 & 325,31 & 60,47 & 274,84 & 52,97 & 205,16 & 42,77 & 120,80 & 29,73 & 36,86 & 7,21 & 0,82 & 0,01 \\
\hline 351,33 & 63,26 & 324,36 & 60,36 & 273,48 & 52,77 & 204,82 & 37,40 & 118,90 & 29,48 & 34,89 & 6,84 & 0,83 & 0,02 \\
\hline 351,06 & 63,24 & 323,41 & 60,23 & 272,11 & 52,56 & 203,01 & 37,12 & 118,45 & 24,07 & 32,96 & 6,38 & 0,83 & 0,02 \\
\hline 350,78 & 63,22 & 322,47 & 60,13 & 270,75 & 52,35 & 201,18 & 36,85 & 115,14 & 28,86 & 31,10 & 5,99 & 0,83 & 0,02 \\
\hline 350,48 & 63,21 & 321,54 & 60,00 & 269,38 & 52,16 & 199,36 & 36,58 & 113,26 & 28,51 & 29,31 & 5,65 & 0,83 & 0,03 \\
\hline 350,16 & 63,20 & 320,59 & 59,87 & 268,00 & 51,95 & 197,52 & 36,31 & 111,38 & 28,21 & 27,56 & 5,27 & 0,84 & 0,03 \\
\hline 349,84 & 63,18 & 319,63 & 59,74 & 266,63 & 51,75 & 195,68 & 36,03 & 109,51 & 27,84 & 25,79 & 4,89 & 0,84 & 0,04 \\
\hline 349,49 & 63,16 & 318,67 & 59,61 & 265,24 & 51,55 & 193,83 & 35,74 & 107,65 & 27,46 & 24,07 & 4,51 & 0,84 & 0,04 \\
\hline 349,14 & 63,13 & 317,71 & 59,48 & 263,86 & 51,34 & 191,99 & 35,46 & 105,77 & 27,12 & 22,37 & 4,20 & 0,00 & 0,00 \\
\hline 348,77 & 63,12 & 316,75 & 59,35 & 262,47 & 51,16 & 190,13 & 35,19 & 103,90 & 26,81 & 20,74 & 3,90 & & \\
\hline 348,38 & 63,09 & 315,77 & 59,23 & 261,07 & 50,94 & 188,27 & 34,89 & 103,45 & 21,41 & 19,20 & 3,56 & & \\
\hline 347,99 & 63,06 & 314,80 & 59,08 & 259,67 & 50,72 & 186,39 & 34,58 & 101,57 & 21,08 & 17,73 & 3,28 & & \\
\hline 347,57 & 63,05 & 313,82 & 58,94 & 258,24 & 50,50 & 184,50 & 34,31 & 99,68 & 20,72 & 16,37 & 3,01 & & \\
\hline 347,14 & 63,01 & 312,86 & 58,80 & 256,82 & 50,30 & 182,61 & 34,03 & 97,81 & 20,36 & 15,08 & 2,75 & & \\
\hline 346,71 & 62,97 & 311,86 & 58,66 & 255,38 & 50,09 & 180,73 & 33,75 & 94,60 & 24,78 & 13,81 & 2,56 & & \\
\hline 346,24 & 62,94 & 310,86 & 58,50 & 253,93 & 49,88 & 178,85 & 33,46 & 92,71 & 24,46 & 12,58 & 2,35 & & \\
\hline 345,76 & 62,88 & 309,85 & 58,35 & 252,47 & 49,66 & 176,96 & 33,17 & 90,83 & 24,07 & 11,39 & 2,12 & & \\
\hline 345,27 & 62,84 & 308,82 & 58,20 & 250,99 & 49,45 & 175,07 & 32,90 & 88,95 & 23,68 & 10,28 & 1,88 & & \\
\hline 344,78 & 62,79 & 307,78 & 58,05 & 249,51 & 49,22 & 173,19 & 32,62 & 87,07 & 23,27 & 9,26 & 1,66 & & \\
\hline 344,26 & 62,75 & 306,73 & 57,89 & 248,02 & 49,00 & 171,30 & 32,33 & 86,53 & 18,10 & 8,32 & 1,49 & & \\
\hline 343,72 & 62,70 & 305,67 & 57,74 & 246,51 & 48,78 & 169,41 & 32,05 & 84,64 & 17,73 & 7,45 & 1,36 & & \\
\hline 343,17 & 62,65 & 304,60 & 57,57 & 245,00 & 48,56 & 167,52 & 31,77 & 82,76 & 17,32 & 6,61 & 1,24 & & \\
\hline 342,61 & 62,60 & 303,51 & 57,41 & 243,47 & 48,34 & 165,63 & 31,48 & 80,87 & 16,91 & 5,82 & 1,10 & & \\
\hline 342,04 & 62,55 & 302,41 & 57,25 & 241,92 & 48,11 & 163,74 & 31,20 & 78,98 & 16,50 & 5,10 & 0,95 & & \\
\hline 341,44 & 62,48 & 301,30 & 57,08 & 240,37 & 47,88 & 161,86 & 30,90 & 77,09 & 16,09 & 4,44 & 0,83 & & \\
\hline 340,83 & 62,43 & 300,16 & 56,91 & 238,80 & 47,67 & 159,97 & 30,62 & 75,21 & 15,66 & 3,84 & 0,71 & & \\
\hline 340,22 & 62,35 & 299,02 & 56,74 & 237,22 & 47,46 & 158,08 & 30,32 & 73,31 & 15,23 & 3,29 & 0,63 & & \\
\hline 339,59 & 62,27 & 297,87 & 56,57 & 235,64 & 47,21 & 156,19 & 30,03 & 71,42 & 14,80 & 2,80 & 0,53 & & \\
\hline 338,93 & 62,19 & 296,70 & 56,39 & 234,04 & 46,98 & 154,30 & 29,74 & 69,51 & 14,38 & 2,35 & 0,48 & & \\
\hline 338,26 & 62,10 & 295,52 & 56,21 & 232,42 & 46,76 & 152,41 & 29,45 & 67,61 & 13,98 & 1,97 & 0,38 & & \\
\hline 337,57 & 62,01 & 294,32 & 56,04 & 230,82 & 46,49 & 150,51 & 29,16 & 65,70 & 13,56 & 1,63 & 0,32 & & \\
\hline 336,86 & 61,94 & 293,11 & 55,84 & 229,19 & 46,23 & 148,62 & 28,87 & 63,79 & 13,16 & 1,36 & 0,25 & & \\
\hline
\end{tabular}


Tabela A.4: Dados coletados pelo GPS - teste 04 do caminhão com massa 15,5 t

\begin{tabular}{|c|c|c|c|c|c|c|c|c|c|c|c|c|c|}
\hline \multicolumn{14}{|c|}{ Coordenadas locais } \\
\hline $\mathbf{x}$ & $\mathbf{y}$ & $\mathbf{x}$ & $\mathbf{y}$ & $\mathbf{x}$ & $\mathbf{y}$ & $\mathbf{x}$ & $\mathbf{y}$ & $\mathbf{x}$ & $\mathbf{y}$ & $\mathbf{x}$ & $\mathbf{y}$ & $\mathbf{x}$ & $\mathbf{y}$ \\
\hline 366,95 & 60,60 & 354,88 & 60,14 & 314,32 & 54,91 & 252,98 & 45,58 & 172,95 & 33,45 & 78,61 & 17,06 & 2,48 & 0,52 \\
\hline 366,93 & 60,60 & 354,26 & 60,10 & 313,19 & 54,76 & 251,39 & 45,34 & 170,98 & 33,14 & 76,46 & 16,59 & 1,99 & 0,42 \\
\hline 366,91 & 60,60 & 353,63 & 60,05 & 312,05 & 54,61 & 249,80 & 45,10 & 169,00 & 32,84 & 74,31 & 16,13 & 1,56 & 0,33 \\
\hline 366,88 & 60,60 & 352,98 & 59,99 & 310,89 & 54,46 & 248,19 & 44,86 & 167,01 & 32,53 & 72,15 & 15,68 & 1,17 & 0,27 \\
\hline 366,85 & 60,60 & 352,31 & 59,93 & 309,72 & 54,31 & 246,57 & 44,61 & 165,02 & 32,23 & 70,00 & 15,22 & 0,84 & 0,21 \\
\hline 366,81 & 60,60 & 351,63 & 59,86 & 308,53 & 54,15 & 244,95 & 44,35 & 163,02 & 31,91 & 67,85 & 14,75 & 0,57 & 0,15 \\
\hline 366,77 & 60,60 & 350,95 & 59,79 & 307,34 & 53,99 & 243,31 & 44,09 & 161,00 & 31,61 & 65,69 & 14,29 & 0,36 & 0,10 \\
\hline 366,71 & 60,59 & 350,24 & 59,73 & 306,12 & 53,83 & 241,67 & 43,82 & 158,98 & 31,29 & 63,53 & 13,80 & 0,20 & 0,06 \\
\hline 366,65 & 60,59 & 349,51 & 59,66 & 304,90 & 53,65 & 240,01 & 43,55 & 156,93 & 30,98 & 61,37 & 13,32 & 0,08 & 0,03 \\
\hline 366,59 & 60,59 & 348,76 & 59,58 & 303,67 & 53,46 & 238,34 & 43,27 & 154,89 & 30,68 & 59,22 & 12,84 & 0,01 & 0,01 \\
\hline 366,52 & 60,59 & 348,01 & 59,50 & 302,43 & 53,26 & 236,67 & 43,00 & 152,85 & 30,37 & 57,06 & 12,34 & 0,00 & 0,00 \\
\hline 366,44 & 60,59 & 347,24 & 59,41 & 301,16 & 53,04 & 234,97 & 42,72 & 150,78 & 30,05 & 54,90 & 11,81 & 0,00 & 0,00 \\
\hline 366,36 & 60,60 & 346,45 & 59,32 & 299,89 & 52,82 & 233,27 & 42,44 & 148,71 & 29,74 & 52,74 & 11,28 & 0,00 & 0,00 \\
\hline 366,26 & 60,59 & 345,65 & 59,22 & 298,60 & 52,61 & 231,55 & 42,16 & 146,63 & 29,42 & 50,58 & 10,79 & 0,03 & 0,02 \\
\hline 366,15 & 60,59 & 344,83 & 59,12 & 297,29 & 52,40 & 229,83 & 41,89 & 144,54 & 29,10 & 48,41 & 10,26 & 0,04 & 0,02 \\
\hline 366,04 & 60,60 & 343,99 & 59,00 & 295,98 & 52,19 & 228,09 & 41,63 & 142,45 & 28,77 & 46,25 & 9,76 & 0,03 & 0,01 \\
\hline 365,91 & 60,59 & 343,13 & 58,90 & 294,65 & 51,97 & 226,34 & 41,37 & 140,34 & 28,44 & 44,06 & 9,27 & 0,01 & 0,01 \\
\hline 365,76 & 60,59 & 342,26 & 58,79 & 293,31 & 51,75 & 224,57 & 41,11 & 138,23 & 28,11 & 41,87 & 8,79 & 0,01 & 0,01 \\
\hline 365,59 & 60,59 & 341,38 & 58,68 & 291,96 & 51,53 & 222,82 & 40,85 & 136,12 & 27,78 & 39,68 & 8,30 & 0,01 & 0,01 \\
\hline 365,41 & 60,59 & 340,47 & 58,57 & 290,59 & 51,31 & 221,06 & 40,60 & 134,01 & 27,44 & 37,53 & 7,80 & 0,02 & 0,01 \\
\hline 365,22 & 60,58 & 339,54 & 58,45 & 289,23 & 51,10 & 219,29 & 40,34 & 131,90 & 27,08 & 35,43 & 7,35 & 0,01 & 0,01 \\
\hline 365,01 & 60,58 & 338,61 & 58,33 & 287,87 & 50,88 & 217,52 & 40,09 & 129,78 & 26,76 & 33,41 & 6,93 & 0,01 & 0,01 \\
\hline 364,78 & 60,58 & 337,66 & 58,21 & 286,50 & 50,68 & 215,75 & 39,85 & 127,67 & 26,36 & 31,43 & 6,45 & 0,01 & 0,01 \\
\hline 364,53 & 60,58 & 336,71 & 58,09 & 285,12 & 50,46 & 213,98 & 39,60 & 125,56 & 26,02 & 29,45 & 5,99 & 0,01 & 0,01 \\
\hline 364,26 & 60,57 & 335,73 & 57,97 & 283,75 & 50,25 & 212,21 & 39,35 & 123,44 & 25,67 & 27,51 & 5,58 & & \\
\hline 363,98 & 60,56 & 334,76 & 57,84 & 282,37 & 50,05 & 210,43 & 39,10 & 121,31 & 25,30 & 25,62 & 5,23 & & \\
\hline 363,68 & 60,55 & 333,79 & 57,72 & 280,98 & 49,84 & 208,64 & 38,83 & 119,19 & 24,93 & 23,80 & 4,85 & & \\
\hline 363,35 & 60,53 & 332,84 & 57,59 & 279,59 & 49,63 & 206,84 & 38,57 & 117,07 & 24,57 & 22,07 & 4,50 & & \\
\hline 363,02 & 60,53 & 331,85 & 57,46 & 278,20 & 49,42 & 205,03 & 38,30 & 114,94 & 24,19 & 20,46 & 4,06 & & \\
\hline 362,65 & 60,51 & 330,87 & 57,33 & 276,81 & 49,21 & 203,21 & 38,03 & 112,81 & 23,81 & 18,90 & 3,72 & & \\
\hline 362,29 & 60,50 & 329,89 & 57,19 & 275,39 & 49,00 & 201,39 & 37,75 & 110,69 & 23,44 & 17,38 & 3,47 & & \\
\hline 361,90 & 60,48 & 328,92 & 57,05 & 273,97 & 48,78 & 199,55 & 37,47 & 108,56 & 23,03 & 15,93 & 3,17 & & \\
\hline 361,50 & 60,48 & 327,93 & 56,90 & 272,54 & 48,57 & 197,71 & 37,20 & 106,42 & 22,69 & 14,53 & 2,88 & & \\
\hline 361,09 & 60,46 & 326,94 & 56,75 & 271,10 & 48,34 & 195,86 & 36,92 & 104,28 & 22,29 & 13,21 & 2,57 & & \\
\hline 360,65 & 60,45 & 325,95 & 56,59 & 269,65 & 48,12 & 194,00 & 36,64 & 102,14 & 21,88 & 11,97 & 2,28 & & \\
\hline 360,19 & 60,45 & 324,95 & 56,44 & 268,19 & 47,89 & 192,13 & 36,35 & 100,01 & 21,48 & 10,79 & 2,07 & & \\
\hline 359,73 & 60,43 & 323,96 & 56,28 & 266,72 & 47,67 & 190,25 & 36,07 & 97,89 & 21,04 & 9,69 & 1,87 & & \\
\hline 359,25 & 60,40 & 322,93 & 56,12 & 265,24 & 47,43 & 188,37 & 35,80 & 95,75 & 20,60 & 8,66 & 1,67 & & \\
\hline 358,76 & 60,38 & 321,90 & 55,96 & 263,74 & 47,20 & 186,47 & 35,51 & 93,62 & 20,17 & 7,67 & 1,50 & & \\
\hline 358,25 & 60,36 & 320,85 & 55,81 & 262,24 & 46,98 & 184,57 & 35,21 & 91,48 & 19,74 & 6,73 & 1,31 & & \\
\hline 357,72 & 60,34 & 319,80 & 55,66 & 260,73 & 46,74 & 182,66 & 34,92 & 89,33 & 19,30 & 5,87 & 1,12 & & \\
\hline 357,19 & 60,31 & 318,73 & 55,51 & 259,21 & 46,51 & 180,73 & 34,64 & 87,19 & 18,85 & 5,07 & 0,97 & & \\
\hline 356,64 & 60,27 & 317,64 & 55,36 & 257,66 & 46,28 & 178,80 & 34,35 & 85,04 & 18,42 & 4,33 & 0,85 & & \\
\hline 356,06 & 60,23 & 316,55 & 55,22 & 256,11 & 46,05 & 176,86 & 34,05 & 82,90 & 17,97 & 3,65 & 0,73 & & \\
\hline 355,48 & 60,19 & 315,44 & 55,06 & 254,55 & 45,81 & 174,91 & 33,75 & 80,76 & 17,52 & 3,04 & 0,62 & & \\
\hline
\end{tabular}


Tabela A.5: Dados coletados pelo GPS - teste 05 do caminhão com massa 15,5 t

\begin{tabular}{|c|c|c|c|c|c|c|c|c|c|c|c|c|c|}
\hline \multicolumn{14}{|c|}{ Coordenadas locais } \\
\hline$\underline{x}$ & $\mathbf{y}$ & $\mathbf{x}$ & $\mathbf{y}$ & $\mathbf{x}$ & $\mathbf{y}$ & $\mathbf{x}$ & $\mathbf{y}$ & $\mathbf{x}$ & $\mathbf{y}$ & $\mathbf{x}$ & $\mathbf{y}$ & $\mathbf{x}$ & $\mathbf{y}$ \\
\hline 400,46 & 56,64 & 380,62 & 61,02 & 335,80 & 58,14 & 273,58 & 48,75 & 192,57 & 36,51 & 95,76 & 20,46 & 7,45 & 1,42 \\
\hline 400,36 & 56,68 & 379,81 & 61,10 & 334,61 & 57,98 & 271,94 & 48,53 & 190,58 & 36,20 & 93,54 & 19,99 & 6,51 & 1,25 \\
\hline 400,25 & 56,71 & 378,98 & 61,18 & 333,43 & 57,84 & 270,29 & 48,30 & 188,59 & 35,91 & 91,32 & 19,51 & 5,63 & 1,09 \\
\hline 400,12 & 56,76 & 378,14 & 61,22 & 332,24 & 57,68 & 268,62 & 48,02 & 186,58 & 35,60 & 89,08 & 19,04 & 4,83 & 0,94 \\
\hline 399,98 & 56,82 & 377,27 & 61,30 & 331,04 & 57,50 & 266,94 & 47,78 & 184,56 & 35,31 & 86,86 & 18,57 & 4,07 & 0,80 \\
\hline 399,83 & 56,88 & 376,41 & 61,35 & 329,84 & 57,34 & 265,26 & 47,57 & 182,53 & 35,00 & 84,63 & 18,08 & 3,40 & 0,68 \\
\hline 399,66 & 56,94 & 375,54 & 61,40 & 328,65 & 57,14 & 263,56 & 47,31 & 180,50 & 34,69 & 82,41 & 17,58 & 2,78 & 0,56 \\
\hline 399,47 & 57,02 & 374,66 & 61,44 & 327,44 & 56,95 & 261,85 & 47,08 & 178,45 & 34,38 & 80,17 & 17,09 & 2,22 & 0,46 \\
\hline 399,27 & 57,09 & 373,79 & 61,47 & 326,21 & 56,77 & 260,14 & 46,85 & 176,39 & 34,07 & 77,95 & 16,57 & 1,73 & 0,36 \\
\hline 399,06 & 57,18 & 372,92 & 61,49 & 324,98 & 56,59 & 258,42 & 46,60 & 174,34 & 33,76 & 75,71 & 16,08 & 1,31 & 0,28 \\
\hline 398,82 & 57,26 & 372,03 & 61,52 & 323,74 & 56,40 & 256,71 & 46,35 & 172,26 & 33,43 & 73,48 & 15,57 & 0,95 & 0,23 \\
\hline 398,57 & 57,35 & 371,14 & 61,53 & 322,50 & 56,20 & 255,00 & 46,08 & 170,18 & 33,12 & 71,25 & 15,06 & 0,65 & 0,16 \\
\hline 398,30 & 57,44 & 370,25 & 61,55 & 321,24 & 55,99 & 253,27 & 45,82 & 168,10 & 32,80 & 69,01 & 14,54 & 0,41 & 0,10 \\
\hline 398,00 & 57,55 & 369,35 & 61,55 & 319,97 & 55,78 & 251,55 & 45,55 & 166,00 & 32,47 & 66,77 & 14,03 & 0,23 & 0,05 \\
\hline 397,69 & 57,67 & 368,45 & 61,55 & 318,70 & 55,58 & 249,83 & 45,29 & 163,89 & 32,15 & 64,53 & 13,52 & 0,10 & 0,03 \\
\hline 397,38 & 57,77 & 367,55 & 61,54 & 317,41 & 55,39 & 248,10 & 45,03 & 161,76 & 31,83 & 62,29 & 13,00 & 0,02 & 0,01 \\
\hline 397,05 & 57,89 & 366,64 & 61,52 & 316,12 & 55,21 & 246,37 & 44,76 & 159,64 & 31,53 & 60,05 & 12,48 & 0,00 & 0,00 \\
\hline 396,69 & 58,00 & 365,74 & 61,49 & 314,81 & 55,01 & 244,63 & 44,49 & 157,50 & 31,21 & 57,79 & 11,96 & 0,00 & 0,00 \\
\hline 396,32 & 58,11 & 364,82 & 61,46 & 313,49 & 54,80 & 242,89 & 44,21 & 155,35 & 30,90 & 55,54 & 11,44 & 0,00 & 0,00 \\
\hline 395,95 & 58,23 & 363,89 & 61,41 & 312,16 & 54,61 & 241,13 & 43,95 & 153,20 & 30,58 & 53,30 & 10,91 & 0,02 & 0,01 \\
\hline 395,54 & 58,33 & 362,95 & 61,36 & 310,82 & 54,40 & 239,37 & 43,68 & 151,04 & 30,25 & 51,05 & 10,43 & 0,05 & 0,01 \\
\hline 395,14 & 58,46 & 362,01 & 61,29 & 309,47 & 54,22 & 237,60 & 43,41 & 148,87 & 29,94 & 48,78 & 9,93 & 0,03 & 0,01 \\
\hline 394,72 & 58,59 & 361,05 & 61,22 & 308,11 & 54,01 & 235,82 & 43,12 & 146,70 & 29,61 & 46,51 & 9,46 & 0,01 & 0,00 \\
\hline 394,28 & 58,71 & 360,08 & 61,12 & 306,73 & 53,79 & 234,04 & 42,87 & 144,51 & 29,28 & 44,23 & 8,97 & 0,00 & 0,00 \\
\hline 393,83 & 58,85 & 359,09 & 61,05 & 305,35 & 53,58 & 232,24 & 42,58 & 142,32 & 28,95 & 42,00 & 8,47 & 0,01 & 0,00 \\
\hline 393,37 & 58,98 & 358,09 & 60,96 & 303,96 & 53,37 & 230,43 & 42,27 & 140,11 & 28,61 & 39,84 & 8,03 & 0,01 & 0,00 \\
\hline 392,88 & 59,12 & 357,07 & 60,87 & 302,53 & 53,16 & 228,63 & 42,05 & 137,91 & 28,24 & 37,74 & 7,57 & 0,01 & 0,01 \\
\hline 392,38 & 59,24 & 356,05 & 60,76 & 301,12 & 52,94 & 226,81 & 41,82 & 135,71 & 27,90 & 35,64 & 7,14 & 0,01 & 0,00 \\
\hline 391,85 & 59,36 & 355,04 & 60,66 & 299,69 & 52,72 & 224,99 & 41,49 & 133,50 & 27,54 & 33,55 & 6,70 & 0,01 & 0,00 \\
\hline 391,34 & 59,47 & 353,99 & 60,54 & 298,25 & 52,50 & 223,16 & 41,23 & 131,30 & 27,16 & 31,49 & 6,25 & 0,01 & 0,01 \\
\hline 390,79 & 59,56 & 352,94 & 60,41 & 296,80 & 52,27 & 221,31 & 40,93 & 129,09 & 26,78 & 29,47 & 5,86 & 0,01 & 0,00 \\
\hline 390,23 & 59,67 & 351,87 & 60,27 & 295,33 & 52,05 & 219,46 & 40,65 & 126,87 & 26,39 & 27,52 & 5,49 & 0,01 & 0,01 \\
\hline 389,65 & 59,78 & 350,79 & 60,15 & 293,86 & 51,82 & 217,60 & 40,36 & 124,66 & 26,02 & 25,65 & 5,12 & 0,01 & 0,00 \\
\hline 389,05 & 59,88 & 349,71 & 60,01 & 292,37 & 51,59 & 215,73 & 40,07 & 122,45 & 25,60 & 23,88 & 4,67 & 0,01 & 0,01 \\
\hline 388,44 & 60,01 & 348,60 & 59,83 & 290,86 & 51,36 & 213,85 & 39,78 & 120,21 & 25,23 & 22,16 & 4,32 & 0,01 & 0,00 \\
\hline 387,81 & 60,14 & 347,47 & 59,66 & 289,36 & 51,11 & 211,97 & 39,47 & 118,00 & 24,82 & 20,50 & 3,98 & 0,01 & 0,01 \\
\hline 387,17 & 60,22 & 346,34 & 59,52 & 287,83 & 50,83 & 210,06 & 39,18 & 115,78 & 24,42 & 18,89 & 3,67 & 0,01 & 0,00 \\
\hline 386,51 & 60,31 & 345,20 & 59,39 & 286,29 & 50,60 & 208,16 & 38,88 & 113,57 & 24,01 & 17,33 & 3,38 & 0,01 & 0,00 \\
\hline 385,83 & 60,40 & 344,03 & 59,22 & 284,74 & 50,39 & 206,25 & 38,57 & 111,34 & 23,59 & 15,87 & 3,07 & 0,01 & 0,00 \\
\hline 385,14 & 60,49 & 342,87 & 59,05 & 283,18 & 50,19 & 204,32 & 38,28 & 109,11 & 23,17 & 14,48 & 2,77 & & \\
\hline 384,43 & 60,58 & 341,69 & 58,89 & 281,61 & 49,93 & 202,38 & 37,99 & 106,89 & 22,72 & 13,14 & 2,49 & & \\
\hline 383,70 & 60,67 & 340,52 & 58,76 & 280,03 & 49,72 & 200,44 & 37,69 & 104,67 & 22,27 & 11,86 & 2,24 & & \\
\hline 382,95 & 60,74 & 339,34 & 58,61 & 278,44 & 49,45 & 198,49 & 37,39 & 102,45 & 21,81 & 10,64 & 2,02 & & \\
\hline 382,19 & 60,85 & 338,17 & 58,44 & 276,83 & 49,21 & 196,53 & 37,10 & 100,22 & 21,35 & 9,49 & 1,82 & & \\
\hline 381,42 & 60,95 & 336,99 & 58,32 & 275,21 & 48,97 & 194,55 & 36,82 & 97,99 & 20,91 & 8,44 & 1,62 & & \\
\hline
\end{tabular}


Tabela A.6: Dados coletados pelo GPS - teste 06 do caminhão com massa 15,5 t

\begin{tabular}{|c|c|c|c|c|c|c|c|c|c|c|c|c|c|}
\hline \multicolumn{14}{|c|}{ Coordenadas locais } \\
\hline$\underline{x}$ & $\mathbf{y}$ & $\mathbf{x}$ & $\mathbf{y}$ & $\mathbf{x}$ & $\mathbf{y}$ & $\mathbf{x}$ & $\mathbf{y}$ & $\mathbf{x}$ & $\mathbf{y}$ & $\mathbf{x}$ & $\mathbf{y}$ & $\mathbf{x}$ & $\mathbf{y}$ \\
\hline 458,41 & 23,75 & 434,09 & 46,30 & 381,78 & 63,88 & 308,70 & 55,15 & 220,73 & 44,87 & 111,82 & 23,82 & 11,27 & 2,63 \\
\hline 458,10 & 24,15 & 433,27 & 46,85 & 380,32 & 63,92 & 306,86 & 54,85 & 218,54 & 44,55 & 109,31 & 23,31 & 10,14 & 2,40 \\
\hline 457,78 & 24,54 & 432,44 & 47,40 & 378,86 & 63,95 & 304,98 & 54,51 & 216,37 & 44,25 & 106,80 & 22,79 & 9,05 & 2,19 \\
\hline 457,45 & 24,92 & 431,62 & 47,97 & 377,42 & 63,98 & 303,09 & 54,19 & 214,15 & 43,91 & 104,25 & 22,25 & 8,02 & 1,98 \\
\hline 457,13 & 25,32 & 430,77 & 48,53 & 375,95 & 63,97 & 301,23 & 53,89 & 211,94 & 43,57 & 100,70 & 17,21 & 7,07 & 1,79 \\
\hline 456,78 & 25,70 & 429,89 & 49,09 & 374,48 & 63,96 & 299,35 & 53,62 & 209,73 & 43,24 & 98,15 & 16,66 & 6,19 & 1,63 \\
\hline 456,45 & 26,10 & 429,02 & 49,67 & 373,01 & 63,92 & 297,45 & 53,33 & 207,50 & 42,90 & 95,65 & 16,11 & 5,37 & 1,48 \\
\hline 456,10 & 26,49 & 428,13 & 50,23 & 371,57 & 63,89 & 295,54 & 53,04 & 205,26 & 42,55 & 93,13 & 15,55 & 4,63 & 1,33 \\
\hline 455,74 & 26,88 & 427,21 & 50,78 & 370,09 & 63,84 & 293,65 & 52,78 & 203,02 & 42,22 & 90,61 & 14,96 & 3,95 & 1,21 \\
\hline 455,39 & 27,27 & 426,30 & 51,36 & 368,60 & 63,75 & 291,72 & 52,51 & 198,04 & 37,85 & 88,10 & 14,38 & 3,34 & 1,08 \\
\hline 455,03 & 27,67 & 425,36 & 51,91 & 367,08 & 63,62 & 289,78 & 52,21 & 195,81 & 37,53 & 85,59 & 13,80 & 2,81 & 0,97 \\
\hline 454,65 & 28,08 & 424,40 & 52,46 & 365,56 & 63,51 & 287,85 & 51,95 & 193,53 & 37,16 & 83,05 & 13,20 & 2,32 & 0,88 \\
\hline 454,25 & 28,49 & 423,43 & 53,01 & 364,04 & 63,37 & 285,90 & 51,66 & 191,23 & 36,82 & 80,54 & 12,63 & 1,92 & 0,79 \\
\hline 453,85 & 28,93 & 422,42 & 53,53 & 362,53 & 63,25 & 283,94 & 51,35 & 188,95 & 36,49 & 78,01 & 12,04 & 1,57 & 0,71 \\
\hline 453,45 & 29,38 & 421,40 & 54,04 & 361,00 & 63,08 & 281,97 & 51,05 & 186,67 & 36,17 & 75,48 & 11,44 & 1,28 & 0,64 \\
\hline 453,04 & 29,84 & 420,36 & 54,56 & 359,48 & 62,92 & 280,01 & 50,76 & 184,35 & 35,83 & 72,94 & 10,85 & 1,04 & 0,58 \\
\hline 452,60 & 30,29 & 419,32 & 55,06 & 357,95 & 62,74 & 278,06 & 50,48 & 182,05 & 35,50 & 70,39 & 10,27 & 0,88 & 0,53 \\
\hline 452,15 & 30,77 & 418,25 & 55,56 & 356,38 & 62,50 & 276,10 & 50,19 & 179,72 & 35,15 & 67,86 & 9,70 & 0,75 & 0,49 \\
\hline 451,69 & 31,25 & 417,15 & 56,04 & 354,82 & 62,28 & 274,13 & 49,90 & 177,40 & 34,81 & 65,32 & 9,12 & 0,67 & 0,46 \\
\hline 451,20 & 31,72 & 416,04 & 56,49 & 353,24 & 62,06 & 272,17 & 49,62 & 175,09 & 34,47 & 62,75 & 8,54 & 0,64 & 0,45 \\
\hline 450,73 & 32,23 & 414,92 & 56,95 & 351,68 & 61,84 & 270,18 & 49,31 & 172,74 & 34,11 & 60,21 & 7,97 & 0,65 & 0,45 \\
\hline 450,23 & 32,73 & 413,78 & 57,41 & 350,09 & 61,59 & 268,21 & 49,03 & 170,39 & 33,76 & 57,67 & 7,40 & 0,69 & 0,46 \\
\hline 449,72 & 33,25 & 412,62 & 57,87 & 348,48 & 61,34 & 266,24 & 48,75 & 168,03 & 33,41 & 55,12 & 6,87 & 0,75 & 0,49 \\
\hline 449,19 & 33,75 & 411,42 & 58,28 & 346,86 & 61,09 & 264,26 & 48,47 & 165,66 & 33,05 & 52,55 & 6,33 & 0,78 & 0,49 \\
\hline 448,65 & 34,28 & 410,22 & 58,69 & 345,21 & 60,81 & 262,24 & 48,14 & 163,29 & 32,69 & 51,48 & 10,93 & 0,79 & 0,49 \\
\hline 448,11 & 34,83 & 409,00 & 59,11 & 343,58 & 60,57 & 260,25 & 47,87 & 160,91 & 32,32 & 48,93 & 10,35 & 0,76 & 0,48 \\
\hline 447,53 & 35,36 & 407,78 & 59,52 & 341,94 & 60,32 & 258,24 & 47,56 & 158,52 & 31,95 & 46,47 & 9,80 & 0,75 & 0,48 \\
\hline 446,95 & 35,91 & 406,52 & 59,90 & 340,29 & 60,09 & 256,22 & 47,24 & 156,14 & 31,67 & 44,07 & 9,30 & 0,74 & 0,48 \\
\hline 446,33 & 36,44 & 405,26 & 60,27 & 338,62 & 59,84 & 254,17 & 46,89 & 153,72 & 31,16 & 41,69 & 8,78 & 0,74 & 0,47 \\
\hline 445,71 & 36,99 & 403,99 & 60,63 & 336,94 & 59,58 & 252,13 & 46,54 & 151,33 & 30,91 & 39,38 & 8,33 & 0,75 & 0,48 \\
\hline 445,06 & 37,54 & 402,66 & 60,96 & 335,24 & 59,33 & 249,37 & 45,20 & 148,92 & 30,53 & 37,08 & 7,85 & 0,75 & 0,48 \\
\hline 444,41 & 38,12 & 401,35 & 61,30 & 333,55 & 59,07 & 247,29 & 44,82 & 146,50 & 30,16 & 34,89 & 7,35 & 0,75 & 0,47 \\
\hline 443,75 & 38,72 & 400,04 & 61,61 & 331,84 & 58,82 & 245,78 & 45,26 & 144,06 & 29,72 & 32,73 & 6,87 & 0,74 & 0,47 \\
\hline 443,08 & 39,32 & 398,70 & 61,91 & 330,11 & 58,55 & 243,13 & 44,10 & 141,61 & 29,30 & 30,65 & 6,44 & 0,74 & 0,46 \\
\hline 442,40 & 39,94 & 397,34 & 62,17 & 328,38 & 58,28 & 240,97 & 43,65 & 139,17 & 28,89 & 28,64 & 6,09 & 0,74 & 0,46 \\
\hline 441,67 & 40,53 & 395,97 & 62,41 & 326,65 & 58,03 & 238,89 & 43,31 & 136,70 & 28,37 & 26,69 & 5,71 & 0,74 & 0,46 \\
\hline 440,92 & 41,11 & 394,57 & 62,64 & 324,89 & 57,75 & 236,83 & 43,05 & 134,25 & 27,93 & 24,85 & 5,33 & 0,74 & 0,45 \\
\hline 440,20 & 41,70 & 393,19 & 62,87 & 323,13 & 57,49 & 234,71 & 42,65 & 131,79 & 27,51 & 23,08 & 4,96 & 0,73 & 0,44 \\
\hline 439,47 & 42,29 & 391,79 & 63,07 & 321,37 & 57,21 & 232,56 & 42,28 & 129,31 & 27,13 & 21,38 & 4,64 & 0,73 & 0,44 \\
\hline 438,74 & 42,88 & 390,36 & 63,24 & 319,59 & 56,93 & 230,50 & 42,07 & 125,78 & 22,13 & 19,73 & 4,33 & 0,31 & 0,14 \\
\hline 438,00 & 43,49 & 388,93 & 63,39 & 317,80 & 56,64 & 228,40 & 41,80 & 123,30 & 21,68 & 18,12 & 4,01 & 0,31 & 0,13 \\
\hline 437,24 & 44,06 & 387,53 & 63,53 & 316,01 & 56,37 & 226,25 & 41,48 & 121,83 & 25,79 & 16,56 & 3,69 & 0,31 & 0,13 \\
\hline 436,45 & 44,63 & 386,10 & 63,66 & 314,20 & 56,07 & 224,10 & 41,17 & 119,37 & 25,33 & 15,09 & 3,39 & 0,00 & 0,00 \\
\hline 435,69 & 45,19 & 384,67 & 63,75 & 312,37 & 55,75 & 221,95 & 40,87 & 116,86 & 24,83 & 13,75 & 3,11 & 0,00 & 0,00 \\
\hline 434,90 & 45,75 & 383,22 & 63,82 & 310,54 & 55,45 & 223,01 & 45,34 & 114,33 & 24,33 & 12,47 & 2,85 & 0,00 & 0,00 \\
\hline
\end{tabular}


Tabela A.7: Dados coletados pelo GPS - teste 07 do caminhão com massa 15,5 t

\begin{tabular}{|c|c|c|c|c|c|c|c|c|c|c|c|c|c|}
\hline \multicolumn{14}{|c|}{ Coordenadas locais } \\
\hline$\underline{x}$ & $\mathbf{y}$ & $\mathbf{x}$ & $\mathbf{y}$ & $\mathbf{x}$ & $\mathbf{y}$ & $\mathbf{x}$ & $\mathbf{y}$ & $\mathbf{x}$ & $\mathbf{y}$ & $\mathbf{x}$ & $\mathbf{y}$ & $\mathbf{x}$ & $\mathbf{y}$ \\
\hline 488,23 & 0,96 & 440,68 & 51,27 & 358,88 & 62,94 & 260,15 & 47,89 & 69,10 & 14,00 & 1,21 & 0,03 & 1,21 & 0,00 \\
\hline 487,41 & 2,08 & 439,20 & 52,15 & 356,86 & 62,66 & 240,59 & 43,19 & 66,33 & 13,39 & 1,21 & 0,03 & 1,21 & 0,00 \\
\hline 486,57 & 3,21 & 438,34 & 53,04 & 354,82 & 62,35 & 238,01 & 42,87 & 63,55 & 12,81 & 1,23 & 0,05 & 1,21 & 0,00 \\
\hline 485,73 & 4,35 & 436,80 & 53,88 & 352,78 & 62,04 & 183,46 & 35,36 & 60,79 & 12,18 & 1,28 & 0,08 & 1,21 & 0,00 \\
\hline 484,87 & 5,47 & 434,94 & 54,90 & 350,74 & 61,78 & 180,81 & 34,99 & 58,09 & 11,60 & 1,32 & 0,09 & 1,21 & 0,00 \\
\hline 484,00 & 6,60 & 433,48 & 55,08 & 348,69 & 61,52 & 178,14 & 34,61 & 55,49 & 11,04 & 1,31 & 0,10 & 1,20 & 0,00 \\
\hline 483,13 & 7,73 & 431,89 & 55,86 & 346,61 & 61,24 & 175,49 & 34,24 & 52,92 & 10,39 & 1,29 & 0,10 & 1,20 & 0,00 \\
\hline 482,25 & 8,87 & 430,27 & 56,60 & 344,54 & 60,94 & 172,83 & 33,86 & 50,29 & 9,85 & 1,27 & 0,11 & 1,20 & 0,00 \\
\hline 481,37 & 10,01 & 428,63 & 57,31 & 342,46 & 60,65 & 170,16 & 33,47 & 47,74 & 9,36 & 1,27 & 0,12 & 1,20 & 0,00 \\
\hline 480,48 & 11,14 & 426,98 & 57,98 & 340,38 & 60,35 & 167,47 & 33,07 & 45,21 & 8,85 & 1,27 & 0,13 & 1,20 & 0,00 \\
\hline 479,59 & 12,29 & 425,32 & 58,61 & 338,27 & 60,03 & 164,80 & 32,64 & 42,78 & 8,29 & 1,27 & 0,14 & 1,20 & 0,00 \\
\hline 478,69 & 13,43 & 423,62 & 59,24 & 336,18 & 59,73 & 162,11 & 32,22 & 40,42 & 7,75 & 1,26 & 0,15 & 1,20 & 0,00 \\
\hline 477,79 & 14,57 & 421,90 & 59,84 & 334,08 & 59,41 & 159,44 & 31,79 & 38,11 & 7,26 & 1,26 & 0,15 & 1,19 & 0,00 \\
\hline 476,89 & 15,72 & 420,14 & 60,39 & 331,97 & 59,08 & 156,74 & 31,34 & 35,85 & 6,79 & 1,26 & 0,16 & 1,20 & 0,00 \\
\hline 475,99 & 16,88 & 418,39 & 60,94 & 329,84 & 58,75 & 154,03 & 30,90 & 33,67 & 6,35 & 1,25 & 0,16 & & \\
\hline 475,07 & 18,03 & 416,65 & 61,45 & 327,71 & 58,41 & 151,34 & 30,46 & 31,56 & 5,94 & 1,25 & 0,17 & & \\
\hline 474,15 & 19,20 & 414,85 & 61,93 & 325,56 & 58,06 & 148,64 & 29,97 & 29,51 & 5,53 & 1,25 & 0,18 & & \\
\hline 473,23 & 20,37 & 413,04 & 62,39 & 323,41 & 57,70 & 145,93 & 29,50 & 27,53 & 5,13 & 1,24 & 0,19 & & \\
\hline 472,30 & 21,56 & 411,22 & 62,83 & 321,26 & 57,33 & 143,22 & 29,01 & 25,04 & 4,91 & 1,24 & 0,19 & & \\
\hline 471,34 & 22,75 & 409,40 & 63,22 & 319,09 & 56,97 & 140,49 & 28,53 & 23,18 & 4,54 & 1,24 & 0,20 & & \\
\hline 470,39 & 23,95 & 407,56 & 63,60 & 316,92 & 56,64 & 137,77 & 28,05 & 21,44 & 4,20 & 1,23 & 0,20 & & \\
\hline 469,43 & 25,16 & 405,69 & 63,95 & 314,72 & 56,22 & 135,04 & 27,82 & 19,82 & 3,86 & 1,23 & 0,21 & & \\
\hline 468,46 & 26,37 & 403,82 & 64,29 & 312,51 & 55,85 & 132,31 & 27,31 & 18,30 & 3,58 & 1,23 & 0,21 & & \\
\hline 467,48 & 27,59 & 401,94 & 64,58 & 310,31 & 55,55 & 129,59 & 26,81 & 16,83 & 3,26 & 1,22 & 0,22 & & \\
\hline 466,46 & 28,79 & 400,06 & 64,81 & 308,10 & 55,21 & 126,84 & 26,29 & 15,42 & 2,99 & 1,22 & 0,23 & & \\
\hline 465,45 & 30,00 & 398,14 & 65,00 & 305,86 & 54,88 & 124,08 & 25,75 & 14,02 & 2,75 & 1,22 & 0,23 & & \\
\hline 464,42 & 31,20 & 396,22 & 65,15 & 303,63 & 54,56 & 121,35 & 25,20 & 12,71 & 2,46 & 1,22 & 0,24 & & \\
\hline 463,36 & 32,42 & 394,29 & 65,25 & 301,38 & 54,23 & 118,61 & 24,64 & 11,50 & 2,22 & 1,21 & 0,24 & & \\
\hline 462,29 & 33,64 & 392,35 & 65,36 & 299,14 & 53,92 & 115,85 & 24,09 & 10,39 & 2,03 & 1,21 & 0,25 & & \\
\hline 461,18 & 34,84 & 390,41 & 65,41 & 296,87 & 53,59 & 113,10 & 23,54 & 9,36 & 1,78 & 1,21 & 0,26 & & \\
\hline 460,06 & 36,02 & 388,46 & 65,42 & 294,61 & 53,23 & 110,34 & 22,97 & 8,39 & 1,57 & 1,21 & 0,26 & & \\
\hline 458,95 & 37,17 & 386,48 & 65,43 & 292,33 & 52,86 & 107,59 & 22,42 & 7,48 & 1,39 & 1,21 & 0,27 & & \\
\hline 457,79 & 38,28 & 384,52 & 65,40 & 290,04 & 52,54 & 104,85 & 21,86 & 6,62 & 1,21 & 1,21 & 0,28 & & \\
\hline 456,60 & 39,37 & 382,58 & 65,34 & 287,75 & 52,20 & 102,10 & 21,28 & 5,81 & 1,04 & 1,23 & 0,00 & & \\
\hline 455,37 & 40,41 & 380,63 & 65,28 & 285,46 & 51,88 & 99,36 & 20,69 & 5,06 & 0,87 & 1,23 & 0,00 & & \\
\hline 454,16 & 41,49 & 378,67 & 65,17 & 283,16 & 51,54 & 96,60 & 20,10 & 4,38 & 0,72 & 1,22 & 0,00 & & \\
\hline 452,94 & 42,58 & 376,69 & 65,02 & 280,85 & 51,19 & 93,85 & 19,53 & 3,77 & 0,57 & 1,22 & 0,00 & & \\
\hline 451,68 & 43,62 & 374,70 & 64,87 & 278,52 & 50,85 & 91,09 & 18,96 & 3,24 & 0,45 & 1,22 & 0,00 & & \\
\hline 450,39 & 44,65 & 372,74 & 64,73 & 276,18 & 50,51 & 88,34 & 18,37 & 2,78 & 0,34 & 1,22 & 0,00 & & \\
\hline 449,08 & 45,66 & 370,81 & 64,55 & 273,85 & 50,17 & 85,59 & 17,77 & 2,38 & 0,25 & 1,22 & 0,00 & & \\
\hline 447,75 & 46,68 & 368,84 & 64,32 & 271,50 & 49,80 & 82,84 & 17,17 & 2,04 & 0,19 & 1,22 & 0,00 & & \\
\hline 446,40 & 47,64 & 366,87 & 64,07 & 269,12 & 49,48 & 80,09 & 16,55 & 1,77 & 0,13 & 1,22 & 0,00 & & \\
\hline 445,01 & 48,58 & 364,86 & 63,81 & 266,74 & 49,13 & 77,34 & 15,92 & 1,55 & 0,08 & 1,22 & 0,00 & & \\
\hline 443,58 & 49,49 & 362,86 & 63,54 & 264,38 & 48,74 & 74,59 & 15,27 & 1,39 & 0,04 & 1,22 & 0,00 & & \\
\hline 442,14 & 50,37 & 360,88 & 63,24 & 261,99 & 48,34 & 71,84 & 14,64 & 1,28 & 0,02 & 1,21 & 0,00 & & \\
\hline
\end{tabular}


Tabela A.8: Dados coletados pelo GPS - teste 08 do caminhão com massa $15,5 \mathrm{t}$

\begin{tabular}{|c|c|c|c|c|c|c|c|c|c|c|c|c|c|}
\hline \multicolumn{14}{|c|}{ Coordenadas locais } \\
\hline$\underline{x}$ & $\mathbf{y}$ & $\mathbf{x}$ & $\mathbf{y}$ & $\mathbf{x}$ & $\mathbf{y}$ & $\mathbf{x}$ & $\mathbf{y}$ & $\mathbf{x}$ & $\mathbf{y}$ & $\mathbf{x}$ & $\mathbf{y}$ & $\mathbf{x}$ & $\mathbf{y}$ \\
\hline 492,20 & 1,07 & 428,12 & 55,73 & 335,19 & 59,66 & 233,44 & 53,05 & 117,40 & 26,85 & 8,97 & 2,21 & 0,50 & 0,30 \\
\hline 491,24 & 2,43 & 426,35 & 56,60 & 332,94 & 59,24 & 230,84 & 52,66 & 114,59 & 26,25 & 7,94 & 2,00 & 0,50 & 0,30 \\
\hline 490,26 & 3,81 & 424,57 & 57,43 & 330,70 & 58,81 & 228,23 & 52,26 & 111,79 & 25,67 & 6,97 & 1,75 & 0,50 & 0,30 \\
\hline 489,30 & 5,20 & 422,78 & 58,22 & 328,45 & 58,41 & 225,61 & 51,85 & 108,97 & 25,11 & 6,06 & 1,53 & 0,50 & 0,30 \\
\hline 488,31 & 6,58 & 420,96 & 58,95 & 326,20 & 58,01 & 222,98 & 51,45 & 106,16 & 24,52 & 5,25 & 1,34 & 0,50 & 0,30 \\
\hline 487,33 & 7,98 & 419,14 & 59,66 & 323,93 & 57,60 & 220,36 & 51,03 & 103,35 & 23,92 & 4,49 & 1,17 & 0,50 & 0,30 \\
\hline 486,33 & 9,39 & 417,28 & 60,29 & 325,70 & 77,88 & 217,72 & 50,62 & 100,53 & 23,35 & 3,81 & 1,03 & 0,73 & 0,00 \\
\hline 485,31 & 10,80 & 414,08 & 58,65 & 323,43 & 77,50 & 215,09 & 50,19 & 97,71 & 22,77 & 3,20 & 0,89 & 0,74 & 0,00 \\
\hline 484,29 & 12,21 & 412,21 & 59,25 & 321,13 & 77,09 & 212,43 & 49,74 & 94,91 & 22,15 & 2,65 & 0,78 & 0,74 & 0,00 \\
\hline 483,24 & 13,62 & 410,32 & 59,86 & 318,82 & 76,66 & 209,77 & 49,33 & 92,11 & 21,52 & 2,16 & 0,67 & 0,74 & 0,00 \\
\hline 482,17 & 15,02 & 408,44 & 60,44 & 316,51 & 76,23 & 207,12 & 48,89 & 89,30 & 20,89 & 1,72 & 0,57 & 0,74 & 0,00 \\
\hline 481,09 & 16,43 & 406,52 & 60,96 & 314,20 & 75,81 & 204,45 & 48,47 & 86,49 & 20,27 & 1,35 & 0,49 & 0,74 & 0,00 \\
\hline 480,00 & 17,83 & 404,58 & 61,47 & 311,88 & 75,40 & 201,77 & 48,07 & 83,68 & 19,63 & 1,04 & 0,43 & 0,74 & 0,00 \\
\hline 478,89 & 19,24 & 402,67 & 61,98 & 309,56 & 74,97 & 199,08 & 47,64 & 80,86 & 18,97 & 0,78 & 0,37 & 0,74 & 0,00 \\
\hline 477,77 & 20,64 & 400,73 & 62,43 & 307,21 & 74,55 & 196,38 & 47,25 & 78,04 & 18,35 & 0,60 & 0,34 & 0,73 & 0,00 \\
\hline 476,62 & 22,04 & 398,76 & 62,82 & 304,86 & 74,15 & 193,68 & 46,83 & 75,24 & 17,69 & 0,46 & 0,30 & 0,73 & 0,00 \\
\hline 475,47 & 23,43 & 396,75 & 63,19 & 302,50 & 73,75 & 190,98 & 46,42 & 72,41 & 17,12 & 0,38 & 0,27 & 0,73 & 0,00 \\
\hline 474,29 & 24,83 & 394,75 & 63,54 & 300,15 & 73,32 & 188,26 & 46,03 & 69,56 & 16,55 & 0,35 & 0,25 & 0,73 & 0,00 \\
\hline 473,08 & 26,22 & 392,75 & 63,83 & 297,78 & 72,93 & 185,55 & 45,62 & 66,73 & 15,94 & 0,38 & 0,26 & 0,73 & 0,00 \\
\hline 471,86 & 27,60 & 390,73 & 64,08 & 295,39 & 72,54 & 182,83 & 45,22 & 63,96 & 15,40 & 0,42 & 0,27 & 0,73 & 0,00 \\
\hline 470,62 & 28,98 & 388,69 & 64,30 & 292,99 & 72,17 & 180,09 & 44,82 & 61,29 & 14,82 & 0,48 & 0,29 & 0,73 & 0,00 \\
\hline 469,34 & 30,32 & 386,65 & 64,45 & 290,58 & 71,81 & 177,36 & 44,41 & 58,68 & 14,17 & 0,50 & 0,29 & 0,73 & 0,00 \\
\hline 468,07 & 31,68 & 384,58 & 64,61 & 288,16 & 71,48 & 174,63 & 44,00 & 56,00 & 13,61 & 0,48 & 0,29 & 0,73 & 0,00 \\
\hline 466,78 & 33,02 & 382,51 & 64,70 & 285,73 & 71,08 & 171,89 & 43,59 & 53,37 & 13,08 & 0,47 & 0,28 & 0,73 & 0,00 \\
\hline 465,48 & 34,35 & 380,44 & 64,75 & 283,30 & 70,73 & 169,16 & 43,14 & 50,78 & 12,55 & 0,47 & 0,29 & 0,73 & 0,00 \\
\hline 464,14 & 35,65 & 378,35 & 64,81 & 280,86 & 70,38 & 166,44 & 42,68 & 48,26 & 12,04 & 0,47 & 0,29 & 0,73 & 0,00 \\
\hline 462,79 & 36,95 & 376,24 & 64,80 & 278,41 & 70,04 & 163,71 & 42,22 & 45,80 & 11,53 & 0,48 & 0,29 & 0,72 & 0,00 \\
\hline 461,41 & 38,22 & 374,15 & 64,80 & 275,94 & 69,70 & 160,95 & 41,77 & 43,42 & 11,00 & 0,48 & 0,30 & 0,73 & 0,00 \\
\hline 460,03 & 39,49 & 372,04 & 64,76 & 273,47 & 69,38 & 158,21 & 41,31 & 41,10 & 10,51 & 0,48 & 0,30 & 0,72 & 0,00 \\
\hline 458,61 & 40,73 & 369,93 & 64,66 & 270,98 & 69,04 & 155,45 & 40,83 & 38,86 & 10,00 & 0,48 & 0,30 & 0,72 & 0,00 \\
\hline 457,18 & 41,95 & 367,76 & 64,17 & 268,50 & 68,73 & 152,68 & 40,36 & 36,68 & 9,60 & 0,48 & 0,30 & & \\
\hline 450,70 & 40,92 & 365,62 & 64,05 & 266,00 & 68,42 & 149,91 & 39,89 & 34,55 & 9,16 & 0,48 & 0,30 & & \\
\hline 454,24 & 44,31 & 363,49 & 63,92 & 263,48 & 68,15 & 147,14 & 39,41 & 32,49 & 8,72 & 0,48 & 0,31 & & \\
\hline 447,70 & 43,26 & 361,35 & 63,76 & 260,96 & 67,86 & 144,36 & 38,92 & 30,46 & 8,31 & 0,49 & 0,30 & & \\
\hline 446,19 & 44,43 & 359,20 & 63,53 & 258,46 & 67,46 & 141,58 & 38,46 & 28,52 & 7,85 & 0,49 & 0,31 & & \\
\hline 449,75 & 47,82 & 357,05 & 63,29 & 255,95 & 67,05 & 138,81 & 37,89 & 26,69 & 7,50 & 0,49 & 0,30 & & \\
\hline 443,13 & 46,71 & 354,87 & 63,01 & 256,48 & 56,67 & 136,03 & 37,38 & 21,29 & 4,89 & 0,49 & 0,30 & & \\
\hline 441,53 & 47,81 & 352,71 & 62,74 & 253,95 & 56,28 & 133,27 & 36,86 & 19,69 & 4,54 & 0,49 & 0,30 & & \\
\hline 439,93 & 48,88 & 350,54 & 62,40 & 251,41 & 55,88 & 130,49 & 36,32 & 18,14 & 4,24 & 0,49 & 0,30 & & \\
\hline 438,29 & 49,90 & 348,37 & 62,06 & 248,87 & 55,48 & 127,71 & 35,77 & 16,62 & 3,92 & 0,49 & 0,30 & & \\
\hline 436,65 & 50,95 & 346,19 & 61,71 & 246,33 & 55,08 & 124,89 & 35,22 & 15,14 & 3,55 & 0,49 & 0,30 & & \\
\hline 434,99 & 51,96 & 344,01 & 61,32 & 243,76 & 54,67 & 128,63 & 29,11 & 13,72 & 3,25 & 0,49 & 0,31 & & \\
\hline 433,29 & 52,93 & 341,82 & 60,93 & 241,19 & 54,27 & 125,84 & 28,55 & 12,37 & 2,94 & 0,50 & 0,30 & & \\
\hline 431,58 & 53,90 & 339,62 & 60,51 & 238,61 & 53,86 & 123,03 & 27,98 & 11,15 & 2,67 & 0,50 & 0,30 & & \\
\hline 429,86 & 54,83 & 337,41 & 60,09 & 236,02 & 53,47 & 120,21 & 27,42 & 10,02 & 2,43 & 0,50 & 0,30 & & \\
\hline
\end{tabular}


Tabela A.9: Dados coletados pelo GPS - teste 01 do caminhão com massa 23,29 t

\begin{tabular}{|c|c|c|c|c|c|c|c|c|c|c|c|c|c|}
\hline \multicolumn{14}{|c|}{ Coordenadas locais } \\
\hline$\underline{x}$ & $\mathbf{y}$ & $\mathbf{x}$ & $\mathbf{y}$ & $\mathbf{x}$ & $\mathbf{y}$ & $\mathbf{x}$ & $\mathbf{y}$ & $\mathbf{x}$ & $\mathbf{y}$ & $\mathbf{x}$ & $\mathbf{y}$ & $\mathbf{x}$ & $\mathbf{y}$ \\
\hline 353,52 & 56,78 & 329,13 & 55,45 & 290,69 & 50,05 & 245,01 & 39,85 & 5,34 & 1,68 & 2,30 & 1,34 & 7,01 & 0,01 \\
\hline 353,15 & 56,78 & 328,40 & 55,38 & 289,69 & 49,91 & 243,85 & 39,70 & 4,82 & 1,58 & 2,28 & 1,35 & 7,04 & 0,00 \\
\hline 352,78 & 56,78 & 327,63 & 55,53 & 288,69 & 49,75 & 240,16 & 39,35 & 4,34 & 1,51 & 2,27 & 1,36 & 7,04 & 0,00 \\
\hline 352,38 & 56,77 & 326,89 & 55,44 & 287,69 & 49,58 & 239,04 & 39,16 & 3,92 & 1,44 & 2,26 & 1,37 & 7,05 & 0,00 \\
\hline 351,96 & 56,78 & 326,16 & 55,36 & 286,68 & 49,43 & 121,72 & 22,85 & 3,59 & 1,36 & 2,26 & 1,37 & 7,05 & 0,00 \\
\hline 351,55 & 56,79 & 325,44 & 55,08 & 285,65 & 49,28 & 120,55 & 22,65 & 3,26 & 1,29 & 2,25 & 1,37 & 7,06 & 0,00 \\
\hline 351,13 & 56,80 & 324,66 & 55,16 & 284,64 & 49,13 & 119,36 & 22,45 & 2,99 & 1,24 & 2,25 & 1,38 & 7,06 & 0,00 \\
\hline 350,70 & 56,80 & 323,92 & 55,06 & 283,60 & 48,96 & 118,20 & 22,26 & 2,76 & 1,20 & 2,25 & 1,38 & 7,07 & 0,00 \\
\hline 350,27 & 56,78 & 323,16 & 54,97 & 282,58 & 48,81 & 117,00 & 22,05 & 2,64 & 1,16 & 2,25 & 1,38 & 7,07 & 0,00 \\
\hline 349,84 & 56,79 & 322,41 & 54,88 & 281,54 & 48,64 & 47,26 & 10,57 & 2,50 & 1,14 & 2,24 & 1,39 & 7,08 & 0,00 \\
\hline 349,40 & 56,79 & 321,64 & 54,77 & 280,48 & 48,49 & 45,96 & 10,31 & 2,44 & 1,12 & 2,24 & 1,40 & 7,08 & 0,00 \\
\hline 348,96 & 56,77 & 320,90 & 54,66 & 279,43 & 48,32 & 44,67 & 10,03 & 2,42 & 1,11 & 2,23 & 1,40 & 7,08 & 0,00 \\
\hline 348,52 & 56,76 & 320,12 & 54,55 & 278,38 & 48,15 & 43,40 & 9,73 & 2,44 & 1,12 & 2,23 & 1,41 & 7,09 & 0,00 \\
\hline 348,07 & 56,74 & 319,33 & 54,44 & 277,31 & 48,00 & 42,07 & 9,45 & 2,47 & 1,14 & 2,24 & 1,41 & 7,08 & 0,00 \\
\hline 347,61 & 56,75 & 318,54 & 54,33 & 276,25 & 47,84 & 40,82 & 9,12 & 2,51 & 1,16 & 2,24 & 1,42 & 7,08 & 0,00 \\
\hline 347,16 & 56,73 & 317,78 & 54,19 & 275,17 & 47,68 & 39,51 & 8,83 & 2,52 & 1,17 & 2,24 & 1,42 & 7,08 & 0,00 \\
\hline 346,71 & 56,73 & 316,96 & 54,08 & 274,10 & 47,50 & 38,20 & 8,54 & 2,50 & 1,18 & 2,25 & 1,42 & 7,08 & 0,00 \\
\hline 346,25 & 56,71 & 316,16 & 53,96 & 273,03 & 47,35 & 36,91 & 8,23 & 2,47 & 1,18 & 2,25 & 1,43 & 7,08 & 0,00 \\
\hline 345,74 & 56,72 & 315,36 & 53,82 & 271,96 & 47,17 & 35,59 & 7,94 & 2,45 & 1,18 & 2,24 & 1,44 & 7,08 & 0,00 \\
\hline 345,25 & 56,70 & 314,53 & 53,71 & 270,87 & 47,02 & 34,25 & 7,65 & 2,44 & 1,19 & 2,22 & 1,46 & 7,07 & 0,00 \\
\hline 344,74 & 56,68 & 313,71 & 53,57 & 269,77 & 46,87 & 32,94 & 7,35 & 2,44 & 1,19 & 2,22 & 1,47 & 7,07 & 0,00 \\
\hline 344,24 & 56,66 & 312,87 & 53,43 & 268,69 & 46,69 & 31,60 & 7,07 & 2,44 & 1,20 & 2,22 & 1,47 & 7,06 & 0,00 \\
\hline 343,72 & 56,63 & 312,04 & 53,29 & 267,59 & 46,50 & 30,26 & 6,78 & 2,43 & 1,20 & 2,23 & 1,47 & 7,06 & 0,00 \\
\hline 343,19 & 56,61 & 311,20 & 53,16 & 266,49 & 46,34 & 28,93 & 6,49 & 2,43 & 1,21 & 2,22 & 1,48 & 7,06 & 0,00 \\
\hline 342,64 & 56,58 & 310,34 & 53,02 & 265,40 & 46,16 & 27,55 & 6,22 & 2,41 & 1,21 & 2,22 & 1,49 & 7,05 & 0,00 \\
\hline 342,09 & 56,55 & 309,48 & 52,87 & 264,30 & 46,00 & 26,21 & 5,90 & 2,41 & 1,21 & 2,22 & 1,49 & 7,04 & 0,00 \\
\hline 341,53 & 56,52 & 308,60 & 52,74 & 263,18 & 45,84 & 24,84 & 5,63 & 2,41 & 1,22 & 2,23 & 1,49 & 7,03 & 0,00 \\
\hline 340,98 & 56,50 & 307,73 & 52,60 & 262,06 & 45,68 & 23,53 & 5,34 & 2,40 & 1,22 & 2,22 & 1,50 & 7,02 & 0,00 \\
\hline 340,39 & 56,48 & 306,85 & 52,46 & 260,97 & 45,50 & 22,23 & 5,09 & 2,39 & 1,23 & 2,22 & 1,51 & 7,02 & 0,00 \\
\hline 339,79 & 56,43 & 305,96 & 52,32 & 259,85 & 45,33 & 20,96 & 4,86 & 2,38 & 1,24 & 2,21 & 1,52 & 7,02 & 0,00 \\
\hline 339,20 & 56,39 & 305,05 & 52,18 & 258,73 & 45,14 & 19,72 & 4,57 & 2,37 & 1,24 & 2,20 & 1,53 & & \\
\hline 338,61 & 56,34 & 304,16 & 52,03 & 261,14 & 42,16 & 18,51 & 4,25 & 2,36 & 1,25 & 2,20 & 1,54 & & \\
\hline 337,99 & 56,29 & 303,24 & 51,90 & 260,00 & 42,00 & 17,24 & 4,03 & 2,36 & 1,26 & 2,20 & 1,54 & & \\
\hline 337,36 & 56,25 & 302,30 & 51,78 & 258,88 & 41,82 & 15,99 & 3,80 & 2,35 & 1,26 & 2,19 & 1,55 & & \\
\hline 336,72 & 56,20 & 301,38 & 51,63 & 254,16 & 44,50 & 14,85 & 3,56 & 2,34 & 1,27 & 2,18 & 1,56 & & \\
\hline 336,07 & 56,14 & 300,44 & 51,48 & 253,04 & 44,32 & 13,76 & 3,35 & 2,34 & 1,28 & 2,17 & 1,57 & & \\
\hline 335,42 & 56,09 & 299,48 & 51,36 & 251,92 & 44,13 & 12,69 & 3,15 & 2,33 & 1,29 & 2,16 & 1,57 & & \\
\hline 334,75 & 56,03 & 298,52 & 51,20 & 250,79 & 43,95 & 11,65 & 2,95 & 2,33 & 1,29 & 2,15 & 1,58 & & \\
\hline 334,07 & 55,97 & 297,54 & 51,09 & 249,70 & 43,73 & 10,68 & 2,76 & 2,33 & 1,30 & 2,15 & 1,59 & & \\
\hline 333,39 & 55,92 & 296,58 & 50,92 & 248,55 & 43,55 & 9,73 & 2,60 & 2,32 & 1,31 & 6,88 & 0,02 & & \\
\hline 332,69 & 55,84 & 295,59 & 50,79 & 247,43 & 43,34 & 8,85 & 2,41 & 2,32 & 1,31 & 6,88 & 0,02 & & \\
\hline 331,98 & 55,78 & 294,62 & 50,65 & 249,72 & 40,45 & 8,01 & 2,23 & 2,32 & 1,32 & 6,91 & 0,02 & & \\
\hline 331,28 & 55,70 & 293,65 & 50,49 & 248,55 & 40,25 & 7,27 & 2,06 & 2,30 & 1,33 & 6,95 & 0,01 & & \\
\hline 330,57 & 55,63 & 292,65 & 50,37 & 247,37 & 40,13 & 6,57 & 1,93 & 2,30 & 1,34 & 6,97 & 0,01 & & \\
\hline 329,86 & 55,54 & 291,67 & 50,20 & 246,20 & 39,99 & 5,89 & 1,81 & 2,30 & 1,34 & 6,99 & 0,01 & & \\
\hline
\end{tabular}


Tabela A.10: Dados coletados pelo GPS - teste 02 do caminhão com massa 23,29 t

\begin{tabular}{|c|c|c|c|c|c|c|c|c|c|c|c|c|c|}
\hline \multicolumn{14}{|c|}{ Coordenadas locais } \\
\hline$\underline{x}$ & $\mathbf{y}$ & $\mathbf{x}$ & $\mathbf{y}$ & $\mathbf{x}$ & $\mathbf{y}$ & $\mathbf{x}$ & $\mathbf{y}$ & $\mathbf{x}$ & $\mathbf{y}$ & $\mathbf{x}$ & $\mathbf{y}$ & $\mathbf{x}$ & $\mathbf{y}$ \\
\hline 301,37 & 55,65 & 288,21 & 53,89 & 258,31 & 49,35 & 211,71 & 42,26 & 150,43 & 31,06 & 86,81 & 21,97 & 18,51 & 6,77 \\
\hline 301,32 & 55,64 & 287,75 & 53,82 & 257,47 & 49,20 & 210,48 & 42,06 & 149,01 & 30,78 & 85,34 & 21,67 & 17,09 & 6,48 \\
\hline 301,26 & 55,64 & 287,27 & 53,75 & 256,61 & 49,07 & 209,27 & 41,86 & 147,60 & 30,51 & 83,88 & 21,40 & 15,71 & 6,22 \\
\hline 301,18 & 55,63 & 286,79 & 53,67 & 255,75 & 48,94 & 207,99 & 41,56 & 146,19 & 30,25 & 82,41 & 21,10 & 14,43 & 5,94 \\
\hline 301,09 & 55,62 & 286,28 & 53,60 & 254,89 & 48,80 & 206,78 & 41,19 & 144,79 & 29,98 & 80,94 & 20,81 & 13,20 & 5,69 \\
\hline 300,98 & 55,61 & 285,76 & 53,52 & 254,01 & 48,67 & 205,54 & 40,98 & 143,39 & 29,72 & 79,47 & 20,51 & 12,03 & 5,46 \\
\hline 300,86 & 55,58 & 285,24 & 53,46 & 253,13 & 48,55 & 204,30 & 40,78 & 142,00 & 29,46 & 77,99 & 20,19 & 10,92 & 5,25 \\
\hline 300,72 & 55,59 & 284,72 & 53,39 & 252,23 & 48,44 & 203,07 & 40,56 & 140,61 & 29,22 & 76,52 & 19,88 & 9,86 & 5,04 \\
\hline 300,59 & 55,59 & 284,18 & 53,30 & 251,33 & 48,33 & 201,82 & 40,32 & 139,23 & 28,97 & 75,04 & 19,57 & 8,85 & 4,84 \\
\hline 300,42 & 55,57 & 283,63 & 53,21 & 250,40 & 48,15 & 200,56 & 40,10 & 138,00 & 30,21 & 73,57 & 19,25 & 7,91 & 4,65 \\
\hline 300,24 & 55,57 & 283,07 & 53,12 & 249,49 & 48,01 & 199,31 & 39,86 & 136,62 & 29,99 & 72,07 & 18,94 & 7,06 & 4,48 \\
\hline 300,06 & 55,55 & 282,50 & 53,04 & 248,56 & 47,90 & 198,03 & 39,65 & 135,23 & 29,78 & 70,58 & 18,60 & 6,27 & 4,34 \\
\hline 299,87 & 55,53 & 281,92 & 52,92 & 247,60 & 47,77 & 196,76 & 39,42 & 133,87 & 29,58 & 69,09 & 18,28 & 5,52 & 4,21 \\
\hline 299,67 & 55,50 & 281,35 & 52,84 & 246,67 & 47,63 & 194,12 & 39,22 & 132,49 & 29,38 & 67,59 & 17,94 & 4,83 & 4,07 \\
\hline 299,47 & 55,46 & 280,74 & 52,74 & 245,71 & 47,51 & 192,82 & 39,00 & 131,13 & 29,20 & 66,11 & 17,59 & 4,21 & 3,96 \\
\hline 299,25 & 55,43 & 280,13 & 52,63 & 244,72 & 47,36 & 191,53 & 38,74 & 129,75 & 28,99 & 64,61 & 17,25 & 3,64 & 3,86 \\
\hline 299,02 & 55,40 & 279,50 & 52,54 & 243,75 & 47,23 & 190,21 & 38,50 & 128,37 & 28,79 & 63,11 & 16,90 & 3,12 & 3,78 \\
\hline 298,77 & 55,36 & 278,88 & 52,44 & 242,76 & 47,08 & 188,91 & 38,25 & 126,99 & 28,60 & 61,59 & 16,54 & 2,64 & 3,68 \\
\hline 298,50 & 55,33 & 278,23 & 52,32 & 241,78 & 46,95 & 187,59 & 38,00 & 125,59 & 28,39 & 60,08 & 16,18 & 2,21 & 3,58 \\
\hline 298,24 & 55,31 & 277,57 & 52,19 & 240,76 & 46,79 & 186,26 & 37,76 & 124,19 & 28,19 & 58,57 & 15,83 & 1,83 & 3,53 \\
\hline 297,95 & 55,27 & 276,91 & 52,05 & 239,75 & 46,65 & 184,93 & 37,52 & 122,80 & 27,99 & 57,05 & 15,46 & 1,50 & 3,47 \\
\hline 297,67 & 55,24 & 276,24 & 51,95 & 238,73 & 46,50 & 183,60 & 37,27 & 121,40 & 27,78 & 55,53 & 15,10 & 1,22 & 3,42 \\
\hline 297,38 & 55,19 & 275,56 & 51,80 & 237,69 & 46,34 & 182,27 & 37,02 & 119,99 & 27,54 & 54,00 & 14,74 & 0,99 & 3,36 \\
\hline 297,08 & 55,15 & 274,87 & 51,66 & 236,64 & 46,19 & 180,93 & 36,77 & 118,60 & 27,35 & 52,48 & 14,37 & 0,80 & 3,30 \\
\hline 296,77 & 55,11 & 274,18 & 51,53 & 235,58 & 46,05 & 179,58 & 36,53 & 117,20 & 27,08 & 51,20 & 13,88 & 0,67 & 3,27 \\
\hline 296,44 & 55,06 & 273,48 & 51,45 & 234,52 & 45,89 & 178,23 & 36,27 & 115,78 & 26,85 & 49,67 & 13,51 & 0,57 & 3,25 \\
\hline 296,10 & 55,04 & 272,78 & 51,31 & 233,45 & 45,73 & 176,88 & 36,01 & 114,39 & 26,64 & 48,16 & 13,15 & 0,52 & 3,24 \\
\hline 295,75 & 54,99 & 272,08 & 51,27 & 232,37 & 45,57 & 175,52 & 35,76 & 113,00 & 26,42 & 46,60 & 12,79 & 0,50 & 3,24 \\
\hline 295,39 & 54,95 & 271,37 & 51,18 & 231,28 & 45,39 & 174,15 & 35,51 & 111,56 & 26,21 & 45,06 & 12,42 & 0,52 & 3,25 \\
\hline 295,02 & 54,91 & 270,67 & 51,13 & 230,19 & 45,23 & 172,79 & 35,26 & 109,93 & 26,05 & 43,50 & 12,07 & 0,57 & 3,25 \\
\hline 294,62 & 54,86 & 269,95 & 51,05 & 229,10 & 45,06 & 171,42 & 35,00 & 108,51 & 25,81 & 41,94 & 11,72 & 0,61 & 3,26 \\
\hline 294,23 & 54,80 & 269,23 & 50,95 & 227,99 & 44,91 & 170,04 & 34,76 & 107,08 & 25,58 & 40,39 & 11,36 & 0,62 & 3,27 \\
\hline 293,84 & 54,73 & 268,50 & 50,84 & 226,87 & 44,75 & 168,67 & 34,49 & 105,64 & 25,33 & 38,84 & 11,03 & 0,61 & 3,27 \\
\hline 293,43 & 54,67 & 267,76 & 50,72 & 225,73 & 44,58 & 167,29 & 34,24 & 104,21 & 25,11 & 37,27 & 10,67 & 0,60 & 3,27 \\
\hline 293,03 & 54,62 & 267,03 & 50,60 & 224,61 & 44,39 & 165,89 & 33,98 & 102,78 & 24,87 & 35,69 & 10,32 & 0,59 & 3,26 \\
\hline 292,63 & 54,57 & 266,28 & 50,51 & 223,47 & 44,21 & 164,51 & 33,72 & 101,33 & 24,61 & 34,14 & 9,97 & 0,57 & 3,26 \\
\hline 292,19 & 54,49 & 265,51 & 50,41 & 222,30 & 44,00 & 163,11 & 33,46 & 99,90 & 24,37 & 32,54 & 9,62 & 0,58 & 3,26 \\
\hline 291,78 & 54,43 & 264,75 & 50,29 & 221,16 & 43,81 & 161,72 & 33,21 & 98,45 & 24,12 & 30,97 & 9,28 & 0,58 & 3,26 \\
\hline 291,36 & 54,38 & 263,96 & 50,17 & 219,98 & 43,59 & 160,31 & 32,93 & 97,01 & 23,86 & 29,36 & 8,92 & 0,58 & 3,26 \\
\hline 290,91 & 54,29 & 263,18 & 50,07 & 218,82 & 43,45 & 158,91 & 32,66 & 95,55 & 23,62 & 27,50 & 8,73 & 0,57 & 3,26 \\
\hline 290,47 & 54,24 & 262,40 & 49,96 & 217,65 & 43,32 & 157,51 & 32,40 & 94,10 & 23,35 & 25,95 & 8,34 & 0,57 & 3,26 \\
\hline 290,03 & 54,17 & 261,59 & 49,83 & 216,47 & 43,14 & 156,10 & 32,13 & 92,64 & 23,09 & 24,44 & 8,05 & 0,57 & 3,26 \\
\hline 289,58 & 54,10 & 260,79 & 49,71 & 215,29 & 43,04 & 154,68 & 31,86 & 91,19 & 22,81 & 22,96 & 7,71 & 0,57 & 3,26 \\
\hline 289,13 & 54,03 & 259,96 & 49,56 & 214,06 & 42,79 & 153,26 & 31,60 & 89,73 & 22,54 & 21,48 & 7,36 & 0,57 & 3,26 \\
\hline 288,67 & 53,95 & 259,14 & 49,44 & 212,89 & 42,67 & 151,85 & 31,32 & 88,26 & 22,25 & 20,00 & 7,07 & 0,57 & 3,26 \\
\hline
\end{tabular}


Tabela A.11: Dados coletados pelo GPS - teste 03 do caminhão com massa 23,29 t

\begin{tabular}{|c|c|c|c|c|c|c|c|c|c|c|c|c|c|}
\hline \multicolumn{14}{|c|}{ Coordenadas locais } \\
\hline $\mathbf{x}$ & $\mathbf{y}$ & $\mathbf{x}$ & $\mathbf{y}$ & $\mathbf{x}$ & $\mathbf{y}$ & $\mathbf{x}$ & $\mathbf{y}$ & $\mathbf{x}$ & $\mathbf{y}$ & $\mathbf{x}$ & $\mathbf{y}$ & $\mathbf{x}$ & $y$ \\
\hline 297,92 & 53,11 & 259,14 & 47,00 & 204,80 & 38,97 & 137,48 & 28,73 & 60,67 & 12,10 & 0,40 & 2,67 & 0,00 & 1,56 \\
\hline 297,21 & 53,01 & 258,07 & 46,88 & 203,44 & 38,77 & 135,86 & 28,48 & 58,95 & 11,63 & 0,24 & 2,64 & 0,00 & 1,49 \\
\hline 296,50 & 52,90 & 257,01 & 46,71 & 202,09 & 38,55 & 134,25 & 28,21 & 57,23 & 11,15 & 0,11 & 2,63 & 0,00 & 1,44 \\
\hline 295,79 & 52,78 & 255,92 & 46,56 & 200,71 & 38,36 & 132,61 & 27,95 & 55,49 & 10,67 & 0,03 & 2,61 & 0,00 & 1,40 \\
\hline 295,09 & 52,64 & 254,83 & 46,42 & 199,32 & 38,17 & 130,98 & 27,68 & 53,77 & 10,17 & 0,00 & 2,59 & 0,00 & 1,39 \\
\hline 294,35 & 52,53 & 253,74 & 46,24 & 197,93 & 37,97 & 129,33 & 27,43 & 52,03 & 9,66 & 0,00 & 2,58 & 0,00 & 1,37 \\
\hline 293,62 & 52,41 & 252,62 & 46,10 & 196,55 & 37,74 & 127,69 & 27,17 & 50,28 & 9,15 & 0,00 & 2,59 & 0,00 & 1,34 \\
\hline 292,87 & 52,31 & 251,51 & 45,92 & 195,15 & 37,53 & 126,04 & 26,90 & 48,55 & 8,64 & 0,03 & 2,61 & 0,00 & 1,34 \\
\hline 292,15 & 52,18 & 250,39 & 45,78 & 193,72 & 37,34 & 124,38 & 26,66 & 46,83 & 8,10 & 0,07 & 2,61 & 0,00 & 1,31 \\
\hline 291,42 & 52,04 & 249,26 & 45,59 & 192,32 & 37,11 & 122,75 & 26,37 & 45,08 & 7,59 & 0,06 & 2,63 & 0,00 & 1,28 \\
\hline 290,66 & 51,92 & 248,12 & 45,44 & 190,87 & 36,94 & 121,09 & 26,11 & 43,34 & 7,07 & 0,05 & 2,63 & 0,00 & 1,25 \\
\hline 289,90 & 51,80 & 246,98 & 45,27 & 189,43 & 36,74 & 119,43 & 25,81 & 41,60 & 6,57 & 0,03 & 2,62 & 0,00 & 1,24 \\
\hline 289,13 & 51,70 & 245,84 & 45,07 & 188,00 & 36,51 & 117,79 & 25,57 & 39,84 & 6,07 & 0,03 & 2,62 & 0,00 & 1,20 \\
\hline 288,38 & 51,54 & 244,69 & 44,92 & 186,55 & 36,31 & 116,10 & 25,33 & 38,06 & 5,55 & 0,02 & 2,62 & 0,00 & 1,18 \\
\hline 287,60 & 51,40 & 243,53 & 44,74 & 185,12 & 36,05 & 114,44 & 24,99 & 36,34 & 5,02 & 0,02 & 2,63 & 0,00 & 1,17 \\
\hline 286,81 & 51,28 & 242,38 & 44,57 & 183,67 & 35,82 & 112,70 & 24,80 & 34,63 & 4,45 & 0,05 & 2,62 & 0,00 & 1,13 \\
\hline 285,99 & 51,17 & 241,21 & 44,41 & 182,20 & 35,60 & 111,06 & 24,49 & 32,95 & 3,99 & 0,05 & 2,63 & 0,00 & 1,09 \\
\hline 285,21 & 51,03 & 240,05 & 44,21 & 180,72 & 35,36 & 109,26 & 24,36 & 31,23 & 3,62 & 0,04 & 2,63 & 0,00 & 1,05 \\
\hline 284,40 & 50,87 & 238,87 & 44,05 & 179,25 & 35,13 & 107,62 & 24,01 & 29,52 & 3,25 & 0,04 & 2,63 & 0,00 & 1,00 \\
\hline 283,58 & 50,73 & 237,71 & 43,84 & 177,76 & 34,91 & 105,96 & 23,65 & 27,83 & 2,82 & 0,04 & 2,64 & 0,00 & 0,98 \\
\hline 282,74 & 50,63 & 236,53 & 43,65 & 176,26 & 34,68 & 104,31 & 23,30 & 26,16 & 2,35 & 0,03 & 2,64 & 0,00 & 0,98 \\
\hline 281,91 & 50,48 & 235,33 & 43,50 & 174,76 & 34,46 & 102,65 & 22,97 & 24,55 & 1,93 & 0,03 & 2,65 & 0,00 & 0,94 \\
\hline 281,05 & 50,35 & 234,11 & 43,34 & 173,26 & 34,22 & 100,99 & 22,60 & 23,02 & 1,52 & 0,03 & 2,65 & 0,00 & 0,91 \\
\hline 280,22 & 50,18 & 232,92 & 43,15 & 171,74 & 34,00 & 99,34 & 22,17 & 21,55 & 1,20 & 0,03 & 2,65 & 0,00 & 0,90 \\
\hline 279,34 & 50,05 & 231,70 & 42,98 & 170,22 & 33,77 & 97,69 & 21,77 & 20,07 & 0,96 & 0,02 & 2,66 & 0,00 & 0,86 \\
\hline 278,48 & 49,88 & 230,48 & 42,80 & 168,71 & 33,54 & 96,03 & 21,36 & 18,66 & 0,72 & 0,02 & 2,66 & 0,00 & 0,84 \\
\hline 277,59 & 49,75 & 229,27 & 42,60 & 167,16 & 33,35 & 94,38 & 20,95 & 17,29 & 0,46 & 0,02 & 2,67 & 0,00 & 0,83 \\
\hline 276,71 & 49,60 & 228,03 & 42,45 & 165,62 & 33,13 & 92,72 & 20,54 & 15,98 & 0,23 & 0,02 & 2,68 & 0,00 & 0,82 \\
\hline 275,82 & 49,46 & 226,80 & 42,26 & 164,10 & 32,88 & 91,05 & 20,12 & 14,76 & 0,00 & 0,01 & 2,68 & 0,00 & 0,79 \\
\hline 274,90 & 49,32 & 225,56 & 42,08 & 162,56 & 32,67 & 89,37 & 19,71 & 10,42 & 4,33 & 0,01 & 2,69 & 0,00 & 0,78 \\
\hline 273,98 & 49,20 & 224,30 & 41,91 & 161,03 & 32,41 & 87,70 & 19,28 & 9,32 & 4,18 & 0,01 & 2,70 & 0,00 & 0,76 \\
\hline 273,06 & 49,07 & 223,07 & 41,70 & 159,49 & 32,19 & 86,05 & 18,84 & 8,28 & 4,02 & 0,01 & 2,70 & 0,00 & 0,75 \\
\hline 272,12 & 48,92 & 221,80 & 41,52 & 157,96 & 31,94 & 82,79 & 17,91 & 7,32 & 3,87 & 0,00 & 2,71 & 0,00 & 0,75 \\
\hline 271,18 & 48,77 & 220,52 & 41,33 & 156,41 & 31,70 & 81,09 & 17,50 & 6,41 & 3,74 & 0,00 & 2,72 & 0,00 & 0,74 \\
\hline 270,22 & 48,65 & 219,26 & 41,12 & 154,86 & 31,47 & 79,40 & 17,07 & 5,59 & 3,61 & 0,00 & 2,72 & 0,00 & 0,72 \\
\hline 269,27 & 48,48 & 217,99 & 40,95 & 153,31 & 31,24 & 77,74 & 16,64 & 4,83 & 3,48 & 0,01 & 2,72 & 0,00 & 0,71 \\
\hline 268,29 & 48,33 & 216,70 & 40,75 & 151,76 & 31,00 & 76,04 & 16,19 & 4,14 & 3,34 & 0,00 & 2,73 & 0,01 & 0,70 \\
\hline 267,32 & 48,19 & 215,40 & 40,55 & 150,21 & 30,76 & 74,36 & 15,77 & 3,50 & 3,21 & 0,00 & 2,74 & 0,01 & 0,71 \\
\hline 266,32 & 48,06 & 214,11 & 40,35 & 148,64 & 30,50 & 72,68 & 15,30 & 2,93 & 3,12 & 0,00 & 2,74 & 0,00 & 0,71 \\
\hline 265,33 & 47,88 & 212,82 & 40,14 & 147,06 & 30,25 & 70,97 & 14,87 & 2,40 & 3,02 & 0,00 & 2,75 & 0,01 & 0,70 \\
\hline 264,33 & 47,73 & 211,49 & 39,97 & 145,48 & 30,03 & 69,27 & 14,42 & 1,94 & 2,94 & 0,03 & 1,86 & 0,01 & 0,71 \\
\hline 263,30 & 47,59 & 210,15 & 39,79 & 143,90 & 29,76 & 67,56 & 13,96 & 1,53 & 2,86 & 0,00 & 1,90 & 0,01 & 0,70 \\
\hline 262,28 & 47,44 & 208,82 & 39,59 & 142,29 & 29,52 & 65,84 & 13,49 & 1,17 & 2,80 & 0,00 & 1,79 & 0,02 & 0,69 \\
\hline 261,23 & 47,31 & 207,50 & 39,38 & 140,69 & 29,27 & 64,12 & 13,04 & 0,86 & 2,74 & 0,00 & 1,68 & 0,02 & 0,69 \\
\hline 260,20 & 47,15 & 206,16 & 39,17 & 139,09 & 29,00 & 62,39 & 12,57 & 0,61 & 2,69 & 0,00 & 1,61 & 0,03 & 0,68 \\
\hline
\end{tabular}


Tabela A.12: Dados coletados pelo GPS - teste 04 do caminhão com massa 23,29 t

\begin{tabular}{|c|c|c|c|c|c|c|c|c|c|c|c|c|c|}
\hline \multicolumn{14}{|c|}{ Coordenadas locais } \\
\hline$\underline{\mathbf{x}}$ & $\mathbf{y}$ & $\mathbf{x}$ & $\mathbf{y}$ & $\mathbf{x}$ & $\mathbf{y}$ & $\mathbf{x}$ & $\mathbf{y}$ & $\mathbf{x}$ & $\mathbf{y}$ & $\mathbf{x}$ & $\mathbf{y}$ & $\mathbf{x}$ & $\mathbf{y}$ \\
\hline 407,22 & 53,66 & 385,18 & 60,13 & 346,77 & 59,62 & 293,33 & 52,08 & 225,68 & 41,23 & 144,52 & 28,94 & 53,11 & 11,04 \\
\hline 406,86 & 53,80 & 384,52 & 60,24 & 345,74 & 59,50 & 291,99 & 51,85 & 224,00 & 40,97 & 142,60 & 28,65 & 51,01 & 10,58 \\
\hline 406,51 & 53,97 & 383,83 & 60,34 & 344,67 & 59,36 & 290,65 & 51,60 & 222,32 & 40,70 & 140,67 & 28,37 & 48,90 & 10,10 \\
\hline 406,14 & 54,11 & 383,15 & 60,47 & 343,62 & 59,21 & 289,30 & 51,33 & 220,63 & 40,46 & 138,72 & 28,06 & 46,78 & 9,63 \\
\hline 405,76 & 54,24 & 382,47 & 60,57 & 342,55 & 58,91 & 287,97 & 50,56 & 218,93 & 40,22 & 136,78 & 27,72 & 44,62 & 9,15 \\
\hline 405,39 & 54,39 & 381,78 & 60,66 & 341,47 & 58,78 & 286,59 & 50,68 & 217,24 & 39,97 & 134,81 & 27,42 & 42,51 & 8,71 \\
\hline 405,01 & 54,55 & 381,08 & 60,76 & 340,38 & 58,62 & 285,21 & 50,46 & 215,52 & 39,71 & 132,85 & 27,09 & 40,43 & 8,22 \\
\hline 404,62 & 54,70 & 380,35 & 60,84 & 339,28 & 58,49 & 283,85 & 49,92 & 213,80 & 39,46 & 130,85 & 26,79 & 38,42 & 7,81 \\
\hline 404,23 & 54,85 & 379,64 & 60,92 & 338,18 & 58,34 & 282,39 & 50,49 & 212,08 & 39,21 & 128,88 & 26,44 & 36,38 & 7,38 \\
\hline 403,84 & 55,01 & 378,91 & 60,99 & 337,07 & 58,19 & 281,05 & 49,47 & 210,35 & 38,94 & 126,90 & 26,12 & 34,35 & 6,94 \\
\hline 403,45 & 55,16 & 378,16 & 61,06 & 335,95 & 58,03 & 279,65 & 49,24 & 208,62 & 38,69 & 124,91 & 25,76 & 32,31 & 6,47 \\
\hline 403,06 & 55,33 & 377,40 & 61,11 & 334,83 & 57,87 & 278,24 & 49,02 & 206,87 & 38,46 & 122,91 & 25,45 & 30,30 & 6,04 \\
\hline 402,65 & 55,48 & 376,65 & 61,16 & 333,71 & 57,75 & 276,81 & 48,83 & 205,13 & 38,18 & 120,90 & 25,12 & 28,36 & 5,66 \\
\hline 402,25 & 55,64 & 375,88 & 61,22 & 332,59 & 57,58 & 275,39 & 48,59 & 203,38 & 37,92 & 119,70 & 25,74 & 26,50 & 5,25 \\
\hline 401,84 & 55,79 & 375,10 & 61,26 & 331,46 & 57,40 & 273,94 & 48,40 & 201,63 & 37,64 & 117,69 & 25,38 & 24,76 & 4,83 \\
\hline 401,41 & 55,95 & 374,31 & 61,30 & 330,31 & 57,23 & 272,50 & 48,17 & 199,89 & 37,38 & 115,69 & 25,03 & 22,99 & 4,44 \\
\hline 401,00 & 56,10 & 373,53 & 61,32 & 329,18 & 57,06 & 271,05 & 47,95 & 198,13 & 37,09 & 112,99 & 23,82 & 21,29 & 4,11 \\
\hline 400,57 & 56,26 & 372,73 & 61,36 & 328,04 & 56,88 & 269,58 & 47,72 & 196,36 & 36,81 & 110,95 & 23,43 & 19,60 & 3,77 \\
\hline 400,14 & 56,41 & 371,92 & 61,39 & 326,89 & 56,71 & 268,11 & 47,51 & 194,59 & 36,53 & 108,92 & 23,06 & 18,00 & 3,42 \\
\hline 399,72 & 56,55 & 371,09 & 61,39 & 325,72 & 56,56 & 266,64 & 47,29 & 192,82 & 36,26 & 106,78 & 22,81 & 16,51 & 3,12 \\
\hline 399,28 & 56,66 & 370,27 & 61,40 & 324,56 & 56,36 & 265,16 & 47,08 & 191,04 & 35,95 & 104,75 & 22,41 & 15,04 & 2,88 \\
\hline 398,84 & 56,79 & 369,43 & 61,40 & 323,40 & 56,18 & 263,67 & 46,85 & 189,25 & 35,65 & 102,73 & 22,01 & 13,67 & 2,61 \\
\hline 398,39 & 56,92 & 368,58 & 61,40 & 322,23 & 55,98 & 262,16 & 46,63 & 187,46 & 35,37 & 100,69 & 21,61 & 12,35 & 2,34 \\
\hline 397,92 & 57,07 & 367,72 & 61,38 & 321,06 & 55,83 & 260,66 & 46,42 & 185,65 & 35,10 & 98,66 & 21,20 & 11,09 & 2,11 \\
\hline 397,44 & 57,22 & 366,85 & 61,35 & 319,86 & 55,62 & 259,14 & 46,21 & 183,86 & 34,78 & 96,61 & 20,79 & 9,90 & 1,90 \\
\hline 396,95 & 57,37 & 365,99 & 61,31 & 318,67 & 55,45 & 257,62 & 46,00 & 182,04 & 34,49 & 94,57 & 20,38 & 8,80 & 1,69 \\
\hline 396,45 & 57,52 & 365,12 & 61,28 & 317,47 & 55,25 & 256,10 & 45,79 & 180,22 & 34,22 & 92,53 & 19,94 & 7,77 & 1,49 \\
\hline 395,96 & 57,64 & 364,22 & 61,25 & 316,26 & 55,06 & 254,55 & 45,55 & 178,40 & 33,94 & 90,48 & 19,49 & 6,82 & 1,31 \\
\hline 395,44 & 57,78 & 363,32 & 61,21 & 315,06 & 54,90 & 253,01 & 45,33 & 176,56 & 33,65 & 88,43 & 19,05 & 5,96 & 1,15 \\
\hline 394,92 & 57,93 & 362,42 & 61,17 & 313,84 & 54,70 & 251,46 & 45,09 & 174,73 & 33,38 & 86,37 & 18,60 & 5,15 & 1,00 \\
\hline 394,37 & 58,08 & 361,51 & 61,13 & 312,61 & 54,50 & 249,90 & 44,87 & 172,89 & 33,10 & 84,31 & 18,15 & 4,41 & 0,86 \\
\hline 393,82 & 58,24 & 360,60 & 61,06 & 311,38 & 54,32 & 248,34 & 44,62 & 171,04 & 32,82 & 82,25 & 17,70 & 3,76 & 0,72 \\
\hline 393,27 & 58,40 & 359,66 & 61,00 & 310,14 & 54,13 & 246,76 & 44,37 & 169,18 & 32,55 & 80,19 & 17,24 & 3,16 & 0,59 \\
\hline 392,72 & 58,50 & 358,72 & 60,93 & 308,89 & 53,95 & 245,18 & 44,13 & 167,33 & 32,26 & 78,12 & 16,79 & 2,60 & 0,51 \\
\hline 392,14 & 58,64 & 357,76 & 60,86 & 307,59 & 54,38 & 243,60 & 43,90 & 165,46 & 32,01 & 76,06 & 16,32 & 2,13 & 0,54 \\
\hline 391,55 & 58,78 & 356,80 & 60,79 & 306,33 & 54,18 & 242,00 & 43,66 & 163,59 & 31,73 & 73,98 & 15,87 & 1,70 & 0,45 \\
\hline 390,95 & 58,91 & 355,83 & 60,69 & 305,06 & 53,98 & 240,40 & 43,41 & 161,71 & 31,47 & 71,91 & 15,40 & 1,33 & 0,36 \\
\hline 390,35 & 59,01 & 354,86 & 60,60 & 303,78 & 53,79 & 238,80 & 43,16 & 159,82 & 31,22 & 69,83 & 14,93 & 1,00 & 0,27 \\
\hline 389,74 & 59,15 & 353,88 & 60,52 & 302,50 & 53,58 & 237,19 & 42,93 & 157,94 & 30,96 & 67,75 & 14,47 & 0,72 & 0,21 \\
\hline 389,09 & 59,33 & 352,88 & 60,40 & 301,21 & 53,36 & 235,56 & 42,67 & 156,04 & 30,65 & 65,67 & 13,97 & 0,49 & 0,16 \\
\hline 388,46 & 59,48 & 351,89 & 60,27 & 299,92 & 53,16 & 233,94 & 42,43 & 154,14 & 30,37 & 63,58 & 13,50 & 0,30 & 0,13 \\
\hline 387,82 & 59,60 & 350,88 & 60,17 & 298,62 & 52,95 & 232,30 & 42,20 & 152,23 & 30,10 & 61,50 & 13,01 & 0,16 & 0,09 \\
\hline 387,17 & 59,75 & 349,88 & 60,04 & 297,30 & 52,72 & 230,65 & 41,94 & 150,32 & 29,81 & 59,41 & 12,51 & 0,06 & 0,07 \\
\hline 386,52 & 59,87 & 348,86 & 59,90 & 295,99 & 52,52 & 229,00 & 41,70 & 148,40 & 29,52 & 57,31 & 12,02 & 0,01 & 0,07 \\
\hline 385,86 & 60,00 & 347,81 & 59,73 & 294,66 & 52,28 & 227,34 & 41,46 & 146,48 & 29,23 & 55,22 & 11,53 & 0,00 & 0,06 \\
\hline
\end{tabular}


Tabela A.13: Dados coletados pelo GPS - teste 05 do caminhão com massa 23,29 t

\begin{tabular}{|c|c|c|c|c|c|c|c|c|c|c|c|c|c|}
\hline \multicolumn{14}{|c|}{ Coordenadas locais } \\
\hline $\mathbf{x}$ & $\mathbf{y}$ & $\mathbf{x}$ & $\mathbf{y}$ & $\mathbf{x}$ & $\mathbf{y}$ & $\mathbf{x}$ & $\mathbf{y}$ & $\mathbf{x}$ & $\mathbf{y}$ & $\mathbf{x}$ & $\mathbf{y}$ & $\mathbf{x}$ & $y$ \\
\hline 456,33 & 19,20 & 419,13 & 50,90 & 358,48 & 61,20 & 283,63 & 50,54 & 196,37 & 37,35 & 97,80 & 20,65 & 7,60 & 1,58 \\
\hline 455,77 & 19,90 & 418,00 & 51,44 & 357,00 & 61,07 & 281,74 & 50,17 & 194,28 & 37,00 & 95,56 & 20,18 & 6,69 & 1,44 \\
\hline 455,19 & 20,59 & 416,86 & 51,99 & 355,50 & 60,94 & 280,04 & 50,01 & 192,20 & 36,67 & 93,34 & 19,74 & 5,78 & 1,23 \\
\hline 454,59 & 21,28 & 415,72 & 52,53 & 354,00 & 60,80 & 278,15 & 49,64 & 190,06 & 36,31 & 91,03 & 19,20 & 5,01 & 1,11 \\
\hline 453,99 & 21,98 & 414,54 & 53,03 & 352,39 & 60,54 & 276,26 & 49,30 & 188,02 & 36,05 & 88,79 & 18,73 & 4,25 & 0,92 \\
\hline 453,40 & 22,69 & 413,38 & 53,53 & 350,87 & 60,35 & 274,44 & 49,03 & 185,86 & 35,68 & 86,53 & 18,23 & 3,66 & 0,86 \\
\hline 452,76 & 23,38 & 412,20 & 54,01 & 349,31 & 60,13 & 272,65 & 48,78 & 183,78 & 35,39 & 84,27 & 17,76 & 2,97 & 0,62 \\
\hline 452,15 & 24,11 & 411,00 & 54,47 & 347,70 & 59,89 & 270,82 & 48,54 & 181,69 & 35,10 & 82,03 & 17,28 & 2,45 & 0,52 \\
\hline 451,51 & 24,83 & 409,81 & 54,95 & 346,17 & 59,71 & 268,92 & 48,18 & 179,55 & 34,76 & 79,68 & 16,71 & 2,01 & 0,48 \\
\hline 450,87 & 25,55 & 408,62 & 55,45 & 344,62 & 59,53 & 267,11 & 47,95 & 177,42 & 34,44 & 77,44 & 16,26 & 1,53 & 0,33 \\
\hline 450,23 & 26,29 & 407,39 & 55,89 & 343,03 & 59,32 & 265,20 & 47,61 & 175,28 & 34,13 & 75,09 & 15,67 & 1,14 & 0,25 \\
\hline 449,56 & 27,03 & 406,14 & 56,31 & 341,47 & 59,15 & 263,43 & 47,45 & 173,12 & 33,77 & 72,88 & 15,26 & 0,80 & 0,18 \\
\hline 448,89 & 27,78 & 404,91 & 56,76 & 339,88 & 58,93 & 261,54 & 47,14 & 171,05 & 33,53 & 70,47 & 14,61 & 0,53 & 0,10 \\
\hline 448,22 & 28,52 & 403,66 & 57,19 & 338,28 & 58,73 & 259,69 & 46,91 & 168,90 & 33,21 & 68,27 & 14,17 & 0,41 & 0,15 \\
\hline 447,53 & 29,27 & 402,43 & 57,61 & 336,62 & 58,48 & 257,77 & 46,59 & 166,64 & 32,79 & 65,93 & 13,61 & 0,20 & 0,09 \\
\hline 446,83 & 30,04 & 401,13 & 57,97 & 335,06 & 58,32 & 255,90 & 46,33 & 164,51 & 32,52 & 63,60 & 13,03 & 0,03 & 0,00 \\
\hline 446,11 & 30,80 & 399,85 & 58,37 & 333,36 & 58,01 & 254,01 & 46,05 & 162,39 & 32,24 & 61,27 & 12,49 & 0,00 & 0,01 \\
\hline 445,39 & 31,56 & 398,52 & 58,71 & 331,71 & 57,77 & 252,03 & 45,69 & 160,13 & 31,83 & 58,99 & 12,01 & 0,00 & 0,04 \\
\hline 444,65 & 32,30 & 397,22 & 59,04 & 330,10 & 57,57 & 250,18 & 45,45 & 157,99 & 31,54 & 56,68 & 11,48 & 0,00 & 0,04 \\
\hline 443,90 & 33,06 & 395,93 & 59,39 & 328,56 & 57,43 & 248,29 & 45,18 & 155,75 & 31,15 & 54,39 & 10,96 & 0,00 & 0,00 \\
\hline 443,13 & 33,82 & 394,57 & 59,69 & 326,81 & 57,10 & 246,31 & 44,82 & 153,58 & 30,85 & 52,08 & 10,46 & 0,01 & 0,00 \\
\hline 442,31 & 34,55 & 393,25 & 60,00 & 325,17 & 56,87 & 244,46 & 44,60 & 151,39 & 30,50 & 49,79 & 10,03 & 0,05 & 0,03 \\
\hline 441,50 & 35,29 & 391,90 & 60,27 & 323,56 & 56,67 & 242,43 & 44,21 & 149,25 & 30,21 & 47,41 & 9,50 & 0,08 & 0,07 \\
\hline 440,67 & 36,03 & 390,52 & 60,51 & 321,88 & 56,41 & 240,51 & 43,93 & 147,00 & 29,81 & 45,15 & 8,99 & 0,08 & 0,08 \\
\hline 439,83 & 36,77 & 389,16 & 60,77 & 320,20 & 56,17 & 238,66 & 43,73 & 144,83 & 29,49 & 42,86 & 8,51 & 0,08 & 0,08 \\
\hline 439,00 & 37,52 & 387,78 & 61,00 & 318,52 & 55,91 & 236,68 & 43,38 & 142,59 & 29,10 & 40,62 & 8,05 & 0,07 & 0,09 \\
\hline 438,12 & 38,26 & 386,41 & 61,20 & 316,79 & 55,62 & 234,77 & 43,14 & 140,30 & 28,67 & 38,38 & 7,54 & 0,07 & 0,07 \\
\hline 437,24 & 39,00 & 384,99 & 61,36 & 315,14 & 55,42 & 232,76 & 42,80 & 138,09 & 28,30 & 36,19 & 7,07 & 0,04 & 0,03 \\
\hline 436,33 & 39,71 & 383,59 & 61,52 & 313,46 & 55,19 & 230,71 & 42,41 & 136,01 & 28,06 & 34,11 & 6,70 & 0,03 & 0,02 \\
\hline 435,44 & 40,43 & 382,17 & 61,65 & 311,77 & 54,97 & 228,76 & 42,13 & 133,83 & 27,73 & 32,02 & 6,27 & 0,09 & 0,09 \\
\hline 434,51 & 41,16 & 380,75 & 61,77 & 310,02 & 54,68 & 226,79 & 41,85 & 131,62 & 27,37 & 30,06 & 5,85 & 0,05 & 0,05 \\
\hline 433,58 & 41,88 & 379,32 & 61,86 & 308,40 & 54,54 & 224,90 & 41,66 & 129,35 & 26,92 & 28,13 & 5,43 & 0,08 & 0,08 \\
\hline 432,62 & 42,58 & 377,88 & 61,94 & 306,59 & 54,19 & 222,74 & 41,19 & 127,06 & 26,44 & 26,21 & 5,01 & 0,03 & 0,04 \\
\hline 431,67 & 43,27 & 376,43 & 62,00 & 304,86 & 53,92 & 220,79 & 40,95 & 124,83 & 26,07 & 24,42 & 4,66 & 0,04 & 0,05 \\
\hline 430,71 & 43,98 & 374,97 & 62,02 & 303,10 & 53,62 & 218,84 & 40,70 & 122,45 & 25,52 & 22,63 & 4,33 & 0,05 & 0,06 \\
\hline 429,72 & 44,67 & 373,52 & 62,05 & 301,40 & 53,38 & 216,86 & 40,45 & 120,24 & 25,13 & 20,96 & 4,08 & 0,06 & 0,07 \\
\hline 428,71 & 45,34 & 372,04 & 62,04 & 299,60 & 53,04 & 214,76 & 40,08 & 118,12 & 24,80 & 19,35 & 3,80 & 0,04 & 0,04 \\
\hline 427,72 & 46,00 & 370,57 & 62,02 & 297,86 & 52,77 & 212,77 & 39,83 & 115,90 & 24,37 & 17,78 & 3,52 & 0,03 & 0,03 \\
\hline 426,68 & 46,65 & 369,07 & 61,96 & 296,18 & 52,58 & 210,71 & 39,50 & 113,65 & 23,95 & 16,25 & 3,22 & 0,03 & 0,03 \\
\hline 425,65 & 47,31 & 367,58 & 61,90 & 294,37 & 52,24 & 208,69 & 39,20 & 111,41 & 23,50 & 14,82 & 2,96 & 0,07 & 0,08 \\
\hline 424,59 & 47,93 & 366,11 & 61,85 & 292,60 & 51,97 & 206,61 & 38,84 & 109,17 & 23,06 & 13,42 & 2,68 & 0,04 & 0,04 \\
\hline 423,52 & 48,55 & 364,60 & 61,74 & 290,81 & 51,67 & 204,59 & 38,56 & 106,85 & 22,53 & 12,17 & 2,50 & 0,03 & 0,04 \\
\hline 422,44 & 49,15 & 363,10 & 61,66 & 289,00 & 51,37 & 202,48 & 38,19 & 104,62 & 22,09 & 10,94 & 2,30 & 0,08 & 0,09 \\
\hline 421,35 & 49,74 & 361,60 & 61,55 & 287,21 & 51,08 & 200,54 & 38,00 & 102,35 & 21,61 & 9,76 & 2,07 & 0,06 & 0,07 \\
\hline 420,24 & 50,33 & 360,06 & 61,39 & 285,48 & 50,87 & 198,40 & 37,61 & 100,12 & 21,18 & 8,62 & 1,81 & 0,05 & 0,06 \\
\hline
\end{tabular}


Tabela A.14: Dados coletados pelo GPS - teste 06 do caminhão com massa 23,29 t

\begin{tabular}{|c|c|c|c|c|c|c|c|c|c|c|c|c|c|}
\hline \multicolumn{14}{|c|}{ Coordenadas locais } \\
\hline $\mathbf{x}$ & $\mathbf{y}$ & $\mathbf{x}$ & $\mathbf{y}$ & $\mathbf{x}$ & $\mathbf{y}$ & $\mathbf{x}$ & $\mathbf{y}$ & $\mathbf{x}$ & $\mathbf{y}$ & $\mathbf{x}$ & $\mathbf{y}$ & $\mathbf{x}$ & $\mathbf{y}$ \\
\hline 386,41 & 67,56 & 293,56 & 59,91 & 197,56 & 38,27 & 87,70 & 18,14 & 4,19 & 0,60 & 0,50 & 2,21 & 0,44 & 2,24 \\
\hline 384,53 & 67,65 & 291,57 & 59,59 & 195,29 & 37,89 & 85,21 & 17,55 & 3,70 & 0,49 & 0,50 & 2,22 & 0,44 & 2,24 \\
\hline 382,63 & 67,64 & 289,56 & 59,28 & 193,00 & 37,54 & 82,70 & 17,02 & 3,28 & 0,39 & 0,50 & 2,22 & 0,44 & 2,24 \\
\hline 380,74 & 67,65 & 287,56 & 58,96 & 190,73 & 37,18 & 80,20 & 16,45 & 2,93 & 0,27 & 0,50 & 2,22 & 0,44 & 2,24 \\
\hline 378,84 & 67,65 & 285,55 & 58,64 & 188,44 & 36,80 & 77,70 & 15,87 & 2,62 & 0,18 & 0,50 & 2,23 & 0,44 & 2,24 \\
\hline 376,89 & 67,61 & 283,53 & 58,34 & 186,13 & 36,46 & 75,19 & 15,28 & 2,36 & 0,12 & 0,50 & 2,23 & 0,44 & 2,24 \\
\hline 374,96 & 67,53 & 281,49 & 58,02 & 183,83 & 36,10 & 72,69 & 14,71 & 2,15 & 0,07 & 0,49 & 2,24 & 0,44 & 2,24 \\
\hline 373,05 & 67,47 & 279,47 & 57,69 & 181,53 & 35,72 & 70,17 & 14,13 & 2,00 & 0,00 & 0,49 & 2,24 & 0,44 & 2,24 \\
\hline 371,19 & 67,39 & 277,43 & 57,38 & 179,21 & 35,37 & 67,66 & 13,55 & 0,45 & 2,10 & 0,49 & 2,24 & 0,43 & 2,24 \\
\hline 369,28 & 67,23 & 275,40 & 57,05 & 176,89 & 35,00 & 65,15 & 12,93 & 0,40 & 2,09 & 0,49 & 2,24 & 0,43 & 2,24 \\
\hline 367,39 & 67,08 & 273,36 & 56,73 & 174,56 & 34,65 & 62,62 & 12,38 & 0,39 & 2,09 & 0,49 & 2,24 & 0,43 & 2,24 \\
\hline 363,47 & 66,74 & 271,30 & 56,38 & 172,23 & 34,30 & 60,09 & 11,84 & 0,42 & 2,10 & 0,49 & 2,24 & 0,43 & 2,24 \\
\hline 361,53 & 66,54 & 269,23 & 56,06 & 169,89 & 33,94 & 57,55 & 11,28 & 0,47 & 2,11 & 0,49 & 2,24 & 0,43 & 2,24 \\
\hline 359,51 & 70,26 & 267,16 & 55,75 & 167,54 & 33,59 & 54,99 & 10,78 & 0,52 & 2,14 & 0,49 & 2,24 & 0,43 & 2,24 \\
\hline 357,69 & 70,08 & 265,09 & 55,44 & 165,20 & 33,23 & 52,51 & 10,18 & 0,55 & 2,16 & 0,48 & 2,24 & 0,43 & 2,24 \\
\hline 355,88 & 69,80 & 263,01 & 55,12 & 162,85 & 32,88 & 50,06 & 9,64 & 0,55 & 2,16 & 0,48 & 2,24 & 0,43 & 2,24 \\
\hline 352,26 & 69,25 & 260,93 & 54,81 & 160,50 & 32,50 & 47,59 & 9,19 & 0,54 & 2,15 & 0,48 & 2,25 & 0,42 & 2,24 \\
\hline 350,44 & 69,01 & 258,82 & 54,51 & 158,12 & 32,14 & 45,18 & 8,67 & 0,52 & 2,13 & 0,47 & 2,25 & 0,42 & 2,24 \\
\hline 348,61 & 68,76 & 256,71 & 54,24 & 155,74 & 31,78 & 42,84 & 8,14 & 0,52 & 2,13 & 0,47 & 2,24 & 0,42 & 2,24 \\
\hline 346,77 & 68,49 & 254,62 & 53,86 & 153,35 & 31,42 & 40,55 & 7,67 & 0,52 & 2,14 & 0,47 & 2,24 & 0,42 & 2,24 \\
\hline 341,31 & 67,60 & 252,52 & 53,52 & 150,98 & 31,03 & 38,34 & 7,25 & 0,52 & 2,14 & 0,47 & 2,24 & 0,42 & 2,24 \\
\hline 339,46 & 67,33 & 248,26 & 52,88 & 148,60 & 30,63 & 36,20 & 6,85 & 0,52 & 2,15 & 0,47 & 2,24 & 0,41 & 2,26 \\
\hline 337,61 & 67,03 & 246,17 & 52,45 & 143,88 & 29,76 & 34,11 & 6,45 & 0,52 & 2,14 & 0,47 & 2,24 & 0,41 & 2,26 \\
\hline 335,76 & 66,74 & 244,05 & 52,08 & 141,50 & 29,35 & 32,09 & 5,97 & 0,52 & 2,15 & 0,47 & 2,24 & 0,41 & 2,26 \\
\hline 333,90 & 66,45 & 243,94 & 45,29 & 139,10 & 28,94 & 30,10 & 5,57 & 0,52 & 2,15 & 0,47 & 2,24 & 0,41 & 2,26 \\
\hline 332,04 & 66,14 & 241,80 & 44,95 & 136,70 & 28,51 & 28,16 & 5,26 & 0,52 & 2,15 & 0,47 & 2,24 & 0,41 & 2,26 \\
\hline 330,17 & 65,84 & 239,65 & 44,60 & 134,28 & 28,09 & 26,32 & 4,99 & 0,52 & 2,15 & 0,46 & 2,24 & 0,41 & 2,26 \\
\hline 328,30 & 65,54 & 237,50 & 44,26 & 131,86 & 27,64 & 24,62 & 4,61 & 0,51 & 2,15 & 0,46 & 2,24 & 0,41 & 2,27 \\
\hline 326,41 & 65,26 & 235,32 & 43,95 & 129,43 & 27,20 & 22,90 & 4,34 & 0,51 & 2,16 & 0,46 & 2,24 & 0,40 & 2,27 \\
\hline 324,54 & 64,94 & 233,14 & 43,62 & 127,01 & 26,73 & 21,23 & 4,07 & 0,51 & 2,16 & 0,46 & 2,24 & 0,40 & 2,26 \\
\hline 322,64 & 64,66 & 230,96 & 43,30 & 124,58 & 26,26 & 19,62 & 3,68 & 0,51 & 2,16 & 0,46 & 2,24 & 0,40 & 2,27 \\
\hline 320,74 & 64,36 & 228,78 & 42,98 & 122,15 & 25,79 & 18,06 & 3,41 & 0,51 & 2,17 & 0,46 & 2,24 & 0,40 & 2,27 \\
\hline 318,85 & 64,05 & 226,59 & 42,67 & 119,70 & 25,29 & 16,63 & 3,22 & 0,51 & 2,17 & 0,46 & 2,24 & 0,40 & 2,26 \\
\hline 316,94 & 63,74 & 224,40 & 42,33 & 117,27 & 24,76 & 15,24 & 3,02 & 0,51 & 2,17 & 0,46 & 2,24 & 0,40 & 2,27 \\
\hline 315,02 & 63,43 & 222,18 & 42,02 & 114,83 & 24,24 & 13,93 & 2,80 & 0,51 & 2,17 & 0,45 & 2,24 & 0,40 & 2,26 \\
\hline 313,09 & 63,13 & 219,97 & 41,70 & 112,38 & 23,72 & 12,69 & 2,56 & 0,51 & 2,18 & 0,45 & 2,24 & 0,39 & 2,26 \\
\hline 311,17 & 62,80 & 217,76 & 41,37 & 109,94 & 23,16 & 11,50 & 2,32 & 0,51 & 2,18 & 0,45 & 2,24 & 0,39 & 2,26 \\
\hline 309,25 & 62,48 & 215,53 & 41,04 & 107,48 & 22,64 & 10,35 & 2,07 & 0,51 & 2,18 & 0,45 & 2,24 & 0,39 & 2,26 \\
\hline 307,31 & 62,15 & 213,31 & 40,70 & 105,02 & 22,06 & 9,30 & 1,83 & 0,51 & 2,19 & 0,45 & 2,24 & 0,17 & 0,03 \\
\hline 305,37 & 61,81 & 211,07 & 40,38 & 102,56 & 21,54 & 8,36 & 1,62 & 0,51 & 2,19 & 0,45 & 2,24 & 0,17 & 0,06 \\
\hline 303,42 & 61,49 & 208,84 & 40,02 & 100,10 & 20,93 & 7,47 & 1,42 & 0,51 & 2,20 & 0,45 & 2,24 & 0,16 & 0,07 \\
\hline 301,45 & 61,17 & 206,59 & 39,68 & 97,62 & 20,41 & 6,69 & 1,22 & 0,51 & 2,20 & 0,45 & 2,24 & 0,16 & 0,06 \\
\hline 299,49 & 60,86 & 204,34 & 39,34 & 95,16 & 19,81 & 5,96 & 1,04 & 0,51 & 2,20 & 0,45 & 2,24 & 0,16 & 0,07 \\
\hline 297,52 & 60,54 & 202,09 & 38,98 & 92,68 & 19,24 & 5,30 & 0,89 & 0,50 & 2,21 & 0,44 & 2,24 & 0,16 & 0,08 \\
\hline 295,54 & 60,22 & 199,84 & 38,61 & 90,20 & 18,68 & 4,71 & 0,75 & 0,50 & 2,21 & 0,44 & 2,24 & 0,16 & 0,09 \\
\hline
\end{tabular}


Tabela A.15: Dados coletados pelo GPS - teste 01 do caminhão com massa 36,92 t

\begin{tabular}{|c|c|c|c|c|c|c|c|c|c|c|c|c|c|}
\hline \multicolumn{14}{|c|}{ Coordenadas locais } \\
\hline $\mathbf{x}$ & $\mathbf{y}$ & $\mathbf{x}$ & $\mathbf{y}$ & $\mathbf{x}$ & $\mathbf{y}$ & $\mathbf{x}$ & y & $\mathbf{x}$ & $\mathbf{y}$ & $\mathbf{x}$ & $\mathbf{y}$ & $\mathbf{x}$ & $\mathbf{y}$ \\
\hline 209,15 & 37,98 & 168,18 & 31,79 & 127,09 & 25,58 & 85,00 & 18,39 & 40,44 & 8,47 & 0,84 & 0,18 & 0,00 & 0,00 \\
\hline 208,30 & 37,85 & 167,25 & 31,67 & 126,18 & 25,46 & 84,05 & 18,19 & 39,37 & 8,23 & 0,62 & 0,13 & 0,01 & 0,00 \\
\hline 207,40 & 37,73 & 166,35 & 31,51 & 125,27 & 25,32 & 83,09 & 18,00 & 38,30 & 7,99 & 0,43 & 0,08 & 0,01 & 0,00 \\
\hline 206,52 & 37,61 & 165,43 & 31,37 & 124,37 & 25,20 & 82,14 & 17,79 & 37,22 & 7,74 & 0,28 & 0,05 & 0,01 & 0,00 \\
\hline 205,63 & 37,49 & 164,51 & 31,23 & 123,45 & 25,07 & 81,19 & 17,58 & 36,15 & 7,49 & 0,15 & 0,03 & 0,01 & 0,01 \\
\hline 204,74 & 37,37 & 163,59 & 31,08 & 122,54 & 24,93 & 80,24 & 17,36 & 35,07 & 7,24 & 0,07 & 0,01 & 0,01 & 0,00 \\
\hline 203,84 & 37,25 & 162,68 & 30,94 & 121,62 & 24,80 & 79,28 & 17,16 & 33,99 & 6,99 & 0,02 & 0,00 & 0,00 & 0,00 \\
\hline 202,95 & 37,11 & 161,76 & 30,80 & 120,70 & 24,67 & 78,33 & 16,94 & 32,89 & 6,75 & 0,00 & 0,00 & 0,00 & 0,00 \\
\hline 202,06 & 36,99 & 160,83 & 30,65 & 119,78 & 24,53 & 77,37 & 16,72 & 31,80 & 6,51 & 0,00 & 0,00 & 0,00 & 0,00 \\
\hline 201,15 & 36,88 & 159,92 & 30,51 & 118,86 & 24,40 & 76,41 & 16,50 & 30,71 & 6,26 & 0,00 & 0,00 & 0,00 & 0,01 \\
\hline 200,26 & 36,75 & 159,01 & 30,37 & 117,94 & 24,27 & 75,46 & 16,27 & 29,62 & 6,00 & 0,01 & 0,00 & 0,01 & 0,00 \\
\hline 199,35 & 36,63 & 158,08 & 30,22 & 117,01 & 24,14 & 74,50 & 16,07 & 28,52 & 5,77 & 0,02 & 0,01 & 0,00 & 0,00 \\
\hline 198,44 & 36,52 & 157,17 & 30,09 & 116,09 & 24,00 & 73,53 & 15,84 & 27,39 & 5,53 & 0,04 & 0,02 & 0,00 & 0,00 \\
\hline 197,54 & 36,37 & 156,25 & 29,94 & 115,17 & 23,87 & 72,57 & 15,64 & 26,23 & 5,28 & 0,03 & 0,02 & 0,00 & 0,01 \\
\hline 196,64 & 36,25 & 155,33 & 29,79 & 114,24 & 23,71 & 71,61 & 15,43 & 25,08 & 5,02 & 0,01 & 0,01 & 0,00 & 0,00 \\
\hline 195,73 & 36,12 & 154,41 & 29,65 & 113,31 & 23,59 & 70,66 & 15,22 & 23,94 & 4,78 & 0,01 & 0,01 & 0,01 & 0,00 \\
\hline 194,82 & 35,99 & 153,49 & 29,50 & 112,38 & 23,45 & 69,70 & 15,00 & 22,88 & 4,57 & 0,00 & 0,00 & 0,01 & 0,00 \\
\hline 193,91 & 35,85 & 152,57 & 29,37 & 111,44 & 23,31 & 68,73 & 14,79 & 21,90 & 4,35 & 0,00 & 0,01 & 0,00 & 0,00 \\
\hline 193,01 & 35,70 & 151,65 & 29,22 & 110,52 & 23,15 & 67,76 & 14,58 & 20,91 & 4,12 & 0,01 & 0,01 & 0,00 & 0,00 \\
\hline 192,08 & 35,57 & 150,74 & 29,06 & 109,57 & 23,01 & 66,78 & 14,38 & 19,77 & 3,88 & 0,01 & 0,01 & 0,00 & 0,00 \\
\hline 191,17 & 35,43 & 149,81 & 28,92 & 108,64 & 22,86 & 65,82 & 14,18 & 18,63 & 3,65 & 0,01 & 0,01 & 0,00 & 0,00 \\
\hline 190,25 & 35,28 & 148,89 & 28,78 & 107,70 & 22,71 & 64,85 & 13,97 & 17,49 & 3,42 & 0,01 & 0,01 & 0,00 & 0,00 \\
\hline 189,34 & 35,13 & 147,98 & 28,64 & 106,75 & 22,58 & 63,88 & 13,75 & 16,43 & 3,20 & 0,01 & 0,01 & 0,00 & 0,01 \\
\hline 188,41 & 35,00 & 147,07 & 28,49 & 105,80 & 22,42 & 62,90 & 13,54 & 15,43 & 2,99 & 0,00 & 0,01 & 0,00 & 0,01 \\
\hline 187,49 & 34,87 & 146,15 & 28,35 & 104,87 & 22,25 & 61,93 & 13,33 & 14,45 & 2,79 & 0,01 & 0,01 & 0,00 & 0,00 \\
\hline 186,57 & 34,72 & 145,25 & 28,21 & 103,91 & 22,11 & 60,95 & 13,11 & 13,48 & 2,61 & 0,01 & 0,01 & 0,00 & 0,00 \\
\hline 185,65 & 34,57 & 144,32 & 28,07 & 103,00 & 21,90 & 59,95 & 12,92 & 12,51 & 2,45 & 0,00 & 0,01 & 0,00 & 0,00 \\
\hline 184,72 & 34,43 & 143,41 & 27,95 & 102,07 & 21,72 & 58,95 & 12,70 & 11,56 & 2,28 & 0,01 & 0,01 & 0,01 & 0,00 \\
\hline 183,80 & 34,28 & 142,50 & 27,80 & 101,11 & 21,56 & 57,96 & 12,48 & 10,63 & 2,09 & 0,01 & 0,00 & 0,01 & 0,00 \\
\hline 182,88 & 34,13 & 141,58 & 27,67 & 100,17 & 21,40 & 56,95 & 12,25 & 9,72 & 1,93 & 0,01 & 0,00 & 0,00 & 0,00 \\
\hline 181,96 & 33,98 & 140,68 & 27,53 & 99,21 & 21,23 & 55,94 & 12,04 & 8,85 & 1,78 & 0,00 & 0,01 & 0,00 & 0,00 \\
\hline 181,04 & 33,84 & 139,76 & 27,40 & 98,29 & 21,03 & 54,93 & 11,81 & 8,06 & 1,62 & 0,01 & 0,00 & 0,00 & 0,00 \\
\hline 180,12 & 33,69 & 138,86 & 27,27 & 97,34 & 20,85 & 53,93 & 11,58 & 7,29 & 1,48 & 0,01 & 0,00 & 0,01 & 0,00 \\
\hline 179,20 & 33,55 & 137,94 & 27,14 & 96,40 & 20,70 & 52,91 & 11,34 & 6,55 & 1,37 & 0,00 & 0,00 & 0,00 & 0,00 \\
\hline 178,28 & 33,40 & 137,04 & 27,00 & 95,45 & 20,51 & 51,89 & 11,11 & 5,85 & 1,24 & 0,01 & 0,00 & 0,00 & 0,01 \\
\hline 177,35 & 33,25 & 136,13 & 26,88 & 94,49 & 20,35 & 50,87 & 10,88 & 5,19 & 1,11 & 0,01 & 0,00 & 0,01 & 0,01 \\
\hline 176,44 & 33,11 & 135,23 & 26,74 & 93,54 & 20,16 & 49,84 & 10,64 & 4,57 & 0,96 & 0,01 & 0,00 & 0,01 & 0,00 \\
\hline 175,52 & 32,96 & 134,32 & 26,61 & 92,61 & 19,96 & 48,80 & 10,41 & 4,00 & 0,83 & 0,01 & 0,00 & 0,00 & 0,00 \\
\hline 174,59 & 32,82 & 133,42 & 26,48 & 91,65 & 19,78 & 47,78 & 10,15 & 3,47 & 0,72 & 0,00 & 0,00 & 0,00 & 0,00 \\
\hline 173,68 & 32,67 & 132,51 & 26,36 & 90,68 & 19,61 & 46,74 & 9,91 & 2,98 & 0,62 & 0,01 & 0,00 & 0,00 & 0,00 \\
\hline 172,76 & 32,53 & 131,61 & 26,22 & 89,75 & 19,40 & 45,71 & 9,68 & 2,54 & 0,53 & 0,01 & 0,01 & 0,00 & 0,00 \\
\hline 171,84 & 32,38 & 130,71 & 26,09 & 88,79 & 19,20 & 44,65 & 9,44 & 2,13 & 0,45 & 0,00 & 0,01 & 0,00 & 0,00 \\
\hline 170,91 & 32,24 & 129,80 & 25,96 & 87,82 & 19,02 & 43,59 & 9,21 & 1,75 & 0,37 & 0,00 & 0,00 & 0,00 & 0,00 \\
\hline 170,01 & 32,08 & 128,90 & 25,84 & 86,88 & 18,83 & 42,55 & 8,98 & 1,40 & 0,30 & 0,01 & 0,00 & 0,00 & 0,01 \\
\hline 169,09 & 31,94 & 127,98 & 25,72 & 85,95 & 18,61 & 41,49 & 8,73 & 1,09 & 0,25 & 0,00 & 0,01 & 0,01 & 0,00 \\
\hline
\end{tabular}


Tabela A.16: Dados coletados pelo GPS - teste 02 do caminhão com massa 36,92 t

\begin{tabular}{|c|c|c|c|c|c|c|c|c|c|c|c|c|c|}
\hline \multicolumn{14}{|c|}{ Coordenadas locais } \\
\hline $\mathbf{x}$ & $\mathbf{y}$ & $\mathbf{x}$ & $\mathbf{y}$ & $\mathbf{x}$ & $\mathbf{y}$ & $\mathbf{x}$ & $\mathbf{y}$ & $\mathbf{x}$ & $\mathbf{y}$ & $\mathbf{x}$ & $\mathbf{y}$ & $\mathbf{x}$ & y \\
\hline 265,81 & 54,54 & 186,76 & 42,62 & 91,86 & 22,03 & 8,87 & 4,76 & 1,13 & 2,13 & 1,60 & 0,93 & 0,12 & 0,01 \\
\hline 264,29 & 54,32 & 184,93 & 42,36 & 89,76 & 21,57 & 7,94 & 4,54 & 1,13 & 2,14 & 1,60 & 0,93 & 0,13 & 0,02 \\
\hline 262,72 & 54,07 & 183,13 & 42,11 & 87,68 & 21,10 & 7,07 & 4,34 & 1,13 & 2,14 & 1,60 & 0,93 & 0,13 & 0,02 \\
\hline 261,16 & 53,82 & 181,28 & 41,84 & 85,58 & 20,64 & 6,26 & 4,16 & 1,13 & 2,15 & 1,60 & 0,94 & 0,12 & 0,02 \\
\hline 259,61 & 53,59 & 179,45 & 41,58 & 83,47 & 20,18 & 5,50 & 3,98 & 1,13 & 2,15 & 1,60 & 0,94 & 0,12 & 0,02 \\
\hline 258,06 & 53,33 & 177,57 & 41,30 & 81,37 & 19,71 & 4,80 & 3,81 & 1,13 & 2,16 & 1,60 & 0,94 & 0,12 & 0,02 \\
\hline 256,48 & 53,08 & 175,72 & 41,02 & 79,25 & 19,25 & 4,15 & 3,65 & 1,13 & 2,17 & 1,60 & 0,94 & 0,12 & 0,02 \\
\hline 254,91 & 52,84 & 173,85 & 40,75 & 77,13 & 18,79 & 3,56 & 3,52 & 1,14 & 2,17 & 1,60 & 0,95 & 0,12 & 0,02 \\
\hline 253,32 & 52,57 & 171,98 & 40,48 & 75,02 & 18,32 & 3,02 & 3,39 & 1,13 & 2,18 & 1,60 & 0,95 & 0,12 & 0,02 \\
\hline 251,71 & 52,33 & 170,10 & 40,19 & 72,89 & 17,85 & 2,55 & 3,28 & 1,14 & 2,19 & 1,60 & 0,95 & 0,12 & 0,02 \\
\hline 250,11 & 52,02 & 168,23 & 39,91 & 70,77 & 17,38 & 2,15 & 3,18 & 1,14 & 2,19 & 1,60 & 0,96 & 0,12 & 0,03 \\
\hline 248,51 & 51,78 & 166,34 & 39,63 & 68,64 & 16,89 & 1,79 & 3,09 & 1,14 & 2,20 & 1,61 & 0,96 & 0,12 & 0,03 \\
\hline 246,89 & 51,55 & 164,45 & 39,34 & 66,51 & 16,43 & 1,92 & 2,17 & 1,14 & 2,21 & 1,61 & 0,96 & 0,12 & 0,03 \\
\hline 245,29 & 51,33 & 162,55 & 39,07 & 64,38 & 15,98 & 1,67 & 2,10 & 1,14 & 2,21 & 1,61 & 0,97 & 0,12 & 0,03 \\
\hline 243,66 & 51,09 & 160,66 & 38,78 & 62,23 & 15,51 & 1,46 & 2,03 & 1,14 & 2,22 & 1,61 & 0,97 & 0,11 & 0,03 \\
\hline 242,03 & 50,83 & 158,75 & 38,48 & 60,08 & 15,05 & 1,30 & 1,97 & 1,14 & 2,23 & 1,61 & 0,97 & 0,11 & 0,02 \\
\hline 240,38 & 50,58 & 156,84 & 38,20 & 57,92 & 14,61 & 1,19 & 1,93 & 1,14 & 2,23 & 1,61 & 0,97 & 0,11 & 0,03 \\
\hline 238,72 & 50,32 & 154,93 & 37,91 & 55,73 & 14,18 & 1,13 & 1,90 & 1,14 & 2,23 & 1,61 & 0,98 & 0,11 & 0,03 \\
\hline 235,26 & 49,79 & 153,01 & 37,62 & 53,53 & 13,75 & 1,11 & 1,90 & 1,14 & 2,24 & 1,61 & 0,98 & 0,11 & 0,02 \\
\hline 233,55 & 49,53 & 151,07 & 37,32 & 51,39 & 13,33 & 1,12 & 1,92 & 1,14 & 2,24 & 1,61 & 0,98 & 0,10 & 0,02 \\
\hline 231,95 & 49,32 & 149,11 & 36,99 & 49,33 & 12,93 & 1,16 & 1,95 & 1,13 & 2,26 & 1,61 & 0,99 & 0,10 & 0,02 \\
\hline 230,28 & 49,05 & 147,15 & 36,68 & 47,30 & 12,51 & 1,18 & 1,97 & 1,13 & 2,27 & 1,61 & 0,99 & 0,10 & 0,02 \\
\hline 228,62 & 48,80 & 145,23 & 36,39 & 45,16 & 12,07 & 1,19 & 1,97 & 1,13 & 2,27 & 1,61 & 0,99 & 0,10 & 0,02 \\
\hline 226,95 & 48,54 & 143,25 & 36,03 & 42,98 & 11,64 & 1,18 & 1,98 & 1,14 & 2,28 & 1,61 & 0,99 & 0,10 & 0,02 \\
\hline 225,24 & 48,28 & 141,32 & 35,73 & 40,95 & 11,22 & 1,16 & 1,97 & 1,14 & 2,29 & 1,61 & 1,00 & 0,10 & 0,02 \\
\hline 223,55 & 48,05 & 139,35 & 35,39 & 38,94 & 10,81 & 1,16 & 1,98 & 1,14 & 2,29 & 1,61 & 1,00 & 0,10 & 0,02 \\
\hline 221,85 & 47,80 & 137,37 & 35,03 & 36,99 & 10,42 & 1,15 & 1,99 & 1,14 & 2,29 & 1,61 & 1,00 & 0,10 & 0,02 \\
\hline 220,18 & 47,56 & 135,39 & 34,68 & 35,11 & 10,04 & 1,16 & 2,00 & 1,57 & 0,91 & 1,60 & 1,01 & 0,09 & 0,02 \\
\hline 216,73 & 47,03 & 133,40 & 34,34 & 33,24 & 9,67 & 1,15 & 2,00 & 1,58 & 0,90 & 1,61 & 1,01 & 0,09 & 0,02 \\
\hline 215,02 & 46,77 & 131,38 & 33,95 & 31,34 & 9,29 & 1,15 & 2,00 & 1,58 & 0,90 & 1,61 & 1,01 & 0,09 & 0,02 \\
\hline 213,31 & 46,52 & 129,41 & 33,59 & 29,46 & 8,92 & 1,14 & 2,01 & 1,58 & 0,90 & 1,61 & 1,01 & 0,09 & 0,03 \\
\hline 211,58 & 46,25 & 123,38 & 32,37 & 27,70 & 8,60 & 1,14 & 2,02 & 1,58 & 0,89 & 1,61 & 1,01 & 0,09 & 0,02 \\
\hline 209,86 & 45,99 & 121,38 & 31,95 & 26,08 & 8,27 & 1,14 & 2,03 & 1,58 & 0,90 & 1,61 & 1,01 & 0,09 & 0,02 \\
\hline 208,12 & 45,73 & 119,40 & 31,53 & 24,55 & 7,93 & 1,14 & 2,04 & 1,59 & 0,90 & 1,61 & 1,01 & 0,08 & 0,02 \\
\hline 206,41 & 45,48 & 117,39 & 31,11 & 23,06 & 7,66 & 1,14 & 2,04 & 1,59 & 0,90 & 1,61 & 1,02 & 0,08 & 0,02 \\
\hline 204,65 & 45,22 & 115,37 & 30,68 & 21,44 & 7,36 & 1,14 & 2,05 & 1,59 & 0,90 & 1,61 & 1,02 & 0,08 & 0,02 \\
\hline 202,91 & 44,96 & 113,33 & 30,23 & 19,82 & 7,04 & 1,13 & 2,06 & 1,59 & 0,90 & 1,61 & 1,02 & 0,08 & 0,02 \\
\hline 201,16 & 44,71 & 111,30 & 29,79 & 18,28 & 6,77 & 1,13 & 2,07 & 1,59 & 0,91 & 1,61 & 1,02 & 0,08 & 0,02 \\
\hline 199,38 & 44,44 & 109,23 & 29,33 & 16,93 & 6,51 & 1,13 & 2,08 & 1,59 & 0,91 & 1,61 & 1,02 & 0,08 & 0,02 \\
\hline 197,59 & 44,19 & 107,19 & 28,89 & 15,69 & 6,23 & 1,13 & 2,08 & 1,59 & 0,91 & 1,61 & 1,03 & 0,08 & 0,02 \\
\hline 195,80 & 43,92 & 105,12 & 28,43 & 14,51 & 5,97 & 1,13 & 2,09 & 1,59 & 0,92 & 1,61 & 1,03 & 0,07 & 0,02 \\
\hline 194,02 & 43,68 & 103,05 & 27,97 & 13,36 & 5,76 & 1,13 & 2,10 & 1,59 & 0,92 & 1,61 & 1,03 & 0,08 & 0,02 \\
\hline 192,21 & 43,41 & 98,07 & 23,40 & 12,12 & 5,52 & 1,13 & 2,11 & 1,59 & 0,92 & 0,10 & 0,00 & 0,07 & 0,02 \\
\hline 190,38 & 43,15 & 95,99 & 22,93 & 10,93 & 5,28 & 1,13 & 2,12 & 1,60 & 0,92 & 0,11 & 0,00 & 0,07 & 0,02 \\
\hline 188,58 & 42,89 & 93,92 & 22,47 & 9,87 & 5,00 & 1,13 & 2,12 & 1,60 & 0,93 & 0,12 & 0,01 & 0,07 & 0,02 \\
\hline
\end{tabular}




\section{ANEXO B: Perfil longitudinal da caixa de retenção}

A Tabela B.1 mostra a declividade a cada metro do comprimento da caixa de retenção, obtidas com auxílio do equipamento de estação total TC 400 Leica. A Figura B.1 ilustra o perfil longitudinal da caixa de acordo com a medida das alturas dos pontos em relação ao equipamento de Estação Total.

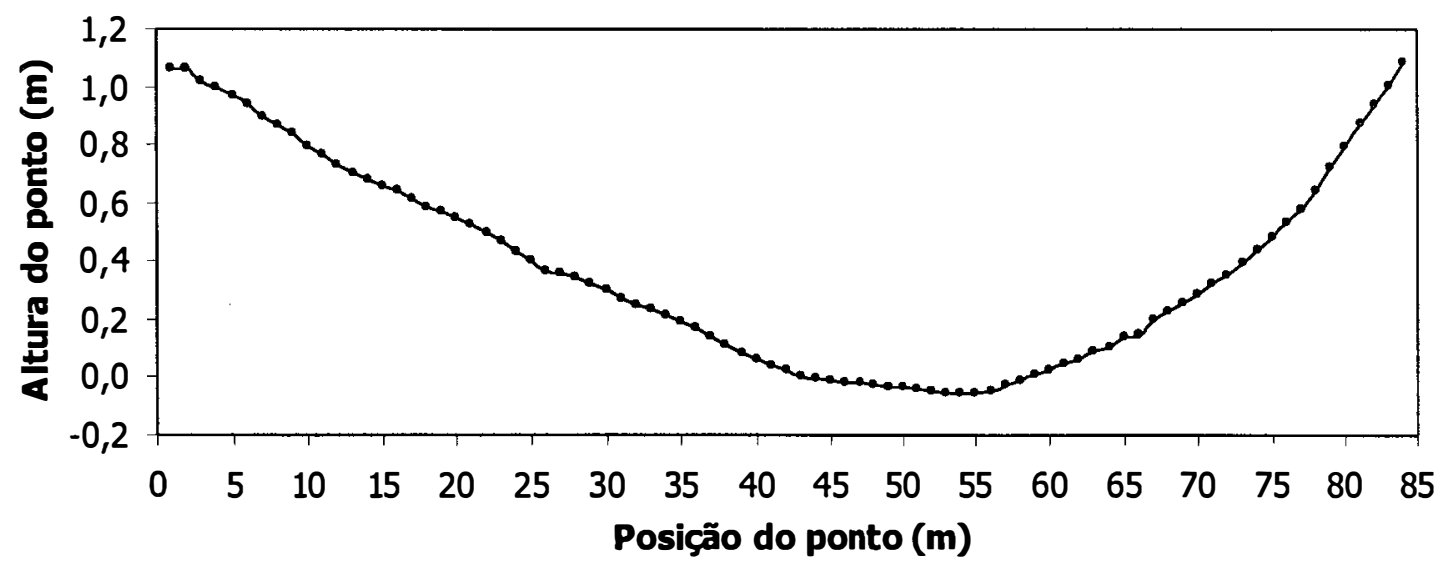

Figura B.1: Perfil longitudinal da caixa de retenção medido em campo 
Tabela B.1: Declividades ao longo do comprimento da caixa de retenção

\begin{tabular}{cccc}
\hline $\begin{array}{c}\text { Posiçáo na caixa } \\
\text { (m) }\end{array}$ & $\begin{array}{c}\text { Declividade } \\
\text { (\%) }\end{array}$ & $\begin{array}{c}\text { Posiçáo na caixa } \\
\text { (m) }\end{array}$ & $\begin{array}{c}\text { Declividade } \\
\text { (\%) }\end{array}$ \\
\hline fim da caixa & 0,50 & 40 & 0,90 \\
81 & 4,00 & 39 & 0,60 \\
80 & 2,50 & 38 & 0,30 \\
79 & 2,60 & 37 & 0,40 \\
78 & 3,30 & 36 & 0,50 \\
77 & 4,00 & 35 & 0,80 \\
76 & 2,90 & 34 & 0,20 \\
75 & 3,20 & 33 & 0,50 \\
74 & 3,90 & 32 & 0,60 \\
73 & 3,20 & 31 & 0,80 \\
72 & 3,30 & 30 & 0,10 \\
71 & 2,80 & 29 & 0,20 \\
70 & 2,50 & 28 & $-0,60$ \\
69 & 2,30 & 27 & $-2,20$ \\
68 & 1,70 & 26 & $-1,70$ \\
67 & 2,70 & 25 & $-2,20$ \\
66 & 2,60 & 24 & $-1,30$ \\
65 & 1,80 & 23 & $-2,40$ \\
64 & 2,10 & 22 & $-1,40$ \\
63 & 1,90 & 21 & $-2,80$ \\
62 & 3,20 & 20 & $-1,60$ \\
61 & 3,10 & 19 & $-3,60$ \\
60 & 3,30 & 18 & $-1,00$ \\
59 & 2,80 & 17 & $-4,80$ \\
58 & 3,60 & 16 & $-2,80$ \\
57 & 1,20 & 15 & $-2,80$ \\
56 & 1,40 & 14 & $-2,80$ \\
55 & 1,90 & 13 & $-3,90$ \\
54 & 2,40 & 12 & $-3,20$ \\
53 & 2,70 & 11 & $-4,40$ \\
52 & 1,90 & 10 & $-4,20$ \\
51 & 1,80 & 9 & $-3,90$ \\
50 & 2,00 & 8 & $-5,30$ \\
49 & 1,90 & 7 & $-4,10$ \\
48 & 2,80 & 6 & $-6,70$ \\
47 & 2,50 & 5 & $-7,80$ \\
46 & 3,00 & 4 & $-7,70$ \\
45 & 2,70 & 3 & $-7,70$ \\
44 & 2,20 & 2 & $-6,70$ \\
43 & 2,30 & 1 & $-6,70$ \\
42 & 1,40 & início da caixa & $-7,90$ \\
41 & 2,40 & & \\
\hline & & &
\end{tabular}


ANEXO C: Arquivos de resultados do GSRS 
Continuous Slope Method

$\begin{array}{cc}* * * * * * * * \text { I N P U T DATA ******** } & \\ & \\ \text { PERCENT DOWNGRADE } & \text { BRAKING LENGTH (MILES) } \\ 2.50 & 0.25 \\ 6.00 & 3.08 \\ 5.50 & 0.37 \\ 4.50 & 0.37 \\ 5.50 & 0.50 \\ 6.00 & 1.49 \\ 5.50 & 0.37 \\ 6.00 & 1.24 \\ 5.50 & 0.30\end{array}$

$* * * * * * * *$ OUTPUT

\begin{tabular}{cccccc} 
& \multicolumn{5}{c}{ BRAKE } \\
MAXIMUM & MAXIMUM & $\begin{array}{c}\text { BRAKE } \\
\text { TEMP }\end{array}$ & $\begin{array}{c}\text { TEMP. } \\
\text { FROM }\end{array}$ & TOTAL & TOTAL \\
TRUCK & SAFE & FROM & EMERGENCY & BRAKE & TRAVEL \\
WEIGHT & SPEED & DECLINE & STOP & TEMP. & TIME \\
(POUNDS) & $($ MPH) & $($ F) & $($ F) & $($ F) & (MIN) \\
100000 & 10 & 476 & 3 & 479 & 47.8 \\
95000 & 11 & 482 & 3 & 485 & 43.5 \\
90000 & 12 & 479 & 4 & 483 & 39.8 \\
85000 & 13 & 468 & 4 & 472 & 36.8 \\
80000 & 15 & 478 & 5 & 483 & 31.9 \\
75000 & 18 & 492 & 7 & 499 & 26.6 \\
70000 & 21 & 484 & 9 & 493 & 22.8 \\
65000 & 27 & 484 & 14 & 498 & 17.7 \\
60000 & 30 & 442 & 16 & 458 & 15.9 \\
55000 & 40 & 448 & 27 & 475 & 12.0
\end{tabular}

NOTE $:$ INITIAL BRAKE TEMPERATURE $=150$

${ }^{*}$ Total Brake Temperature is between $500^{\circ} \mathrm{F}$ and $530^{\circ} \mathrm{F}$

$\begin{array}{llllll}* 85000 & 14 & 500 & 5 & 505 & 34.0 \\ * 70000 & 22 & 496 & 10 & 506 & 21.0 \\ * 65000 & 28 & 490 & 15 & 506 & 17.0 \\ * 60000 & 31 & 488 & 17 & 506 & 15.0\end{array}$

NOTE $:$ INITIAL BRAKE TEMPERATURE $=150$ 
Brake Temperature Profile

\begin{tabular}{|c|c|c|c|c|}
\hline \multicolumn{3}{|c|}{$\begin{array}{l}\text { TRUCK WEIGHT (LBS) } \\
100000\end{array}$} & \multicolumn{2}{|c|}{$\begin{array}{l}\text { SPEED LIMIT (MPH) } \\
40\end{array}$} \\
\hline$* * * * * * * * *$ OU & PUT ****** & $* * * * *$ & & \\
\hline $\begin{array}{c}\text { GRADE } \\
\text { (PERCENT) }\end{array}$ & $\begin{array}{c}\text { SEGMENT } \\
\text { LENGTH } \\
\text { OF } \\
\text { GRADE } \\
\text { (MILES) }\end{array}$ & $\begin{array}{c}\text { BRAKE } \\
\text { TEMP } \\
\text { FROM } \\
\text { DECLINE } \\
(\mathrm{F})\end{array}$ & $\begin{array}{c}\text { BRAKE } \\
\text { TEMP. } \\
\text { FROM } \\
\text { EMERGENCY } \\
\text { STOP } \\
\text { (F) }\end{array}$ & $\begin{array}{c}\text { TOTAL } \\
\text { BRAKE } \\
\text { TEMP. } \\
(\mathrm{F})\end{array}$ \\
\hline 2.50 & 0.25 & 157 & 49 & 206 \\
\hline 6.00 & 0.50 & 228 & 49 & 277 \\
\hline 6.00 & 1.00 & 297 & 49 & 346 \\
\hline 6.00 & 1.50 & 365 & 49 & 414 \\
\hline 6.00 & 2.00 & 430 & 49 & 479 \\
\hline 6.00 & 2.50 & 494 & 49 & 543 \\
\hline 6.00 & 3.00 & 555 & 49 & 604 \\
\hline 6.00 & 3.08 & 565 & 49 & 614 \\
\hline 5.50 & 0.37 & 604 & 49 & 653 \\
\hline 4.50 & 0.37 & 629 & 49 & 678 \\
\hline 5.50 & 0.50 & 679 & 49 & 728 \\
\hline 6.00 & 0.50 & 736 & 49 & 785 \\
\hline 6.00 & 1.00 & 791 & 49 & 840 \\
\hline 6.00 & 1.49 & 843 & 49 & 892 \\
\hline 5.50 & 0.37 & 876 & 49 & 925 \\
\hline 6.00 & 0.50 & 927 & 49 & 976 \\
\hline 6.00 & 1.00 & 977 & 49 & 1026 \\
\hline 6.00 & 1.24 & 1000 & 49 & 1049 \\
\hline 5.50 & 0.30 & 1024 & 49 & 1073 \\
\hline
\end{tabular}

Brake Temperature Profile 


\section{REFERÊNCIAS BIBLIOGRÁFICAS}

AASHTO [1994] A Policy on Geometric Design of Highways and Streets. American Association of State Highway and Transportation Officials. Cap. III: Elements of Design, p. 268-279.

Abdelwahab, W.; Morral, J. F. [1997] Determining Need for and Location of Truck Escape Ramps. Journal of Transportation Engineering, set/out, p. 350-356.

ADoT [1993] Arizona Department of Transportation. Full-Scale Arrester Bed Testing Leads to More Cost-Effective Design, TR News, n. 166, may/june.

Allison, J. R.; Hahn, K. C.; Bryden J. E. [1979] Performance of a Gravel-Bed TrckArrester System. New York State Department of Transportation. Transportation Research Record 736, p. 43-47.

Bowman, B. L.; Coleman, J. A. [1990] Grade Severity Rating System. Institute of Transportation Engineers Journal, jul., p. 19-24.

Canale, A. C. [1989] Automobilística: dinâmica e desempenho. São Paulo, Érica. Cap. 5: Dinâmica da Frenagem, p. 78-99.

COBREQ [2002] Fabricante de pastilhas e lonas de freios. Informações técnicas. Características essenciais das lonas e pastilhas de freio. Disponível em: $<$ http://www.cobreq.com.br/home.htm>. Acesso em: 09/Abr/2002.

Cocks, G. C. e Goodram L. W. [1982] The Design os Vehicle Arrester Beds. Proceedings of the Australian Road Research Board, Vol. 11, Part 3, p. 24-34.

CONTRAN [1998] Resolução 12/98: Estabelece os limites de peso e dimensões para veículos que transitem por vias terrestres. Conselho Nacional de Trânsito, Ministério da Justiça do Brasil, Brasília, DF.

CONTRAN [1999] Resolução $n^{0}$ 102: Dispõe sobre a tolerância máxima de peso bruto de veículos. Conselho Nacional de Trânsito, Ministério da Justiça do Brasil, Brasilia, DF.

Couto, R. [1999] Decisão de Peso. Auto Esporte, Ano 35, n. 413, out. 
Tetard, C.; Quincy R.; Romegoux J. P.; Vulin D. [1992] L'Insecurite des Poids Lourds lês Longues Descentes. Rappot INRETS 152, Institut National de Recherche Sur les Transports et leur Securite.

Wambold, J. C.; Rivera-Ortiz, L. A.; Wang, M. C. [1988] Truck Escape Ramps Design Methodology, Vol. 2: Final Report, Pennsylvania Transportation Institute, Pennsylvania University, 231 p. Citado por Witheford (1992)

Waples, I. et al. [1992] Development of Design Standards for Steep Downgrades. Design and Survey Branch, Transport Technology, Queensland Department of Transport.

Witheford, D. K. [1992] Truck Escape Ramps. NCHPR Synthesis 178, Transportation Reasearch Board, National Research Council, Washinton, D.C. 